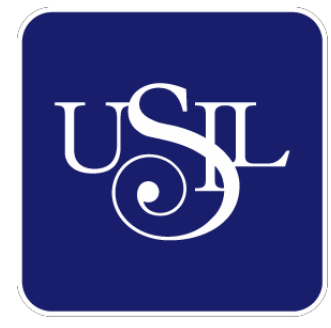

UNIVERSIDAD

SAN IGNACIO

DE LOYOLA

ESCUELA DE POSTGRADO

\title{
PLAN ESTRATÉGICO PARA LA CADENA DE POLLERÍAS NORKY'S PARA EL PERIODO 2018 - 2020 EN LIMA
}

Trabajo de Investigación para optar el Grado de:

NESTOR ALEJANDRO CHIRINOS VILLANUEVA Maestro en Ciencias Empresariales con Mención en Gestión del Capital Humano

ELIZABETH VANESSA GANOZA AGUILAR Maestro en Ciencias Empresariales con Mención en Gestión de Proyectos

\section{JOSÉ OLIVERA RIMACHI}

Maestro en Ciencias Empresariales con Mención en Gestión de Proyectos

\section{CARMEN ROSA ZAMBRANO BOHORQUEZ}

Maestro en Ciencias Empresariales con Mención en Gestión de Proyectos

Asesor:

Dr. Edmundo Rafael Casavilca Maldonado

$$
\text { Lima - Perú }
$$




\section{Tabla de Contenido}

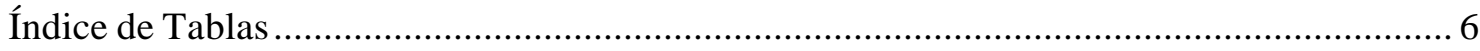

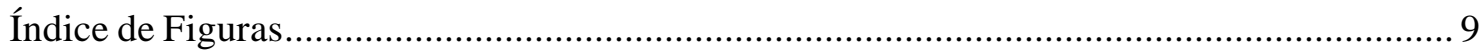

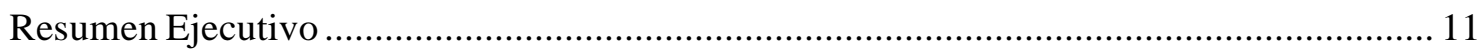

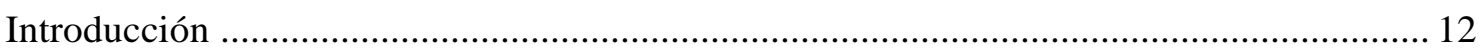

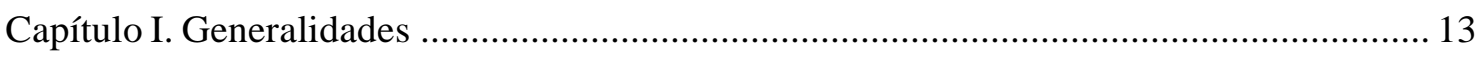

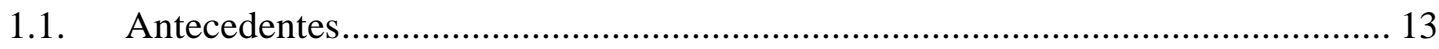

1.2. Determinación del Problema u Oportunidad ................................................... 15

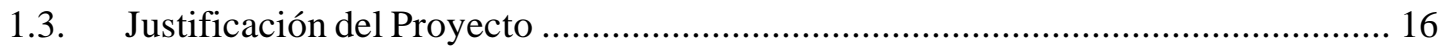

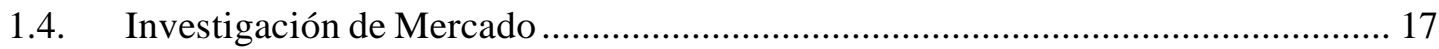

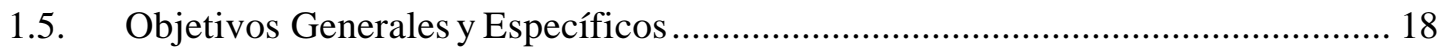

1.6. Alcances y Limitaciones de la Investigación................................................. 20

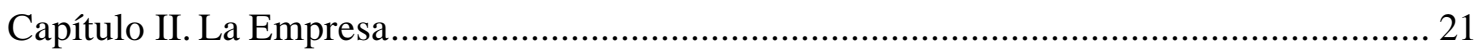

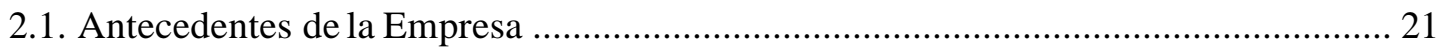

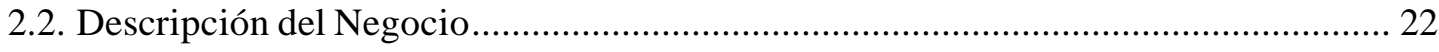

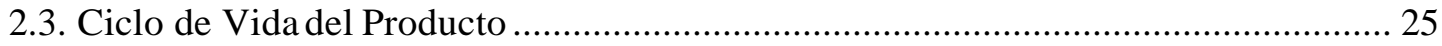

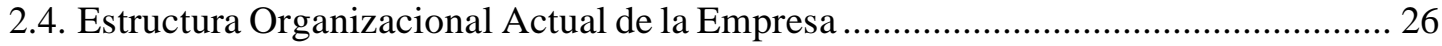

2.5. Situación de Mercado y Financiera Actual del Sector ............................................. 32

Capítulo III. Formulación de Visión, Misión y Valores de la Empresa ................................ 37

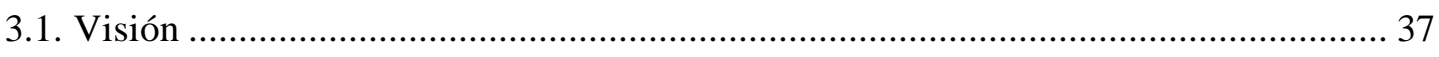

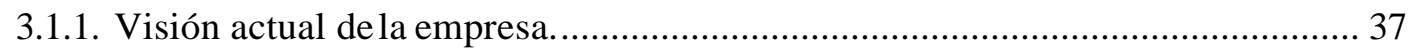

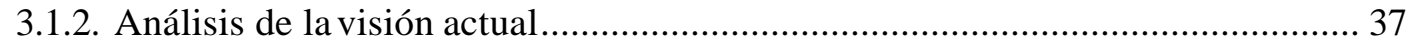

3.1.3. Matriz de la visión propuesta para la empresa.................................................. 38

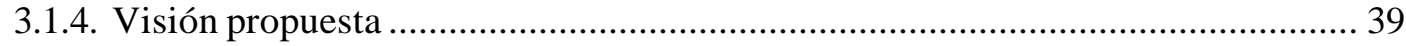




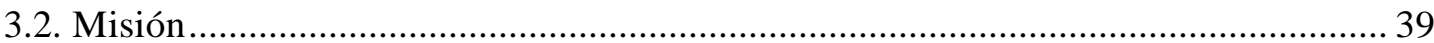

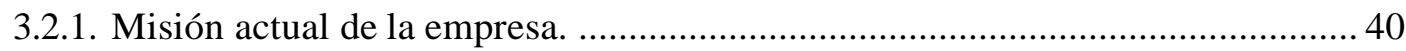

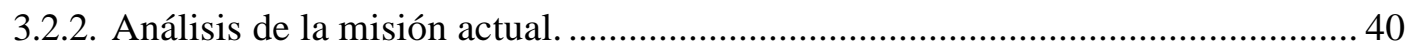

3.2.3. Elementos de la misión propuesta para la empresa........................................... 41

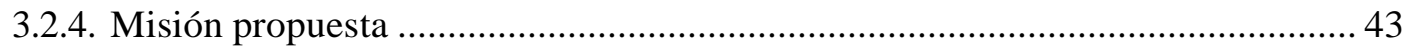

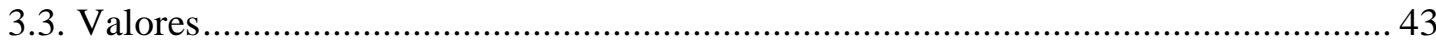

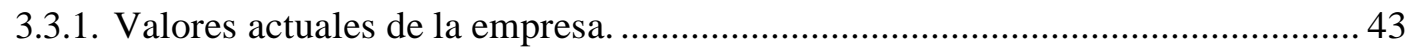

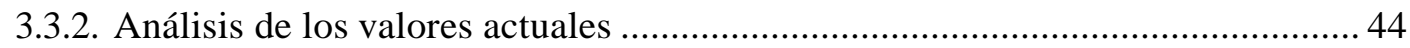

3.3.3. Elementos de los valores propuestos para la empresa. ................................... 45

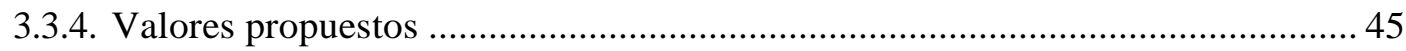

3.4. Alineamiento Estratégico de la Visión, Misión y Valores de la Empresa ................... 46

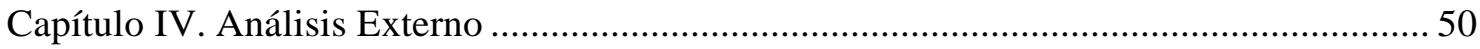

4.1. Tendencias de las Variables del Entorno................................................................. 50

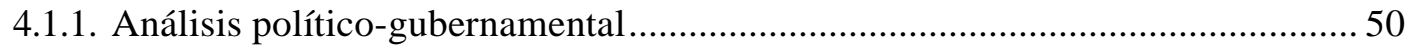

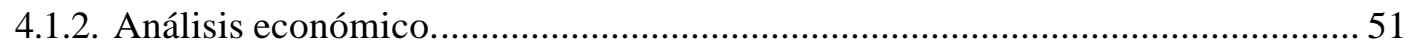

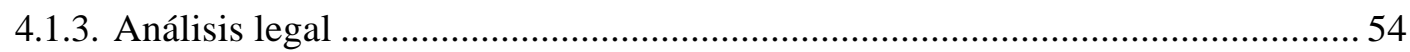

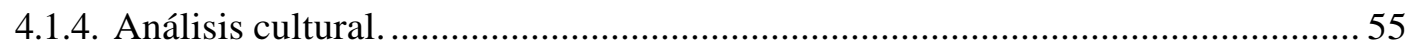

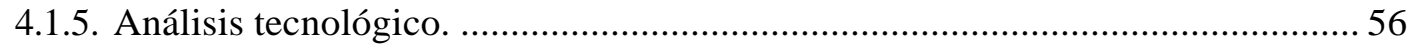

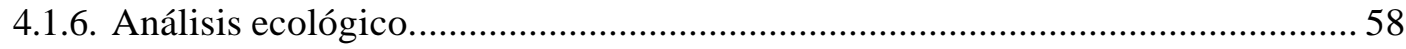

4.2. Impacto en Clientes/Proveedores de cada una de las Variables del Entorno...............59

4.3. Efecto en la Empresa de cada una de las Variables del Entorno.................................63 63

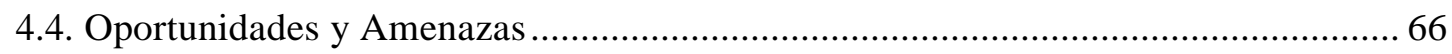

4.5. Matriz de Evaluación de los Factores Externos EFE ............................................ 68

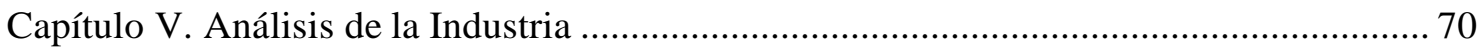

5.1. Descripción del Mercado (Demanda) e Industria (Oferta) …................................... 70 
5.2. Descripción de las Cinco Fuerzas Competitivas de la Industria 71

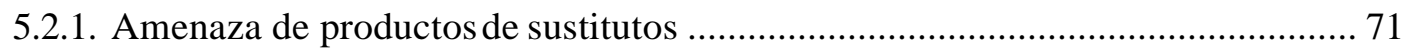

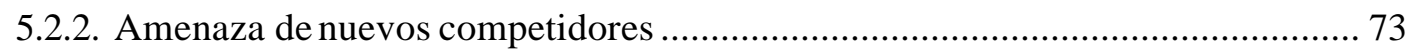

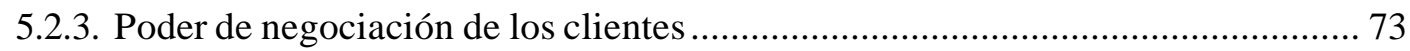

5.2.4. Poder de negociación de los proveedores ......................................................... 74

5.2.5. Competencia en el mismo sector ................................................................ 75

5.3. Matriz de Atractividad de cada una de las Cinco Fuerzas .......................................... 77

5.4. Análisis del Grado de Atractividad de la Industria .............................................. 80

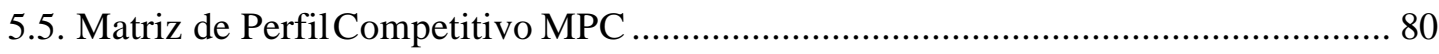

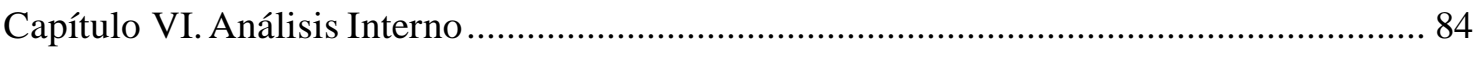

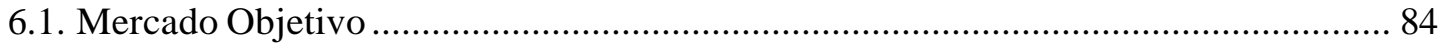

6.2. Descripción de las Actividades de la Cadena de Valor de la Empresa ...................... 85

6.3. Indicadores de cada una de las Actividades de la Cadena de Valor .......................... 95

6.4. Benchmarking y Comparación con los Líderes de la Industria de cada una de las

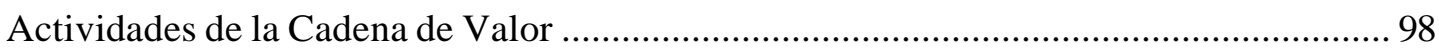

6.5. Determinar las Competencias de la Empresa ...................................................... 99

6.6. Identificación y Determinación de las Ventajas Competitivas de la Empresa .......... 100

6.7. Matriz de Evaluación de los Factores Internos EFI ............................................ 101

Capítulo VII. Formulación de los Objetivos y Diseño de las Estrategias ........................... 106

7.1. Alcance y Planteamiento de los Objetivos Estratégicos ....................................... 106

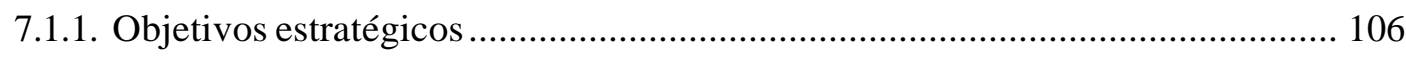

7.1.2. Análisis de los objetivos estratégicos ....................................................... 106

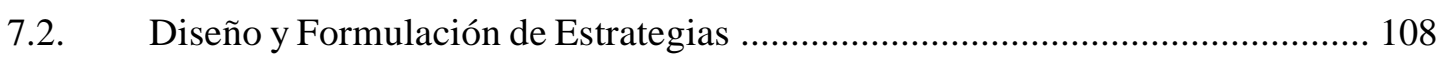

7.2.1. Matrices de formulación de estrategias .................................................... 108

7.3. Resumen de las Estrategias Formuladas ................................................ 117 


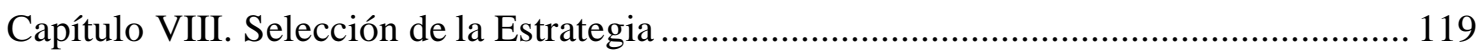

8.1. Matriz de Planeación Estratégica Cuantitativa MPEC .......................................... 119

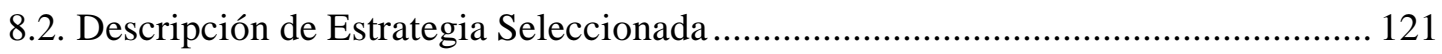

8.3. Descripción de Estrategia Contingente ............................................................ 121

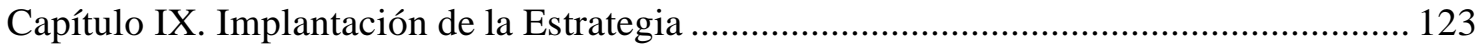

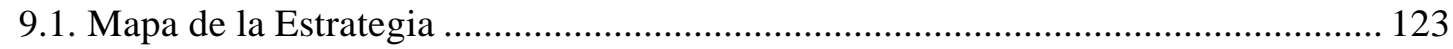

9.2. Objetivos Específicos según el Mapa de la Estrategia ......................................... 125

9.3. Indicadores para cada uno de los Objetivos Específicos ....................................... 126

9.4. Metas para cada uno de los Objetivos Específicos ................................................ 126

9.5. Iniciativas para cada uno de los Objetivos Específicos .................................... 127

9.6. Responsable de cada una de las Iniciativas ...................................................... 129

9.7. Presupuesto de cada una de las Iniciativas ......................................................... 130

9.8. Cronograma de cada una de las Iniciativas ........................................................ 136

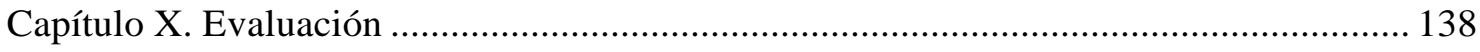

10.1. Evaluación Financiera de la Estrategia........................................................... 138

10.1.1. Estado de resultados (situación actual y con la nueva estrategia) ................... 138

10.1.2. Balance general (situación actual y con la nueva estrategia) ......................... 139

10.1.3. Proyección de flujos (situación actual y con la nueva estrategia) ................... 141

10.1.4. Evaluación financiera (VAN, TIR y ratios financieros). ............................... 143

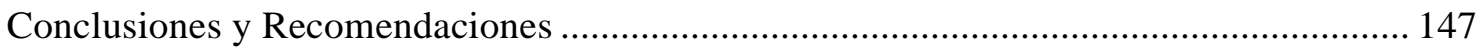

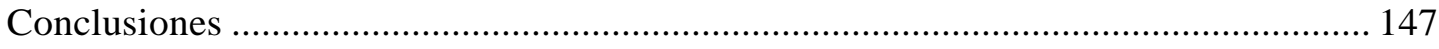

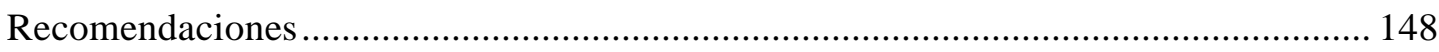

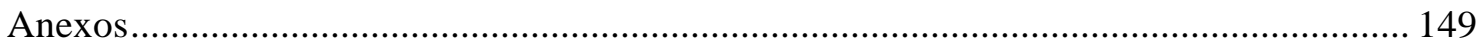

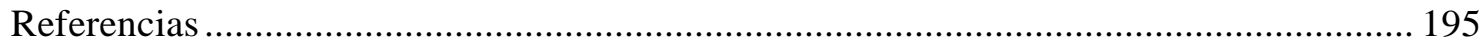




\section{Índice de Tablas}

Tabla 1. Platos de Norky's 22

Tabla 2. Distribución de Niveles Socioeconómicos por Zona en Lima Metropolitana 24

Tabla 3. Redacción de una Declaración de Visión. Qué hacer, qué evitar. 38

Tabla 4. Matriz de la Visión Propuesta para Norky’s..... 39

Tabla 5. Matriz de Evaluación de la Declaración de la Misión de Norky’s 41

Tabla 6. Interrogantes para definir el Negocio de Norky's 42

Tabla 7. Elementos de la Misión Propuesta para Norky's 42

Tabla 8. Definición de los Valores Actuales de Norky's 44

Tabla 9. Alineamiento Estratégico de la Visión, Misión y Valores de Norky's. 48

Tabla 10. Canasta Básica de Alimentos. Periodo 2012 - 2016. 53

Tabla 11. MatrizEFE de Norky's 69

Tabla 12. Principales Cadenas de Pollerías en Lima Metropolitana. 76

Tabla 13. Matriz de Atractividad de la Fuerza Competitiva: Amenaza de productos de sustitutos 77

Tabla 14. Matriz de Atractividad de la Fuerza Competitiva: Amenaza de nuevos competidores 78

Tabla 15. Matriz de Atractividad de la Fuerza Competitiva: Poder de negociación de los clientes 78

Tabla 16. Matriz de Atractividad de la Fuerza Competitiva: Poder de negociación de los proveedores..... 79

Tabla 17. Matriz de Atractividad de la Fuerza Competitiva: Competencia en el mismo sector

Tabla 18. Matriz de Atractividad de las Cinco Fuerzas 80

Tabla 19. Matriz MPC de Norky's 83 
Tabla 20. Rango de Edades, Distribución de Edades y Género de los Colaboradores en las

Tiendas 84

Tabla 21. Indicadores de las Actividades de la Cadena de Valor 96

Tabla 22. Benchmarking y Comparación con el Líder de la Industria. 99

Tabla 23. Matriz para determinar las Ventajas Competitivas de Norky's 101

Tabla 24. Matriz EFIde Norky's 104

Tabla 25. Matriz FODA de Norky's. 109

Tabla 26. Matriz PEYEA de Norky's. 110

Tabla 27. Matriz Resumen de las Estrategias Formuladas de Norky's 118

Tabla 28. Matriz de Planeamiento Estratégico Cuantitativo de Norky's 119

Tabla 29. Objetivos Específicos según el Mapa de la Estrategia de Norky’s 125

Tabla 30. Indicadores para cada uno de los Objetivos Específicos de Norky's 126

Tabla 31. Metas para cada uno de los Objetivos Específicos de Norky's..... 127

Tabla 32. Iniciativas para cada uno de los Objetivos Específicos de Norky's 128

Tabla 33. Responsable de cada una de las Iniciativas de Norky's

Tabla 34. Presupuesto para la realización de encuestas de satisfacción 130 Tabla 35. Presupuesto para el incremento de interacción con los clientes por medio de las publicaciones en Facebook.

Tabla 36. Presupuesto para la determinación de los procesos manuales requeridos para la automatización 131

Tabla 37. Presupuesto para el ajuste de check list operativo real al ideal. 132

Tabla 38. Presupuesto para la homologación de los datos de sistema. 132

Tabla 39. Presupuesto para el desarrollo del MOF.

Tabla 40. Presupuesto para la formalización de las reuniones semanales entre los administradores y sus equipos de trabajo. 
Tabla 41. Presupuesto para el desarrollo de eventos deportivos 134

Tabla 42. Presupuesto para el desarrollo de políticas de bonificación para los supervisores de operaciones y coordinadores de servicio 134

Tabla 43. Presupuesto para la identificación de las escuelas requeridas y su desarrollo... 135

Tabla 44. Presupuesto de cada una de las Iniciativas de Norky's (Expresado en soles)..... 135

Tabla 45. Cronograma de cada una de las Iniciativas de Norky's

Tabla 46. Estado de Resultados de la Situación Actual de Norky’s (Expresado en soles)... 138

Tabla 47. Estado de Resultados con la Nueva Estrategia de Norky's (Expresado en soles) 139

Tabla 48. Diferencia entre la Situación Actual y con la Nueva Estrategia de Norky's (Expresado en soles) 139

Tabla 49. Balance General de la Situación Actual de Norky’s (Expresado en soles).......... 140

Tabla 50. Balance General con la Nueva Estrategia de Norky’s (Expresado en soles)....... 141

Tabla 51. Flujo de Efectivo de la Situación Actual de Norky's (Expresado en soles).......... 142

Tabla 52. Flujo de Efectivo con la Nueva Estrategia de Norky's (Expresado en soles) ...... 142

Tabla 53. Diferencial del Flujo de Efectivo de Norky's (Expresado en soles)..................... 143

Tabla 54. Variables para la Evaluación Financiera ....................................................... 143

Tabla 55. Ratios de Liquidez de Norky's (Expresado en soles) ........................................ 144

Tabla 56. Ratios de Gestión de Norky's (Expresado en días) ........................................... 145

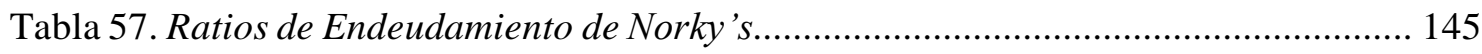

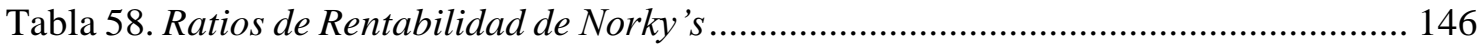

Tabla 59. Porcentaje de ingreso de las utilidades por producto ....................................... 155 


\section{Índice de Figuras}

Figura 1. Inicio y Crecimiento de Norky’s. 22

Figura 2. Cantidad de Tiendas por Distrito en Lima Metropolitana de Norky’s. 23

Figura 3. Ciclo de vida del pollo a la brasa en Norky's ................................................ 26

Figura 4. Organigrama de MACROSCEM S.A.C................................................... 28

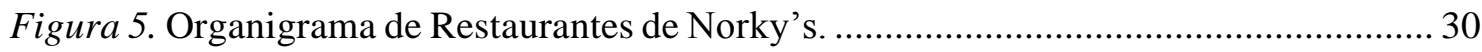

Figura 6. Organigrama de Patios de Norky's............................................................... 31

Figura 7. Evolución Mensual de la Actividad de Restaurantes, 2013-2016 (Variación \% respecto a similar periodo del año anterior). ....................................................... 33

Figura 8. Perú. Producción Nacional de Aves, MINAGRI, 2015 ...................................... 34

Figura 9. Perú. Producción de ave viva. Enero 2016- Noviembre 2017, MINAGRI, 2017 .. 35

Figura 10. Cadenas de Pollerías en Lima Metropolitana a Diciembre 2017. ....................... 36

Figura 11. Evolución de la inversión privada y PBI ............................................................ 52

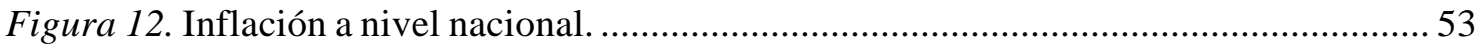

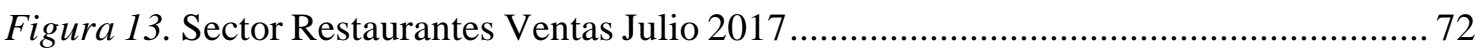

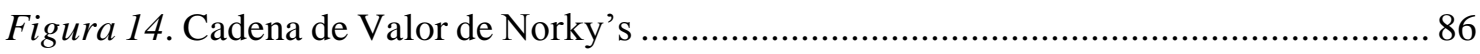

Figura 15. Proceso de Atención a los Comensales de Norky's. ....................................... 89

Figura 16. Resultado de la Matriz PEYEA de Norky’s ............................................... 112

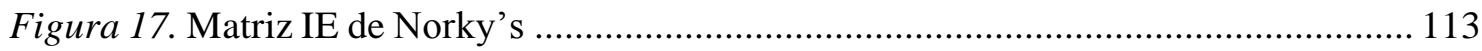

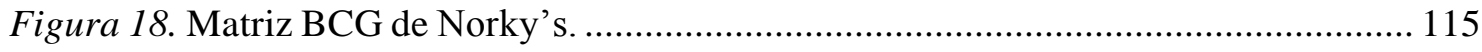

Figura 19. Matriz de la Gran Estrategia de Norky's. .................................................... 116

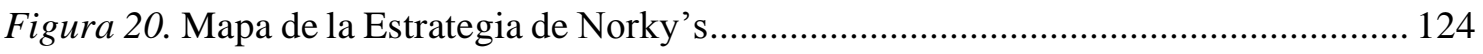

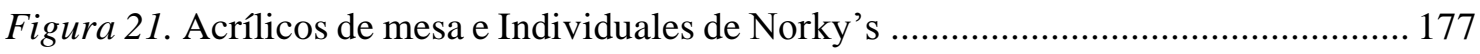

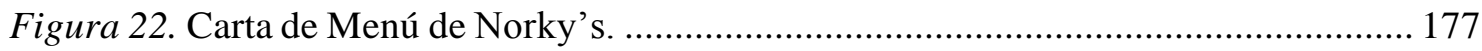

Figura 23. Backlights de Norky's en un patio de comidas ........................................... 177 
Figura 24. Afiches de pared o ventana, imantados y tarjetas de presentación de Norky's. . 178

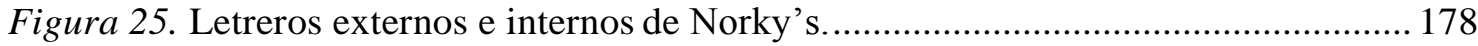




\section{Resumen Ejecutivo}

La Cadena de Pollerías Norky’s (Norky’s) es una de las empresas más representativas y exitosas del mercado peruano, ya que cuenta con 41 años de experiencia en el sector y posee 136 tiendas a nivel nacional, siendo su foco principal Lima Metropolitana, en la cual se concentran 92 de sus tiendas.

Sin embargo, a pesar del éxito obtenido, no ha desarrollado un plan estratégico que le permita tener claridad sobre su situación actual, situación deseada y el camino a seguir para lograrlo, derivando en no contar con una visión, misión y valores, documentos expuestos a nivel organizacional, que puedan guiar y comprometer a sus colaboradores con los objetivos de la empresa. Asimismo, no se ha impulsado la institucionalización debida en sus procesos operativos y administrativos que garantice el óptimo funcionamiento de sus actividades.

En ese sentido, el objetivo de la investigación fue proponer un plan estratégico que conduzca a la institucionalización de la empresa, mediante la automatización y estandarización de los procesos.

La propuesta planteada dentro del plan estratégico frente a la situación actual permitió obtener un impacto positivo en la rentabilidad del negocio, expresado en un VAN de S/10,689,886 y una TIR de 53\%.

Finalmente, si bien la organización tiene una gran acogida a nivel nacional, debe ir de la mano de una institucionalización que garantice un mayor orden en la realización de sus operaciones. 


\section{Introducción}

El desarrollo de un plan estratégico para Norky's tiene gran importancia organizacional, ya que se convierte en una valiosa herramienta para que los líderes plasmen el rumbo deseado y se generen sinergias entre las áreas para la consecución de los objetivos deseados.

En ese sentido, el objetivo del presente trabajo se basa en proponer un plan estratégico que garantice la institucionalización de la empresa generando un impacto positivo en la rentabilidad del negocio.

Para tal cometido, el plan estratégico se centra en Lima Metropolitana con un horizonte de tres años, abarcando la formulación de la visión, misión y valores, el análisis del ambiente interno y externo, la determinación de los objetivos y estrategias para alcanzarlos, y la evaluación financiera. 


\section{Capítulo I. Generalidades}

\subsection{Antecedentes}

La inversión privada en el Perú disminuyó en 5.7\% para el año 2016, esto no se veía desde el 2009, año de crisis a nivel mundial en que cayó 9.1\%. Respecto a los sectores económicos, durante el año 2016, la inversión fue impulsada principalmente por los sectores primarios, debido a la mayor producción de cobre. Los sectores no primarios se vieron afectados por una débil demanda interna y las tasas de crecimiento fueron negativas en sectores como construcción y manufactura no primaria, también los sectores de comercio y servicios sufrieron una desaceleración (Banco Central de Reserva del Perú [BCRP], 2016).

Durante los últimos años, la economía mundial y la peruana han tenido un reajuste después de la crisis económica y financiera del año 2009, cuando se registró el Producto Bruto Interno (PBI) al 1.1\%. A partir del año 2014, se empieza a ver un ligero incremento en 2.4\%; en el año 2015, en 3.3\%; y el año 2016, cerró en 3.9\%, pese a que el contexto internacional no fue favorable. América Latina muestra los mismos síntomas en su economía desde el año 2012 y entra a un periodo de recesión en el año 2015-2016. Se resalta que, en el Perú, el PBI por habitante creció a una tasa media anual de 3.5\%, registrándose desde 13,634 soles, en el año 2011, a 15,914 soles, en el año 2016. Este alto incremento no se había visto desde el año 1950 (Instituto Nacional de Estadística e Informática [INEI], 2017). Estos datos muestran que existe estabilidad económica, es decir no hay grandes variaciones en la producción, renta y empleo, además de una baja inflación para los inversionistas de distintos sectores e industrias, lo cual les permite evaluar nuevos proyectos.

Sobre la base de lo mencionado anteriormente, el sector de restaurantes se vio favorecido, a pesar de que no ha crecido en los últimos años con relación al PBI. Los datos económicos han permitido, junto al crecimiento demográfico y a los hábitos oscilantes del 
consumidor peruano, que los inversionistas tomen riesgos, innoven e inviertan en el tipo de servicio, y apuesten por la tendencia gastronómica, a través de fusiones, franquicias y concesiones. El boom de la cocina peruana es uno de los principales factores para que la inversión en restaurantes se dé en forma sostenida, dando lugar al crecimiento de una industria que antes era inexistente o postergada (El boom de la cocina peruana, apega.pe, 2010).

En ese contexto, la economía peruana y el boom gastronómico tuvieron una participación importante en el mercado, ya que empezaron a nacer muchas empresas de comida, y, entre ellas, el modelo de negocio de cadena de pollerías a la brasa se empezó a expandir en las principales ciudades del Perú. En Lima, existen varias cadenas de pollerías a la brasa, así como pollerías con locales individuales que solo brindan el servicio en determinados distritos. Según Euromonitor International, las principales cadenas de pollerías con mayores ventas son Pardos, Roky's, Norky's, Las Canastas y Don Belisario, entre otros restaurantes (KFC, Norky's y Rocky's son los restaurantes con mayores ventas en su rubro en el Perú, peru-retail.com, 2017). En su reporte semanal, Scotiabank dio a conocer que el consumo de pollo en el Perú, se debe a que es la carne preferida por los peruanos en un 54\%, por encima del pescado que llega al 30\%, el vacuno al $8 \%$, el porcino al $6 \%$ y otras carnes al $2 \%$. Esto se refleja en la población, cuando hace uso de su poder adquisitivo en el consumo del pollo, ya que hay una expansión de cadenas de pollerías a nivel nacional (Sector avícola seguiría siendo impulsado por consumo interno, scotiabank.com.pe, octubre 2016).

La principal cadena de pollerías que tiene presencia en la mayoría de los distritos de Lima y está dirigido principalmente a los niveles socioeconómicos C y D, es Norky’s (Pardos Chicken y Norky’s lideran preferencia de pollerías en Lima, peru-retail.com, 2014). El crecimiento sostenido de Norky's se debe a que el precio es asequible y ofrece diversas promociones durante todo el año. Además, en los últimos años se ha dado impulso al 
consumo del pollo a la brasa, ya que desde el año 2010, cada tercer domingo de julio se celebra el Día del Pollo a la Brasa.

\subsection{Determinación del Problema u Oportunidad}

Se ha detectado como problema que durante el crecimiento de Norky's, no se ha desarrollado la institucionalización debida en sus procesos administrativos y operativos, tales como: manuales de procedimientos y funciones, definición de políticas de bienestar y reconocimiento, instructivos de las herramientas tecnológicas, automatización de los procesos manuales, y estandarización de los procesos operativos; impidiéndole así, que no exista un orden que permita un soporte óptimo a la continuidad del negocio, comunicación de objetivos y estrategias hacia las tiendas, y que se incidan en costos y gastos superiores a lo esperado. Adicionalmente, existen otros problemas, tales como:

- No existe un plan estratégico.

- Falta de estructuración en el funcionamiento de la empresa, ya que no cuenta con un organigrama definido a nivel funcional, visión, misión, valores y estrategias alineadas a los objetivos de la empresa.

- Falta de Manual de Organización y Funciones (MOF) que permita tener personal alineado a los perfiles requeridos.

Por otro lado, también se han encontrado oportunidades que se derivan de la situación actual del país:

Según el BCRP, la economía peruana en estos últimos años ha tenido una desaceleración en el crecimiento del PBI; sin embargo, no deja de ser una economía estable. Hacia el año 2018, se tiene una mayor expectativa de crecimiento, a diferencia de los otros países de la región (Reporte de Inflación: Junio 2017, Panorama actual y proyecciones macroeconómicas 2017-2018, bcrp.gob.pe, 2017). Por otro lado, la Cámara de Comercio de 
Lima, señala que entre el año 2011 y 2015, hubo un crecimiento de $36.5 \%$ de la clase media, el cuál es el público objetivo de Norky’s, clasificado como "emergente" y ubicado principalmente en los conos de Lima (13,6 millones de peruanos pertenecerían a la clase media al 2018, camaralima.org.pe, 2016). El crecimiento de la clase media dio impulso a la actividad de restaurantes, que ofrecen servicios de preparación de comidas y bebidas, el cual tuvo un crecimiento de $1.25 \%$ hasta el año 2017. La mejora frente al año anterior se debe a una mayor concurrencia de consumidores, servicios especiales y diversas promociones, en base a estrategias de marketing e implementación de nuevas cartas (Crecimiento de sector restaurantes en enero, semanaeconomica.com, 2017).

Según el INEI, el consumo de pollo a la brasa en la población peruana se da en mayor proporción en la ciudad de Lima, además que el gasto promedio de los peruanos cuando visitan una pollería es S/35 (¿Cuántos pollos a la brasa comemos los peruanos al año?, gestion.com, 2016). Lo mencionado anteriormente, ha generado que la producción de este plato tradicional haya tenido un crecimiento de $3.46 \%$, aumentando así la compra de pollo en Lima y Callao (Al año se consume en promedio 24 kilos de pollos a la brasa, inei.gob.pe, 2015).

\subsection{Justificación del Proyecto}

En primer lugar, la planificación estratégica es un listado de acciones que se configuran de tal forma que permita concretar objetivos en un plazo determinado. Asimismo, esta planificación estratégica se enmarca en tomar decisiones actuales teniendo en cuenta el impacto de las mismas en el futuro, involucrando a todas las personas dentro de la empresa (Ayestarán, Rangel, \& Sebastián, 2012).

En base a lo expuesto anteriormente, el proyecto se enmarca en la importancia de contar con un plan estratégico que, a través de acciones estratégicas organizacionales, 
permita tener un rumbo competitivo, satisfaciendo las expectativas de los diferentes grupos de interés (Sainz, 2015). Lo precisado repercutirá en analizar y entender la situación actual de la organización, definir los objetivos estratégicos, determinar las metas e indicadores que se deben alcanzar en un lapso definido, precisar y construir los caminos estratégicos, y vincular todo ello con los recursos que se disponen para alcanzar el futuro deseado (Proceso de Planeamiento Estratégico del Ministerio de Agricultura y Riego [MINAGRI], minagri.gob.pe, 2014).

Por otro lado, no contar con un plan estratégico deriva en la presencia de problemas, tales como: aparición recurrente de situaciones imprevistas, falta de control de un verdadero éxito o fracaso de la empresa, ausencia de una guía concreta y clara, falta de variables que permitan decidir nuevas inversiones y gastos a realizar, así como desperdicios y malas gestiones que repercuten en pérdidas económicas e insolvencia organizacional (Martínez, 2014).

Se hace apremiante tener en consideración la elaboración de un plan estratégico para Norky's, ya que, a pesar de tener un crecimiento sostenido en el mercado peruano por la calidad de sus productos, éste no ha sido acompañado de una institucionalización que eleve su competitividad, penetración y participación en el sector. En esa línea, el plan estratégico ayudará a tecnificar a la organización, facilitando tener respuestas a: ¿Cómo estamos hoy?, ¿Dónde queremos ir? y ¿Cómo vamos a llegar?, y de esa forma, garantizar el éxito organizacional.

\subsection{Investigación de Mercado}

El desarrollo del trabajo se realizó por medio de la investigación en fuentes primarias y secundarias. Las fuentes primarias reúnen documentos corporativos conformados por los manuales de procedimientos operativos, diagnóstico y plan de acción de Norky’s, protocolos 
de atención al cliente, check lists de áreas operativas, cuadros de principales proveedores, inventario interno de puestos de trabajo y locales, materiales de mercadotecnia, así como entrevistas a diversas gerencias de la empresa y a un experto externo a la empresa, tales como:

- Gerente General de 29 tiendas de Norky’s.

- Gerente de Operaciones de MACROSCEM.

- Gerente de Marketing de MACROSCEM.

- Jefe de Sistemas de MACROSCEM.

- Gerente de Auditoría y Control de MACROSCEM.

- Gerente General de Pollerías a la Casa.

Por otro lado, las fuentes secundarias reúnen bibliografías académicas, documentos de investigación cuantitativos y artículos web.

\subsection{Objetivos Generales y Específicos}

El objetivo general de la investigación es elaborar un plan estratégico para Norky's para el periodo 2018-2020, con el fin de institucionalizar, mediante la automatización y estandarización, los procesos administrativos y operativos, que permita incrementar el nivel de satisfacción de los colaboradores y clientes, y, por ende, impactar positivamente en el margen operativo, a través de una adecuada gestión de las áreas que dan soporte a la operación.

Los objetivos específicos de la investigación son:

- Diagnosticar la situación en que se encuentra la empresa, la problemática que enfrenta y/o la oportunidad presente en el mercado. 
- Explicar la situación actual de la empresa, describir el negocio, los productos que se ofrecen, así como el ciclo de vida de estos. Además, mostrar la estructura organizacional de la empresa, y su situación de mercado y financiera.

- Formular la visión y misión, y determinar los valores para la empresa.

- Realizar un análisis de cada una de las variables externas (político-gubernamental, económico, legal, cultural, tecnológico y ecológico), tendencias e impacto que generan en la empresa, clientes y proveedores.

- Realizar un análisis de cada una de las Cinco Fuerzas Competitivas del sector, así como de la demanda y oferta del mercado.

- Realizar un análisis de cada una de las actividades de la cadena de valor, hacer un comparativo con los líderes de la industria y determinar las ventajas competitivas de la empresa.

- Definir el alcance y planteamiento de los objetivos estratégicos de la empresa, y realizar el diseño y formulación de las estrategias en base a las matrices propuestas.

- Definir los criterios de selección que se tomarán en cuenta para la selección de la estrategia, así como los escenarios a considerar y describir la estrategia seleccionada y la estrategia contingente.

- Elaborar el cuadro de mando integral o mapa de la estrategia y definir los objetivos específicos, así como los indicadores, metas e iniciativas a llevar a cabo para cada objetivo. Además, determinar el responsable, presupuesto y cronograma para cada una de las iniciativas.

- Realizar una evaluación cualitativa de la estrategia, en base a criterios definidos, y una evaluación financiera, haciendo una comparación entre la situación actual y la situación proyectada con la nueva estrategia. 


\subsection{Alcances y Limitaciones de la Investigación}

El alcance de la investigación consiste en elaborar un Plan Estratégico para Norky’s en Lima Metropolitana, para el periodo 2018-2020.

Las principales limitaciones de la investigación son:

- La información histórica de la empresa no se encuentra debidamente estructurada, lo que dificulta el análisis de la misma.

- No hay una fuente de comunicación óptima que facilite la captación de información. 


\section{Capítulo II. La Empresa}

\subsection{Antecedentes de la Empresa}

Norky's es una empresa familiar, fundada por el señor Kiyotake Tamashiro, que tuvo sus inicios en el mes de setiembre de 1976, teniendo como primer local el ubicado en el Centro de Lima, e iniciando así, la venta de pollos a la brasa en el mercado nacional. Norky's es una de las empresas pioneras que ofrece pollos a la brasa acompañado de un servicio de calidad y una infraestructura adecuada.

Entre los años 2013 y 2014, debido al crecimiento sostenido de la empresa, Carlyle Group e Intercorp estuvieron interesados en la compra de la Norky's; sin embargo, ninguna oferta tuvo éxito, por lo que la empresa siguió con el funcionamiento regular.

Los años de ardua labor y la aceptación del producto por parte del público han permitido a Norky's inaugurar varios locales en Lima, así como en provincias, sobre todo en aquellas que tienen mayor protagonismo económico. Actualmente, Norky’s cuenta con 136

tiendas a nivel nacional (ver Figura 1), representada cada una por una razón social con la denominación de Sociedad Anónima Cerrada (S.A.C.), y es una de las pollerías más recordada y preferida en el mercado peruano (Un gusto por conquistar, arellanomarketing.com, 2013). Estas tiendas reciben un soporte administrativo exclusivo de Macro’s Consultores Empresariales Sociedad Anónima Cerrada (MACROSCEM S.A.C.), representado por el señor Diego Abel Buendía Ramírez. 


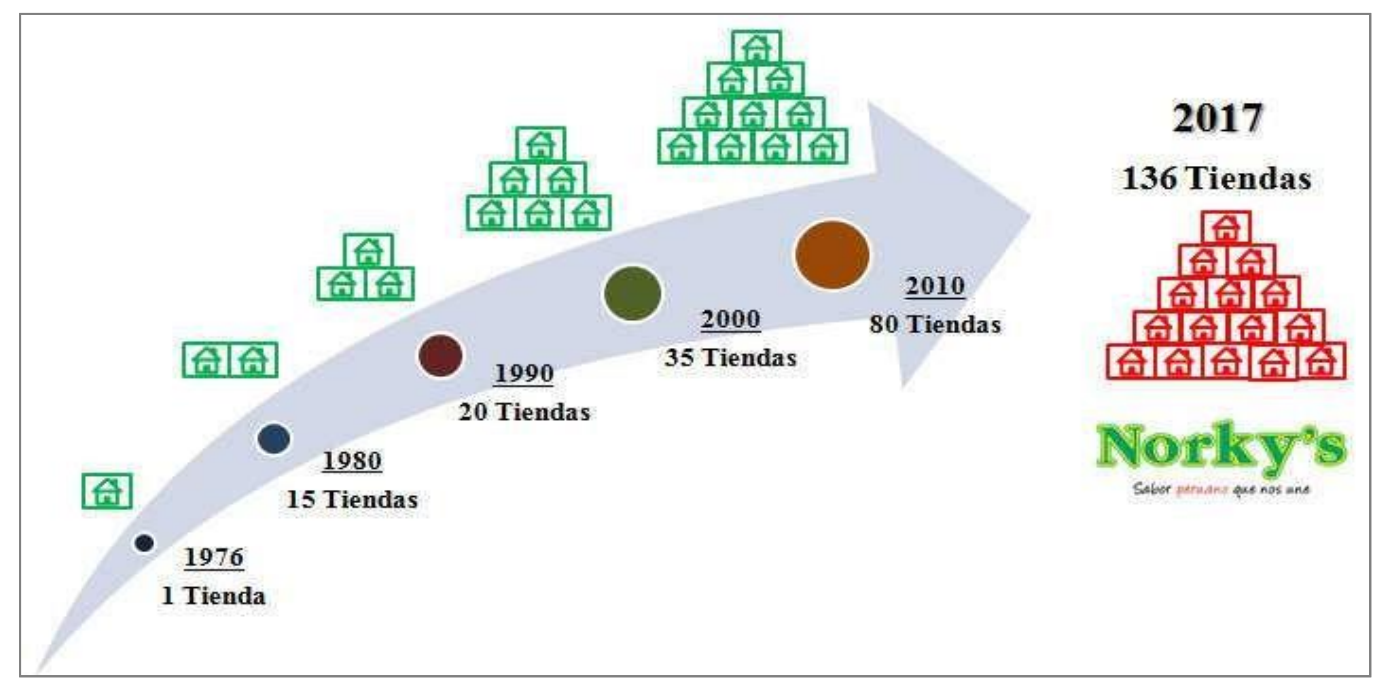

Figura 1. Inicio y Crecimiento de Norky's.

\subsection{Descripción del Negocio}

El negocio de Norky's se centra en la venta de pollos a la brasa, a través de sus

diferentes locales a nivel nacional, acompañado de un servicio de calidad y una

infraestructura adecuada para la satisfacción del cliente. Además de su producto bandera,

ofrece una gran variedad de platos con la misma calidad y buen sabor (ver Tabla 1).

Tabla 1

Platos de Norky's

\begin{tabular}{lll}
\hline Entradas y Piqueos & Parrillas & Salteados \\
\hline Mollejitas & Parrilla Fina Norky's & Tallarín Saltado de Pollo \\
Yuquitas & Parrilla del Chef & Tallarín Saltado de Carne \\
PiqueosNorky's & Parrilla Especial Norky's & Arroz Chaufa de Pollo \\
Anticuchos & 1/2 Parrilla Norky's & Arroz Chaufa de Carne \\
Nuggets & & Saltado de Pollo \\
& & Saltado de Carne \\
\hline Ensaladas & Pechugas a la Parrilla & Carnes a la Parrilla \\
\hline Ensalada Primavera & Pechuga Norky's & Churrasco a lo Pobre \\
Ensalada Mixta Doble & Pechuga Light & Chuleta \\
Ensalada Mixta Especial & Pechuga Campesina & Lomo Fino \\
Ensalada Cocida & Pechuga de Pavita BBQ & \\
Ensalada Norky's & Pechuga de Pavita Norky's & \\
\hline
\end{tabular}

Nota. Tomado de Página Web de Norky's. Recuperado de http://norkys.pe/\#MENU 
Norky’s se centra básicamente en Lima Metropolitana, donde cuenta con 92 tiendas (ver Anexo 1), lo cual representa el 62\% del total a nivel nacional. De estas tiendas, los distritos más representativos son San Juan de Lurigancho (11 tiendas), Cercado de Lima (9 tiendas) y Ate (7 tiendas) (ver Figura 2).

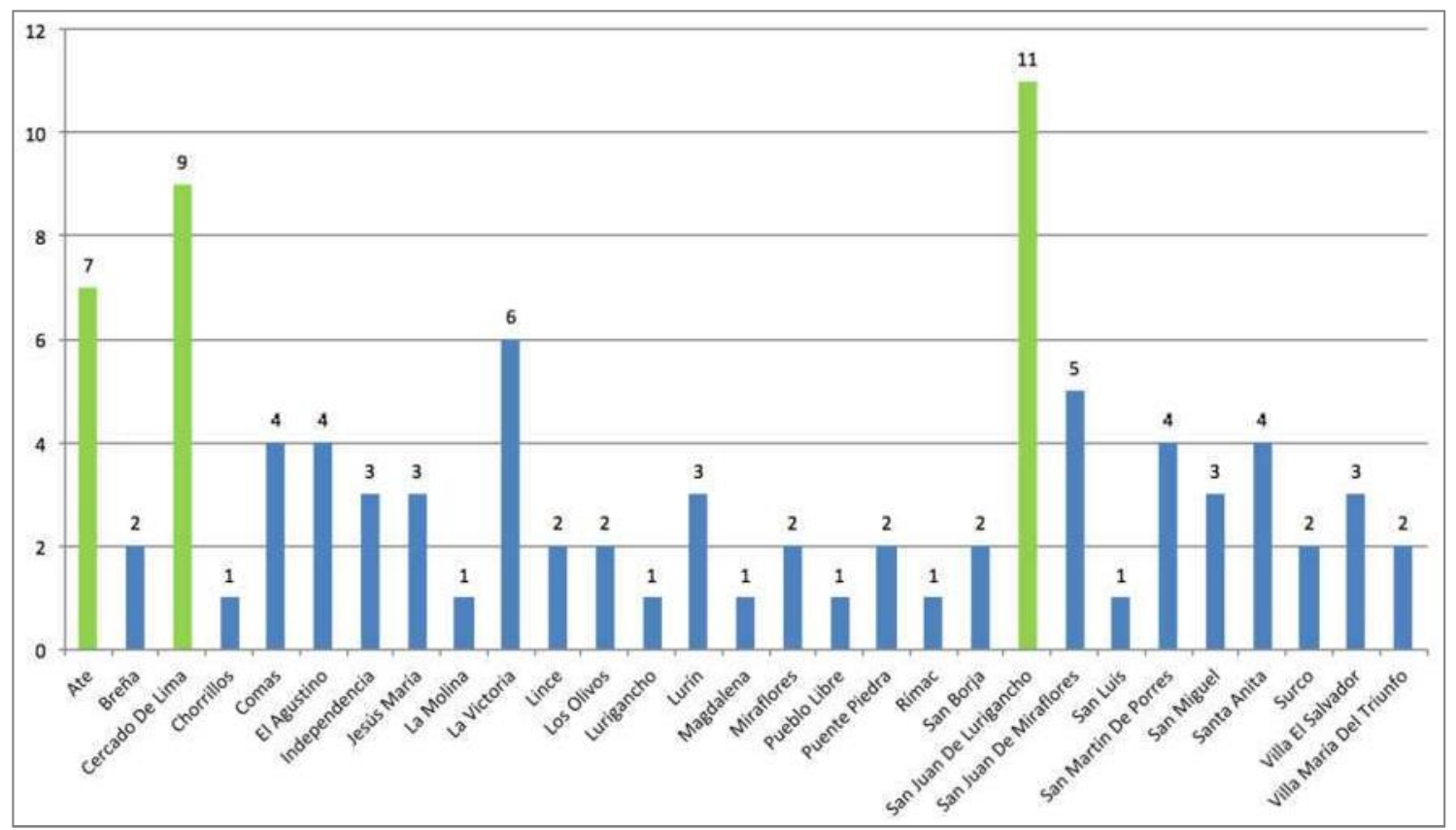

Figura 2. Cantidad de Tiendas por Distrito en Lima Metropolitana de Norky's. Recuperado de http://norkys.pe/restaurantes

Asimismo, teniendo en cuenta la distribución de los niveles socioeconómicos, las zonas 4 y 5 son aquellas donde se concentra la mayor cantidad de tiendas, con 18 y 17 respectivamente (ver Tabla 2) (Asociación Peruana de Investigación de Mercados [APEIM], 2016). 
Tabla 2

Distribución de Niveles Socioeconómicos por Zona en Lima Metropolitana

\begin{tabular}{|c|c|c|c|c|c|c|c|}
\hline \multirow{2}{*}{ Zona } & \multirow{2}{*}{$\begin{array}{l}\mathrm{N}^{\circ} \text { de } \\
\text { Tiendas }\end{array}$} & \multicolumn{6}{|c|}{ Niveles Socioeconómicos } \\
\hline & & NSA & NSB & NSC & NSD & NSE & TOT. \\
\hline $\begin{array}{l}\text { Zona } 1 \text { (Puente Piedra, Comas, } \\
\text { Carabayllo) }\end{array}$ & 6 & $5.20 \%$ & $22.30 \%$ & $40.50 \%$ & $24.30 \%$ & $7.70 \%$ & $100 \%$ \\
\hline $\begin{array}{l}\text { Zona } 2 \text { (Independencia, Los } \\
\text { Olivos, San Martín de Porres) }\end{array}$ & 9 & $1.00 \%$ & $10.70 \%$ & $44.30 \%$ & $31.50 \%$ & $12.50 \%$ & $100 \%$ \\
\hline Zona 3 (San Juan de Lurigancho) & 11 & $1.90 \%$ & $23.10 \%$ & $51.50 \%$ & $21.00 \%$ & $2.50 \%$ & $100 \%$ \\
\hline $\begin{array}{l}\text { Zona } 4 \text { (Cercado de Lima, } \\
\text { Rímac, Breña, La Victoria) }\end{array}$ & 18 & $3.80 \%$ & $26.70 \%$ & $45.00 \%$ & $19.90 \%$ & $4.60 \%$ & $100 \%$ \\
\hline $\begin{array}{l}\text { Zona } 5 \text { (Ate, Chaclacayo, } \\
\text { Lurigancho, Santa Anita, San } \\
\text { Luis, El Agustino) }\end{array}$ & 17 & $2.00 \%$ & $12.10 \%$ & $40.60 \%$ & $36.30 \%$ & $8.90 \%$ & $100 \%$ \\
\hline $\begin{array}{l}\text { Zona } 6 \text { (Jesús María, Lince, } \\
\text { Pueblo Libre, Magdalena, San } \\
\text { Miguel) }\end{array}$ & 10 & $13.60 \%$ & $58.00 \%$ & $22.40 \%$ & $5.20 \%$ & $0.70 \%$ & $100 \%$ \\
\hline $\begin{array}{l}\text { Zona } 7 \text { (Miraflores, San Isidro, } \\
\text { San Borja, Surco, La Molina) }\end{array}$ & 7 & $34.60 \%$ & $45.20 \%$ & $14.00 \%$ & $5.00 \%$ & $1.20 \%$ & $100 \%$ \\
\hline $\begin{array}{l}\text { Zona } 8 \text { (Surquillo, Barranco, } \\
\text { Chorrillos, San Juan de } \\
\text { Miraflores) }\end{array}$ & 6 & $4.20 \%$ & $27.80 \%$ & $43.30 \%$ & $20.10 \%$ & $4.60 \%$ & $100 \%$ \\
\hline $\begin{array}{l}\text { Zona } 9 \text { (Villa el Salvador, Villa } \\
\text { María, Lurín, Pachacamac) }\end{array}$ & 8 & $0.00 \%$ & $6.10 \%$ & $42.70 \%$ & $38.70 \%$ & $12.50 \%$ & $100 \%$ \\
\hline
\end{tabular}

Nota. Tomado de Niveles Socioeconómicos 2016. Recuperado de

http://www.apeim.com.pe/wp-content/themes/apeim/docs/nse/APEIM-NSE-2016.pdf

La venta de pollos a la brasa ha hecho crecer a la empresa, tal como se muestra en la

Figura 1, ya que ha ido acompañado de un adecuado servicio. Por esta razón, la empresa

busca analizar el servicio brindado, a través de un formato de evaluación del servicio

aplicado por clientes incógnitos (ver Anexo 2), los cuales tienen como función evaluar tres

variables fundamentales del servicio: (a) instalación, (b) presentación, y (c) atención al cliente, arrojando como resultado un indicador servicio. 
En la instalación se considera la infraestructura del local; en la presentación, el montaje de la mesa; y en la atención al cliente, el trato que reciben los mismos. Las tres variables están por encima del promedio, según el índice de evaluación del servicio (ver Anexo 3).

\subsection{Ciclo de Vida del Producto}

El ciclo de vida de un producto pasa por diferentes etapas, desde el momento en el que se lanza al mercado hasta que se retira; la curva de vida es una sucesión progresiva de etapas en el que se aprecia el comportamiento de la demanda sobre un producto. La finalidad de conceptualizar el ciclo de vida de un producto, permite centrarse estratégicamente en optimizar el desarrollo e implementación de nuevos posibles productos en un mercado (Munuera \& Rodríguez, 2007).

El pollo a la brasa se ha convertido en un símbolo de la comida peruana, ya que los consumidores lo prefieren al momento de realizar una salida gastronómica, debido a su sabor especial y condimentado. Otra de las principales razones de su éxito en el mercado peruano es que "es un producto para todos", posicionándolo así, como uno de los platos preferidos de las familias peruanas (Arellano, 2015).

En la Figura 3 se observa que el ciclo de vida del pollo a la brasa de Norky’s presenta un crecimiento lento, por lo tanto, se puede afirmar que el producto se encuentra en una etapa de madurez, esto se basa en las utilidades generadas por cada producto de la empresa, siendo el pollo a la brasa el producto más representativo con una utilidad del 66\% (ver Anexo 4). 


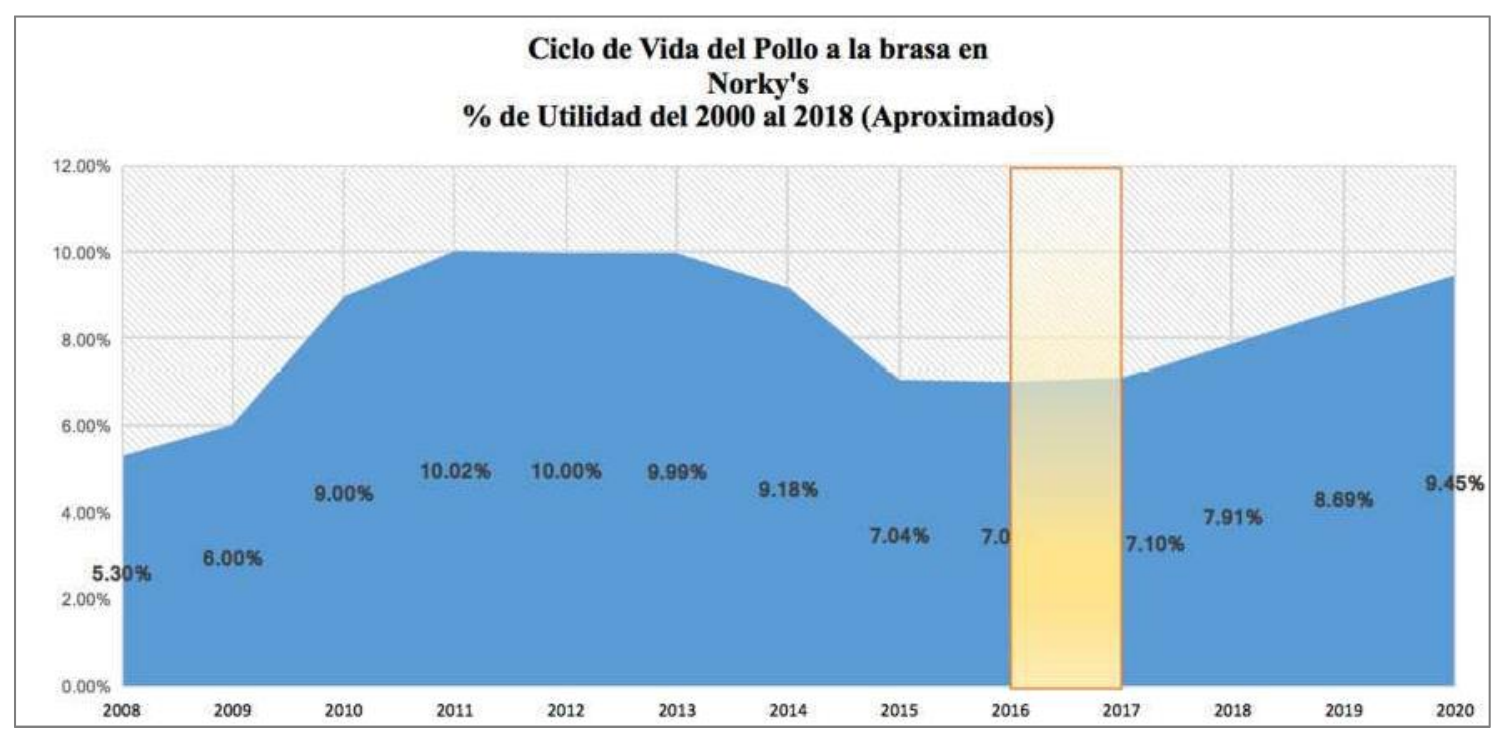

Figura 3. Ciclo de vida del pollo a la brasa en Norky's

\subsection{Estructura Organizacional Actual de la Empresa}

La estructura organizacional es un factor clave dentro de una empresa, ya que puede influir en la forma de gestionar un proyecto o dirigir una empresa, así como en la disponibilidad de los recursos (Project Management Institute [PMI], 2013).

Norky's es una empresa familiar, de primera y segunda generación, que tiene una estructura organizacional funcional y que no cuenta con un plan de sucesión. Asimismo, se resalta que algunos puestos estratégicos están ocupados por miembros de la familia. Según el PMI (2013), la estructura funcional es la más utilizada en las organizaciones, ya que consiste en una jerarquía claramente definida, donde cada empleado tiene un superior directo.

La estructura organizacional de Norky's se basa en dos frentes: Back Office y Front Office. El primero se encuentra conformado por las áreas que brindan apoyo y soporte al negocio, y es representado por la empresa MACROSCEM S.A.C. (ver Figura 4); y el segundo, por un equipo de personas que se encuentran en las tiendas, las cuales se dividen en restaurantes y patios. 
La estructura organizacional de las tiendas de Norky’s, que son el público objetivo del trabajo, presentan las siguientes características funcionales obtenidas a través del cuestionario del clima laboral (ver Anexo 5):

- La comunicación no es la adecuada debido a la insuficiente constancia y expresión comunicativa de los jefes inmediatos y colaboradores.

- El trabajo en equipo es adecuado, ya que existe una percepción favorable de ello y buenos resultados; sin embargo, hay que mejorar el seguimiento de los resultados por parte de los jefes inmediatos.

- El liderazgo es aceptable, ya que, si bien los jefes inmediatos tienen influencia en la realización de las tareas de los colaboradores, falta desarrollar un mejor ambiente de trabajo y solidarizarse con los colaboradores para el logro de las tareas encomendadas.

- La motivación es adecuada, ya que los colaboradores se sienten motivados al trabajar con sus compañeros y precisan que hay un reconocimiento de sus logros por parte de la empresa; sin embargo, es importante mejorar el reconocimiento de los logros por los jefes inmediatos.

- La identidad de los colaboradores con la empresa y sus tareas es aceptable; sin embargo, al ser una empresa con un tiempo significativo en el mercado, debería tener una identidad más intensa.

- Finalmente, el clima laboral está en 70\%, según el índice de evaluación (ver Anexo 6), pero el objetivo a mediano plazo es llegar a $85 \%$. 


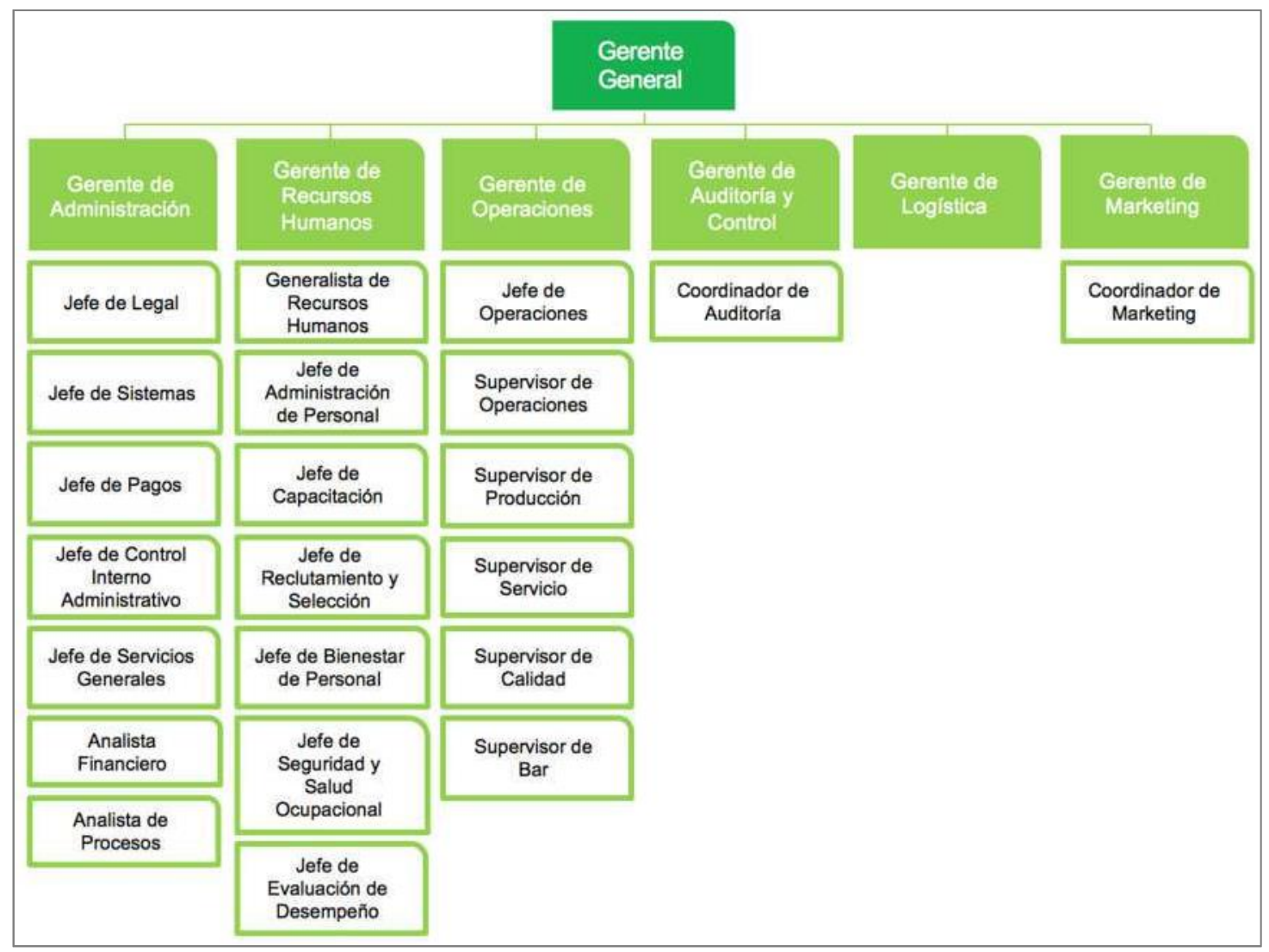

Figura 4. Organigrama de MACROSCEM S.A.C.

El área de Administración está conformada por el Gerente de Administración, y los Jefes de las áreas Legal, Sistemas, Pagos, Control Interno Administrativo y Servicios Generales, así como el Analista Financiero, Analista de Procesos y asistentes. Esta área tiene como función principal dar soporte a los procesos de negocio de la empresa, donde el área Legal se encarga de gestionar los reclamos y quejas presentados por los consumidores en el Libro de Reclamaciones y representar legalmente a la empresa en situaciones jurídicas; el área de Sistemas, de asegurar la disponibilidad y operatividad de los sistemas y equipos informáticos, y dar soporte técnico a los usuarios; el área de Pagos, de programar y realizar los pagos a los proveedores; el área de Control Interno Administrativo, de proteger los activos de la empresa; y el área de Servicios Generales, de proporcionar los servicios necesarios para la operatividad de las tiendas. 
El área de Recursos Humanos está conformada por el Gerente de Recursos Humanos, el Generalista de Recursos Humanos, los Jefes de Administración de Personal, Capacitación, Reclutamiento y Selección, Bienestar de Personal, Seguridad y Salud Ocupacional, y Evaluación de Desempeño, así como los asistentes. El área de Administración de Personal se encarga de realizar los pagos y administrar las vacaciones del personal; el área de Capacitación, de dirigir las escuelas de formación para Administradores, Cajeros, Jefes de Mozo, Mozos, Cocineros y Horneros; el área de Reclutamiento y Selección, de responder oportunamente a las necesidades de personal que se presenten en las áreas; el área de Bienestar de Personal, de atender las necesidades de los colaboradores y gestionar los trámites documentarios; el área de Seguridad y Salud Ocupacional, de gestionar y controlar los factores que ponen en riesgo a los colaboradores; y el área de Evaluación de Desempeño, de medir el grado de cumplimiento de los objetivos de cada colaborador.

El área de Operaciones está conformada por el Gerente de Operaciones, los Jefes de Operaciones, los Supervisores de Operaciones, Producción, Servicio, Calidad y Bar, así como los Analistas de Procesos y asistentes. Esta área tiene como función principal administrar los recursos necesarios para elaborar el producto final y garantizar la calidad del mismo, donde los Supervisores de Operaciones controlan directamente a los administradores de las tiendas.

El área de Auditoría y Control está conformada por el Gerente de Auditoría y Control, el Coordinador de Auditoría, así como los asistentes. Esta área tiene como función principal asegurar que las actividades de la empresa se lleven a cabo respetando las normas y procedimientos establecidos de manera interna, por las gerencias de la empresa, o externa, por organismos públicos.

El área de Logística está conformada por el Gerente de Logística y los asistentes, quienes se encargan de gestionar óptimamente el aprovisionamiento de la materia prima, 
ejecutar y controlar las funciones de la cadena de suministro, y llevar a cabo las actividades de compra, transporte, almacenaje y distribución de una manera óptima.

El área de Marketing está conformada por el Gerente de Marketing, el Coordinador de Marketing, así como los asistentes, quienes se encargan principalmente de investigar el mercado, los consumidores y la competencia, crear un plan de acción para hacer más atractiva la marca, implementar el plan y monitorear los resultados.

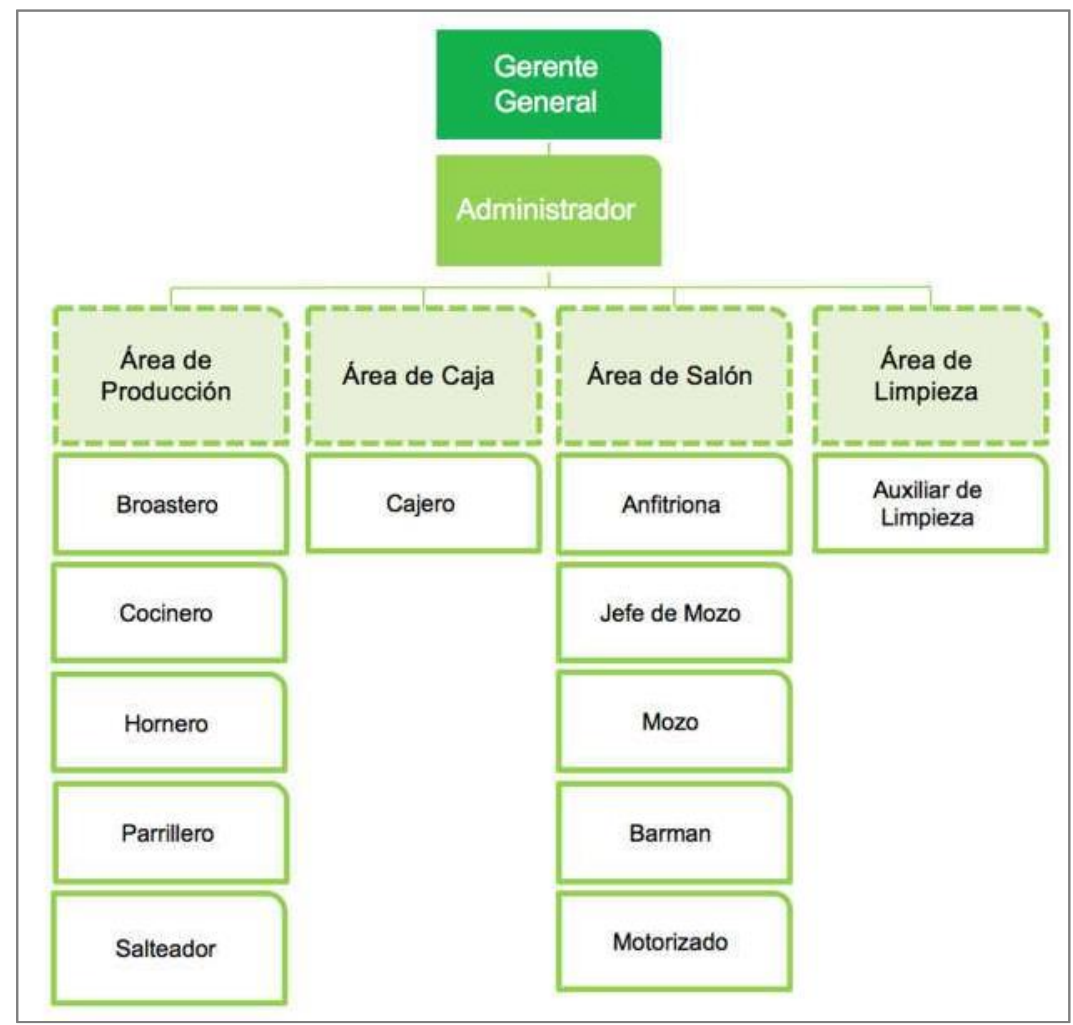

Figura 5. Organigrama de Restaurantes de Norky's. 


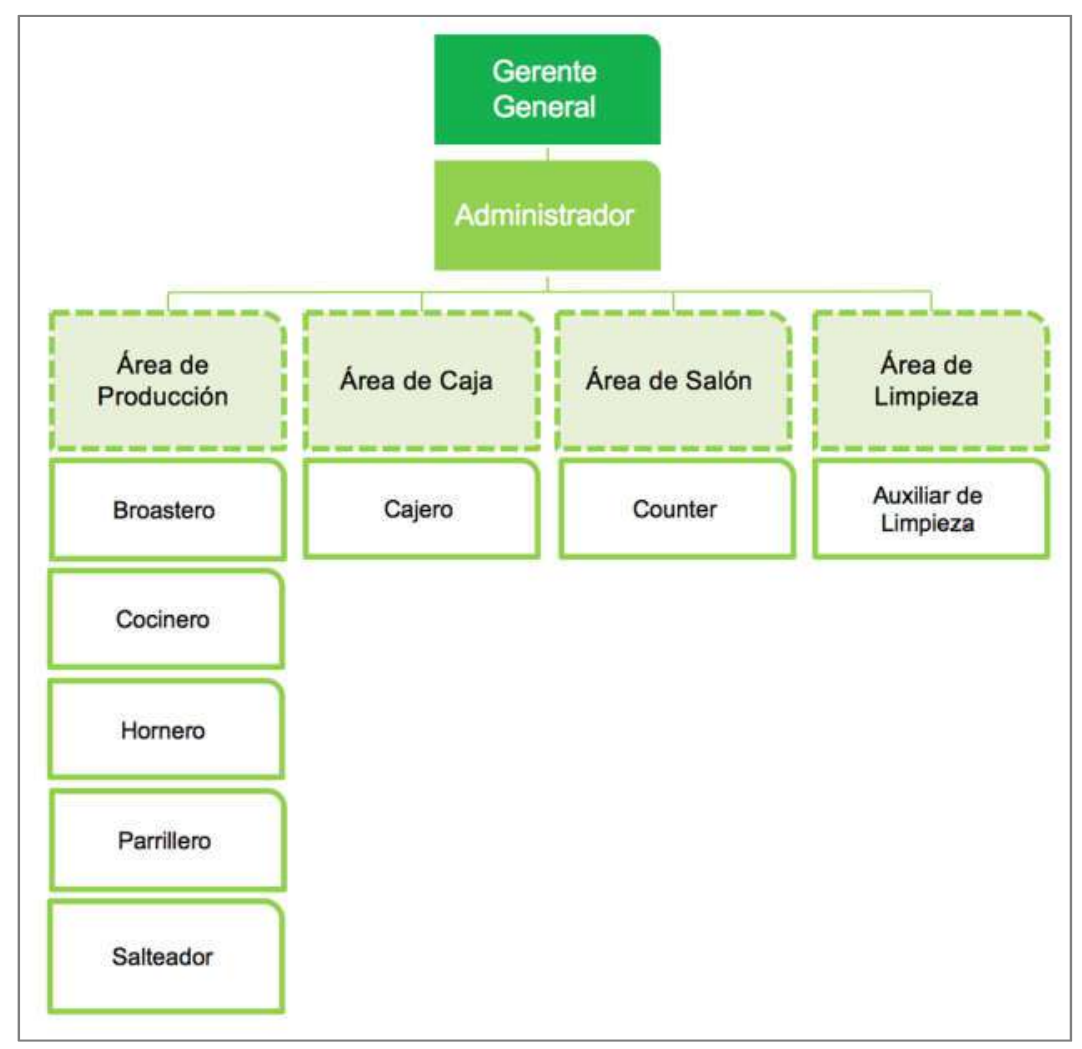

Figura 6. Organigrama de Patios de Norky's.

Como se precisó líneas arriba, las tiendas están divididas en restaurantes y patios (ver Figura 5 y 6), los restaurantes son aquellos que tienen un establecimiento exclusivo y cuentan con un equipo en el área de salón para atender a los comensales, y los patios son los que se encuentran en los centros comerciales y tiene un modelo de autoservicio.

Las tiendas están representadas por un Gerente General, quien es el representante legal de la razón social, y un administrador, quien reporta directamente al Supervisor de Operaciones. Bajo la dirección del administrador se encuentran los miembros del área de Producción, Caja, Salón y Limpieza, quienes realizan las actividades operativas, con el fin de brindar el mejor servicio a los clientes. 


\subsection{Situación de Mercado y Financiera Actual del Sector}

El sector de Alojamientos y Restaurantes (INEI, 2016), se divide en diferentes industrias de restaurantes, tales como: comidas rápidas, chifas, pollerías, cevicherías, entre otros. La evolución de la actividad de restaurantes, entre los años 2015 y 2016, se ha mantenido a un ritmo lento (ver Figura 7). Por ello, se afirma que el ciclo de vida de este sector se encuentra en una etapa de madurez (Encuesta Mensual del Sector Servicios, inei.gob.pe, 2017). 


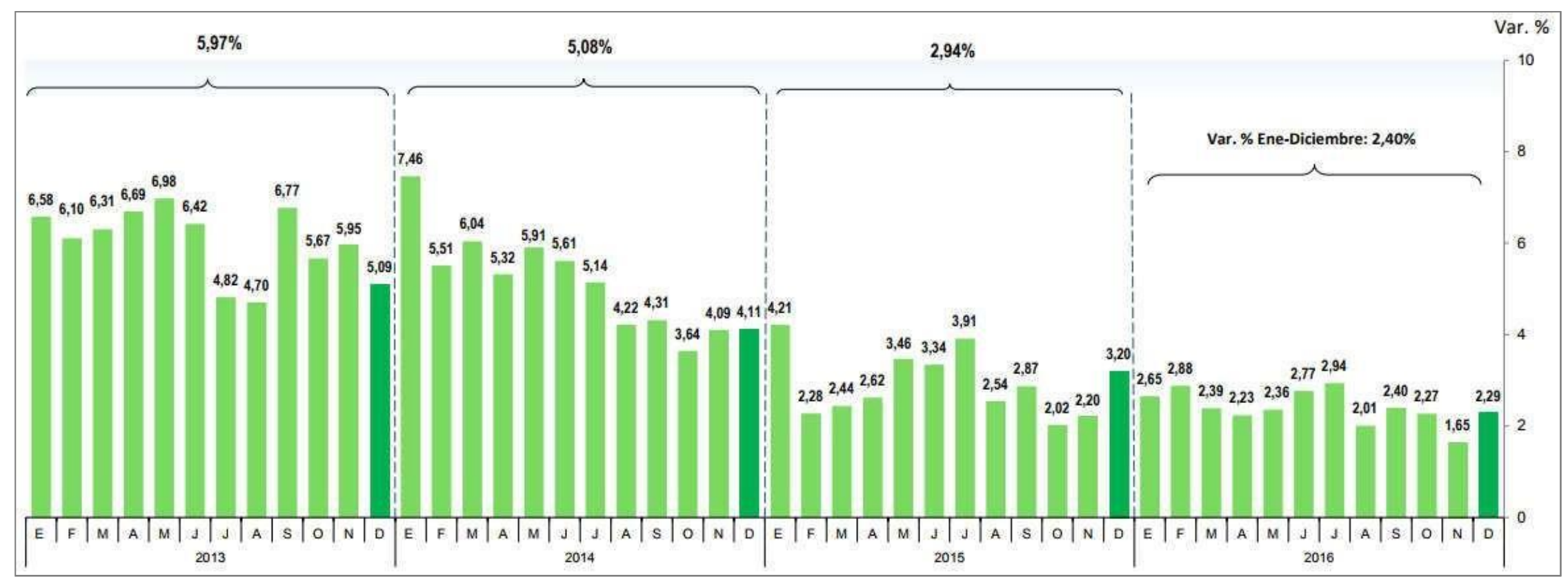

Figura 7. Evolución Mensual de la Actividad de Restaurantes, 2013-2016 (Variación \% respecto a similar periodo del año anterior). Tomado de “Encuesta Mensual del Sector Servicios", por el INEI, 2017. Recuperado de https://www.inei.gob.pe/media/MenuRecursivo/boletines/boletinestadistico-del-sector-servicios-n-07-julio-2017.pdf 
Para identificar la demanda de pollo en el sector de restaurantes, se tiene que conocer primero la industria avícola en el Perú, la cual se refleja, a través del comportamiento de la producción de pollos generado en los últimos años. La producción avícola nacional ha tenido un crecimiento de $6.16 \%$ a diciembre 2015, 5.80\% a diciembre 2016 y $2.43 \%$ en el año 2017 (ver Figura 8 y 9) (MINAGRI, 2015). La producción avícola del año 2017 creció solo el $2.43 \%$, debido a que la oferta de carne de ave presentó un decremento de $4.1 \%$ en el año 2017 (MINAGRI, 2017).

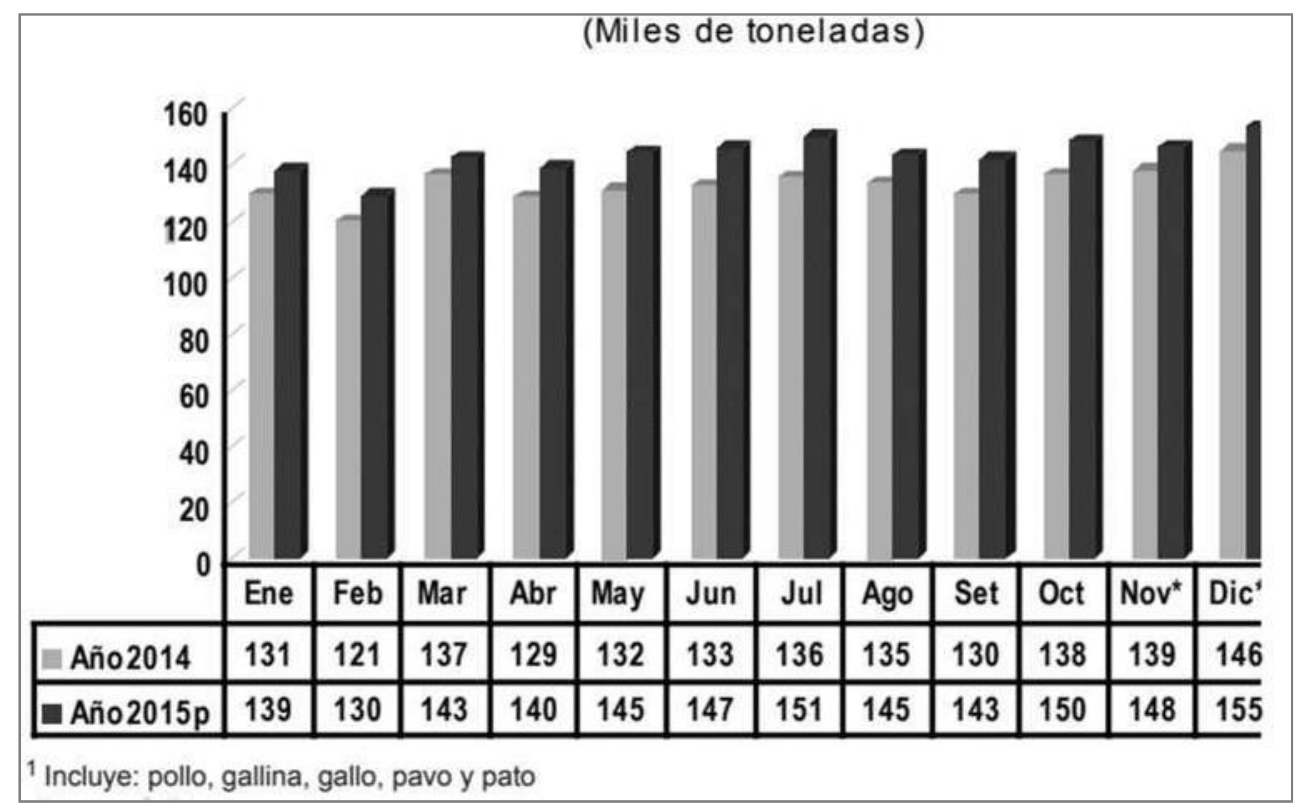

Figura 8. Perú. Producción Nacional de Aves, MINAGRI, 2015. Recuperado de http://minagri.gob.pe/portal/boletin-estadistico-mensual-de-la-produccion-ycomercializacion-avicola/sector-avicola-2015?download=8773: diciembre-2015 


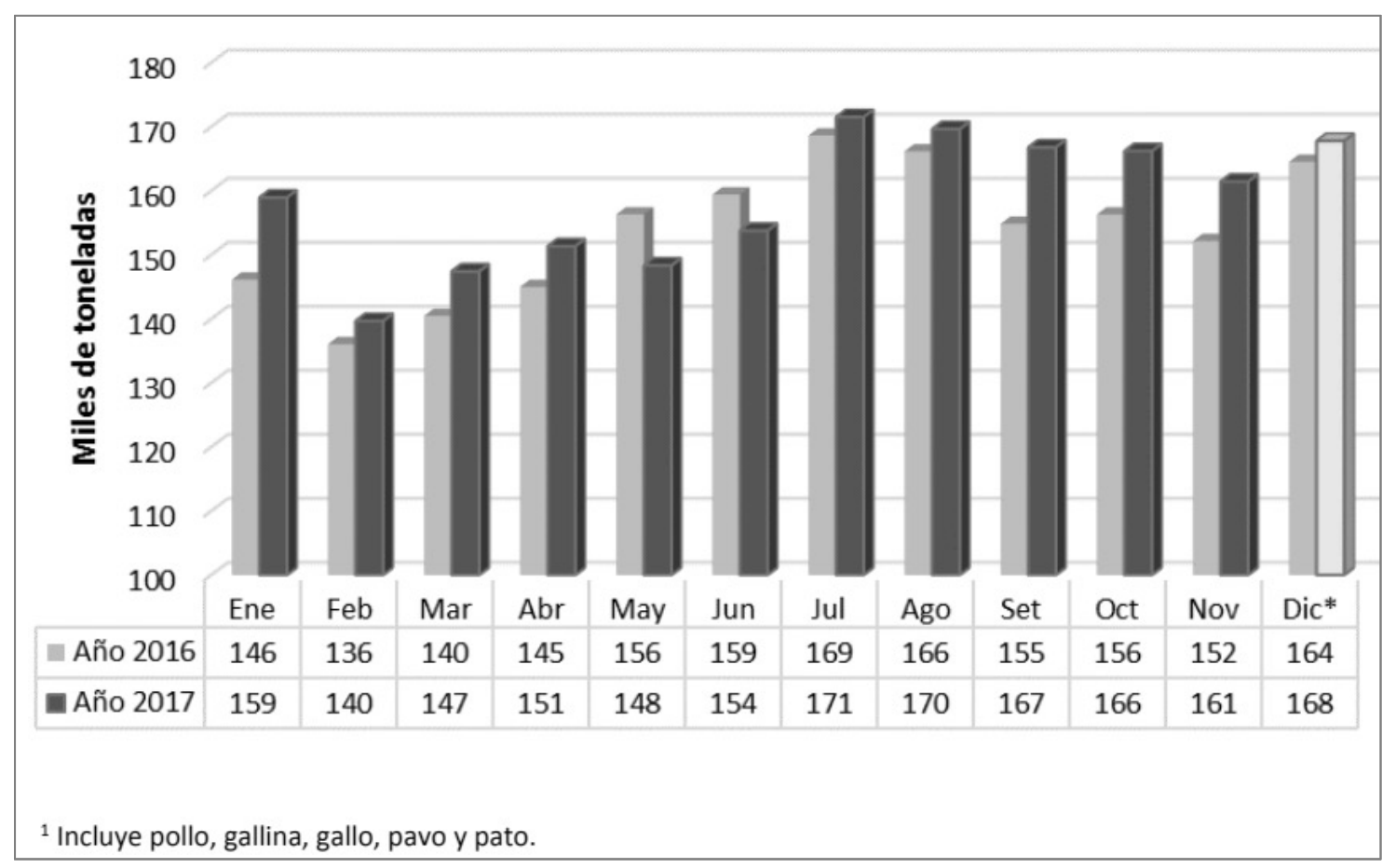

Figura 9. Perú. Producción de ave viva. Enero 2016- Noviembre 2017, MINAGRI, 2017.

Recuperado de http://minagri.gob.pe/portal/boletin-estadistico-mensual-de-la-produccion-ycomercializacion-avicola/sector-avicola-2017?download=12338:sector-avicola-noviembre2017

Los grupos de empresas que utilizan la misma estrategia en un mercado focalizado son denominados grupos estratégicos (Kotler, 2012). En la Figura 10, se puede apreciar las diferentes pollerías que conforman un grupo estratégico a nivel de cadenas de pollerías. En ese sentido, Norky's viene utilizando la estrategia de la expansión de tiendas en el mercado nacional, debido al incremento de la demanda total de mercado, lo que le permite tener mayor participación de mercado y recordación. La participación de preferencia es fuerte debido a los costos y el servicio que brindan a los clientes, y también le da poder de negociación frente a los proveedores, ya que garantiza el consumo de sus productos. 


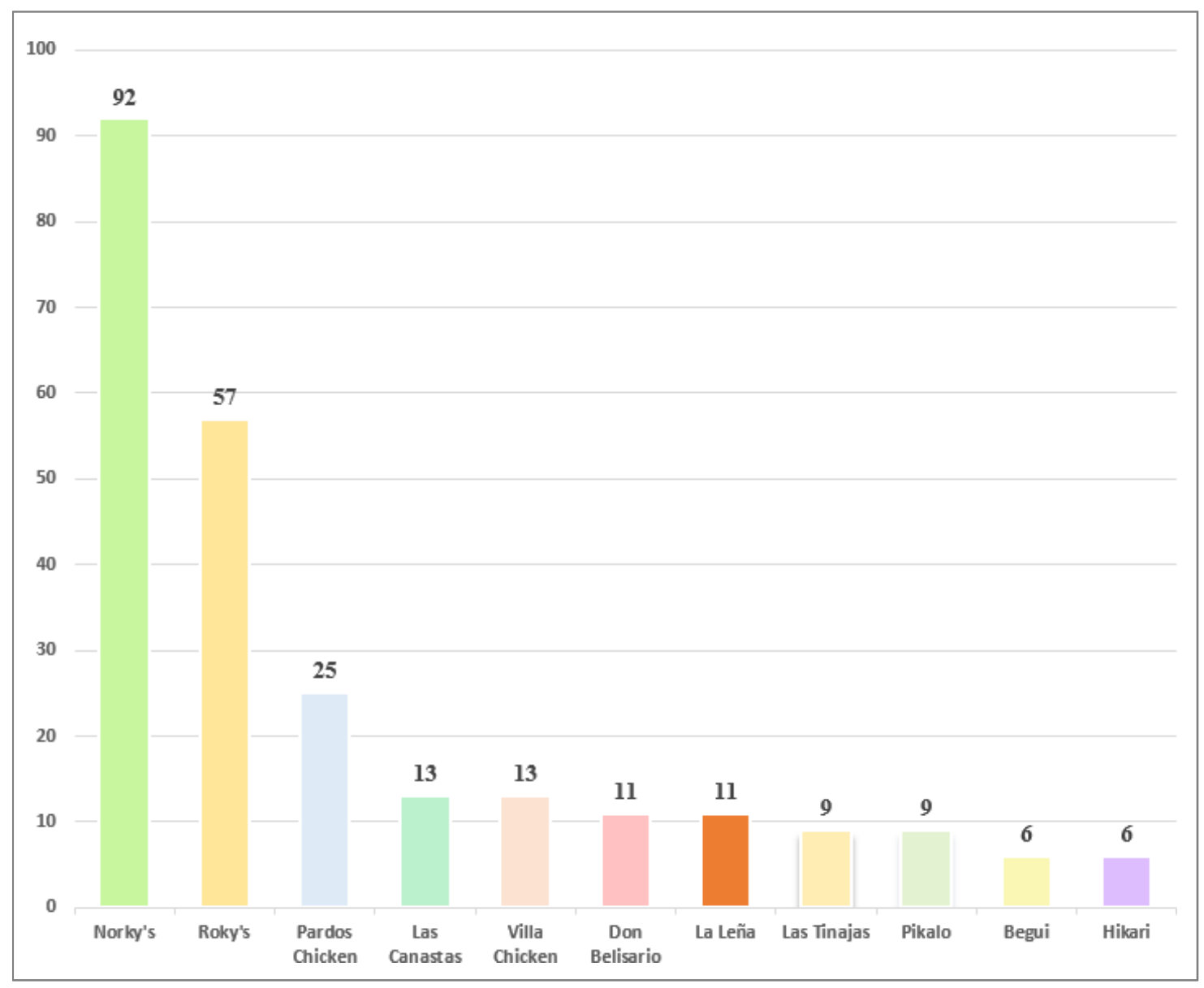

Figura 10. Cadenas de Pollerías en Lima Metropolitana a Diciembre 2017. Recuperado de http://norkys.pe/restaurantes, http://rokys.com/locales/, http://www.pardoschicken.pe/restaurantes/, http://www.lascanastas.com/\#gotolocal, https://www.villachicken.com.pe/villaweb/app/\#/locales, http://www.donbelisario.com.pe/locales-reservas, http://www.lalena.com.pe/pollos-a-la-lena/, http://www.lastinajas.pe/\#local, http://pikalo.com.pe/locales.php, http://www.pollosbegui.com.pe/locales, http://hikari.pe/ 


\section{Capítulo III. Formulación de Visión, Misión y Valores de la Empresa}

\subsection{Visión}

La visión es una manifestación que debe responder a la pregunta: “¿Qué queremos llegar a ser?", es decir, qué pretende hacer realidad la empresa en un periodo de tiempo definido. Una visión bien realizada otorga fundamento para realizar una misión integral, por ello la importancia de realizar una visión inicialmente. Cabe agregar que la visión debe ser corta y su elaboración debe contar con la participación de tantos gerentes como sea posible (David, 2013).

\subsubsection{Visión actual de la empresa.}

Norky's no cuenta con una declaración formal de la visión que represente un compromiso real para los miembros de la empresa; sin embargo, en el año 2016, el área de Recursos Humanos planteó la siguiente visión para la empresa:

"Llegar a consolidarse como la cadena más exitosa de pollos a la brasa y parrillas a nivel nacional."

\subsubsection{Análisis de la visión actual.}

De acuerdo a lo manifestado por los autores Thompson, Peteraf, Gamble, y Strickland (2012) sobre qué se debe hacer y qué evitar al elaborar una declaración de visión, se presenta lo siguiente (ver Tabla 3): 
Tabla 3

Redacción de una Declaración de Visión. Qué hacer, qué evitar

\begin{tabular}{l} 
Qué hacer \\
\hline Asegúrese de su viabilidad. El camino de la \\
empresa debe esbozarse sobre posibilidades \\
razonables de alcanzar. \\
Mantenga el tema. Toda visión debe ser lo \\
suficientemente específica para ofrecer a la \\
empresa una guía para la toma de decisiones y \\
una correcta asignación de recursos.
\end{tabular}

Procure que sea fácil de recordar. La visión debe plantearse de tal forma que se pueda comunicar de manera sencilla, permitiendo una fácil recordación por parte de los miembros de la organización.
Qué evitar

No sea genérico. Una visión que pueda aplicarse a varias empresas derivará en una ausencia de identidad organizacional.

No exprese la visión en términos sosos o poco inspiradores. Una poderosa visión es aquella que sirve de inspiración a los miembros de toda la empresa.

No recurra solo a los superlativos. Para una visión no basta el uso de superlativos tales como: "el más exitoso", "líder", "el mejor", sino que además deben ir acompañados de aspectos específicos que se plantea la empresa.

Nota. Tomado de Administración Estratégica (p. 24), por A.A. Thompson, M.A. Peteraf, J.E.

Gamble y A.J. Strickland, 2012, México, D.F., México: Mc Graw-Hill/Interamericana

Editores.

En ese sentido, se observan aspectos que se debieron evitar al elaborar la visión actual, tales como: la visión se podría aplicar a cualquier cadena de pollerías, ya que carece de identidad derivando en un rumbo genérico ("Genérica"), la visión usa la palabra "exitosa", que es muy ambiciosa pero vacía a la vez, ya que no se precisa en qué se desea ser exitosa

("Uso de superlativo"), y la visión no posee términos, más que el ser "exitosa", que motiven e inspiren al personal y alta dirección ("Poco inspiradora").

\subsubsection{Matriz de la visión propuesta para la empresa.}

Para la declaración de la visión, se realizó una matriz en base a los componentes propuestos por los autores Mastrantonio, Cáliz, Mármol, Rjadell, Coduras, Tapias y Pacreu (2016), teniendo como resultado lo siguiente (ver Tabla4): 
Tabla 4

Matriz de la Visión Propuesta para Norky's

\begin{tabular}{ll}
\hline Componentes & Norky’s \\
\hline ¿Hacia dónde nos dirigimos? & $\begin{array}{l}\text { La cadena de pollerías está dirigida a los niveles } \\
\text { socioeconómicos C y D de Lima y Provincias. }\end{array}$ \\
¿Qué cosas nuevas pretendemos buscar? & $\begin{array}{l}\text { Mejorar el servicio, intensificar la capacitación, y } \\
\text { adquirir herramientas y equipos contemporáneos. }\end{array}$ \\
$\begin{array}{l}\text { ¿Cuál será nuestro modelo de negocios en los } \\
\text { próximos cinco años? }\end{array}$ & $\begin{array}{l}\text { La institucionalización de los procesos y la } \\
\text { focalización hacia el servicio. }\end{array}$ \\
¿En qué clase de organización queremos & $\begin{array}{l}\text { En una organización que siga los siguientes } \\
\text { convertirnos? }\end{array}$ \\
& $\begin{array}{l}\text { Equipo, Calidad en el Servicio, Excelencia } \\
\text { Operativa e Identidad. }\end{array}$
\end{tabular}

¿Cuál es la posición de mercado que Ser una empresa reconocida, no solo por su buen pretendemos lograr dentro de cinco años? sabor, sino por un servicio de excelencia.

Nota. Tomado de Cómo hacer un plan de empresa EUNCET, por P. Mastrantonio, R. Cáliz,

M. Mármol, M. Rjadell, O. Coduras, X. Tapias, y J. Pacreu, 2016: Editorial OmniaScience.

\subsubsection{Visión propuesta.}

Según el análisis realizado en el punto anterior, la visión propuesta para Norky’s es:

“Ser reconocidos como la cadena de pollerías líder en Lima Metropolitana por ofrecer pollos a la brasa y parrillas de sabor inigualable acompañado de un servicio de excelencia.”

\subsection{Misión}

Los conceptos de la misión, que actualmente se encuentran en los libros, están basados en las directrices establecidas por Peter Drucker, a mediados de la década de los setenta. Drucker menciona que la declaración de una misión debe responder a la pregunta “¿Cuál es nuestro negocio?”, ya que debe transmitir claramente el propósito de la empresa y qué lo distingue de otra que ofrece un producto o servicio similar (David, 2013).

La declaración de una misión es fundamental, ya que ayuda a los colaboradores a entender cuál es la razón de ser de la empresa. Además, una correcta declaración de la misión 
permitirá establecer los objetivos y estrategias de la empresa con mayor facilidad. Por otro lado, algunos autores como Rarick y Vitton concluyeron que las empresas que tienen una declaración de una misión formal, tienen un mayor rendimiento promedio que las empresas sin una misión (David, 2013).

La declaración de la misión de una empresa debe ser creada en conjunto por los empleados y gerentes, ya que la participación es la mejor forma de comprometer a las personas. Esto permitirá que los colaboradores se sientan identificados con el propósito de la empresa y puedan transmitir ese sentimiento a otros colaboradores (David, 2013).

\subsubsection{Misión actual de la empresa.}

Norky's no cuenta con una declaración formal de la misión que represente un compromiso real con los colaboradores; sin embargo, en el año 2016, el área de Recursos Humanos propuso la siguiente misión para la empresa:

“Atención, comodidad y entretenimiento en un ambiente familiar".

\subsubsection{Análisis de la misión actual.}

David (2013) menciona que las declaraciones de la misión pueden variar en forma y fondo; sin embargo, la mayoría de personas que estudian o trabajan en dirección estratégica, consideran que existen nueve componentes básicos que una declaración de misión debe incluir:

- Clientes: Identificar los clientes de la empresa.

- Productos: Identificar los principales productos o servicios de la empresa.

- Mercados: Determinar los mercados donde compite la empresa.

- Tecnología: Indicar si la empresa está actualizada en aspectos tecnológicos. 
- Interés en la supervivencia, el crecimiento y la rentabilidad: Indicar si la empresa está comprometida con el crecimiento financiero.

- Filosofía: Identificar las creencias, valores, aspiraciones y prioridades éticas de la empresa.

- Concepto propio: Determinar la ventaja competitiva de la empresa.

- Preocupación por la imagen pública: Indicar si la empresa es sensible a temas sociales, comunitarios o ambientales.

- Interés en los empleados: Indicar si los empleados representan un activo valioso en la empresa.

Luego de analizar la declaración de la misión actual de Norky’s, se elaboró una matriz para evaluar el cumplimiento de cada componente mencionado anteriormente (ver Tabla 5).

Tabla 5

Matriz de Evaluación de la Declaración de la Misión de Norky's

\begin{tabular}{ll}
\hline Componente & Norky's \\
\hline Clientes & No \\
Productos o servicios & No \\
Mercados & No \\
Tecnología & No \\
Interés en la supervivencia, el crecimiento y la rentabilidad & No \\
Filosofía & Sí \\
Concepto propio & No \\
Preocupación por laimagen pública & No \\
Interés en los empleados & Sí \\
\hline
\end{tabular}

Nota. Tomado de Conceptos de Administración Estratégica (p. 69), por F. David, 2013,

México, D.F., México: Prentice Hall. Copyrigth 2013 por Pearson Education.

\subsubsection{Elementos de la misión propuesta para la empresa.}

Según Abell y Hammond (1992), para elaborar una misión es importante definir cuál es el negocio de la organización y para ello propone tres interrogantes (ver Tabla 6), las 
cuales fueron desarrolladas con la información entregada en las entrevistas a los gerentes

funcionales de Norky's (ver Anexo 7).

Tabla 6

Interrogantes para definir el Negocio de Norky's

\begin{tabular}{ll}
\hline Interrogante & Norky's \\
\hline ¿A quién? & $\begin{array}{l}\text { Familias de los sectores económicos C y D que se reúnen para } \\
\text { compartir momentos juntos. }\end{array}$ \\
¿Qué necesidades? & $\begin{array}{l}\text { Necesidades fisiológicas (alimentación) y sociales, } \\
\text { básicamente de un plato tradicional como es el pollo a la brasa. } \\
\text { ¿Cómo? }\end{array}$ \\
\hline
\end{tabular}

Nota. Tomado de Planeación Estratégica de Mercado: Problemas y Enfoques Analíticos, por

D.F. Abell y J.S. Hammond, 1992, México, D.F., México: Editorial Continental.

Adicionalmente, en la Tabla 7 se muestra el análisis de los nueve componentes

básicos que también serán utilizados para declarar la misión formal para Norky’s.

\section{Tabla 7}

Elementos de la Misión Propuesta para Norky’s

\begin{tabular}{ll}
\hline Componente & Norky's \\
\hline Clientes & $\begin{array}{l}\text { Los principales clientes son las familias que se reúnen para } \\
\text { compartir momentos juntos. }\end{array}$ \\
Productos o servicios & $\begin{array}{l}\text { La empresa tiene como principales productos los pollos a la } \\
\text { brasa y parrillas; y como principales servicios, la atención de } \\
\text { calidad, el delivery y los juegos para los niños. }\end{array}$ \\
& $\begin{array}{l}\text { La empresa compite en Lima y Provincias, en los niveles } \\
\text { socioeconómicos C y D. }\end{array}$ \\
Mercados & $\begin{array}{l}\text { La empresa está implementando gradualmente nuevas } \\
\text { tecnologías en sus procesos. }\end{array}$ \\
Tecnología & $\begin{array}{l}\text { La empresa busca seguir expandiendo el negocio a nivel } \\
\text { nacional. }\end{array}$ \\
Interés en la supervivencia, el \\
crecimiento y la rentabilidad \\
Filosofía & $\begin{array}{l}\text { Los principales valores de la empresa son: Comunicación, } \\
\text { Honradez, Trabajo en Equipo, Calidad en el Servicio, } \\
\text { Excelencia Operativa e Identidad. } \\
\text { La ventaja competitiva de la empresa es la calidad del } \\
\text { producto, los precios asequibles y la masificación de las } \\
\text { tiendas. }\end{array}$ \\
\hline
\end{tabular}




\begin{tabular}{ll}
\hline Componente & Norky's \\
\hline $\begin{array}{l}\text { Preocupación por la imagen } \\
\text { pública }\end{array}$ & $\begin{array}{l}\text { La principal preocupación de Norky's es la salubridad, así } \\
\text { como la seguridad y salud ocupacional de sus trabajadores. }\end{array}$ \\
Interés en los empleados & $\begin{array}{l}\text { La empresa desarrolla a los empleados, a través de escuelas de } \\
\text { formación, para que puedan tener una línea de carrera dentro de } \\
\text { la empresa. }\end{array}$ \\
\hline
\end{tabular}

Nota. Tomado de Conceptos de Administración Estratégica (p. 69), por F. David, 2013,

México, D.F., México: Prentice Hall. Copyrigth 2013 por Pearson Education.

\subsubsection{Misión propuesta.}

Según el análisis realizado en el punto anterior, la misión propuesta para Norky’s es:

"Ofrecer pollos a la brasa y parrillas con insumos de calidad a un precio asequible, contando con un personal capacitado y comprometido con los valores de la empresa para ofrecer el mejor servicio a nuestros clientes".

\subsection{Valores}

Los valores de una empresa, también denominados valores esenciales, son las creencias, características y normas conductuales, que tienen como objetivo fundamental el cumplimiento de la visión y misión. Por lo general, la mayoría de las compañías redactan una declaración de valores para reafirmar la expectativa de que los valores se reflejen en la conducción de las operaciones de la compañía y en la conducta de su personal (Thompson, Peteraf, Gamble, \& Strickland, 2012).

\subsubsection{Valores actuales de la empresa.}

Norky's actualmente no cuenta con una definición de valores esenciales, que los oriente en la consecución de sus objetivos; sin embargo, existe un listado de valores planteados por el área de Recursos Humanos en el año 2016: 
- Servicio

- Honestidad

- Responsabilidad

- Respeto

- Trabajo en Equipo

\subsubsection{Análisis de los valores actuales.}

Tomando como referencia a los autores Thompson, Peteraf, Gamble, y Strickland (2012), los principales valores que se considerarán deben adherirse a los valores esenciales de integridad, compromiso, calidad e innovación. En la Tabla 8 se analizan cada uno de los valores actuales de Norky's:

Tabla 8

Definición de los Valores Actuales de Norky's

\begin{tabular}{|c|c|}
\hline Valores actuales & Definición \\
\hline Servicio & $\begin{array}{l}\text { Servicio es una actividad operativa diaria que se brinda a los } \\
\text { comensales; sin embargo, este valor no considera el trato eficiente que } \\
\text { se le debe de dar a los clientes. }\end{array}$ \\
\hline Honestidad & $\begin{array}{l}\text { Honestidad es un valor esencial que se requiere para todos los } \\
\text { colaboradores, ya sea en áreas de soporte o áreas operativas. }\end{array}$ \\
\hline Responsabilidad & $\begin{array}{l}\text { Responsabilidad es un valor esencial relacionado con el compromiso, } \\
\text { que guía a la consecución de los objetivos. }\end{array}$ \\
\hline Respeto & $\begin{array}{l}\text { Respeto es un atributo mencionado en el reglamento de conducta, el } \\
\text { cual debe de ser acatado como principio. }\end{array}$ \\
\hline Trabajo en Equipo & $\begin{array}{l}\text { El trabajo en equipo es un valor esencial que ha permitido a las tiendas } \\
\text { brindar un servicio oportuno a los comensales, es decir es un valor } \\
\text { fundamental yprimario. }\end{array}$ \\
\hline
\end{tabular}

De acuerdo a la definición de los valores en la Tabla 8, se puede afirmar que aún no conglomeran todos los valores que se requieren para obtener los resultados definidos en la misión y visión propuesta, por esta razón, deben ser complementados con otros valores para obtener un óptimo desenvolvimiento de los objetivos. Para ello se tomarán en cuenta los 
cuatro valores esenciales del modelo propuesto por Thompson, Peteraf, Gamble, y Strickland (2012), con la finalidad de obtener valores que guíen las actividades de los colaboradores en el día a día.

\subsubsection{Elementos de los valores propuestos para la empresa.}

Para elaborar la propuesta de los valores de Norky's, se han considerado los cuatro valores esenciales del modelo propuesto por Thompson, Peteraf, Gamble, y Strickland (2012).

- Integridad: Se basa en decir la verdad, mantener la palabra y brindar un trato con imparcialidad y respeto hacia los demás.

- Calidad: Entregar valor a los clientes, empleados, accionistas y otros socios comerciales.

- Compromiso: Realizar el mejor esfuerzo para cumplir con las expectativas en el corto y largo plazo.

- Innovación: Inventar, diseñar y desarrollar productos y servicios que motiven a los clientes a consumirlos.

\subsubsection{Valores propuestos.}

Según lo valores esenciales de Thompson, Peteraf, Gamble, y Strickland (2012) y los valores analizados en la Tabla 8 , se ha considerado los siguientes valores propuestos para Norky's:

- Calidad operativa: Se basa en la mejora continua de los procesos del área operativa, promover las competencias y capacidades esenciales de los colaboradores, con el fin de crear ventajas competitivas que diferencien a Norky's de sus competidores.

- Excelencia en el servicio: Consiste en que los colaboradores brinden una atención servicial a los clientes. Mediante el conocimiento del cliente, los colaboradores deben 
anticiparse a lo que el cliente desea y ser proactivo; además deben transmitir una percepción que satisfaga al cliente, obteniendo así la excelencia en el servicio.

- Comunicación: Basado en promover el diálogo abierto y transparente entre los colaboradores, para lograr así la confianza entre ellos. También consiste en tomar en cuenta las ideas y sugerencias de los colaboradores durante las reuniones.

- Honradez: Consiste en inculcar el compromiso con la honradez entre los colaboradores y brindar la oportunidad de confianza y respeto para esperar lo mismo a cambio.

- Identidad: La forma de trabajar debe ser única, ofrecer el sentido de "pertenencia" a los colaboradores y mantener vivos los relatos de hazañas del personal, donde se manifiestan los valores éticos.

- Trabajo en equipo: Consiste en fortalecer la dinámica de trabajo compartido y conjunto entre los colaboradores, que garantice un trabajo coordinado y de respuesta oportuna hacia el cliente.

\subsection{Alineamiento Estratégico de la Visión, Misión y Valores de la Empresa}

Generalmente, la estrategia es producto de un proceso de planeación formal y la dirección es una función importante en este proceso. Aunque en el camino se encuentren estrategias que no se habían planificado, es importante tener en cuenta una planeación formal y estructurada (Hill, Jones \& Schilling, 2015).

El alineamiento estratégico permite que las direcciones de las empresas tomen decisiones que los lleven a obtener desempeños y resultados óptimos en las organizaciones, no solo en ambientes competitivos presentes, sino en ambientes competitivos futuros. Para ello, se utilizan técnicas para distintos escenarios, donde se involucran a diversos gerentes, tanto estratégicos como operativos, para así conseguir las metas en base a la planeación 
estratégica (Hill, Jones \& Schilling, 2015). La visión, misión y valores son producto de un análisis interno exhaustivo de la situación actual de la organización y de su posición en la industria, así como del sector donde se encuentra y cómo se visualiza la empresa en el futuro.

La visión de Norky’s “Ser reconocidos como la cadena de pollerías líder en Lima Metropolitana por ofrecer pollos a la brasa y parrillas de sabor inigualable acompañado de un servicio de excelencia." está formulada y definida para saber en qué se desea convertir la organización en un futuro, e involucra a cada uno de los integrantes de la misma. Es decir, toda la organización tiene un objetivo claro de liderar el mercado peruano, a través del trabajo que realizan, y se manifiesta, a través de un producto acompañado de un servicio de excelencia, dándoles pertenencia a Norky's e identidad frente a la sociedad. Asimismo, la organización tiene metas y objetivos que deberán alcanzarse para el año 2022.

La misión propuesta para Norky’s es “Ofrecer pollos a la brasa y parrillas con insumos de calidad a un precio asequible, contando con un personal capacitado y comprometido con los valores de la empresa para ofrecer el mejor servicio a nuestros clientes", que tiene claramente identificado sus recursos y ventajas competitivas, los cuales derivan en un producto y servicio aceptado por el mercado objetivo.

Los valores se convierten en la plataforma o los cimientos de la organización, que norman y dirigen la conducta de los integrantes de la misma. Sin estos, la organización no tendría su propia filosofía, es decir carecería de creencias, tradiciones, actitudes y personalidad (D'Alessio, 2013). Los valores propuestos para Norky's son los siguientes: calidad operativa, excelencia en el servicio, comunicación, honradez, identidad y trabajo en equipo.

Por lo tanto, de acuerdo a la visión, misión y valores propuestos para Norky’s, se realizan dos lineamientos que permiten ver la estrategia que está detrás de la planeación. 
Tabla 9

Alineamiento Estratégico de la Visión, Misión y Valores de Norky's

\begin{tabular}{|c|c|c|}
\hline Visión & Misión & Valores \\
\hline $\begin{array}{l}\text { Ser reconocidos como la } \\
\text { cadena de pollerías líder en } \\
\text { Lima Metropolitana. }\end{array}$ & $\begin{array}{l}\text { Ofrecer pollos a la brasa y } \\
\text { parrillas con insumos de } \\
\text { calidad a un precio asequible. }\end{array}$ & $\begin{array}{l}\text { Calidad operativa y Excelencia en el } \\
\text { servicio. }\end{array}$ \\
\hline $\begin{array}{l}\text { Por ofrecer pollos a labrasa } \\
\text { y parrillas de sabor } \\
\text { inigualable acompañado de } \\
\text { un servicio de excelencia. }\end{array}$ & $\begin{array}{l}\text { Contando con un personal } \\
\text { capacitado y comprometido } \\
\text { con los valores de la empresa } \\
\text { para ofrecer el mejor servicio } \\
\text { a nuestros clientes. }\end{array}$ & $\begin{array}{l}\text { Comunicación, Honradez, Identidad } \\
\text { y Trabajo en equipo. }\end{array}$ \\
\hline
\end{tabular}

En la Tabla 9 se puede ver que para el primer lineamiento se toma parte de la visión que hace referencia a lo que se quiere lograr y será posible si en la misión se tiene identificado el producto que el mercado demanda, además de los recursos que necesitan. La primera parte de la misión "Ofrecer pollos a la brasa y parrillas con insumos de calidad a un precio asequible" se alinea con la visión de la organización. En esta parte de la visión y misión, se requieren valores que le den el soporte necesario para llevar adelante esta parte de la estrategia, para ello se requieren valores como calidad operativa y excelencia en el servicio. La calidad operativa es necesaria para que se manipulen correctamente los insumos y disminuyan las mermas de los productos que derivan en sobrecostos, lo cual conlleva al liderazgo en calidad y costos del producto. En cuanto a la excelencia en el servicio, esta es necesaria para que el producto entregado al cliente, siempre esté acompañado de un servicio que les brinde satisfacción.

El segundo lineamiento toma parte de la visión "Por ofrecer pollos a la brasa y parrillas de sabor inigualable acompañado de un servicio de excelencia", donde se identifica que el producto aspira a tener diferenciadores, tanto para el producto como para el servicio, frente a la competencia, y será posible si el personal está preparado y tiene las aptitudes necesarias para llevarlo a cabo. En la segunda parte de la misión se declara "Contando con un 
personal capacitado y comprometido con los valores de la empresa para ofrecer el mejor servicio a nuestros clientes", por ello se logra alinear tanto la visión como la misión para la estrategia que se tiene para el futuro de la organización, acompañados de valores como la comunicación, honradez, identidad y trabajo en equipo entre los miembros de la organización. 


\section{Capítulo IV. Análisis Externo}

\subsection{Tendencias de las Variables del Entorno}

Con el análisis externo se tendrá un panorama claro de la situación en la que se encuentra el sector de restaurantes y permitirá considerar los factores que intervienen en la empresa para tomar acciones estratégicas que permitan hacer frente al entorno y aprovechar las oportunidades que se presenten (Fahey \& Narayanan, 1985).

\subsubsection{Análisis político-gubernamental.}

En el análisis político-gubernamental, el gobierno ha establecido, a través de la Presidencia del Consejo de Ministros (PCM) y el Ministerio de Economía y Finanzas (MEF), tres ejes fundamentales en el que se desarrollará la política económica, las cuales son: consolidación del crecimiento, impulso a la productividad y mejora del sector público. Carlos Oliva, ministro de Economía y Finanzas, puntualizó que el objetivo principal es consolidar el crecimiento económico, a través de las medidas en materia tributaria junto al ajuste en el gasto público y la mejora en la calidad de la misma. El segundo eje fundamental está en el impulso a la productividad, el cual será medido con el crecimiento del PBI y tiene como objetivo lograr que vuelva al 5 o 6\%. Para ello, el MEF trabajará con el sector privado, los trabajadores y gremios. Por último, el tercer eje involucra el impulso de medidas que el MEF tomará para acercarse a los sectores vulnerables y se manifestará a través de los sectores de la salud, educación y demás (Perú: lineamientos de política económica tendrán tres ejes fundamentales, andina.pe, 2018).

El Ministerio de Comercio Exterior y Turismo (MINCETUR) tiene un Sistema de Aplicación de Buenas Prácticas (SABP), la cual es parte de su Plan Nacional de Calidad Turística (CALTUR) que tiene por objetivo capacitar y brindar asistencia técnica en buenas prácticas de gestión de servicio a las empresas turísticas y gastronómicas, con el fin de 
insertarlos en un proceso de mejora continua (MINCETUR instruirá a responsables de hospedajes, agencias de viaje y restaurantes en atención de calidad, mincetur.gob.pe, 2018).

\subsubsection{Análisis económico.}

El análisis económico hace referencia a aquellas fuerzas macroeconómicas que influyen en el dinamismo económico del mercado. En ese sentido, variables económicas como el PBI, la inversión privada, la inflación y el poder adquisitivo del consumidor son variables relevantes para el sector de restaurantes.

A pesar de la crisis económica y financiera presentada en el 2009 con un PBI de $1.1 \%$; en el 2014 se inicia un ligero crecimiento de $2.4 \%$; en el 2015 , de $3.3 \%$; y $3.9 \%$ en el año 2016 (INEI, 2017).

Como se precisó en el capítulo II, la producción de pollos ha venido creciendo mensualmente en relación al periodo del año anterior. En ese sentido, se muestra una tendencia positiva de la producción del pollo, lo cual se consolida con la proyección de la Dirección General de Seguimiento y Evaluación de Políticas del MINAGRI (2017), haciendo referencia a que la producción nacional del pollo llegará a 1'785,000 toneladas en el 2017, lo que representaría un incremento de 5.3\% con relación a lo registrado en el 2016 (MINAGRI: Producción de pollo mantendrá niveles óptimos este 2017, larepublica.pe, 2017).

Por otro lado, según una encuesta elaborada por Centrum Opinión (2017), se precisó que el $31 \%$ de los empresarios consultados tienen una expectativa favorable de la reactivación de la inversión para el segundo trimestre del 2017, el 33.1\% para el primer trimestre del 2018 y el $31.7 \%$ para el segundo trimestre del 2018. Sin embargo, analizando los números de los recientes años, la inversión privada en el Perú no ha sido tan alentadora, ya que registró tasas negativas de crecimiento: -2\% en el 2014, -4\% en 2015 y $-6.1 \%$ en 2016. No obstante, siguiendo la línea optimista de la encuesta, el MEF espera tener tasas 
positivas, tales como: $0.5 \%$ en el $2017,5 \%$ en el $2018,5.7 \%$ en el $2019,6.3 \%$ en el 2020 y 6.5\% en el 2021 (ver Figura 11). Por otro lado, el economista Jorge González Izquierdo señaló que la inversión privada representa alrededor del 17\% del PBI, por lo que hay un impacto directo en el empleo y consumo privado (Conoce la evolución y proyección de la inversión privada, peru21.pe, 2017).

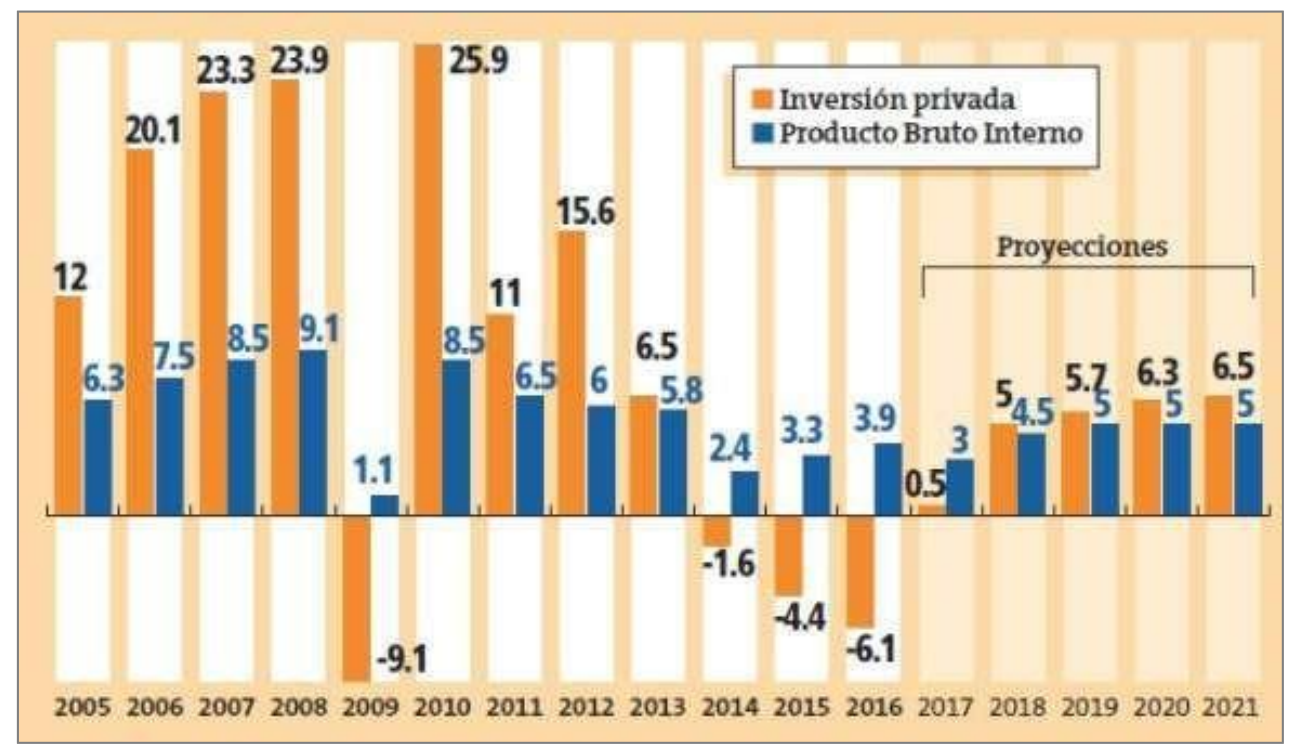

Figura 11. Evolución de la inversión privada y PBI. Tomado de "Conoce la evolución y proyección de la inversión privada”, por peru21.pe, 2017. Recuperado de https://peru21.pe/economia/conoce-evolucion-proyeccion-inversion-privada-75633

Según el INEI, el año 2016 cerró con un aumento de la inflación de $0.33 \%$ en Lima Metropolitana y acumuló un 3.23\% a nivel nacional (ver Figura 12), pero si bien esta cifra superó el rango de meta impuesta por el BCRP, que oscila entre $1 \%$ y $3 \%$, el resultado obtenido el año pasado es significativamente menor a la cifra alcanzada en el 2015 donde se obtuvo un 4.4\% de inflación (Inflación cerró el 2016 en 3.23\%, sobre rango meta del BCR, elcomercio.pe, 2017). 


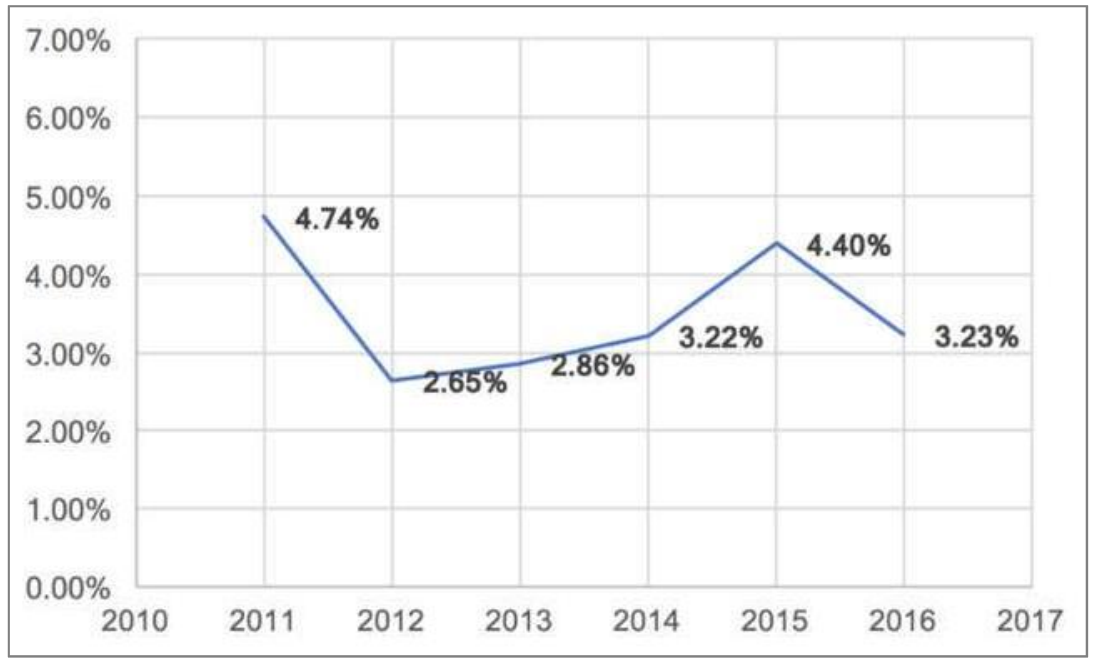

Figura 12. Inflación a nivel nacional. Tomado de "Reporte de Inflación”, por el BCRP, 2017. Recuperado de http://www.bcrp.gob.pe/docs/Publicaciones/ReporteInflacion/2017/marzo/reporte-de-inflacion-marzo-2017.pdf

Según reporte del INEI (2016), en el Perú cubrir el costo promedio mensual de la canasta básica familiar por persona es de S/328 y para una familia de cuatro personas es de S/1,312, costos que han tenido un crecimiento en los últimos años (ver Tabla 10).

Tabla 10

Canasta Básica de Alimentos. Periodo 2012 - 2016

\begin{tabular}{ccc}
\hline Año & Costo promedio mensual & $\begin{array}{c}\text { Costo promedio mensual de un hogar de } \\
\text { cuatro miembros }\end{array}$ \\
\hline 2012 & $\mathrm{~S} / 284$ & $\mathrm{~S} / 1,136$ \\
2013 & $\mathrm{~S} / 292$ & $\mathrm{~S} / 1,168$ \\
2014 & $\mathrm{~S} / 303$ & $\mathrm{~S} / 1,212$ \\
2015 & $\mathrm{~S} / 315$ & $\mathrm{~S} / 1,260$ \\
2016 & $\mathrm{~S} / 328$ & $\mathrm{~S} / 1,312$ \\
\hline
\end{tabular}

Nota. Tomado de Sube el costo de la canasta básica y aún no está del todo cubierta.

Recuperado de

http://www.camaralima.org.pe/repositorioaps/0/0/par/r786_2/info_esp_786.pdf 
Finalmente, según el INEI (2017), el ingreso promedio mensual ha venido creciendo entre el periodo 2007 - 2016 en un $6.5 \%$ anual, lo cual deriva en un mayor poder de compra en la población (El ingreso promedio mensual por trabajo entre los peruanos asciende a S/ 1,366, diariocorreo.pe, 2017).

\subsubsection{Análisis legal.}

En el aspecto legal, el sector de restaurantes está regulado por la municipalidad del distrito, la Dirección General de Salud Ambiental (DIGESA), MINCETUR y el Instituto Nacional de Defensa de la Competencia y de la Protección de la Propiedad Intelectual (Indecopi), a través de las siguientes normas o leyes:

- Norma Sanitaria para el Funcionamiento de Restaurantes y Servicios Afines (Resolución Ministerial N³63-2005/MINSA).

- $\quad$ Ley General de Residuos Sólidos (Ley N²7314).

- Reglamento de Restaurantes (Decreto Supremo Nº09-2017-MINCETUR).

- Disposiciones sobre Establecimientos que expenden Comidas y Bebidas (R.M. No 081-94-ITINCI).

- Código de Protección y Defensa del Consumidor (Ley No 29571).

Adicionalmente, se debe tener en cuenta el proyecto de ley, elaborado por el Ministerio del Ambiente (MINAM), que plantea prohibir gradualmente el uso de bolsas de plástico, sorbetes y envases de tecnopor. Esta medida está orientada a reducir el nivel de contaminación y a concientizar a las personas en el cuidado del medio ambiente (Aprueban dictamen que propone reducir uso y fabricación de plásticos, elcomercio.pe, 2018). 


\subsubsection{Análisis cultural.}

La ciudad de Lima ha tenido muchos cambios en distintos ámbitos, incluido los niveles socioeconómicos. Hace 30 años los estudios y datos mostraban que la riqueza en Lima estaba concentrada en los niveles socioeconómicos A y B, en distritos tradicionalmente identificados como de igual nivel socioeconómico, tales como Miraflores y San Isidro, entre otros, y la clase media se encontraba en distritos como Jesús María y Lince. La clase más pobre se encontraba en los distritos de condición de vida precarios, con algunos servicios básicos, donde había llegado población del interior del país. En la actualidad, la realidad es otra, ya que ha cambiado en gran medida debido a que se puede encontrar riqueza en Miraflores y San Isidro, y en distritos emergentes como Los Olivos y Comas.

Adicionalmente, los niveles socioeconómicos, como se explica en líneas anteriores, no crecen por zonas uniformemente y dadas las condiciones económicas del país, gran parte de la población se sitúa en los niveles socioeconómicos C y D, por lo que no se puede hablar de una pirámide, en términos económicos, donde la minoría está arriba y la mayoría abajo, sino de un rombo. Por ello, se pueden ver muchas inauguraciones de centros comerciales y servicios conglomerados de diversos tipos, como centros de estudios, centros de salud y cuidado de la imagen en zonas donde no eran usuales, como el este, norte y sur de Lima (Arellano, 2010).

Las redes sociales, en los últimos años, han tenido un alto poder de penetración por usuario. De acuerdo a un estudio realizado por ComScore acerca del futuro digital de América Latina, en el caso de Perú, las redes sociales son utilizadas para acceder a noticias y buscar información en un 93\%, y, entre ellas, la que ha tenido un mayor ingreso de usuarios es Facebook (E1 93\% de peruanos usan las redes sociales para buscar noticias o información de interés, gestion.pe, 2015). El avance de la tecnología es incontrolable y la población hace 
uso a diario de ello, a través de las redes sociales. El Diario Expansión de España informa que la tendencia ya no es solo compartir fotos y vídeos, sino estar en vivo y en directo, en una comunicación inmersa entre las personas. A nivel mundial, la red social más utilizada y que apuesta por la innovación es Facebook, unida a su otra red Instagram, y en el camino han aparecido otras redes como Snapchat y Periscope, que están teniendo mucha acogida (Entérese cómo serán las redes sociales en el 2017, gestion.pe, 2017).

Por otro lado, el consumidor peruano tiene muy arraigada la gastronomía como parte de su cultura y uno de los platos favoritos es el pollo a la brasa, básicamente por sus condimentos especiales (Día del Pollo a la Brasa, dearteycultura.com, 2013). Según Arellano (2010), la gastronomía peruana ha crecido debido a la riqueza y variedad de ingredientes e insumos con los que cuenta, así empezó a desarrollarse de manera organizada y sostenida. Además, el pollo a la brasa fue reconocido como Patrimonio Cultural de la Nación por el Instituto Nacional de la Cultura del Perú (INC) en el año 2010. (¿Cuántos pollos a la brasa comemos los peruanos al año?, gestion.com, 2016).

Finalmente, la alimentación es la principal condición para tener una buena salud, ya que los nutricionistas mencionan que, si se le presta atención y cuidado a lo que ingresa a nuestro cuerpo, este se desarrolla, crece y funciona de manera saludable. Por ello, la tendencia de la población mundial es llevar una cultura de prevención, a través del consumo de alimentos saludables (Entérate sobre el avance de la alimentación saludable en el Perú, elcomercio.pe, 2017). En este caso la industria, tiene un reto que la obliga a crear estrategias que alcancen las nuevas tendencias en cuanto a necesidades alimenticias.

\subsubsection{Análisis tecnológico.}

En el aspecto tecnológico, los beneficios obtenidos por el uso de herramientas tecnológicas son diversos, esto se da utilizando softwares que permiten una adecuada gestión 
de restaurantes. Es decir, las herramientas tecnológicas permiten administrar los pedidos y los interiores del restaurante, generar estadísticas de ventas, controlar stocks, administrar almacenes, integrar procesos, administrar los recursos humanos, y centralizar todo en un sistema de gestión de contenidos de las empresas (Europa: Los restaurantes hacen frente a las innovaciones tecnológicas, peru-retail.com, 2018). El beneficio que se obtiene al utilizar la tecnología se puede resumir en una palabra "automatización" porque permite utilizar eficientemente los recursos de la empresa, personal, tiempo y documentación. De esa forma, la productividad de los restaurantes mejora sustancialmente en costos y calidad, y se gestiona ordenada y oportunamente.

Las variables que tienen mayor impacto en el sector de restaurantes son:

- Las normas ISO traen muchos beneficios para la empresa, tales como: mejorar la imagen, optimizar los recursos, promover la mejora continua, fidelizar a los clientes, entre otros. La norma ISO 9001 es una norma internacional de sistemas de gestión de la calidad aplicable a cualquier tipo de organización, incluyendo restaurantes, y se enfoca en la estandarización de los procesos y satisfacción de los clientes. La norma ISO 14001 es una norma internacional de sistemas de gestión ambiental que también es aplicable a cualquier tipo de organización y permite gestionar los riesgos ambientales como parte de los procesos de la empresa.

- El comercio electrónico es otra de las variables que se ha incrementado con fuerza en los últimos años y está presente en distintos rubros, entre ellos la comida. Uno de los casos de éxito en el Perú es Lima Delivery, que cuenta con un modelo de negocio de comida delivery online y actúa como intermediario entre el consumidor y el restaurante. Lima Delivery cuenta con una plataforma web y una aplicación móvil, donde los usuarios pueden encontrar alrededor de 1,000 establecimientos de comida de diversos tipos, entre los cuales se encuentran pollos a la brasa, pizzas, chifas, 
sushis, entre otros (Emprendedor.21: 'Lima Delivery', a la puerta de tu casa, peru21.pe, 2017).

\subsubsection{Análisis ecológico.}

La variable ecológica debe ser considerada como un instrumento útil en la empresa, que permite incrementar la productividad de los recursos y operar con seguridad y eficiencia, siempre que esté alineada a la estrategia competitiva (Porter, 2006).

La industria de pollerías involucra la utilización de hornos, leña de algarrobo y otros elementos necesarios para la elaboración del plato, los cuales generan combustión y contaminan el medio ambiente. En la lista de mayores contaminantes, la combustión mencionada está después del transporte y de otras industrias (Día del Pollo a la brasa: humo de los hornos son los principales contaminantes del aire, diariocorreo.pe, 2018).

La gestión de los residuos sólidos generados por la industria de los restaurantes está bajo la responsabilidad de los gobiernos locales, debido a que estas entidades están capacitadas para el correcto tratamiento y desecho de los residuos. Además, son asesorados y acompañados técnicamente por el MINAM, con la finalidad de no afectar la salud de la población (MINAM: “Manejo de residuos sólidos es responsabilidad de gobiernos locales”, elcomercio.pe, 2018).

Por otro lado, el experto oncólogo Elmer Huertas manifiesta que, los plásticos, esto incluye el tecnopor y bolsas plásticas utilizadas en la industria, emanan sustancias químicas dañinas para la salud y contaminan el medio ambiente, ya que tardan hasta 500 años en degradarse (Los plásticos [incluido el tecnopor] y la salud [del ser humano y del medio ambiente], elcomercio.pe, 2017). Las empresas tienen que considerar que los empaques son dañinos para el consumidor y tienen que buscar métodos que contrarresten este problema. 


\subsection{Impacto en Clientes/Proveedores de cada una de las Variables del Entorno}

Es este punto se realizará un análisis de cada una de las variables del entorno identificadas anteriormente, para determinar su impacto en los clientes y/o proveedores.

- Impacto de las variables político-gubernamentales

El impacto que la variable político-gubernamental tendrá en el cliente es positivo, ya que el crecimiento económico del país permitirá que el cliente tenga más posibilidades de consumo y empleo. En el caso de los proveedores, el impacto también es positivo, ya que las empresas tendrán mayor demanda, impactando así en sus operaciones económicas e industriales, y en el aumento de su productividad.

Respecto al CALTUR, impulsado por el MINCETUR, el impacto es positivo en los clientes, debido a que recibirán una mejor atención, incrementando la demanda de servicios y apertura de restaurantes. Los proveedores también son afectados de manera positiva, ya que, al incrementarse la demanda de servicios, se incrementará la compra de insumos e ingredientes.

En ese sentido, la variable político-gubernamental se muestra como una oportunidad para los clientes y proveedores.

- Impacto de las variables económicas

El impacto de la variable económica es positivo, ya que, como se observó en el análisis de la variable, el PBI nacional tiene proyecciones positivas al igual que la inversión privada, lo cual alienta a un mayor dinamismo económico favoreciendo a los clientes al tener, por un lado, mayor oferta de bienes y servicios, y, por otro, mayor empleabilidad ante el aumento de las empresas en el mercado. Asimismo, los proveedores (productores) se ven favorecidos, ya que el aumento de empresas o inversionistas aumenta su cartera de clientes, 
aunque podrían entrar nuevos competidores, pero en menor medida ante las altas barreras de entrada. Cabe agregar que, la inflación tiene variaciones bajas y/o a niveles controlados por el BCRP, lo cual no afecta considerablemente a los clientes. En ese sentido, la variable económica se muestra como una oportunidad para los clientes, al tener productos competitivos a mejores precios y para los proveedores, al incrementar sus ventas por aparición de nuevos empresarios.

- Impacto de las variables legales

El rol fiscalizador que cumple la municipalidad del distrito, DIGESA, MINCETUR e Indecopi en el sector de restaurantes, a través de evaluaciones e inspecciones, son favorables para los clientes, ya que velan por la salud y seguridad de los mismos. Asimismo, el proyecto de ley para reducir el uso de bolsas plásticas beneficia a los clientes, ya que permite reducir la contaminación en el medio ambiente; sin embargo, perjudica a los proveedores, ya que tendrán que adecuarse a las especificaciones requeridas por el proyecto de ley. Por lo tanto, se considera que esta variable tiene un impacto positivo en los clientes y negativo en los proveedores.

- Impacto de las variables culturales

Las redes sociales tienen un impacto positivo, ya que se han convertido en una fuente de información importante, tanto para los clientes como los proveedores. En el caso de los clientes, se convierte en fuente de información de las tendencias y preferencias de sus grupos cercanos. En el caso de los proveedores principales de pollo y papas pre fritas, las redes sociales les permiten conocer los gustos y preferencias de la población en un mercado dinámico, donde interactúan junto a sus clientes directos y competidores. Por otro lado, las redes sociales se pueden convertir en una amenaza para la cadena, si se comparte información 
sensible o negativa que no es acorde con sus valores y dañe su reputación en la sociedad y opinión pública.

Respecto al consumidor peruano y como cliente, la cultura gastronómica es parte de su identidad, lo cual lo hace de gran importancia para su estilo de vida y consumo. En cuanto a los proveedores, de la misma forma, la gastronomía exige ingredientes con características especiales, lo cual representa una oportunidad para ellos también. Cabe agregar, que el pollo a la brasa fue reconocido como Patrimonio Cultural de la Nación por el Instituto Nacional de la Cultura del Perú (INC) en el año 2010. (¿Cuántos pollos a la brasa comemos los peruanos al año?, gestion.com, 2016).

Finalmente, la alimentación se torna en un factor valorado por parte de los clientes, ya que es una tendencia que se ha masificado a nivel mundial y en la sociedad peruana, por cuanto es beneficioso para la salud. Por lo tanto, es positivo que los clientes consideren la alimentación saludable dentro de la variable cultural. A los proveedores les impacta negativamente debido a que se ven en la difícil tarea de suplir la necesidad de la población por alimentos saludables, ya que esto involucra nuevos o más laboriosos procesos, por ende, el costo se incrementa y esto no es aceptado fácilmente por los clientes.

- Impacto de las variables tecnológicas

El impacto de la tecnología en los clientes se manifiesta en una mejor calidad del servicio, ya que se gestionan mejores tiempos de atención y se acumula información de consumo de los clientes, permitiendo conocer mejor al público objetivo y fortaleciendo la relación con ellos. Respecto a los proveedores, la información que se recoja permitirá que se realicen pedidos más planificados y exactos en cantidades y costos, evitando los desperdicios y teniendo un mejor control en la compra de materias primas y materiales, así como un mejor uso del tiempo y recursos. 
Las normas ISO mejoran la satisfacción de los clientes, ya que permiten a las empresas mejorar sus procesos y, por ende, brindar un mejor producto y servicio. Además, los proveedores también se benefician, ya que le permite mejorar sus procesos.

El comercio electrónico es otra de las tecnologías que facilita el proceso de realizar un pedido. A través de una plataforma web o una aplicación móvil, los clientes pueden encontrar diversas opciones de restaurantes y realizar un pedido desde cualquier lugar, de la forma más rápida y sencilla, sin necesidad de llamar a un call center. Lima Delivery es una de las empresas con este modelo de negocio que agrupa a más de 1,000 restaurantes y está presente a nivel nacional.

En ese sentido, la variable tecnológica se muestra como una oportunidad para los clientes y proveedores.

- Impacto de las variables ecológicas

El impacto del humo contaminante de las pollerías es negativo para los clientes, ya que su salud se verá perjudicada en el largo plazo. Respecto a los proveedores, el impacto también es negativo porque tendrán que cambiar los productos que afectan al medio ambiente, implicando una reingeniería de procesos y aumento de costos.

La utilización de empaques plásticos, incluido las bolsas pláticas y el tecnopor, pueden causar daño a la salud de los clientes, impactando negativamente en ellos. Por ende, buscarán aquellas empresas que les brinden alternativas de empaque. En cuanto a los proveedores, ellos tendrán que realizar investigaciones para contrarrestar este problema, ya que en otros países las bolsas plásticas y el tecnopor están prohibidos.

En ese sentido, la variable ecológica se muestra como una amenaza para los clientes y proveedores. 


\subsection{Efecto en la Empresa de cada una de las Variables del Entorno}

Es este punto se realizará un análisis de cada una de las variables del entorno identificadas anteriormente, para determinar su efecto en la empresa.

- Impacto de las variables político-gubernamentales

El rol del gobierno en el manejo de diversas políticas, impartido por medio de sus entes gubernamentales, no representa una oportunidad o amenaza para la empresa, ya que el impacto de estas reformas recae en todos los sectores del país.

El SABP representa una oportunidad para la empresa, ya que permite mejorar la calidad y excelencia del servicio, generando mayores ingresos.

- Impacto de las variables económicas

El impacto de la variable económica es positiva para Norky's, ya que el indicador de crecimiento del PBI implica un aumento de la demanda, lo cual se ajusta al incremento de sus ventas, impactando directamente en su rentabilidad. Sin embargo, se debe considerar que el aumento de la inversión privada originará la aparición de nuevos competidores, lo cual podría perjudicar la participación de la empresa en el mercado, pero a su vez, este indicador también favorece la política de expansión de Norky’s, al haber mayores inversionistas interesados en el negocio. En resumen, si bien la aparición de nuevos competidores por la proyección positiva de la inversión privada, podría convertirse en una amenaza por la aparición de nuevos competidores, el crecimiento del PBI ofrece una oportunidad para la expansión de la empresa ante el aumento de la demanda, impactando directamente en el incremento de sus ventas. 
- Impacto de las variables legales

El rol fiscalizador que cumple la municipalidad del distrito, DIGESA, MINCETUR e Indecopi en el sector de restaurantes, a través de evaluaciones e inspecciones, no representan una oportunidad para la empresa, ya que evalúan el cumplimiento de normas y leyes que se deben cumplir de manera obligatoria. Sin embargo, estos organismos estatales pueden incrementar el requerimiento de licencias, certificaciones, permisos y trámites para abrir y operar los restaurantes. Asimismo, el proyecto de ley para reducir el uso de bolsas plásticas podría afectar los costos de ventas. Por ello, el impacto de esta variable se considera una amenaza para Norky's.

- Impacto de las variables culturales

En cuanto al efecto de las variables culturales en Norky's, los niveles socioeconómicos C y D se encuentran en crecimiento, lo cual impacta positivamente al negocio, ya que representa un incremento del público objetivo de la empresa.

En el caso de las redes sociales, estas permiten que Norky's pueda involucrarse más con su mercado objetivo, y promocionar los productos y servicios que ofrece, dándole prioridad a la red social Facebook, la cual es la más utilizada en el Perú y no representa altos gastos.

Por otro lado, las redes sociales también pueden constituirse en una amenaza para Norky's, ya que al difundirse en corto tiempo las malas experiencias en el servicio o producto que se le pueda brindar a un usuario, esto puede traer consigo opiniones contrarias al buen prestigio de la empresa y a lo que realmente se les ofrece a los clientes.

Finalmente, la alimentación saludable es una de las tendencias que se ha impuesto en la población. Norky's ofrece un alimento nutritivo, pero no necesariamente saludable debido 
a sus acompañamientos, por eso se consume ocasionalmente. Por lo tanto, la alimentación saludable se considera una amenaza para la empresa.

- Impacto de las variables tecnológicas

La tecnología representa una oportunidad para la empresa porque mejora la gestión administrativa, aumentando la productividad y el análisis de la información obtenida para planificar las operaciones en las distintas áreas.

Las normas ISO permiten a las empresas mejorar continuamente sus procesos, optimizar sus recursos, fidelizar a sus clientes y, por ende, mejorar su imagen. Por ello, el impacto de esta variable se considera una oportunidad para Norky's.

El comercio electrónico es otra de las tecnologías que facilita el proceso de realizar un pedido. Lima Delivery, una de las empresas con un modelo de negocio de comida delivery online que agrupa a más de 1,000 restaurantes y está presente a nivel nacional, afirma que este servicio genera más ingresos a los restaurantes y mejora el posicionamiento del negocio ante los consumidores. Por ello, el impacto de esta variable se considera una oportunidad para Norky's.

- Impacto de las variables ecológicas

En el caso de las variables ecológicas, la gestión ambiental permite a Norky’s consolidar las buenas prácticas de manufactura, las cuales son amigables con el medio ambiente y benefician a la sociedad. Sin embargo, acerca de los empaques, la tendencia es que ya no se utilicen bolsas plásticas y tecnopor. En ese sentido, la empresa tendría que evaluar la incorporación de alternativas para empaquetar los productos, lo cual puede traer un aumento en los costos. Por ello, el impacto de esta variable se considera una amenaza para Norky's. 


\subsection{Oportunidades y Amenazas}

- Las normas ISO representan una oportunidad para la empresa, ya que les permite mejorar continuamente sus procesos, optimizar sus recursos, fidelizar a sus clientes y, por ende, mejorar su imagen.

- El modelo de negocio de comida delivery online utilizado por Lima Delivery representa una oportunidad para la empresa, ya que permite potenciar el canal de venta, aumentando así, los ingresos y mejorando el posicionamiento del negocio ante los consumidores.

- La proyección positiva del crecimiento del PBI representa una oportunidad para la empresa, ya que impulsa una mayor demanda y disponibilidad de ingresos para las compras, permitiendo a la empresa gozar de mayores clientes e incrementar sus ventas.

- La determinación de los estilos de vida de la población peruana representa una oportunidad para la empresa, ya que ayuda a entender el comportamiento, costumbres y preferencias de la población, para que de ese modo se dirijan mejor a su mercado objetivo.

- El crecimiento de los niveles socioeconómicos C y D en Lima Metropolitana representa una oportunidad para la empresa, ya que implica una mayor cantidad de población que requieran del producto y servicio que la empresa ofrece, es decir que la empresa puede atender a más clientes, ya sea con la misma capacidad instalada o abrir nuevos locales cercanos a esa población.

- El incremento del uso de las redes sociales para promocionar los productos representa una oportunidad para la empresa, ya que permite otorgar beneficios a los usuarios y ser recordado por ellos, ese hecho incrementa las ventas y posiciona a la empresa en el mercado virtual. 
- El uso de herramientas tecnológicas utilizada en la gestión administrativa de la industria representa una oportunidad para la empresa, ya que le permite mejorar la gestión de la organización de modo integral y medir el crecimiento.

- La capacitación del Estado en buenas prácticas de gestión de servicio representa una oportunidad para la empresa, ya que con ello mejoraría la propuesta de valor de la empresa y la relación con clientes.

- La escasa disponibilidad de locales en zonas de alto tránsito, donde la instalación de las tiendas de Norky's son oportunas, representa una amenaza para la empresa, ya que el $60 \%$ de los locales son arrendados. Además, los contratos de arrendamiento con el arrendatario del local generalmente son de corto plazo y con alza de costos, impidiendo así una oportuna continuidad del negocio.

- El posible ingreso de nuevos competidores en el sector ante la proyección favorable de la inversión privada representa una amenaza para la empresa, ya que impulsa el ingreso de nuevos competidores, lo cual podría reducir la participación de los locales donde la empresa está presente.

- La información negativa que difunden los consumidores en las redes sociales representa una amenaza para la empresa, ya que, si sucediera el caso de un mal servicio, se podría dar a conocer en corto tiempo a miles de clientes y usuarios, además de los medios de comunicación y la opinión pública.

- La baja fidelidad del cliente representa una amenaza para la empresa, debido a que, si se varían las condiciones en la oferta o si aparece otra empresa con mejores precios, ellos no tendrían problemas en cambiar de pollería.

- La tendencia por la alimentación saludable representa una amenaza para la empresa, debido a que los acompañamientos del producto principal no son saludables y va en contra del hábito que está adquiriendo la población. 
- La posible ley de prohibición de bolsas plásticas y envases de tecnopor representa una amenaza para la empresa, ya que las alternativas para empaquetar los productos aumentarían los costos.

\subsection{Matriz de Evaluación de los Factores Externos EFE}

Según David (2013), una matriz de evaluación del factor externo permite resumir y evaluar la información de las variables político-gubernamentales, económicas, legales, culturales, tecnológicas y ecológicas, para determinar la manera en que la empresa responde a las oportunidades y amenazas presentes en el sector.

En la Tabla 11 se muestra la matriz EFE para Norky's, basada en las oportunidades y amenazas identificadas anteriormente. Cabe resaltar que el valor y la clasificación se asignaron en base a la información entregada por los gerentes funcionales de Norky’s durante las entrevistas (ver Anexo 7). 
Tabla 11

Matriz EFE de Norky's

\begin{tabular}{|c|c|c|c|c|}
\hline & Factores Clave & Valor & Clasificación & Valor ponderado \\
\hline & \multicolumn{4}{|l|}{ Oportunidad } \\
\hline 1 & Las normas ISO 9001 y 14001. & 0.03 & 1 & 0.03 \\
\hline 2 & El modelo de negocio de comida delivery online. & 0.06 & 2 & 0.12 \\
\hline 3 & La proyección positiva del crecimiento del PBI. & 0.12 & 3 & 0.36 \\
\hline 4 & $\begin{array}{l}\text { La determinación de los estilos de vida de la } \\
\text { población peruana. }\end{array}$ & 0.05 & 2 & 0.10 \\
\hline 5 & $\begin{array}{l}\text { El crecimiento de los NSE C y D en Lima } \\
\text { Metropolitana. }\end{array}$ & 0.16 & 3 & 0.48 \\
\hline 6 & $\begin{array}{l}\text { El incremento del uso de las redes sociales para } \\
\text { promocionar los productos. }\end{array}$ & 0.12 & 3 & 0.36 \\
\hline 7 & El uso de herramientas tecnológicas. & 0.11 & 2 & 0.22 \\
\hline \multirow[t]{2}{*}{8} & $\begin{array}{l}\text { Las capacitaciones del Estado en buenas prácticas de } \\
\text { gestión de servicio. }\end{array}$ & 0.02 & 1 & 0.02 \\
\hline & Amenazas & & & \\
\hline 9 & $\begin{array}{l}\text { La escasa disponibilidad de locales en zonas de alto } \\
\text { tránsito. }\end{array}$ & 0.11 & 2 & 0.22 \\
\hline \multicolumn{2}{|r|}{$\begin{array}{l}10 \text { El posible ingreso de nuevos competidores en el } \\
\text { sector. }\end{array}$} & 0.03 & 2 & 0.06 \\
\hline \multicolumn{2}{|r|}{$\begin{array}{l}11 \text { La información negativa que difunden los } \\
\text { consumidores en las redes sociales. }\end{array}$} & 0.07 & 2 & 0.14 \\
\hline \multicolumn{2}{|r|}{12 La baja fidelidad del cliente. } & 0.04 & 2 & 0.08 \\
\hline \multicolumn{2}{|r|}{13 La tendencia por la alimentación saludable. } & 0.06 & 2 & 0.12 \\
\hline \multicolumn{2}{|r|}{$\begin{array}{l}14 \text { La posible ley de prohibición de bolsas plásticas y } \\
\text { envases de tecnopor. }\end{array}$} & 0.02 & 1 & 0.02 \\
\hline & Valor ponderado total & 1.00 & & 2.31 \\
\hline
\end{tabular}

El valor ponderado total obtenido para Norky's es 2.31, el cual está ligeramente por debajo del promedio e indica que, a pesar de que la empresa responde regularmente a las oportunidades y amenazas, las estrategias de la empresa no están aprovechando eficientemente las oportunidades del sector, ni evitando las amenazas. 


\section{Capítulo V. Análisis de la Industria}

\subsection{Descripción del Mercado (Demanda) e Industria (Oferta)}

Según el INEI, en el Perú se consume un promedio de 16 pollos a la brasa al año por familia y en Lima Metropolitana este número se eleva a 19, mientras que en las zonas rurales desciende a 10. Según la APA, los peruanos consumen 130 millones de pollos a la brasa al año, lo cual representa la quinta parte del total de pollos producidos en el país. Asimismo, la consultora Flanqueo señala que los peruanos gastan alrededor de S/35 cuando visitan una pollería (¿Cuántos pollos a la brasa comemos los peruanos al año?, gestion.com, 2016). Lo mencionado anteriormente, ha generado que la producción del pollo a la brasa haya registrado un crecimiento de $3.46 \%$, incrementando así la producción de ave en pie y carne de ave en Lima Metropolitana y Callao (Al año se consume en promedio 24 kilos de pollos a la brasa, inei.gob.pe, 2015).

Finalmente, el aumento del consumo de pollo a la brasa se debe a que este plato se ha convertido en un ícono de la gastronomía peruana, ya que fue reconocido como Patrimonio Cultural de la Nación por el Instituto Nacional de la Cultura del Perú (INC) en el año 2010. Este mismo año, MINAGRI declaró el Día del Pollo a la Brasa, el cual se celebra cada tercer domingo de julio y mueve más de S/3,500 millones al año (¿Cuántos pollos a la brasa comemos los peruanos al año?, gestion.com, 2016).

Por otro lado, la industria de pollerías ha tenido una expansión en los últimos cinco años, según se precisa en un estudio elaborado por Euromonitor International (2016), ya que el número de locales ha crecido 53\%, registrándose al cierre del 2016 un número de 45,582 pollerías a nivel nacional (¿Qué empresas de pollos a la brasa lideran el mercado peruano?, pymex.pe, 2017). De estas pollerías, sobresalen aquellas que tienen varios locales, las cuales son denominadas cadenas de pollerías y, dentro de estas, se encuentran las tres cadenas más 
representativas dentro del mercado: Norky's, Roky's y Pardos Chicken, teniendo una incidencia mayor en Lima Metropolitana, como se precisó en líneas anteriores, con 92, 57, 25 tiendas respectivas.

Asimismo, según Euromonitor, el pollo a la brasa sigue siendo el producto dominante, captando el $63 \%$ de las ventas totales del sector de restaurantes, que al cierre del año 2016 se estimaron en S/6,872.2 millones (¿Qué empresas de pollos a la brasa lideran el mercado peruano?, pymex.pe., 2017).

\subsection{Descripción de las Cinco Fuerzas Competitivas de la Industria}

Las cinco fuerzas competitivas ofrecen un marco analítico de qué focos debe tener una empresa para ser más rentable en el sector, por eso la importancia de comprender las fuerzas, de tal forma que la empresa pueda anticiparse a la competencia e influir en ella en un plazo determinado, es decir, conocer las fuerzas dentro de un sector posibilita a la empresa a defenderse de estas y moldearlas a su propio beneficio (Porter, 2008). Adicionalmente, se medirá el grado de atractividad de la industria, según la matriz de Hax y Majluf (2004), donde se cuantificarán las fuerzas evaluadas.

\subsubsection{Amenaza de productos de sustitutos.}

Los productos sustitutos satisfacen las mismas necesidades y pertenecen al mismo sector. La amenaza de los productos sustitutos estará siempre rondando y muchas veces no serán identificados porque pueden ser distintos al producto del sector (Porter, 2008).

Los sustitutos que satisfacen las mismas necesidades y pueden reemplazar al pollo a la brasa son variados, ya que existen lugares donde se puede disfrutar de una comida fuera de casa con las mismas o similares condiciones de atención que los estilos de vida de los clientes exigen. Esto se puede observar, a través del crecimiento de las ventas del sector de restaurantes en el país, que el INEI informa para el mes de julio de 2017. El crecimiento más 
alto se dio en las sangucherías en un $10.3 \%$, comida criolla en $6.2 \%$, restaurantes turísticos en $2.9 \%$, carnes y parrillas en $2.4 \%$, restaurantes en $1.6 \%$, comidas rápidas en $1.6 \%$ y pollerías en $0.8 \%$; en el caso de los chifas, disminuyeron en $2.7 \%$ y las cevicherías en $4.2 \%$ (Encuesta Mensual del Sector Servicios, inei.gob.pe, 2017). Estos datos dan a entender que en otros tipos de negocios el crecimiento es mayor porque hay un público que los demanda y existe una gama variada de productos sustitutos que pueden quitar rentabilidad a las cadenas de pollerías (ver Figura 13).

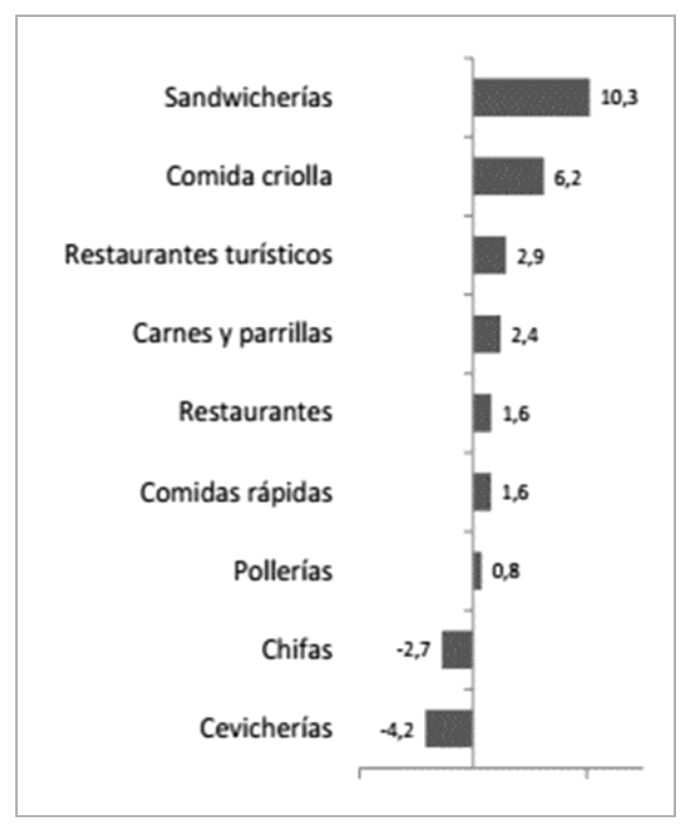

Figura 13. Sector Restaurantes Ventas Julio 2017. Tomado de “Encuesta Mensual del Sector Servicios”, por el INEI, 2017. Recuperado de https://www.inei.gob.pe/media/MenuRecursivo/boletines/boletin-estadistico-del-sectorservicios-n-07-julio-2017.pdf

Por otro lado, el pollo a la brasa tiene como sustitutos a las distintas presentaciones de pollo que se ofrecen en los supermercados y centros comerciales, tal como el pollo rostizado. En el primer caso, el producto se puede encontrar en los ambientes exclusivos preparados para los clientes de los supermercados, que procuran obtener los mejores precios a un mismo 
nivel de servicio y rendimiento. En el segundo caso, se encuentran los patios de comida compartidos, donde se puede encontrar comida rápida, típica, buffet y pizzerías.

Sin embargo, a pesar de la amplia variedad de alternativas similares, el pollo a la brasa es un plato típico y su sabor no puede ser reemplazado fácilmente. Por ello, se concluye que el nivel de impacto de esta fuerza competitiva es medio.

\subsubsection{Amenaza de nuevos competidores.}

Según Porter (2008), las barreras de entrada son aquellas ventajas que tienen los actores actuales en comparación con los nuevos entrantes. Una de las principales barreras de entrada que existe en el sector de restaurantes es la dificultad de adquirir terrenos o locales en alquiler para la implementación de restaurantes, ya que actualmente es difícil encontrar un local que tenga una ubicación estratégica, es decir un local que se encuentre en una zona con alto tránsito.

Los competidores que deseen ingresar a este sector, deben contar con capacidad de inversión para los activos tangibles (compra de equipos para la producción, mobiliario, ambientación de local, entre otros) e intangibles (recurso humano óptimo para el manejo del servicio al cliente). Además, deben tener conocimientos mínimos y experiencia en el rubro para poder desenvolverse en el mercado y ofrecer un producto que otorgue valor a los consumidores, haciendo frente a la competencia existente.

Por lo tanto, se concluye que el nivel de impacto de esta fuerza competitiva es medio.

\subsubsection{Poder de negociación de los clientes.}

El poder de negociación de los clientes se da cuando estos obligan a las empresas a bajar sus precios y mejorar la calidad de sus productos y servicios, lo que ocasiona que los participantes del sector compitan entre ellos (Porter, 2008). 
Los clientes más representativos son pertenecientes a los niveles socioeconómicos $\mathrm{C}$ y D, y los que se ajustan a los estilos de vida adaptados (hombres) y conservadoras (mujeres). Asimismo, algunas de las características de estos tipos de clientes son: buscan un ambiente familiar, tradicional y amical, y su decisión de compra se basa principalmente en el precio.

Las personas pertenecientes a los niveles socioeconómicos C y D tienen planificado un presupuesto personal o familiar para su canasta básica que no les permite incrementar sus gastos. Además, la oferta de los productos en el mercado es amplia.

Por ello, a pesar de que los productos y servicios del sector son similares, la diferenciación es baja y el precio es determinante para tomar una decisión de compra. Por lo tanto, se concluye que el nivel de impacto de esta fuerza competitiva es medio.

\subsubsection{Poder de negociación de los proveedores.}

El poder de negociación de los proveedores se da cuando el valor es contenido por ellos y de ese modo se retiene la calidad o los servicios, aumentando los costos hacia sus clientes o el sector (Porter, 2008).

Los principales proveedores del sector son los que suministran los insumos básicos del producto final, tales como pollos, papas y vegetales. En el caso de los pollos, los principales proveedores son San Fernando, Avinka y Redondos, empresas reconocidas que compiten entre ellas por ofrecer un producto idóneo con un precio acorde al consumo que la cadena realiza. Esto es favorable para las empresas, ya que no existe un monopolio que domine el mercado avícola. En el caso de las papas y vegetales, los proveedores son diversos y se encuentran en los mercados mayoristas y minoristas.

Por lo tanto, se concluye que el poder de negociación de los proveedores es bajo, ya que existe una variedad de alternativas de compra. 


\subsubsection{Competencia en el mismo sector.}

Según Porter (2008), la rivalidad de los competidores de un sector puede adoptar muchas formas familiares, tales como: descuentos de precios, lanzamiento de nuevos productos, campañas publicitarias y mejora en la atención del cliente, y la alta rivalidad entre ellos limita la rentabilidad del sector. En el sector de restaurantes se encuentra una alta concentración de competencia, tales como: Roky’s, Pardos Chicken, Las Canastas, Villa Chicken, Don Belisario, La Leña, Las Tinajas, Pikalo, Begui y Hikari, compitiendo como cadena de pollerías; por otro lado, están las pollerías individuales ubicadas en los diferentes distritos donde se posicionan los niveles socioeconómicos $\mathrm{C}$ y D.

En la Tabla 12 se detalla la cantidad de tiendas de las principales cadenas de pollerías en Lima y los distritos donde están ubicadas. Además, se puede observar que las tiendas se encuentran concentradas, en su mayoría, en los distritos donde los niveles socioeconómicos $\mathrm{C}$ y D están posicionados. 
Tabla 12

Principales Cadenas de Pollerías en Lima Metropolitana

\begin{tabular}{|c|c|c|}
\hline $\begin{array}{l}\text { Cadena de } \\
\text { Pollerías }\end{array}$ & $\begin{array}{l}\text { Cantidad } \\
\text { de Tiendas }\end{array}$ & Distritos \\
\hline Norky’s & 92 & $\begin{array}{l}\text { Ate, Breña, Cercado de Lima, Comas, Chorrillos, El } \\
\text { Agustino, Independencia, Jesús María, La Victoria, La } \\
\text { Molina, Lince, Los Olivos, Lurín, Miraflores, Pueblo } \\
\text { Libre, Rímac, San Borja, San Juan de Lurigancho, San } \\
\text { Juan de Miraflores, San Luis, San Martin de Porres, } \\
\text { Santa Anita, Surco, San Luis, Villa el Salvador y Villa } \\
\text { María. }\end{array}$ \\
\hline Roky’s & 57 & $\begin{array}{l}\text { Breña, Villa el Salvador, Lince, Pueblo Libre, } \\
\text { Surquillo, La Victoria, San Juan de Lurigancho, Santa } \\
\text { Anita, El Agustino, Los Olivos, Independencia, Rímac, } \\
\text { San Martin de Porres y Surco. }\end{array}$ \\
\hline Pardos Chicken & 25 & $\begin{array}{l}\text { Independencia, San Juan de Lurigancho, Bellavista, San } \\
\text { Miguel, Pueblo Libre, Lima Cercado, Chorrillos, } \\
\text { Miraflores, Surco, La Molina, San Isidro y San Borja. }\end{array}$ \\
\hline Las Canastas & 13 & $\begin{array}{l}\text { San Miguel, Magdalena, Lima Norte, Chorrillos, Surco, } \\
\text { Miraflores y La Molina. }\end{array}$ \\
\hline Villa Chicken & 13 & $\begin{array}{l}\text { Pueblo libre, Magdalena, San juan de Lurigancho, los } \\
\text { Olivos, San Borja, San Miguel, Lince, Cercado de Lima } \\
\text { y Jesús María. }\end{array}$ \\
\hline Don Belisario & 11 & $\begin{array}{l}\text { La Molina, Surco, Miraflores, San Miguel, Real Plaza } \\
\text { Salaverry, Real Plaza Pro y Plaza Norte. } \\
\text { Independencia, Rímac, San Martin de Porres, La }\end{array}$ \\
\hline La Leña & 11 & $\begin{array}{l}\text { Molina, Pueblo Libre, Comas, San Juan de Lurigancho, } \\
\text { Los Olivos, Cercado de Lima y San Miguel. }\end{array}$ \\
\hline Las Tinajas & 9 & $\begin{array}{l}\text { Cercadode Lima, Pueblo libre, Chorrillos, San Borja, } \\
\text { La Molina, Surco y Barranco. }\end{array}$ \\
\hline Pikalo & 9 & $\begin{array}{l}\text { Los Olivos, Independencia, San Martin de Porres, San } \\
\text { Borja y Surco. }\end{array}$ \\
\hline Begui & 6 & $\begin{array}{l}\text { Los Olivos, Zarate, San Juan de Lurigancho, Lima } \\
\text { Cercado y Lince. }\end{array}$ \\
\hline Hikari & 6 & $\begin{array}{l}\text { Los Olivos, San Miguel, Rímac, San Juan de } \\
\text { Lurigancho y La Molina. }\end{array}$ \\
\hline
\end{tabular}

Nota. Tomado de Cadenas de Pollerías en Lima Metropolitana. Recuperado de

http://norkys.pe/restaurantes, http://rokys.com/locales/,

http://www.pardoschicken.pe/restaurantes/, http://www.lascanastas.com/\#gotolocal,

https://www.villachicken.com.pe/villaweb/app/\#/locales, 
http://www.donbelisario.com.pe/locales-reservas, http://www.lalena.com.pe/pollos-a-la-lena/, http://www.lastinajas.pe/\#local, http://pikalo.com.pe/locales.php, http://www.pollosbegui.com.pe/locales, http://hikari.pe/

La alta concentración y rivalidad de este sector generan que las pollerías busquen un posicionamiento de la marca, ofreciendo mejoras en diferentes aspectos, tales como: aderezo del pollo, calidad de las papas, acompañamientos, promociones y servicio complementario.

Por lo tanto, se concluye que el nivel de impacto de esta fuerza competitiva es alto.

\subsection{Matriz de Atractividad de cada una de las Cinco Fuerzas}

La matriz de atractividad permite resumir cada uno de los factores que previamente se analizaron en las Cinco Fuerzas de Porter, para así asignarle un valor y grado de atractividad, e identificar aquellos factores que tienen mayor incidencia en la empresa.

Según la Tabla 13, se puede concluir que la amenaza de productos sustitutos del sector restaurante tiene un valor de 1, es decir un nivel bajo de atractividad, ya que este sector cuenta con productos sustitutos similares, diversas variedades en productos y variaciones en los precios convirtiéndolo en un sector poco atractivo.

Tabla 13

Matriz de Atractividad de la Fuerza Competitiva: Amenaza de productos de sustitutos

\begin{tabular}{|c|c|c|c|}
\hline Factores & Peso & Atractividad & Valor \\
\hline Productos sustitutos similares al pollo a la brasa & 0.4 & 1 & 0.4 \\
\hline $\begin{array}{l}\text { Variedad de productos en el sector de } \\
\text { restaurantes }\end{array}$ & 0.3 & 1 & 0.3 \\
\hline Variación en el precio de los productos & 0.3 & 1 & 0.3 \\
\hline Total & 1.0 & & 1.0 \\
\hline
\end{tabular}

Según la Tabla 14, se puede concluir que la amenaza de nuevos competidores del sector restaurante tiene un valor de 1.9, es decir un nivel bajo de atractividad, ya que este 
sector cuenta con un alto nivel de competidores, además de escasos terrenos o inmuebles para la apertura de nuevos locales, convirtiéndolo en un sector poco atractivo.

Tabla 14

Matriz de Atractividad de la Fuerza Competitiva: Amenaza de nuevos competidores

\begin{tabular}{|c|c|c|c|}
\hline Factores & Peso & Atractividad & Valor \\
\hline Inversión para ingresar al mercado & 0.2 & 3 & 0.6 \\
\hline Conocimiento y experiencia del sector & 0.1 & 3 & 0.3 \\
\hline Disponibilidad de locales & 0.4 & 1 & 0.4 \\
\hline Número de competidores actuales en Lima & 0.3 & 2 & 0.6 \\
\hline & 1.0 & & 1.9 \\
\hline
\end{tabular}

Según la Tabla 15, se puede concluir que el poder de negociación de los clientes del sector restaurante tiene un valor de 2.3, es decir un nivel medio de atractividad, ya que en este sector existe una gran demanda del pollo a la brasa, pero una selección del producto basado en el precio, considerando además la calidad del producto y servicio ofrecido.

\section{Tabla 15}

Matriz de Atractividad de la Fuerza Competitiva: Poder de negociación de los clientes

\begin{tabular}{|c|c|c|c|}
\hline Factores & Peso & Atractividad & Valor \\
\hline Sensibilidad con relación al precio & 0.3 & 1 & 0.3 \\
\hline Oferta de productos en el mercado & 0.2 & 1 & 0.2 \\
\hline Búsqueda de calidad en el producto y servicio & 0.2 & 3 & 0.6 \\
\hline Demanda del producto & 0.3 & 4 & 1.2 \\
\hline Total & 1.0 & & 2.3 \\
\hline
\end{tabular}

Según la Tabla 16, se puede concluir que el poder de negociación de los proveedores del sector restaurante tiene un valor de 4.4, es decir un nivel alto de atractividad, ya que en este sector existe diversidad de proveedores para los diferentes insumos, haciéndolo un sector atractivo. 
Tabla 16

Matriz de Atractividad de la Fuerza Competitiva: Poder de negociación de los proveedores

\begin{tabular}{|c|c|c|c|}
\hline Factores & Peso & Atractividad & Valor \\
\hline Número de proveedores & 0.4 & 5 & 2.0 \\
\hline Diferenciación de insumos & 0.3 & 4 & 1.2 \\
\hline Cumplimiento en la entrega de productos & 0.3 & 4 & 1.2 \\
\hline & 1.0 & & 4.4 \\
\hline
\end{tabular}

Según la Tabla 17, se puede concluir que la competencia en el mismo sector restaurante tiene un valor de 2 , es decir un nivel medio de atractividad, ya que en este sector existen diversos competidores y un bajo posicionamiento de las marcas, haciéndolo poco atractivo.

Tabla 17

Matriz de Atractividad de la Fuerza Competitiva: Competencia en el mismo sector

\begin{tabular}{|c|c|c|c|}
\hline Factores & Peso & Atractividad & Valor \\
\hline Número de competidores & 0.3 & 1 & 0.3 \\
\hline Diferenciación de productos y servicio & 0.3 & 3 & 0.9 \\
\hline Posicionamiento de la marca en el sector & 0.4 & 2 & 0.8 \\
\hline & 1.0 & & 2.0 \\
\hline
\end{tabular}

En la Tabla 18 se muestra la matriz de atractividad de las Cinco Fuerzas de Porter, con un valor ponderado de 2.76 , lo cual indica que la atractividad de la industria está dentro del promedio. 
Tabla 18

Matriz de Atractividad de las Cinco Fuerzas

\begin{tabular}{|c|c|c|c|}
\hline Factores & Peso & Atractividad & Valor \\
\hline Amenaza de productos de sustitutos & 0.1 & 1.0 & 0.10 \\
\hline Amenaza de nuevos competidores & 0.1 & 1.9 & 0.19 \\
\hline Poder de negociación de los clientes & 0.3 & 3.3 & 0.99 \\
\hline Poder de negociación de los proveedores & 0.2 & 4.4 & 0.88 \\
\hline Competencia en el mismo sector & 0.3 & 2.0 & 0.60 \\
\hline & 1.0 & & 2.76 \\
\hline
\end{tabular}

\subsection{Análisis del Grado de Atractividad de la Industria}

La fuerza predominante es la competencia en el mismo sector, ya que existen varios competidores que tienen cadenas de pollerías en los diferentes distritos donde predominan los niveles socioeconómicos $\mathrm{C}$ y D, los cuales representan el público objetivo de Norky’s. Las cadenas de pollerías Roky’s, Pardos Chicken, Las Canastas, Villa Chicken, Pikalo, La Leña, Las Tinajas, Hikari y Begui compiten en todas las líneas de producto, ya que ofrecen platos similares a los que ofrece Norky's (ver Tabla 1). El posicionamiento en el mercado nacional de estos establecimientos también es considerable, ya que cuentan con cierta trayectoria en el mercado.

La amenaza de nuevos competidores es la fuerza que tiene menor impacto, debido a que Norky's cuenta con conocimiento y experiencia en el sector, siendo así una de las principales barreras frente a los nuevos competidores interesados en invertir en el mismo.

\subsection{Matriz de Perfil Competitivo MPC}

Según David (2013), una matriz de perfil competitivo permite hacer una comparación entre la empresa en estudio y sus principales competidores, en relación a las principales fortalezas y debilidades en las áreas funcionales. 
A continuación, se detallan las fortalezas y debilidades de Norky's:

- La alta cobertura en Lima y expansión a nivel nacional representan una fortaleza mayor para la empresa, ya que permite crear espacios de acceso para los clientes en diversos puntos del país, concentrándose, en mayor medida, en Lima por su dinamismo económico. Esto permite a la empresa captar una mayor cantidad de clientes impactando, directamente, en el incremento de sus ventas.

- La recordación de la marca representa una fortaleza mayor para la empresa, debido a la trayectoria que ha mantenido en el mercado de los niveles socioeconómicos $\mathrm{C}$ y D, posicionándola en la mente de los consumidores como un lugar donde pueden consumir un producto de calidad y pasar un buen momento familiar (Un gus to por conquistar, arellanomarketing.com, 2013).

- El alto poder de negociación con los proveedores representa una fortaleza mayor para la empresa, debido a que la compra de los insumos y materia prima se negocia, a través de la compra por volumen, permitiéndole así, convertirse en un importante cliente para los mismos y tener acceso a menores costos.

- La gran diversidad de productos en la carta representa una fortaleza mayor para la empresa, ya que los clientes tienen una variada disposición de productos para escoger, además del tradicional pollo a la brasa, lo cual acrecienta la idea de satisfacer varias preferencias en un solo lugar (ver Tabla 1).

- Los productos de calidad representan una fortaleza mayor para la empresa, ya que los proveedores de los insumos principales son empresas reconocidas en el sector por la calidad de sus productos. Adicionalmente, los trabajadores que son parte del proceso de elaboración del producto final son capacitados constantemente por un especialista en Buenas Prácticas de Manufactura (BPM) para manipular adecuadamente los alimentos. 
- La buena atención representa una fortaleza menor para la empresa, ya que los trabajadores de las tiendas, que están en contacto directo con los clientes, son capacitados constantemente en protocolos de servicio, a través de las escuelas de formación (Un gusto por conquistar, arellanomarketing.com, 2013).

- La falta de estandarización y automatización de los procesos representa una debilidad mayor para la empresa, ya que existen muchos procesos administrativos que se realizan manualmente y, considerando el gran número de tiendas que se tienen a nivel nacional, el tiempo de respuesta de ellos es alto. Además, los procesos operativos que se realizan en las tiendas no se llevan a cabo de la misma manera, ya que no hay un procedimiento estándar para ellos.

- La alta rotación de personal joven representa una debilidad mayor para la empresa, ya que hoy en día los jóvenes buscan tener un trabajo que les brinde una mejor calidad de vida y tiempo para compartirlo en familia, en lugar de una permanencia en la empresa. Por ello, incluso evitan hacer horas extras en sus puestos de trabajo.

En la Tabla 19 se muestra la matriz MPC para Norky's, basada en las fortalezas y debilidades identificadas anteriormente. Cabe resaltar que los valores de la empresa en estudio se asignaron en base a la información entregada por los gerentes funcionales de Norky's durante las entrevistas (ver Anexo 7). 
Tabla 19

Matriz MPC de Norky's

\begin{tabular}{|c|c|c|c|c|c|}
\hline \multirow{2}{*}{ Factores Críticos de Éxito } & \multirow{2}{*}{ Valor } & \multicolumn{2}{|l|}{ Norky's } & \multicolumn{2}{|l|}{ Roky's } \\
\hline & & Clasificación & Puntaje & Clasificación & Puntaje \\
\hline Cobertura a nivel nacional & 0.13 & 4 & 0.52 & 4 & 0.52 \\
\hline Recordación de la marca & 0.16 & 4 & 0.64 & 4 & 0.64 \\
\hline Poder de negociación con los proveedores & 0.10 & 4 & 0.40 & 4 & 0.40 \\
\hline Diversidad de productos en la carta & 0.05 & 4 & 0.20 & 4 & 0.20 \\
\hline Productos de calidad & 0.19 & 4 & 0.76 & 4 & 0.76 \\
\hline Atención al cliente & 0.17 & 3 & 0.51 & 3 & 0.51 \\
\hline $\begin{array}{l}\text { Estandarización y automatización de los } \\
\text { procesos }\end{array}$ & 0.12 & 1 & 0.12 & 3 & 0.36 \\
\hline Rotación de personal joven & 0.08 & 1 & 0.08 & 1 & 0.08 \\
\hline Total & 1.00 & & 3.23 & & 3.47 \\
\hline
\end{tabular}

Según el cuadro expuesto, se puede apreciar que comparando las cadenas de pollerías Norky's y Roky's, la segunda tiene un ligero mejor desempeño en el mercado con una puntuación de 3.47, en comparación con su competidor que obtuvo 3.23. Con relación a la cadena de pollerías Roky's, el factor donde obtiene una diferencia a favor es en la automatización de los procesos con una calificación de 0.36 , en relación al 0.12 obtenido por Norky's. Cabe agregar que ambas cadenas son muy similares, no solo por los factores descritos sino por el público objetivo al que se dirigen y el significativo tiempo que se encuentran en el mercado nacional. 


\section{Capítulo VI. Análisis Interno}

\subsection{Mercado Objetivo}

El plan estratégico a desarrollar generará un impacto sobre los colaboradores

pertenecientes a las 92 tiendas, las cuales cuentan con 961 colaboradores pertenecientes a los diferentes puestos mostrados en la Figura 5. Asimismo, en la Tabla 20 se puede observar la descripción de los puestos y porcentajes de género por cada grupo de edad de los colaboradores.

Tabla 20

Rango de Edades, Distribución de Edades y Género de los Colaboradores en las Tiendas

\begin{tabular}{|c|c|c|c|c|}
\hline \multirow{2}{*}{$\begin{array}{l}\text { Rango de } \\
\text { Edades }\end{array}$} & \multirow{2}{*}{ Nombres de los Puestos } & \multirow{2}{*}{$\begin{array}{l}\text { Distribución } \\
\text { de Edades }\end{array}$} & \multicolumn{2}{|c|}{ Género } \\
\hline & & & Femenino & Masculino \\
\hline 18 - 21 años & $\begin{array}{l}\text { Anfitriona, ayudante de cocina, azafata, azafata } \\
\text { karaoke, barman, cajero/a, cocinero, counter, } \\
\text { hornero (ayudante), limpieza, motorizado, } \\
\text { mozo, mozo part time. }\end{array}$ & $33 \%$ & $48 \%$ & $52 \%$ \\
\hline 22 - 26 años & $\begin{array}{l}\text { Anfitriona, ayudante de cocina, azafata, barman, } \\
\text { cajero/a, cocinero, counter, hornero (ayudante), } \\
\text { limpieza, motorizado, mozo, mozo part time. }\end{array}$ & $32 \%$ & $31 \%$ & $69 \%$ \\
\hline 27 - 31 años & $\begin{array}{l}\text { Anfitriona, auxiliar de limpieza de tienda, } \\
\text { ayudante de cocina, azafata, barman, cajero/a, } \\
\text { cocinero, counter, hornero (ayudante), limpieza, } \\
\text { motorizado, mozo, mozo part time. }\end{array}$ & $16 \%$ & $24 \%$ & $76 \%$ \\
\hline 32 - 39 años & $\begin{array}{l}\text { Ayudante de cocina, azafata, cajero/a, cocinero, } \\
\text { hornero (ayudante), limpieza, motorizado, } \\
\text { mozo. }\end{array}$ & $13 \%$ & $19 \%$ & $81 \%$ \\
\hline 40 - 45 años & $\begin{array}{l}\text { Ayudante de cocina, azafata, barman, cajero/a, } \\
\text { cocinero, hornero (ayudante), motorizado, } \\
\text { mozo. }\end{array}$ & $4 \%$ & $41 \%$ & $59 \%$ \\
\hline $46-49$ años & $\begin{array}{l}\text { Azafata, barman, cocinero, hornero (ayudante), } \\
\text { limpieza, motorizado, mozo. }\end{array}$ & $1 \%$ & $33 \%$ & $67 \%$ \\
\hline $50-60$ años & Azafata, cajero/a, limpieza, mozo. & $1 \%$ & $63 \%$ & $38 \%$ \\
\hline
\end{tabular}

En la Tabla 20 se puede ver que el mercado objetivo está conformado principalmente por personas jóvenes, entre 17 y 26 años, los cuales tienden a buscar un trabajo que les brinde 
una mejor calidad de vida y tiempo para compartirlo en familia, en lugar de una permanencia en la empresa. Por esta razón, la alta rotación del personal joven es una de las principales debilidades de Norky's.

\subsection{Descripción de las Actividades de la Cadena de Valor de la Empresa}

La cadena de valor propuesta por Michael Porter, es una herramienta que ayuda a crear o incrementar valor para el cliente. De acuerdo al modelo, cada empresa tiene, en resumidas cuentas, actividades que se desarrollan desde el diseño, producción, comercialización, entrega y apoyo al producto. La cadena de valor está compuesta por dos grupos de actividades estratégicas, primarias y de apoyo, las cuales crean valor y costos en un negocio. En el caso de las actividades primarias, estas involucran actividades como logística de entrada, operaciones, logística de salida, marketing y ventas, y servicios. Las actividades de apoyo involucran actividades especializadas como aprovisionamiento, desarrollo de la tecnología, gestión de recursos humanos e infraestructura de la empresa (Kotler, 2012). La cadena de valor le permite a la empresa evaluar cada actividad que genera valor y realizar las mejoras que se requieran para así obtener mejor rendimiento de sus costos.

En la Figura 14, se muestran las actividades primarias y de apoyo de la cadena de valor de Norky's. 


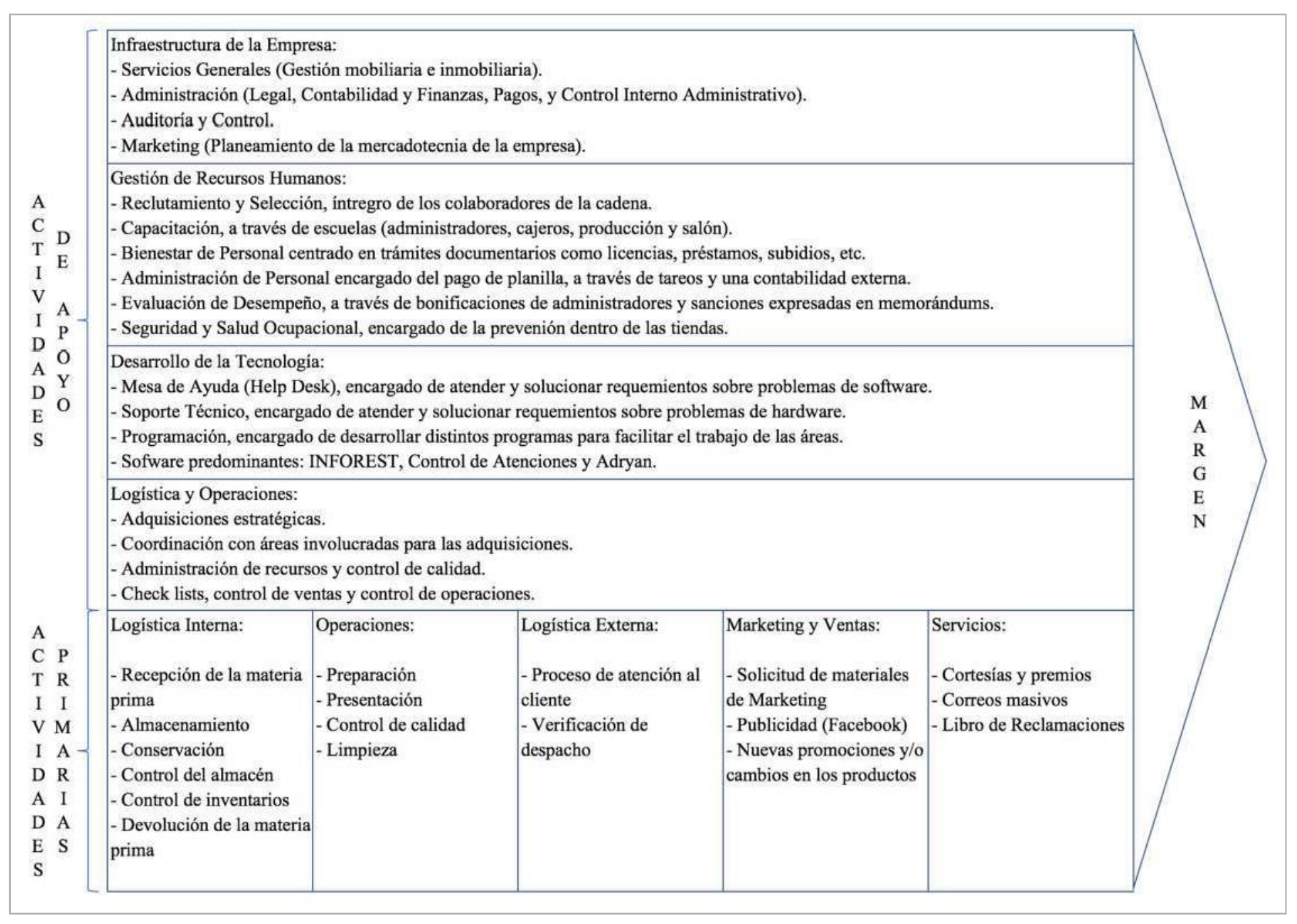

Figura 14. Cadena de Valor de Norky's. 


\section{- Logística Interna}

La recepción de la mercadería es llevada a cabo por el administrador de la tienda, quien verifica que ésta se encuentre en óptimas condiciones y cumpla con lo especificado en el documento. Si todo está conforme, el administrador solicita el comprobante (guía o factura), sella el documento y coloca la fecha de recepción, así como su nombre, DNI y firma. Finalmente, rellena el formato de "Recepción de materia prima e ingredientes".

En caso de que la mercadería esté en mal estado, el administrador rechaza inmediatamente los productos y genera una "Hoja de devolución al proveedor”. En caso de que los productos no sean correctos, el administrador informa por teléfono al supervisor de operaciones para coordinar si puede ser recibida o no, y qué acción tomar ante la posible falta de insumos.

Luego de que la mercadería es aceptada por el administrador, el personal de la tienda se encarga de posicionarlo correctamente en el almacén. Posteriormente, el administrador verifica que los productos estén correctamente almacenados, en sus respectivos envases para evitar la contaminación cruzada, y debidamente refrigerados en caso de ser necesario.

Finalmente, antes del cierre de tienda, el administrador realiza un control de stock, y verifica el abastecimiento y almacenamiento de producto y equipos.

El control de inventarios es llevado a cabo por el inventariador de MACROSCEM S.A.C. una o dos veces al mes, para ello el administrador hace entrega de los cuadernos de control diario de cada área para su revisión, así como las notificaciones sobre los faltantes encontrados durante el periodo de inventario. El administrador también entrega las hojas de incidencia de pedidos pendientes (notas de crédito, devolución o cambio) para que sea considerado dentro de los ajustes a realizar. Al finalizar el inventario, el administrador recibirá un informe sobre diferencias valorizadas, el cual debe firmar esté conforme o no con 
el resultado. En caso de que el administrador no esté conforme, puede solicitar una revisión al coordinador de auditoría dentro de las 72 horas desde la recepción del informe.

La automatización de los procesos de la logística interna permitirá aumentar la eficiencia e incrementar los niveles de productividad de Norky's.

- Operaciones

Antes de iniciar con las actividades de preparación, el administrador verifica el estado de los productos que quedaron el día anterior (pollos, papas, cremas, verduras, entre otros) y los insumos necesarios para la preparación de los alimentos, en base a la proyección de ventas del día.

La preparación de los alimentos es llevada a cabo por el personal de producción de la tienda, quien ha sido capacitado en la escuela de formación de Norky’s para realizar las tareas de preparación y presentación del producto final. Además, el mismo personal ha participado en el curso de Higiene Alimentaria y Buenos Hábitos de Trabajo Seguro dictado por un especialista en Buenas Prácticas de Manufactura (BPM) de MACROSCEM S.A.C para ofrecer un producto de calidad, basado en las mejores prácticas.

La limpieza del salón es llevada a cabo por el auxiliar de limpieza tres veces al día y una vez a la semana realiza una limpieza profunda. Antes de la apertura de la tienda, el administrador se encarga de verificar la limpieza del salón y la correcta higiene del personal.

Las actividades de operaciones permiten a Norky's ofrecer un producto de calidad, basado en las mejores prácticas, para lograr la satisfacción del cliente. 


\section{- Logística Externa}

La logística externa de Norky’s consiste en el siguiente proceso de atención a los comensales, como se observa en la Figura 15.

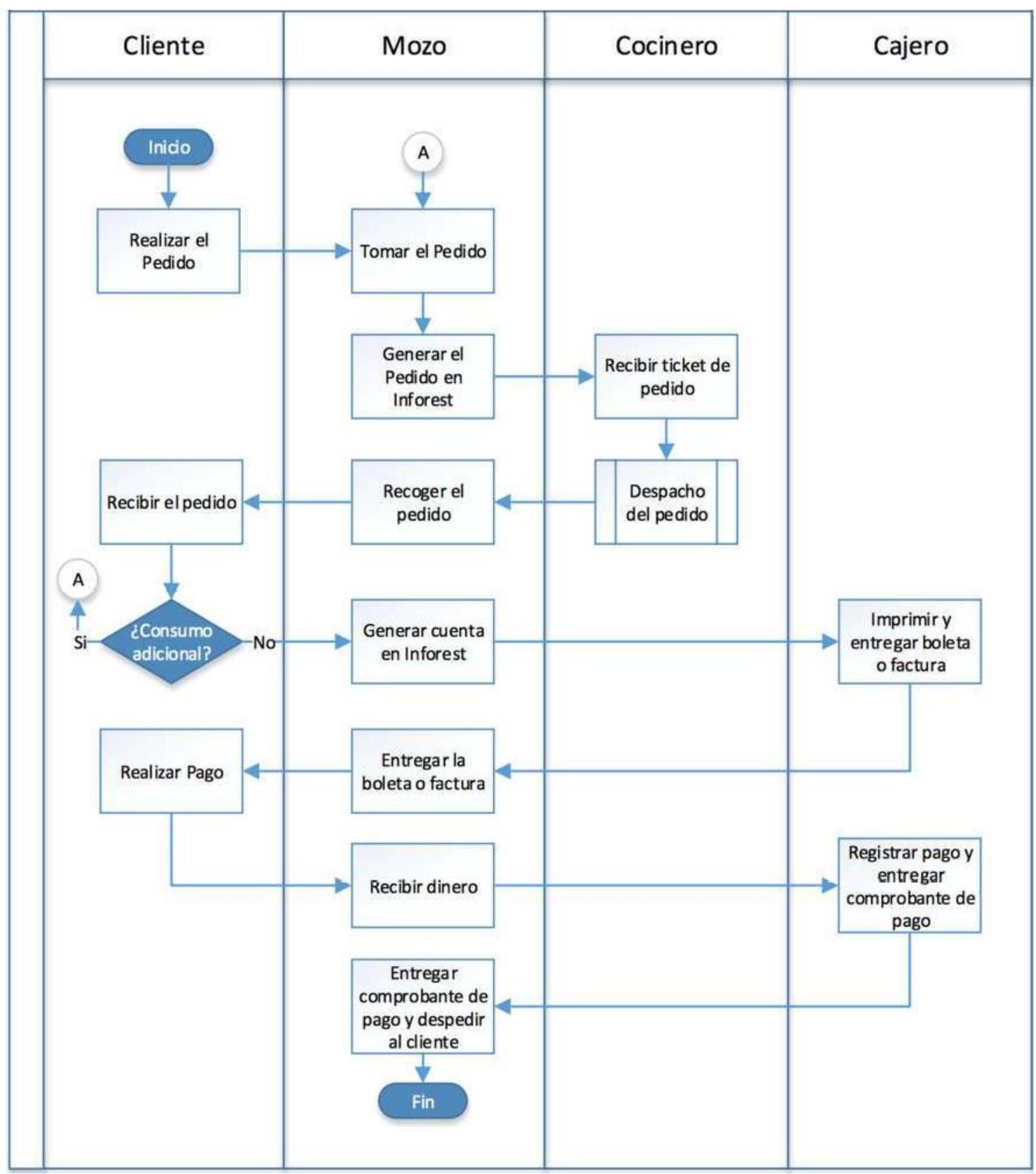

Figura 15. Proceso de Atención a los Comensales de Norky's. 
Complementando el proceso de atención, el administrador verifica que se esté produciendo y despachando un buen producto a los comensales (textura, temperatura y presentación), y durante los turnos de atención donde la afluencia del público es mayor, el administrador es más riguroso en la supervisión de atención a los mismos.

La logística externa permite a Norky’s entregar un producto ajustado al requerimiento del cliente, en un tiempo oportuno, y tiene como principal objetivo mantener la eficiencia en el proceso de atención al cliente.

- Marketing y Ventas

El administrador es responsable de cumplir con las directivas del área de marketing y el proceso se inicia a través de una solicitud de materiales de marketing, tales como: volantes, imantados, cartas de presentación, banners, libros de reclamaciones, tarjetas de presentación, acrílicos de mesa y afiches, como se puede observar en el Anexo 8. La periodicidad de la solicitud es mensual y debe contar con la aprobación del Gerente de Operaciones. El administrador recibe la producción del material en un plazo de una a tres semanas, a través de una ruta programada por el área de Logística.

La publicidad de Norky's es impulsada mediante la red social Facebook, donde se realizan publicaciones diarias, informando las nuevas promociones en las tiendas y promoviendo la participación de diversos concursos a los clientes.

Por otro lado, los letreros externos generan un impacto visual en el público que transita cerca de las tiendas, como se puede observar en el Anexo 8.

La introducción de nuevas promociones o cambios de productos serán notificados, por medio de un correo masivo por el área de Marketing, a los administradores de tienda, dentro del correo corporativo se encontrarán datos como el nombre del producto, canal de venta, precio del producto y fecha de inicio. 
El marketing y ventas de Norky's tiene como principal finalidad impulsar las ventas, ya que permite que los clientes conozcan los productos y promociones, a través de diferentes medios, tales como: volantes, vallas, banners, entre otros.

\section{- Servicios}

Norky's ofrece cortesías a los cumpleañeros, tales como una porción de torta o una bola de helado. Además, ofrece premios en los shows musicales y fiestas infantiles llevados a cabo en las tiendas. Otro de los medios que utiliza para llegar a los clientes, después de una compra, es el envío de correos masivos, enviándoles la promoción de temporada y posibles aperturas de nuevos locales. La periodicidad del envío de correos masivos es semestral.

Según lo anterior, este proceso se realiza con la finalidad de brindar un servicio donde los consumidores se sientan especiales, tales como entrega de cortesías y premios.

\section{- Infraestructura de la Empresa}

Servicios Generales es el área de soporte creada para la gestión general inmobiliaria y mobiliaria de las tiendas, ya que generan grandes costos para la empresa y, a su vez, entregan valor al cliente. Asimismo, es responsable de las instalaciones, equipamiento y gestiones administrativas de licencias, autorizaciones y trámites de las tiendas; además, vela por entregar las mejores condiciones de trabajo a los empleados, así como la mejor atención a los clientes. Servicios Generales gestiona aquellos requerimientos especiales de inmuebles y mobiliario para cada tienda, así como equipamiento, utensilios, seguridad y mantenimiento de las mismas, esto en coordinación con las áreas de Logística y Operaciones. También gestiona los trámites para la apertura de tiendas, tales como licencias de funcionamiento, certificados de Defensa Civil y MINCETUR, así como aquellos certificados que permitan operar. Servicios Generales concentra las actividades descritas anteriormente para que el 
personal de cada tienda pueda concentrarse en producir un buen producto y dar un mejor servicio a los clientes.

El área de Administración es donde se centralizan las actividades especializadas de apoyo, tales como: Legal, Contabilidad y Finanzas, Pagos, y Control Interno Administrativo. Esta oficina permite que se desarrollen las actividades principales de Norky's con normalidad. El área Legal realiza actividades de soporte que permite a Norky’s llevar adelante los acuerdos comerciales, los cuales involucran contratos con proveedores, arrendadores, inversionistas, empleados y distintos entes públicos, para así tener la certeza de que los acuerdos y condiciones que se tomen son adecuados para la empresa y están dentro del marco jurídico. Además, brinda asesoría frente a casos de fiscalización de Indecopi, atención del libro de reclamaciones y asuntos de índole normativa jurídica que involucren interesados internos y externos. Contabilidad y Finanzas es el área especializada en los registros de las operaciones económicas de la cadena, y asuntos tributarios e impuestos; así como el suministro de la información necesaria para los inversionistas y demás áreas internas interesadas. El área de Pagos es responsable de realizar los cálculos, descuentos y transacciones económicas y financieras, además de mantener las buenas relaciones con los proveedores. Finalmente, el área de Control Interno Administrativo es responsable de velar por el control diario de insumos, higiene de personal, limpieza de las tiendas y control de atenciones en formatos especiales preparados. La importancia del área de Administración reside en atender las necesidades especiales de Norky's para que los empleados, inversionistas y clientes tengan la tranquilidad de saber que existe personal capacitado para atender cada una de sus necesidades.

Marketing es el área responsable de realizar la mercadotecnia de Norky’s, es decir que planifica su estructura de trabajo y elabora los objetivos, estrategias y planes de acción del marketing de Norky's, así como el presupuesto que requieren, es decir que, el área de 
Marketing puede brindar asesoría especializada en un campo muy cambiante, esto permite a Norky's tener un equipo que lo ayude a posicionarse y tener presencia de manera estratégica en el mercado.

Auditoría y Control es el área de soporte que realiza, en coordinación con Contabilidad y Finanzas, los análisis de los estados financieros y flujos de caja, vela por el patrimonio e inversiones de Norky's, y audita los procedimientos de compras, acuerdos con proveedores o arrendadores, entre otros. Asimismo, el área realiza la auditoria interna de los procedimientos de pagos e inversiones, y el control de las operaciones económicas. El área de Auditoría y Control brinda información importante a los inversionistas de Norky's e interesados que les permite conocer cómo se obtuvieron los indicadores, ya sean positivos o negativos.

- Gestión de Recursos Humanos

El área de Recursos Humanos está conformada por las siguientes divisiones: Reclutamiento y Selección, Capacitación, Bienestar de Personal, Administración de Personal, Evaluación de Desempeño, y Seguridad y Salud Ocupacional. El área tiene un rol trascendental dentro de la empresa, ya que de esta depende el constante desarrollo de la operación, a través de la adecuada gestión del personal que se expresa en el reclutamiento y selección del personal idóneo; la capacitación, a través de las escuelas (administradores cajeros, producción y salón); el correcto pago de la planilla, el cual se da mediante tareos y una contabilidad externa; la tramitación de licencias, préstamos, asignación familiar, descansos médicos y subsidios; la gestión de bonificaciones (administradores) y sanciones; y la prevención dentro de las tiendas. El área está en una etapa de automatización, ya que hay varios procesos manuales y mucha documentación. Asimismo, si bien hay perfiles de puestos, estos no se han masificado a todos los existentes dentro de la empresa, lo cual deriva 
en la ausencia de MOF. Por otro lado, se han incorporado indicadores para medir el rendimiento de cada división y así controlar los procesos realizados.

Por lo expresado, el área está enfocándose en generar eficiencia administrativa, capacitación del personal y tener un impacto positivo en la retención del personal con su gestión.

- Desarrollo de la Tecnología

El área de Sistemas está conformada por las siguientes divisiones: Mesa de Ayuda (Help Desk), Soporte Técnico y Programación. El área tiene una labor cada vez más protagónica por la etapa de automatización en la que se encuentra la empresa; su importancia radica en la atención sobre los sistemas que se manejan, reparación de equipos, y desarrollo y ejecución de programas que reduzcan tiempos y trabajos manuales. Por otro lado, el área maneja una base de datos central para el desarrollo de diversos programas, entre los cuales se encuentran: INFOREST (software modular de planificación, gestión, evaluación y control de ventas), Control de Atenciones (software modular de planificación, gestión, evaluación y control de programas desarrollados para las distintas áreas de la empresa, así como la atención y solución de problemas con el software y hardware) y Adryan (software modular de asistencia y planilla).

Por lo expresado, el área está centrándose en generar eficiencia, a través de la automatización de los procesos, expresado en el desarrollo y ejecución de programas.

\section{- Logística y Operaciones}

El área de Logística de Norky’s se encarga de identificar las necesidades de las tiendas, a través de los administradores, y gestionar la autorización de estas, por parte de la Gerencia General. Esta área opera en coordinación con Servicios Generales para buscar proveedores y solicitar cotizaciones, tomando en consideración los costos, calidad, stock, 
tiempo de entrega, plazo de pago y ubicación, para luego involucrar al área Legal en la contratación y realizar la logística y seguimiento de la cadena de suministro. Por otro lado, Operaciones tiene la responsabilidad de realizar la administración y control de insumos necesarios para la elaboración de los productos finales en las tiendas, así como controlar la calidad de ellos. Asimismo, el área de Operaciones es responsable de realizar el seguimiento (y proponer nuevos) de los check lists ejecutados en las tiendas, para llevar el control de las tareas del personal, vencimiento de alimentos perecibles y abastecimiento de los productos e insumos. Operaciones también realiza el control de las ventas en las tiendas e informa cuál es la participación de estas. Logística y Operaciones permiten a Norky’s obtener y conducir los recursos necesarios para obtener el mejor producto y que estos lleguen a los clientes.

\subsection{Indicadores de cada una de las Actividades de la Cadena de Valor}

En la Tabla 21 se muestra una matriz con los indicadores de cada una de las actividades de la cadena de valor de Norky's. 
Tabla 21

Indicadores de las Actividades de la Cadena de Valor

\begin{tabular}{|c|c|c|}
\hline Indicador & Fórmula & Propósito \\
\hline \multicolumn{3}{|l|}{ Logística Interna } \\
\hline Indicador de stock & Stock real / Stock ideal & $\begin{array}{l}\text { Evaluar si la tienda tiene el stock } \\
\text { adecuado de los insumos en el } \\
\text { Almacén. }\end{array}$ \\
\hline $\begin{array}{l}\% \text { de pedidos devueltos } \\
\text { por proveedor }\end{array}$ & $\begin{array}{l}\text { N. de pedidos devueltos / N. de } \\
\text { pedidos }\end{array}$ & $\begin{array}{l}\text { Identificar a los proveedores que } \\
\text { cometen más errores en la entrega de } \\
\text { pedidos. }\end{array}$ \\
\hline \multicolumn{3}{|l|}{ Operaciones } \\
\hline $\begin{array}{l}\text { Check list de control de } \\
\text { calidad }\end{array}$ & Puntaje real / Puntaje esperado & $\begin{array}{l}\text { Medir el cumplimiento de la calidad } \\
\text { en las tiendas. }\end{array}$ \\
\hline Check list de limpieza & Puntaje real / Puntaje esperado & $\begin{array}{l}\text { Medir el cumplimiento de la limpieza } \\
\text { en las tiendas. }\end{array}$ \\
\hline \multicolumn{3}{|l|}{ Logística Externa } \\
\hline $\begin{array}{l}\text { Check list del } \\
\text { cumplimiento del proceso } \\
\text { de atención }\end{array}$ & Puntaje real / Puntaje esperado & $\begin{array}{l}\text { Evaluar por medio de un cliente } \\
\text { incógnito la efectividad de la atención } \\
\text { al cliente. }\end{array}$ \\
\hline \multicolumn{3}{|l|}{ Marketing y Ventas } \\
\hline $\begin{array}{l}\text { Likes y seguidores en la } \\
\text { página oficial de Norky's }\end{array}$ & $\begin{array}{l}\text { N. de Likes y seguidores de la } \\
\text { página oficial }\end{array}$ & $\begin{array}{l}\text { Medir la cantidad de seguidores de la } \\
\text { página oficial de Norky's en } \\
\text { Facebook. }\end{array}$ \\
\hline \multicolumn{3}{|l|}{ Servicios } \\
\hline $\begin{array}{l}\text { Descargos en el libro de } \\
\text { reclamaciones }\end{array}$ & $\begin{array}{l}\text { N. de descargos en el libro de } \\
\text { reclamaciones }\end{array}$ & Medir la disconformidad del cliente. \\
\hline \multicolumn{3}{|l|}{$\begin{array}{l}\text { Infraestructura de la } \\
\text { Empresa }\end{array}$} \\
\hline $\begin{array}{l}\text { \% de atención de } \\
\text { solicitudes de trabajo } \\
\text { (SSGG) }\end{array}$ & $\begin{array}{l}\text { N. de solicitudes de trabajo } \\
\text { atendidas / N. de solicitudes de } \\
\text { trabajo generadas }\end{array}$ & $\begin{array}{l}\text { Evaluar la atención de las solicitudes } \\
\text { de trabajo presentadas. }\end{array}$ \\
\hline $\begin{array}{l}\text { Cumplimiento de plazos } \\
\text { del proceso de apertura o } \\
\text { cierre de una tienda } \\
\text { (SSGG) }\end{array}$ & $\begin{array}{l}\text { N. días utilizados - N. días } \\
\text { esperado }\end{array}$ & $\begin{array}{l}\text { Medir el cumplimento de los plazos } \\
\text { del proceso de apertura o cierre de una } \\
\text { tienda. }\end{array}$ \\
\hline $\begin{array}{l}\text { Liquidez Corriente } \\
\text { (Contabilidad) }\end{array}$ & $\begin{array}{l}\text { Activo Corriente / Pasivo } \\
\text { Corriente }\end{array}$ & $\begin{array}{l}\text { Medir la capacidad de la empresa para } \\
\text { hacer frente a sus deudas a corto } \\
\text { plazo. }\end{array}$ \\
\hline $\begin{array}{l}\text { Margen Operativo } \\
\text { (Contabilidad) }\end{array}$ & Utilidad Operativa / Ventas & $\begin{array}{l}\text { Medir la utilidad operativa de la } \\
\text { empresa. }\end{array}$ \\
\hline ROA (Auditoría y Control) & Utilidad Neta / Activo Total & $\begin{array}{l}\text { Medir la rentabilidad en base a lo } \\
\text { invertido en activos. }\end{array}$ \\
\hline ROE (Auditoría y Control) & Utilidad Neta / Patrimonio & $\begin{array}{l}\text { Medir la rentabilidad en base al } \\
\text { patrimonio total (o por tienda). }\end{array}$ \\
\hline
\end{tabular}




\begin{tabular}{|c|c|c|}
\hline Indicador & Fórmula & Propósito \\
\hline \multicolumn{3}{|l|}{$\begin{array}{l}\text { Gestión de Recursos } \\
\text { Humanos }\end{array}$} \\
\hline$\%$ de rotación de personal & $\begin{array}{l}\text { (N. de ingresos - N. de egresos) } \\
\text { / N. de personal }\end{array}$ & Medir la rotación del personal. \\
\hline $\begin{array}{l}\text { Ranking de canales de } \\
\text { reclutamiento }\end{array}$ & $\begin{array}{l}\text { N. de postulantes por canal de } \\
\text { reclutamiento }\end{array}$ & $\begin{array}{l}\text { Identificar los canales más } \\
\text { importantes. }\end{array}$ \\
\hline $\begin{array}{l}\text { Cumplimiento de plazos } \\
\text { del proceso de selección }\end{array}$ & $\begin{array}{l}\text { N. días utilizados para la } \\
\text { selección - N. de días } \\
\text { solicitados para la selección }\end{array}$ & $\begin{array}{l}\text { Medir el cumplimento de los plazos } \\
\text { del proceso de selección. }\end{array}$ \\
\hline $\begin{array}{l}\text { Eficacia del proceso de } \\
\text { selección }\end{array}$ & $\begin{array}{l}\text { N. de personal seleccionado / } \\
\text { N. de personal requerido }\end{array}$ & $\begin{array}{l}\text { Medir el cumplimiento de los } \\
\text { requerimientos de personal. }\end{array}$ \\
\hline $\begin{array}{l}\text { Seguimiento de personal } \\
\text { por tienda }\end{array}$ & $\begin{array}{l}\text { N. de horas reales / N. de horas } \\
\text { ideales }\end{array}$ & Controlar el personal por tienda. \\
\hline$\%$ de atención de trámites & $\begin{array}{l}\text { N. de trámites atendidos / N. de } \\
\text { trámites presentados }\end{array}$ & Medir la atención de los trámites. \\
\hline $\begin{array}{l}\text { Ranking de } \\
\text { administradores que } \\
\text { llegaron a la meta }\end{array}$ & $\begin{array}{l}\mathrm{N} \text {. de administradores que } \\
\text { llegaron a la meta }\end{array}$ & $\begin{array}{l}\text { Identificar a los administradores que } \\
\text { cumplieron con la meta requerida. }\end{array}$ \\
\hline Disciplina & $\begin{array}{l}\text { Suma de los pesos de las } \\
\text { sanciones / N. de } \\
\text { memorándums }\end{array}$ & Evaluar la disciplina del personal. \\
\hline \multicolumn{3}{|l|}{$\begin{array}{l}\text { Desarrollo de la } \\
\text { Tecnología }\end{array}$} \\
\hline $\begin{array}{l}\text { \% de atención de } \\
\text { solicitudes de software }\end{array}$ & $\begin{array}{l}\text { N. de solicitudes de software } \\
\text { atendidas / N. de solicitudes de } \\
\text { software generadas }\end{array}$ & $\begin{array}{l}\text { Evaluar la atención de las solicitudes } \\
\text { de software presentadas. }\end{array}$ \\
\hline $\begin{array}{l}\% \text { de atención de } \\
\text { solicitudes de hardware }\end{array}$ & $\begin{array}{l}\text { N. de solicitudes de hardware } \\
\text { atendidas / N. de solicitudes de } \\
\text { hardware generadas }\end{array}$ & $\begin{array}{l}\text { Evaluar la atención de las solicitudes } \\
\text { de hardware presentadas. }\end{array}$ \\
\hline $\begin{array}{l}\% \text { de cumplimiento de } \\
\text { solicitudes de nuevos } \\
\text { programas }\end{array}$ & $\begin{array}{l}\text { N. de nuevos programas } \\
\text { creados / N. de solicitudes de } \\
\text { nuevos programas }\end{array}$ & $\begin{array}{l}\text { Medir el cumplimiento de los } \\
\text { programas solicitados. }\end{array}$ \\
\hline \multicolumn{3}{|l|}{ Logística y Operaciones } \\
\hline Margen Neto por tienda & $\begin{array}{l}\text { Utilidad Neta por tienda / } \\
\text { Ventas por tienda }\end{array}$ & Medir la utilidad neta de cada tienda. \\
\hline $\begin{array}{l}\% \text { de variación de costo de } \\
\text { insumos principales }\end{array}$ & $\begin{array}{l}\text { Costo de insumos principales } \\
\text { presente / Costo de insumos } \\
\text { mes pasado (o periodo) }\end{array}$ & $\begin{array}{l}\text { Medir la variación de los costos de los } \\
\text { insumos principales. }\end{array}$ \\
\hline $\begin{array}{l}\text { Margen de Contribución } \\
\text { real }\end{array}$ & $\begin{array}{l}\text { (Precio de Venta - Costo Total } \\
\text { Directo) / Costo Directo Total }\end{array}$ & $\begin{array}{l}\text { Medir el margen sobre el costo del } \\
\text { producto. }\end{array}$ \\
\hline $\begin{array}{l}\text { Check list de tareas en } \\
\text { tienda }\end{array}$ & Puntaje real / Puntaje esperado & $\begin{array}{l}\text { Medir el cumplimiento de las tareas en } \\
\text { tienda. }\end{array}$ \\
\hline
\end{tabular}

Nota. Tomado de Información Corporativa de Norky's 


\subsection{Benchmarking y Comparación con los Líderes de la Industria de cada una de las Actividades de la Cadena de Valor}

De acuerdo a las entrevistas realizadas a los gerentes funcionales de Norky's (ver Anexo 7), el principal competidor es Roky's, ya que ambas pertenecen al mismo grupo estratégico y tienen similar cobertura de tiendas, presencia de marca y participación de mercado. En la Tabla 22 se compara cada una de las actividades de la cadena de valor de Norky’s y Roky’s, y se observa que Roky’s tiene cuatro puntos, uno más que Norky’s en cada una de las actividades de apoyo, debido a que en los últimos años ha automatizado sus procesos. La automatización de procesos en la industria permite obtener información valiosa, la cual impacta positivamente en la gestión del negocio, tanto en la planificación, organización y dirección de los recursos, así como en los controles que se requieren para medir el desempeño y obtener mayores beneficios.

También se observa que Norky's y Roky’s tienen el mismo valor ponderado en cuatro de las actividades primarias (logística interna, operaciones, logística externa y servicios), debido a que tienen los mismos proveedores y similares procedimientos para realizar las operaciones y atender a los clientes.

A partir del 2016, Norky's ha prestado especial atención al marketing, utilizando todo tipo de materiales para la difusión de los productos y la red social Facebook para captar y fidelizar a sus clientes, dar a conocer sus promociones y nuevos productos, y organizar concursos. Esto le ha permitido a Norky's obtener una ligera ventaja sobre Roky's en la actividad primaria Marketing y Ventas.

Las empresas Norky's y Roky's tienen un promedio ponderado total de 32 y 35 respectivamente, lo cual indica que tienen similar nivel de utilización de recursos. 
Tabla 22

Benchmarking y Comparación con el Líder de la Industria

\begin{tabular}{lcc}
\hline & Norky’s & Roky’s \\
\hline Actividades de Apoyo & & \\
\hline Infraestructura de la Empresa & 3 & 4 \\
Gestión de Recursos Humanos & 3 & 4 \\
Desarrollo de la Tecnología & 3 & 4 \\
Logística y Operaciones & 3 & 4 \\
\hline Actividades Primarias & & \\
\hline Logística Interna & 4 & 4 \\
Operaciones & 4 & 4 \\
Logística Externa & 4 & 4 \\
Marketing y Ventas & 4 & 3 \\
Servicios & 4 & 4 \\
\hline & 32 & 35 \\
\hline
\end{tabular}

\subsection{Determinar las Competencias de la Empresa}

Las competencias son aquellas herramientas expresadas en acciones que facilitan alcanzar los objetivos trazados para una empresa (Determinación de competencias organizacionales y capacitación en empresas del sector servicios, esan.edu.pe, 2016). En ese sentido, se detallan las competencias de Norky's, en base a la información entregada por los gerentes funcionales de Norky's durante las entrevistas (ver Anexo 7).

- Calidad del producto: Es una competencia resaltante en la empresa, expresada por los reconocidos proveedores que la abastecen de insumos principales, menciónese San Fernando y Alicorp; los correctos procesos de preparación del plato; y el personal capacitado que participa en dichos procesos, ya que se encuentra capacitado no solo en el desarrollo del proceso en sí, sino también en las buenas prácticas de manipulación de los productos. 
- Calidad del servicio: Es una competencia que se ha venido intensificando, ya que se manejan escuelas de inducción sobre el adecuado trato hacia los clientes, reflejado en un protocolo de atención.

- Manejo de costos de insumos bajos: Es una competencia resaltante en la empresa, ya que por el volumen de insumos que utiliza, a través de sus diversas tiendas, puede negociar costos más bajos con los proveedores, permitiéndole ofrecer un precio competitivo en el sector.

\subsection{Identificación y Determinación de las Ventajas Competitivas de la Empresa}

Las ventajas competitivas permiten a una empresa diferenciar sus productos y obtener costos más bajos que sus competidores, y se convierten en competencias centrales cuando cumplen cuatro características: valiosa, rara, costosa y difícil de sustituir (Hill, Jones \& Schilling, 2015).

- Valiosa: Permite a la empresa contrarrestar las amenazas, aprovechar las oportunidades y crear valor para el cliente.

- Rara: Poco común, innovador y creativo.

- Costosa: Implica una gran inversión de dinero o esfuerzo para ser imitada.

- Difícil de sustituir: Analizar si alguna otra propuesta, aunque diferente, pudiera ser un sustituto significativo de la nuestra.

En la Tabla 23 se muestra una matriz para determinar las ventajas competitivas de Norky's, en base a sus fortalezas y una combinación de criterios. Cabe resaltar que las preguntas fueron respondidas por los gerentes funcionales de Norky's durante las entrevistas (ver Anexo 7). 
Tabla 23

Matriz para determinar las Ventajas Competitivas de Norky's

\begin{tabular}{|c|c|c|c|c|c|}
\hline Capacidad & ¿Valiosa? & ¿Rara? & ¿Costosa? & $\begin{array}{l}\text { ¿Difícil de } \\
\text { sustituir? }\end{array}$ & $\begin{array}{l}\text { Competencia Central } \\
\text { Fuente de Ventaja } \\
\text { Competitiva }\end{array}$ \\
\hline $\begin{array}{l}\text { Alta cobertura en Lima y } \\
\text { expansión a nivel nacional. }\end{array}$ & SI & SI & SI & SI & $\begin{array}{l}\text { Ventaja competitiva } \\
\text { sostenible }\end{array}$ \\
\hline Recordación de la marca. & SI & NO & NO & SI & Paridad competitiva \\
\hline $\begin{array}{l}\text { Alto poder de negociación } \\
\text { con los proveedores. }\end{array}$ & SI & SI & SI & SI & $\begin{array}{l}\text { Ventaja competitiva } \\
\text { sostenible }\end{array}$ \\
\hline $\begin{array}{l}\text { Gran diversidad de } \\
\text { productos en la carta. }\end{array}$ & SI & NO & $\mathrm{NO}$ & SI & Paridad competitiva \\
\hline Productos de calidad. & SI & SI & SI & SI & $\begin{array}{l}\text { Ventaja competitiva } \\
\text { sostenible }\end{array}$ \\
\hline Buena atención. & SI & NO & NO & SI & Paridad competitiva \\
\hline
\end{tabular}

Las ventajas competitivas sostenibles demuestran un rendimiento superior al promedio, las ventajas temporales, un rendimiento promedio o superior, y las ventajas con paridad competitiva, un rendimiento promedio. En ese sentido, la alta cobertura en Lima y expansión a nivel nacional, el alto poder de negociación con los proveedores y productos de calidad son ventajas competitivas sostenibles para la empresa.

\subsection{Matriz de Evaluación de los Factores Internos EFI}

Según David (2013), una matriz de evaluación del factor interno es una herramienta para la formulación de la estrategia que permite resumir y evaluar las principales fortalezas y debilidades en las áreas funcionales de una empresa. A continuación, se detallan las fortalezas y debilidades de Norky's:

- La alta cobertura en Lima y expansión a nivel nacional representan una fortaleza mayor para la empresa, ya que permite crear espacios de acceso para los clientes en diversos puntos del país, concentrándose, en mayor medida, en Lima por su 
dinamismo económico. Esto permite a la empresa captar una mayor cantidad de clientes impactando, directamente, en el incremento de sus ventas.

- La recordación de la marca representa una fortaleza mayor para la empresa, debido a la trayectoria que ha mantenido en el mercado de los niveles socioeconómicos $\mathrm{C}$ y D, posicionándola en la mente de los consumidores como un lugar donde pueden consumir un producto de calidad y pasar un buen momento familiar.

- El alto poder de negociación con los proveedores representa una fortaleza mayor para la empresa, debido a que la compra de los insumos y materia prima se negocia, a través de la compra por volumen, permitiéndole así, convertirse en un importante cliente para los mismos y tener acceso a menores costos.

- La gran diversidad de productos en la carta representa una fortaleza mayor para la empresa, ya que los clientes tienen una variada disposición de productos para escoger, además del tradicional pollo a la brasa, lo cual acrecienta la idea de satisfacer varias preferencias en un solo lugar.

- Los productos de calidad representan una fortaleza mayor para la empresa, ya que los proveedores de los insumos principales son empresas reconocidas en el sector por la calidad de sus productos. Adicionalmente, los trabajadores que participan en el proceso de elaboración del producto final son capacitados constantemente para manipular adecuadamente los alimentos, a través de las escuelas de formación.

- La buena atención representa una fortaleza menor para la empresa, ya que los trabajadores de las tiendas, que están en contacto directo con los clientes, son capacitados constantemente en protocolos de servicio, a través de las escuelas de formación.

- La falta de estandarización y automatización de los procesos representa una debilidad mayor para la empresa, ya que existen muchos procesos administrativos que se 
realizan manualmente y, considerando el gran número de tiendas que se tienen a nivel nacional, el tiempo de respuesta de ellos es alto. Además, los procesos operativos que se realizan en las tiendas no se llevan a cabo de la misma manera, ya que no hay un procedimiento estándar para ellos.

- La insuficiente inversión en tecnología representa una debilidad mayor para la empresa, ya que no permite cubrir las necesidades actuales que tienen las tiendas a nivel nacional. La falta de herramientas tecnológicas que ayuden a mejorar la eficiencia y productividad de la empresa es una muestra de ello, así como el limitado número de personal en el área de Sistemas para que brinde soporte a las tiendas.

- La alta rotación de personal joven representa una debilidad mayor para la empresa, ya que hoy en día los jóvenes buscan tener un trabajo que les brinde una mejor calidad de vida y tiempo para compartirlo en familia, en lugar de una permanencia en la empresa. Por ello, incluso evitan hacer horas extras en sus puestos de trabajo.

- La ausencia de un MOF representa una debilidad mayor para la empresa, ya que es una muestra de la falta de profesionalización y tecnificación dentro de los procedimientos de recursos humanos de Norky's, que hasta la actualidad ha impedido que se definan las actividades y responsabilidades de cada uno de los puestos de la organización.

- La ausencia de un Plan Estratégico representa una debilidad mayor para la empresa y se debe a que ha sido dirigida como una empresa familiar, por lo cual no se veía en la necesidad de plantear formalmente una misión, visión, valores, objetivos organizacionales o estrategias. En la actualidad, la empresa se encuentra en una transición de una empresa familiar a una empresa organizacional.

- Las insuficientes políticas de bienestar y reconocimiento representan una debilidad menor para la empresa y se debe a la falta de profesionalización y tecnificación dentro 
de la organización. Las políticas que actualmente existen no son suficientes para permitir el óptimo desarrollo del recurso humano.

- La insuficiente comunicación representa una debilidad mayor para la empresa, debido a la insuficiente constancia y expresión comunicativa de los jefes inmediatos y colaboradores.

En la Tabla 24 se muestra la matriz EFI para Norky's, basada en las fortalezas y debilidades identificadas anteriormente. Cabe resaltar que el valor y la clasificación se asignaron en base a la información entregada por los gerentes funcionales de Norky's durante las entrevistas (ver Anexo 7).

Tabla 24

Matriz EFI de Norky's

\begin{tabular}{|c|c|c|c|c|}
\hline & Factores Clave & Valor & Clasificación & Valor ponderado \\
\hline \multicolumn{5}{|c|}{ Fortalezas } \\
\hline 1 & Alta cobertura en Lima y expansión a nivel nacional. & 0.10 & 4 & 0.40 \\
\hline 2 & Recordación de la marca. & 0.11 & 4 & 0.44 \\
\hline 3 & Alto poder de negociación con los proveedores. & 0.09 & 4 & 0.36 \\
\hline 4 & Gran diversidad de productos en la carta. & 0.03 & 4 & 0.12 \\
\hline 5 & Productos de calidad. & 0.12 & 4 & 0.48 \\
\hline 6 & Buena atención. & 0.11 & 3 & 0.33 \\
\hline \multicolumn{5}{|c|}{ Debilidades } \\
\hline 7 & $\begin{array}{l}\text { Falta de estandarización y automatización de los } \\
\text { procesos. }\end{array}$ & 0.10 & 1 & 0.10 \\
\hline 8 & Insuficiente inversión en tecnología. & 0.07 & 1 & 0.07 \\
\hline 9 & Alta rotación de personal joven. & 0.06 & 1 & 0.06 \\
\hline \multicolumn{2}{|c|}{10 Ausencia de un MOF. } & 0.04 & 1 & 0.04 \\
\hline \multicolumn{2}{|c|}{11 Ausencia de un Plan Estratégico. } & 0.06 & 1 & 0.06 \\
\hline \multicolumn{2}{|r|}{$\begin{array}{l}12 \text { Insuficientes políticas de bienestar y } \\
\text { reconocimiento. }\end{array}$} & 0.03 & 2 & 0.06 \\
\hline \multirow{2}{*}{\multicolumn{2}{|c|}{13 Insuficiente comunicación interna. }} & 0.08 & 1 & 0.08 \\
\hline & Valor ponderado total & 1.00 & & 2.60 \\
\hline
\end{tabular}

Según la matriz EFI, se puede apreciar que el valor ponderado total es 2.60, es decir, un ponderado mayor al promedio, lo cual significa que la empresa, si bien tiene una posición 
interna fuerte, esta no es significativa. En ese sentido, será importante acrecentar las fortalezas y disminuir las amenazas para aumentar el valor total ponderado y ser más competitivo en el sector. 


\section{Capítulo VII. Formulación de los Objetivos y Diseño de las Estrategias}

\subsection{Alcance y Planteamiento de los Objetivos Estratégicos}

\subsubsection{Objetivos estratégicos.}

En base al análisis de los capítulos anteriores, se plantearon los siguientes objetivos estratégicos para Norky's:

- Maximizar la rentabilidad

- Incrementar el nivel de satisfacción de los clientes

- Mejorar los procesos

- Incrementar el nivel de satisfacción de los colaboradores

\subsubsection{Análisis de los objetivos estratégicos.}

1. Maximizar la rentabilidad: Se basará, por un lado, en la estandarización de los procesos operativos que permitirá reducir los costos de ventas y, por otro lado, en el ajuste del gasto de la planilla que impactará en reducir los gastos de administración. En ese sentido, se plantean los siguientes objetivos específicos en un plazo de tres años:

- Reducir los costos de ventas en $1 \%$ anualmente. Actualmente, la línea base de los costos de ventas es $45 \%$ (ver Anexo 7).

- Reducir los gastos de administración en 1\% anualmente. Actualmente, la línea base de los gastos de administración es 20\% (ver Anexo 7).

2. Incrementar el nivel de satisfacción de los clientes: Permitirá a Norky’s cumplir con su visión de brindar un servicio de excelencia y será posible, ya que el proceso de selección de personal estará basado en perfiles y se fortalecerá la atención y relación con los clientes. En ese sentido, se plantean los siguientes objetivos específicos en un plazo de tres años: 
- Implementar encuestas de satisfacción para el 2018.

- Incrementar la interacción de los clientes, a través de las redes sociales en $10 \%$ anualmente. Actualmente, la línea base de respuesta de los clientes a través de las redes sociales es de 40\% (ver Anexo 7).

- Mejorar el índice de evaluación del servicio en 3\% anualmente. Actualmente, la línea base del índice de evaluación del cliente es 76\% (ver Anexo 7).

3. Mejorar los procesos: Se basa en la institucionalización de los mismos, lo cual permitirá reducir los costos y gastos generados por ineficiencia, y será posible, ya que la Gerencia General está enfocada en la automatización de los procesos manuales, estandarización de los procesos operativos, homologación de datos de los sistemas que utilizan las áreas, e implementación de un plan estratégico y un MOF. La medición se llevará a cabo, a través de check list que midan el cumplimiento. En ese sentido, se plantean los siguientes objetivos específicos en un plazo de tres años:

- Automatizar los procesos manuales requeridos en $10 \%$ anualmente. Actualmente, la línea base de la automatización de procesos manuales es de 60\% (ver Anexo 7).

- Estandarizar los procesos operativos de las tiendas en 3\% anualmente. Actualmente, la línea base de la automatización de procesos operativos es de 85\% (ver Anexo 7).

- Homologar los datos de los sistemas que utilizan las áreas en 10\% en el 2018. Actualmente, la línea base de la homologación de datos de los sistemas es de 90\% (ver Anexo 7).

- Implementar un MOF en el 2019.

4. Incrementar el nivel de satisfacción de los colaboradores: Permitirá aumentar la retención del personal y mejorar el servicio hacia el cliente, y será posible, ya que el área de Recursos Humanos tiene predisposición por mejorar el clima laboral y 
ahondar en la capacitación de los colaboradores. En ese sentido, se plantean los siguientes objetivos específicos en un plazo de tres años:

- Mejorar el clima laboral en 5\% anualmente. Actualmente, la línea base del clima laboral es de 70\% (ver Anexo 7).

- Añadir una escuela de habilidades blandas en el 2019.

\subsection{Diseño y Formulación de Estrategias}

\subsubsection{Matrices de formulación de estrategias.}

\subsubsection{Matriz FODA.}

La matriz FODA es una herramienta de análisis situacional atribuida a Weihrich (1982), que exige un exhaustivo razonamiento del entorno y la competencia para generar estrategias dentro de los cuatro cuadrantes que presenta, menciónese, fortalezas y oportunidades (FO), debilidades y oportunidades (DO), fortalezas y amenazas (FA), y debilidades y amenazas (DA) (D’Alessio, 2013). En ese sentido, en la Tabla 25 se aplica la herramienta a la empresa Norky's, en base a las matrices EFI y EFE desarrolladas anteriormente. 
Tabla 25

Matriz FODA de Norky's

\begin{tabular}{ll}
\hline OPORTUNIDADES & AMENAZAS \\
\hline O1: Las normas ISO 9001 y 14001. & A1: Bajo poder de \\
O2: El modelo de negocio de comida & negociación en contratos de \\
delivery online. & arrendamiento. \\
O3: La proyección positiva del & A2: El posible ingreso de \\
crecimiento del PBI. & nuevos competidores en el \\
O4: La determinación de los estilos & sector. \\
de vida de la población peruana. & A3: La información negativa \\
O5: El crecimiento de los niveles & que difunden los \\
socioeconómicos C y D en Lima & consumidores en las redes \\
Metropolitana. & sociales. \\
O6: El incremento del uso de las & A4: La baja fidelidad del \\
redes sociales para promocionar los & cliente. \\
productos. & A5: La tendencia por la \\
O7: El uso de herramientas & alimentación saludable. \\
tecnológicas. & A6: La posible ley de \\
O8: Las capacitaciones del Estado en & prohibición de bolsas plásticas \\
buenas prácticas de gestión de & y envases de tecnopor. \\
servicio. & \\
\hline ESTRATEGIA FO & ESTRATEGIA FA \\
\hline (F5, O1, O7) & (F4, F5, F6, A2, A4, A5) \\
- Estrategia: Institucionalizar los & - Estrategia: Desarrollar \\
procesos. & nuevos productos. \\
(F3, O3, O5) & (F1, F4, A4) \\
- Estrategia: Desarrollar economías de - Estrategia: Penetrar en el \\
escala. & mercado. \\
(F1, F2, O2, O4, O6) & (F6, A3) \\
- Estrategia: Penetrar en el mercado. & - Estrategia: Desarrollar un \\
& servicio de excelencia. \\
&
\end{tabular}

F5: Productos de calidad.

F6: Buena atención.

\begin{tabular}{lll}
\hline DEBILIDADES & ESTRATEGIA DO & ESTRATEGIA DA \\
\hline D1: Falta de estandarización & (D1, D4, D5, D6, O3, O5) & (D3, D6, A2, A6) \\
y automatización de los & - Estrategia: Institucionalizar los & - Estrategia: Desarrollar una \\
procesos. & procesos. & cultura organizacional. \\
D2: Insuficiente inversión en & (D2, D6, O3, O5) & \\
tecnología. & - Estrategia: Aumentar las ventas. & \\
D3: Alta rotación de & (D1, D4, D5, O3, O5) & \\
personal joven. & - Estrategia: Disminuir los costos y & \\
D4: Ausencia de un MOF. & gastos. & \\
$\begin{array}{l}\text { D5: Ausencia de un Plan } \\
\text { Estratégico. }\end{array}$ & \\
$\begin{array}{l}\text { D6: Insuficientes políticas de } \\
\text { bienestar y reconocimiento. }\end{array}$ & \\
$\begin{array}{l}\text { D7: Insuficiente } \\
\text { comunicación interna. }\end{array}$ & \\
\hline
\end{tabular}


En base a la matriz evaluada, se concluye que en los cuadrantes FO y FA se centraliza el mayor número de estrategias, debido a la predominancia de las fortalezas en la empresa.

\subsubsection{Matriz PEYEA.}

La matriz PEYEA es una herramienta de posición estratégica y evaluación de la acción, atribuida a Dickel como creador, que mediante cuatro cuadrantes expresados en dos ejes que conciertan factores relativos a la industria (fortaleza de la industria y estabilidad del entorno) y otros dos ejes que conciertan factores relativos a la organización (fortaleza financiera y ventaja competitiva), determinan un marco de postura estratégica básica, ya sea agresiva, conservadora, defensiva o competitiva (D’Alessio, 2013). En ese sentido, en la Tabla 26 y Figura 16 se aplica la herramienta a la empresa Norky's, en base a la información entregada por los gerentes funcionales de Norky's durante las entrevistas (ver Anexo 7) y los datos obtenidos durante el desarrollo del plan estratégico.

Tabla 26

Matriz PEYEA de Norky's

\begin{tabular}{lr}
\hline POSICIÓN ESTRATÉGICA EXTERNA & \\
\hline Factores Determinantes de la Estabilidad del Entorno (EE) & 3 \\
\hline 1. Cambios tecnológicos & 6 \\
2. Tasa de inflación & 2 \\
3. Variabilidad de la demanda & 4 \\
4. Rango de precios de productos competitivos & 4 \\
5. Barreras de entrada del mercado & 1 \\
6. Rivalidad competitiva & 2 \\
7. Elasticidad de precios de la demanda & 4 \\
8. Presión de productos sustitutos & -2.75 \\
\hline Promedio (-6) & 3 \\
\hline Factores Determinantes de la Fortaleza de la Industria (FI) & 4 \\
\hline 1. Potencial de crecimiento & 4 \\
3. Potencial de utilidades & 2 \\
4. Estabilidad financiera & 3 \\
5. Utilización de los recursos & \\
\hline
\end{tabular}




\begin{tabular}{lr}
\hline Factores Determinantes de la Fortaleza de la Industria (FI) & 4 \\
\hline 6. Intensidad de capital & 4 \\
7. Facilidad de entrada al mercado & 4 \\
8. Productividad/Utilización de la capacidad & 1 \\
9. Poder de negociación de los proveedores & 3.22 \\
\hline Promedio & 5 \\
\hline POSICIÓN ESTRATÉGICA INTERNA & 5 \\
\hline Factores Determinantes de las Ventajas Competitivas (VC) & 2 \\
1. Participación del mercado & 4 \\
3. Calidad del producto de vida del producto & 2 \\
4. Ciclo del reemplazo del producto & 4 \\
5. Lealtad del consumidor & 2 \\
6. Utilización de la capacidad de los competidores & 1 \\
7. Conocimiento tecnológico & 4 \\
8. Integración vertical & -2.78 \\
9. Velocidad de introducción de nuevos productos. & \\
\hline Promedio (-6) & 5 \\
\hline Factores Determinantes de las Fortalezas Financieras (FF) & 4 \\
\hline 1. Retorno de la inversión & 4 \\
2. Apalancamiento & 2 \\
3. Liquidez & 4 \\
5. Capital requerido vs capital disponible & 5 \\
9. Rajilidad de salida del mercado & 5 \\
\hline Promedio involucrado en el negocio & 5 \\
\hline
\end{tabular}




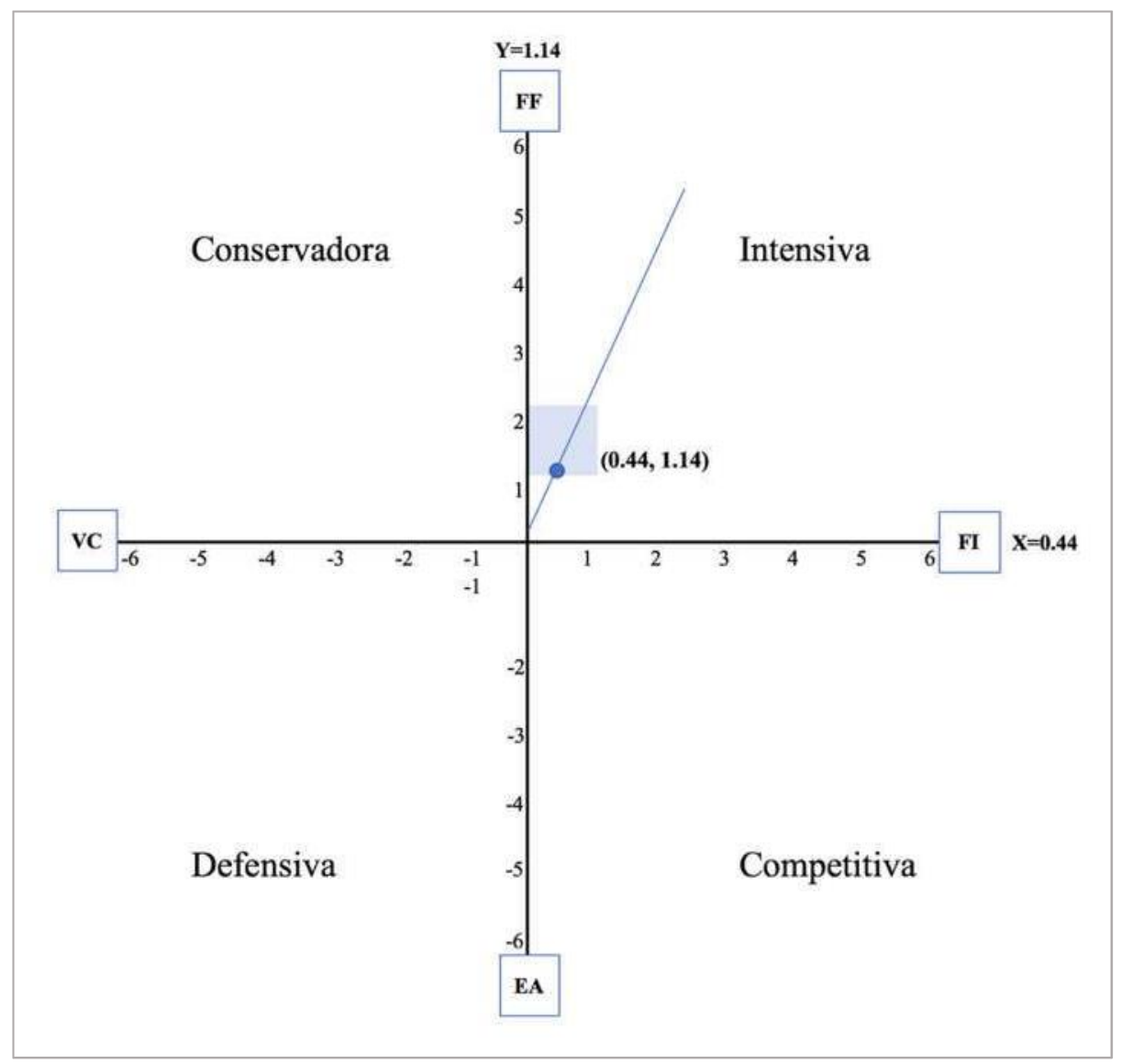

Figura 16. Resultado de la Matriz PEYEA de Norky's.

Según las coordenadas que se desprenden de la matriz PEYEA, podemos visualizar que el vector está ubicado en el cuadrante intensivo, donde debería enfocarse en estrategias relacionadas con el desarrollo de productos, a través de la creación de mezclas de productos; y penetración en el mercado, a través de la creación de promociones, reforzamiento de la imagen de la marca en las redes sociales y promoción del servicio de delivery online en las tiendas y redes sociales. En ese sentido, el primer paso es superar las debilidades internas de la empresa, a través de la automatización y estandarización de los procesos, con el propósito de aprovechar las oportunidades. 


\subsubsection{Matriz interna externa.}

La matriz IE es una herramienta multidivisional, ya que consta de nueve celdas por medio de dos dimensiones que involucran las matrices EFE y EFI, de tal forma que permita mayor amplitud para la evaluación de las complejidades de la empresa (D’Alessio, 2013).

En ese sentido, en la Figura 17 se refleja la herramienta para la empresa Norky's, teniendo en cuenta que la matriz EFE tuvo un valor ponderado de 2.31, mientras que la matriz EFI tuvo un 2.60.

\section{Evaluación de Factores Internos (EFI)}

3

2

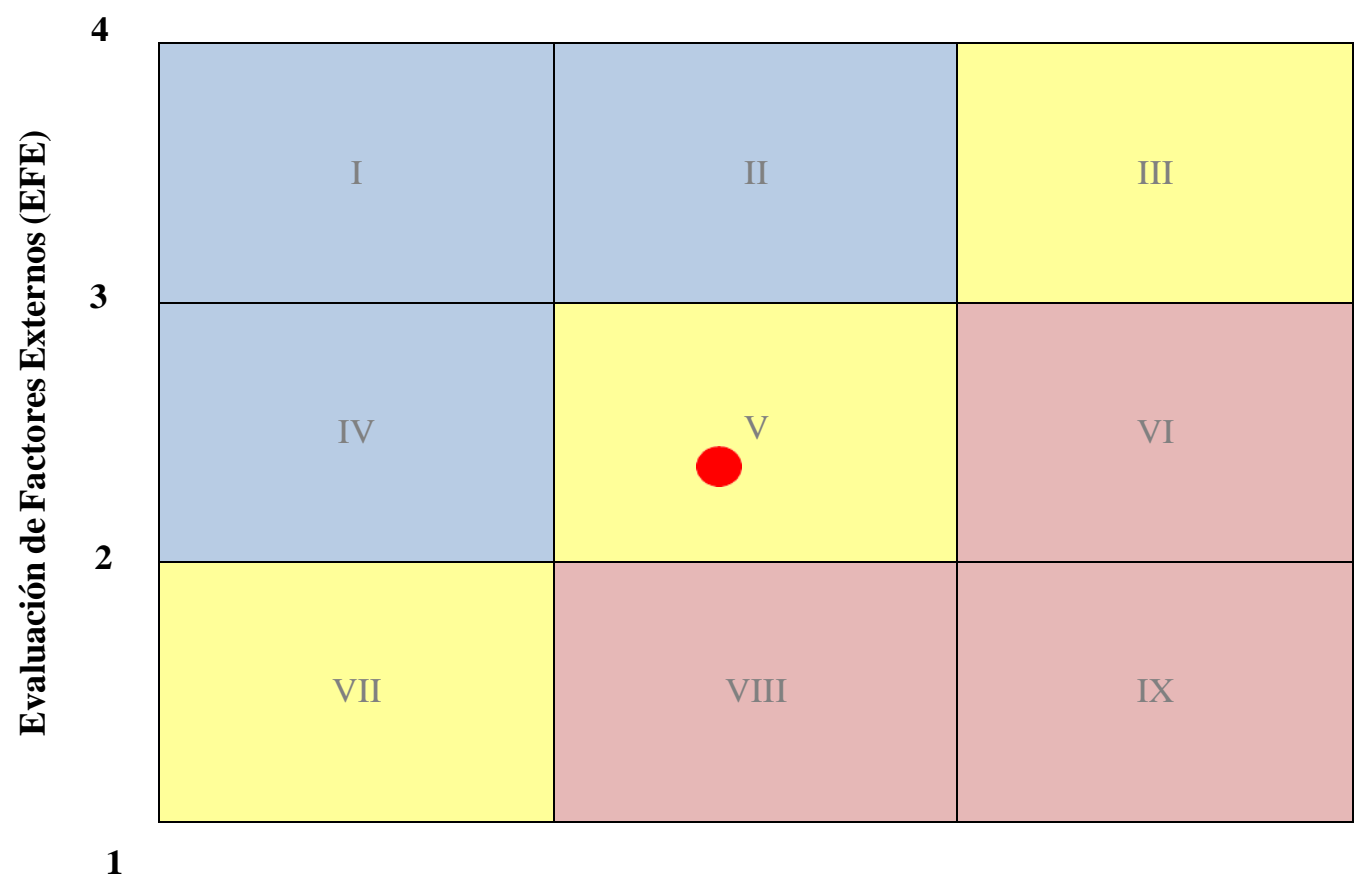

Figura 17. Matriz IE de Norky's.

Según la matriz realizada, se puede apreciar que la empresa se encuentra en la celda $\mathrm{V}$, lo cual implica centrarse en estrategias, tales como desarrollo de productos, a través de la creación de mezclas de productos; y penetración en el mercado, a través de la creación de promociones, reforzamiento de la imagen de la marca en las redes sociales y promoción del 
servicio de delivery online en las tiendas y redes sociales. En ese sentido, el primer paso es superar las debilidades internas de la empresa, a través de la automatización y estandarización de los procesos, con el propósito de aprovechar las oportunidades.

\subsubsection{Matriz Boston Consulting Group.}

La matriz BCG propuesta por el Grupo de Consultoría de Boston en el año 1974, realiza la relación entre la participación de mercado y lo que genera como efectivo, e incluye en ello la tasa de crecimiento de las ventas del mercado con el uso del efectivo. Además, ayuda a graficar las distintas divisiones y la posición de estas frente a la competencia que tiene una empresa. La matriz BCG permite realizar una evaluación de la estrategia para cada división, producto y ayuda a manejar el portafolio de la organización (D’Alessio, 2013).

A continuación, se resume la ubicación y el significado de cada cuadrante de la matriz BCG y, en ese sentido, en la Figura 18 se aplica la herramienta a la empresa Norky's.

- Signo de Interrogación: El problema de no saber cómo será el comportamiento del producto una vez ingresado al mercado. Puede convertirse en estrella o perro si la organización decide realizar estrategias de crecimiento o abandonar el negocio, va a depender que tan cercano esté del cuadrante de la estrella o perro.

- Estrella: La cuota de mercado y el crecimiento son altos, y esto se constituye a largo plazo. Aquí, el foco está en que el mercado se vuelva maduro hasta convertirse en una vaca lechera.

- Vaca lechera: El crecimiento es bajo, pero la cuota de mercado es alta. La unidad de negocio está en la capacidad de generar nuevas estrellas.

- Perros: No hay crecimiento y la cuota de mercado es baja, además de consumir recursos, la rentabilidad es baja o negativa. Se recomienda aplicar estrategias de liquidación, reducción o desinversión de la división o del producto. 


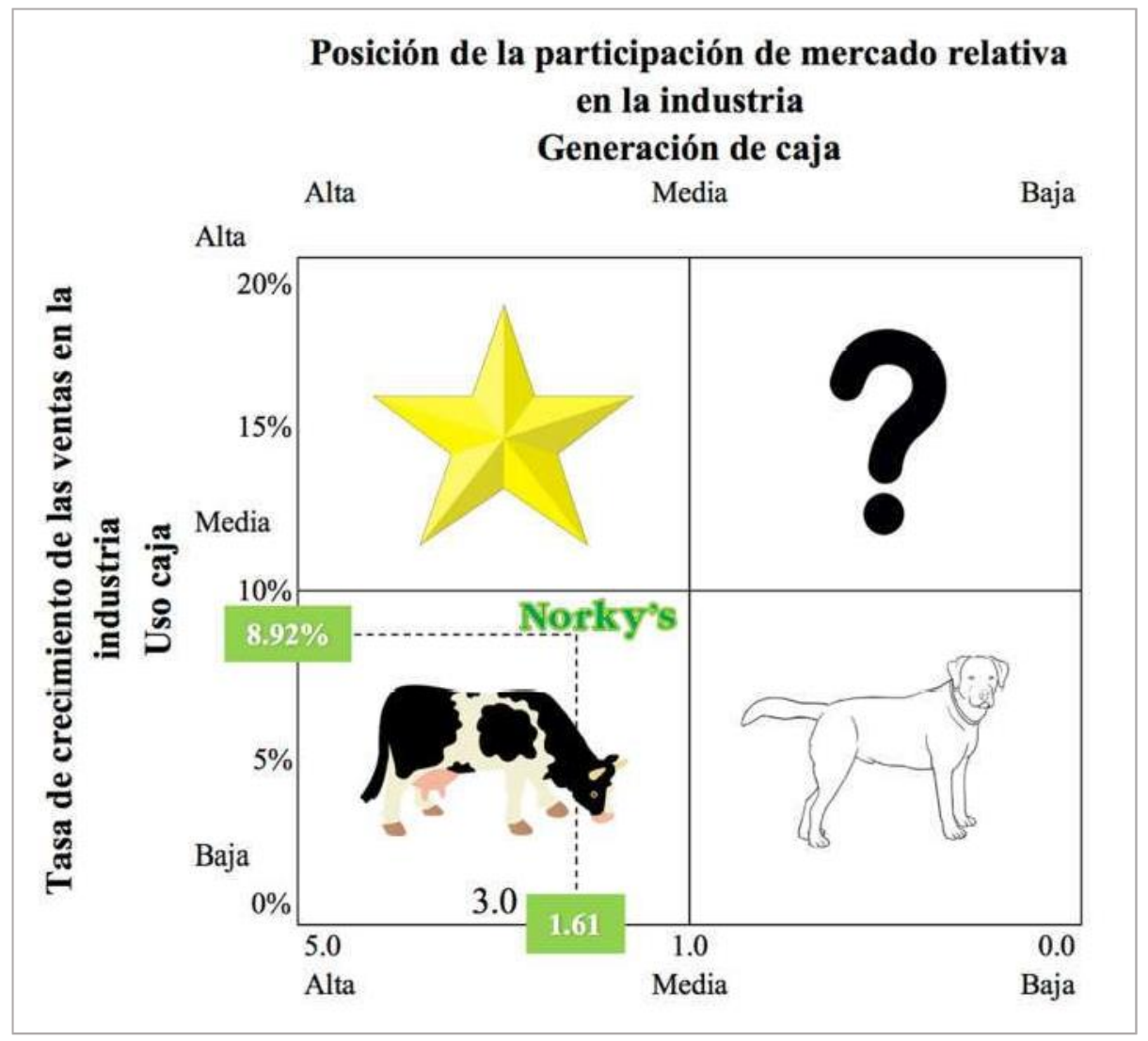

Figura 18. Matriz BCG de Norky’s.

De acuerdo al análisis realizado con datos del año 2016, los resultados muestran para la posición de participación de mercado un puntaje de 1.61. Este dato se obtuvo realizando la relación de ventas de Norky's y el principal competidor Roky’s. En la tasa de crecimiento de la industria se obtuvo un porcentaje de $8.92 \%$, cálculo que se obtiene al utilizar las ventas totales de la industria para el año 2016 y 2015.

Por lo tanto, Norky's se ubica en el cuadrante de vaca lechera, ello implica que la empresa se encuentra en una etapa de madurez, ya que cuenta con una cuota de mercado importante, la marca está muy presente en la industria, además, genera efectivo lo que le permite a la empresa evaluar la creación de productos estrellas o incursionar en una nueva división de producto. 
Finalmente, se observa que Norky's, a pesar de estar en una etapa de madurez, podría seguir creciendo, a través de la fidelización de clientes, desarrollo de productos y realizando estrategias de marketing que involucren regalos, descuentos y promociones, y utilizando canales alternativos de venta como aplicaciones móviles y páginas de internet. Esto permitirá a Norky's incrementar el volumen de ventas y mantenerse en el cuadrante de vaca lechera.

\subsubsection{Matriz de la gran estrategia.}

Según Christensen, Berg, y Salter, la matriz de la gran estrategia permite evaluar y afinar la elección apropiada de estrategias para la organización. El fundamento de la matriz está basado en dos dimensiones de valoración: el crecimiento del mercado y la posición competitiva de la empresa categorizadas en cuatro cuadrantes, las cuales sugieren alternativas de estrategias en orden de atractivo para la selección de la gran estrategia (D’Alessio, 2013).

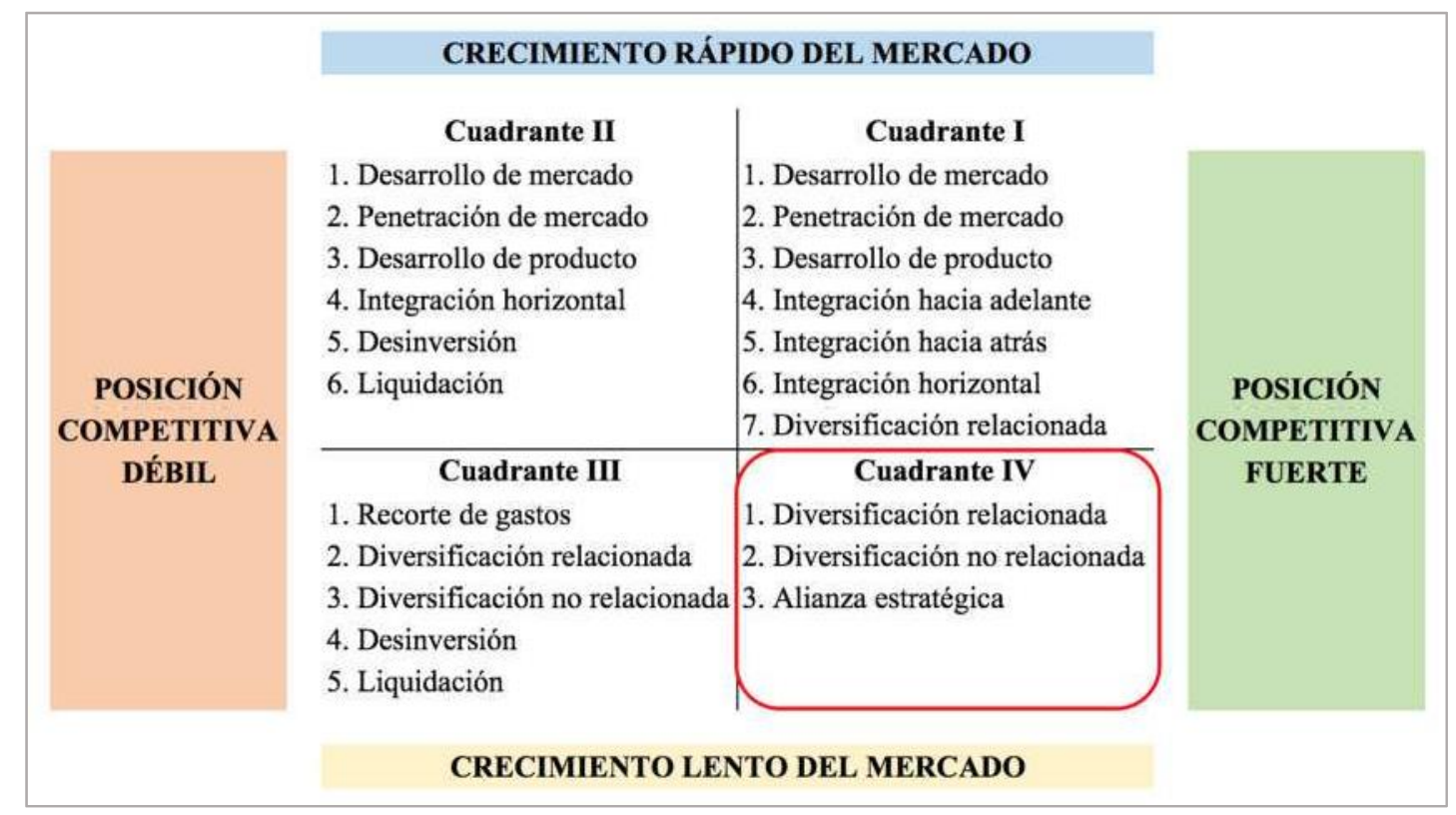

Figura 19. Matriz de la Gran Estrategia de Norky's.

Con el análisis de los factores internos y externos de Norky's, se concluye que la empresa se encuentra ubicada en el cuadrante IV de la matriz (ver Figura 19), la cual señala 
que Norky's tiene una posición competitiva fuerte junto con un crecimiento lento del mercado. La posición competitiva fuerte se ve sustentada por la alta cobertura en Lima, productos de calidad y alto poder de negociación con los proveedores que Norky's posee en el mercado, colocándola como una empresa con mayor recordación entre los consumidores de los niveles socioeconómicos C y D. Por otro lado, el crecimiento del sector de restaurantes ha sido de $2.4 \%$ en el año 2016 (ver Figura 7), impulsando a Norky's a considerar estrategias de diversificación relacionada, diversificación no relacionada y posibles alianzas estratégicas.

Teniendo en cuenta lo anterior, Norky's se encuentra en la evaluación de la estrategia de diversificación no relacionada, en la cual se está considerando realizar una alta inversión en otros rubros a corto plazo.

En ese sentido, el primer paso es superar las debilidades internas de la empresa, a través de la automatización y estandarización de los procesos, con el propósito de aprovechar las oportunidades.

\subsection{Resumen de las Estrategias Formuladas}

La Tabla 27 resume las estrategias formuladas en las matrices FODA, PEYEA, IE, BCG y GE, y permite identificar aquellas que tienen más repeticiones para que sean evaluadas, a través de la Matriz de Planeación Estratégica Cuantitativa. 
Tabla 27

Matriz Resumen de las Estrategias Formuladas de Norky's

\begin{tabular}{lcccccc}
\hline Estrategias & FODA & PEYEA & IE & BCG & GE & Total \\
\hline Institucionalizar los procesos. & $\mathrm{X}$ & $\mathrm{X}$ & $\mathrm{X}$ & $\mathrm{X}$ & $\mathrm{X}$ & 5 \\
Desarrollar nuevos productos. & $\mathrm{X}$ & $\mathrm{X}$ & $\mathrm{X}$ & $\mathrm{X}$ & & 4 \\
Penetrar en el mercado. & $\mathrm{X}$ & $\mathrm{X}$ & $\mathrm{X}$ & $\mathrm{X}$ & & 4 \\
Desarrollar economías de escala. & $\mathrm{X}$ & & & & & 1 \\
Desarrollar un servicio de excelencia. & $\mathrm{X}$ & & & & & 1 \\
Disminuir los costos y gastos. & $\mathrm{X}$ & & & & & 1 \\
Aumentar las ventas. & $\mathrm{X}$ & & & & & 1 \\
Desarrollar una cultura organizacional. & $\mathrm{X}$ & & & & & \\
\hline
\end{tabular}




\section{Capítulo VIII. Selección de la Estrategia}

\subsection{Matriz de Planeación Estratégica Cuantitativa MPEC}

La matriz PEC es una herramienta que permite valorar las estrategias posibles de una empresa, basándose en la determinación previa de factores críticos de éxito, tanto a nivel externo como interno. Asimismo, para valorar las estrategias se debe contar con un buen juicio intuitivo para discernir acertadamente la atractividad de cada una con las oportunidades, amenazas, fortalezas y debilidades evaluadas (D’Alessio, 2013). En ese sentido, en la Tabla 28 se refleja la herramienta para la empresa Norky's, en base a la información entregada por los gerentes funcionales de Norky’s durante las entrevistas (ver Anexo 7).

Tabla 28

Matriz de Planeamiento Estratégico Cuantitativo de Norky's

\begin{tabular}{|c|c|c|c|c|c|c|c|c|}
\hline & & \multirow[b]{2}{*}{ Peso } & \multicolumn{2}{|c|}{$\begin{array}{c}\text { ESTRATEGIA } 1 \\
\text { Penetrar en el } \\
\text { mercado } \\
\end{array}$} & \multicolumn{2}{|c|}{$\begin{array}{l}\text { ESTRATEGIA } 2 \\
\text { Desarrollar } \\
\text { nuevos productos }\end{array}$} & \multicolumn{2}{|c|}{$\begin{array}{c}\text { ESTRATEGIA } 3 \\
\text { Institucionalizar } \\
\text { los procesos } \\
\end{array}$} \\
\hline & & & $\begin{array}{l}\text { Grado } \\
\text { atractivo }\end{array}$ & Puntaje & $\begin{array}{l}\text { Grado } \\
\text { atractivo }\end{array}$ & Puntaje & $\begin{array}{l}\text { Grado } \\
\text { atractivo }\end{array}$ & Puntaje \\
\hline & Factor Clave Externo & & & & & & & \\
\hline 1 & Las normas ISO 9001 y 14001. & 0.03 & 1 & 0.03 & 1 & 0.03 & 4 & 0.12 \\
\hline 2 & $\begin{array}{l}\text { El modelo de negocio de comida } \\
\text { delivery online. }\end{array}$ & 0.06 & 2 & 0.12 & 3 & 0.18 & 2 & 0.12 \\
\hline 3 & $\begin{array}{l}\text { La proyección positiva del } \\
\text { crecimiento del PBI. }\end{array}$ & 0.12 & 3 & 0.36 & 1 & 0.12 & 2 & 0.24 \\
\hline 4 & $\begin{array}{l}\text { La determinación de los estilos de } \\
\text { vida de la población peruana. }\end{array}$ & 0.05 & 2 & 0.10 & 3 & 0.15 & 1 & 0.05 \\
\hline 5 & $\begin{array}{l}\text { El crecimiento de los niveles } \\
\text { socioeconómicos C y D en Lima } \\
\text { Metropolitana. }\end{array}$ & 0.16 & 2 & 0.32 & 4 & 0.64 & 3 & 0.48 \\
\hline 6 & $\begin{array}{l}\text { El incremento del uso de las redes } \\
\text { sociales para promocionar los } \\
\text { productos. }\end{array}$ & 0.12 & 3 & 0.36 & 3 & 0.36 & 2 & 0.24 \\
\hline 7 & El uso de herramientas tecnológicas. & 0.11 & 3 & 0.33 & 2 & 0.22 & 3 & 0.33 \\
\hline 8 & $\begin{array}{l}\text { Las capacitaciones del Estado en } \\
\text { buenas prácticas de gestión de } \\
\text { servicio. }\end{array}$ & 0.02 & 2 & 0.04 & 1 & 0.02 & 3 & 0.06 \\
\hline 9 & $\begin{array}{l}\text { La escasa disponibilidad de locales } \\
\text { en zonas de alto tránsito. }\end{array}$ & 0.11 & 1 & 0.11 & 1 & 0.11 & 1 & 0.11 \\
\hline
\end{tabular}




\begin{tabular}{|c|c|c|c|c|c|c|c|c|}
\hline & & & \multicolumn{2}{|c|}{$\begin{array}{l}\text { ESTRATEGIA } 1 \\
\text { Penetración del } \\
\text { mercado }\end{array}$} & \multicolumn{2}{|c|}{$\begin{array}{l}\text { ESTRATEGIA } 2 \\
\text { Desarrollo de } \\
\text { productos }\end{array}$} & \multicolumn{2}{|c|}{$\begin{array}{c}\text { ESTRATEGIA } 3 \\
\text { Automatización y } \\
\text { estandarización de } \\
\text { los procesos }\end{array}$} \\
\hline & & Peso & $\begin{array}{c}\text { Grado } \\
\text { atractivo }\end{array}$ & Puntaje & $\begin{array}{l}\text { Grado } \\
\text { atractivo }\end{array}$ & Puntaje & $\begin{array}{c}\text { Grado } \\
\text { atractivo }\end{array}$ & Puntaje \\
\hline & Factor Clave Externo & & & & & & & \\
\hline 10 & $\begin{array}{l}\text { El posible ingreso de nuevos } \\
\text { competidores en el sector. }\end{array}$ & 0.03 & 1 & 0.03 & 1 & 0.03 & 3 & 0.09 \\
\hline 11 & $\begin{array}{l}\text { La información negativa que } \\
\text { difunden los consumidores en las } \\
\text { redes sociales. }\end{array}$ & 0.07 & 1 & 0.07 & 4 & 0.28 & 1 & 0.07 \\
\hline 12 & La baja fidelidad del cliente. & 0.04 & 1 & 0.04 & 3 & 0.12 & 1 & 0.04 \\
\hline 13 & $\begin{array}{l}\text { La tendencia por la alimentación } \\
\text { saludable. }\end{array}$ & 0.06 & 2 & 0.12 & 4 & 0.24 & 1 & 0.06 \\
\hline \multirow[t]{3}{*}{14} & La posible ley de prohibición de & 0.02 & 1 & 0.02 & 1 & 0.02 & 1 & 0.02 \\
\hline & Total & 1.00 & & & & & & \\
\hline & Factor Clave Interno & & & & & & & \\
\hline 1 & $\begin{array}{l}\text { Alta cobertura en Lima y expansión } \\
\text { a nivel nacional }\end{array}$ & 0.10 & 4 & 0.40 & 4 & 0.40 & 4 & 0.40 \\
\hline 2 & Recordación de la marca & 0.11 & 4 & 0.44 & 3 & 0.33 & 1 & 0.11 \\
\hline 3 & $\begin{array}{l}\text { Alto poder de negociación con los } \\
\text { proveedores }\end{array}$ & 0.09 & 3 & 0.27 & 4 & 0.36 & 3 & 0.27 \\
\hline 4 & $\begin{array}{l}\text { Gran diversidad de productos en la } \\
\text { carta }\end{array}$ & 0.03 & 3 & 0.09 & 4 & 0.12 & 3 & 0.09 \\
\hline 5 & Productos de calidad & 0.12 & 3 & 0.36 & 3 & 0.36 & 3 & 0.36 \\
\hline 6 & Buena atención & 0.11 & 3 & 0.33 & 1 & 0.11 & 3 & 0.33 \\
\hline 7 & $\begin{array}{l}\text { Falta de estandarización y } \\
\text { automatización de los procesos }\end{array}$ & 0.10 & 1 & 0.10 & 1 & 0.10 & 4 & 0.40 \\
\hline 8 & Insuficiente inversión en tecnología & 0.07 & 1 & 0.07 & 1 & 0.07 & 4 & 0.28 \\
\hline 9 & Alta rotación de personal joven & 0.06 & 1 & 0.06 & 1 & 0.06 & 3 & 0.18 \\
\hline 10 & Ausencia de un MOF & 0.04 & 1 & 0.04 & 1 & 0.04 & 4 & 0.16 \\
\hline 11 & Ausencia de un Plan Estratégico & 0.06 & 1 & 0.06 & 1 & 0.06 & 4 & 0.24 \\
\hline 12 & $\begin{array}{l}\text { Insuficientes políticas de bienestar y } \\
\text { reconocimiento }\end{array}$ & 0.03 & 1 & 0.03 & 1 & 0.03 & 4 & 0.12 \\
\hline 13 & Insuficiente comunicación interna. & 0.08 & 3 & 0.24 & 3 & 0.24 & 4 & 0.32 \\
\hline & Total & 1.00 & & 4.54 & & 4.80 & & 5.29 \\
\hline
\end{tabular}

Según la matriz descrita, se puede apreciar que las tres estrategias evaluadas tienen una alta puntuación, lo cual refleja la importancia que tienen para la empresa. Sin embargo, la estrategia de automatización y estandarización de los procesos es la más representativa de las tres, al tener un puntaje de 5.29, siendo de esa forma la estrategia más atractiva de desarrollar. 


\subsection{Descripción de Estrategia Seleccionada}

En base al análisis realizado anteriormente, se determina que la estrategia seleccionada es la institucionalización de los procesos, ya que es la que obtuvo un mayor puntaje en la matriz PEC. Esta estrategia pretende superar las debilidades que tiene Norky's como son la falta de estandarización y automatización de procesos, ausencia de plan estratégico y MOF, e insuficientes políticas de bienestar, desarrollo y reconocimiento. Esta estrategia se llevará a cabo, a través de las siguientes acciones, y estará apoyada por un plan estratégico y MOF.

- Automatizar los procesos manuales.

- Estandarizar los procesos operativos de las tiendas.

- Fortalecimiento de la comunicación entre los administradores y su equipo de trabajo.

- Implementación de nuevas escuelas a nivel operativo.

- Check list de control.

- Homologación de los datos de los sistemas.

- Motivación de personal: Incremento de los eventos de integración del personal e implementación de nuevas políticas de bonificación para los supervisores de operaciones y coordinadores de servicio.

\subsection{Descripción de Estrategia Contingente}

En base al análisis realizado anteriormente, se determina que la estrategia contingente es desarrollo de productos, ya que tiene un alto puntaje en la MPEC, después de la estrategia seleccionada. Para ello, Norky’s se deberá enfocar en las siguientes acciones:

- Adaptación de los productos actuales: Norky’s modificará las características o atributos de los productos para ajustarse a la tendencia por la alimentación saludable. 
- Mezcla de productos: Norky's creará combos que se adapten a las diversas necesidades del público objetivo. 


\section{Capítulo IX. Implantación de la Estrategia}

\subsection{Mapa de la Estrategia}

En la Figura 20, se muestra el mapa de la estrategia de Norky's basado en la herramienta Balance Scorecard creada por Kaplan y Norton (2009), la cual permite enlazar los objetivos específicos, a través de cuatro perspectivas: Financiera, Clientes, Procesos internos y Aprendizaje y desarrollo, con el fin de cumplir con los objetivos estratégicos identificados anteriormente. 


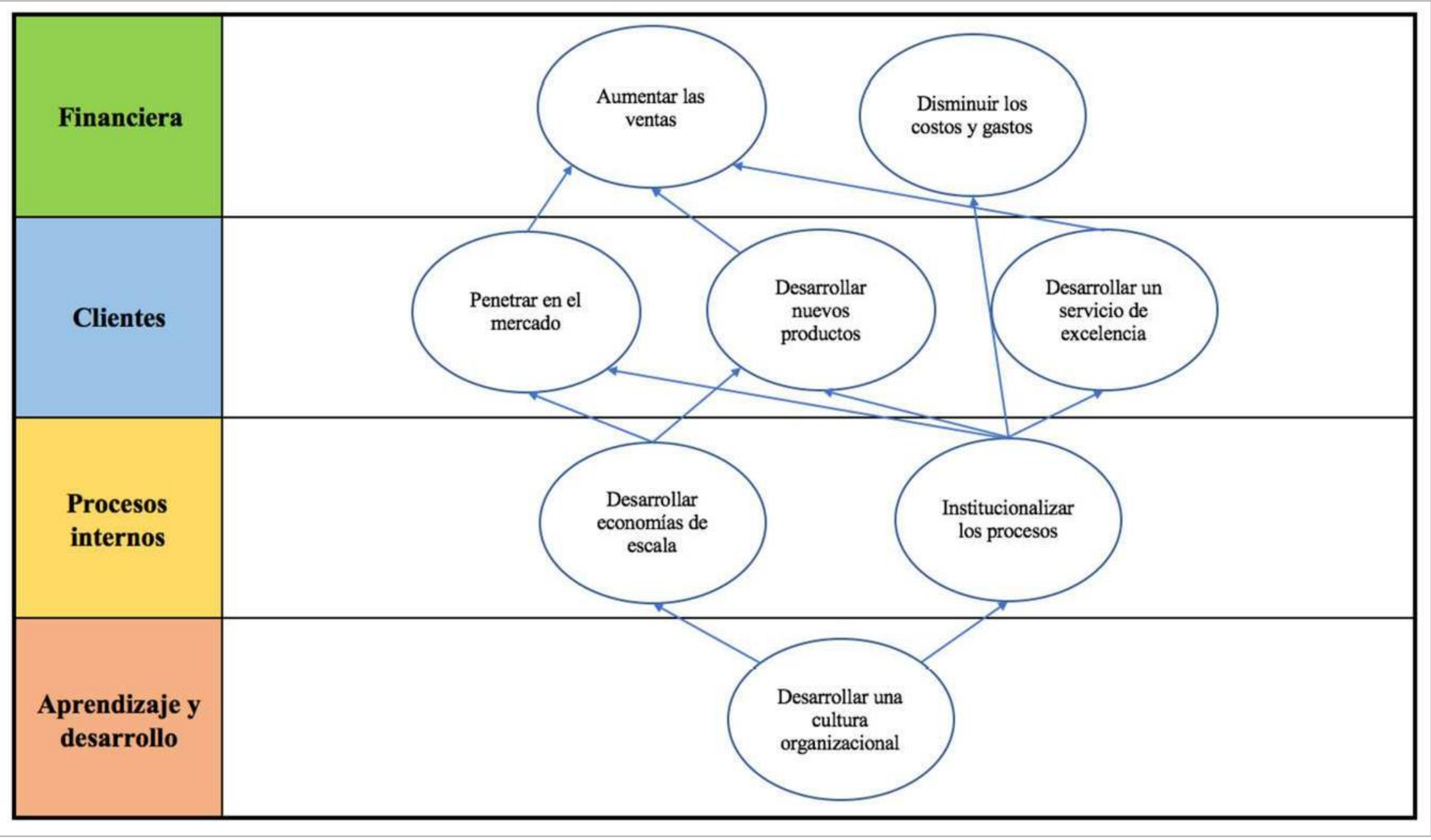

Figura 20. Mapa de la Estrategia de Norky's. 


\subsection{Objetivos Específicos según el Mapa de la Estrategia}

En la Tabla 29, se detallan los objetivos específicos según el mapa de la estrategia, con el fin de cumplir con los objetivos estratégicos identificados anteriormente.

Tabla 29

Objetivos Específicos según el Mapa de la Estrategia de Norky’s

\begin{tabular}{|c|c|c|}
\hline Perspectiva & Objetivos Estratégicos & Objetivos Específicos \\
\hline \multirow[t]{2}{*}{ Financiera } & \multirow[t]{2}{*}{ Maximizar la rentabilidad. } & Reducir los costos de ventas. \\
\hline & & $\begin{array}{l}\text { Reducir los gastos de } \\
\text { administración. }\end{array}$ \\
\hline \multirow[t]{3}{*}{ Clientes } & \multirow[t]{3}{*}{$\begin{array}{l}\text { Incrementar el nivel de } \\
\text { satisfacción de los clientes. }\end{array}$} & $\begin{array}{l}\text { Implementar encuestas de } \\
\text { satisfacción. }\end{array}$ \\
\hline & & $\begin{array}{l}\text { Incrementar la interacción de los } \\
\text { clientes. }\end{array}$ \\
\hline & & $\begin{array}{l}\text { Mejorar el índice de evaluación del } \\
\text { servicio. }\end{array}$ \\
\hline \multirow[t]{4}{*}{ Procesos internos } & \multirow[t]{4}{*}{ Mejorar los procesos. } & $\begin{array}{l}\text { Automatizar los procesos manuales } \\
\text { requeridos. }\end{array}$ \\
\hline & & $\begin{array}{l}\text { Estandarizar los procesos operativos } \\
\text { de las tiendas. }\end{array}$ \\
\hline & & $\begin{array}{l}\text { Homologar los datos de los sistemas } \\
\text { que utilizan las áreas. }\end{array}$ \\
\hline & & Implementar MOF. \\
\hline \multirow[t]{2}{*}{ Aprendizaje y desarrollo } & \multirow{2}{*}{$\begin{array}{l}\text { Incrementar el nivel de } \\
\text { satisfacción de los colaboradores. }\end{array}$} & Mejorar el clima laboral. \\
\hline & & $\begin{array}{l}\text { Añadir una escuela de habilidades } \\
\text { blandas. }\end{array}$ \\
\hline
\end{tabular}




\subsection{Indicadores para cada uno de los Objetivos Específicos}

En la Tabla 30, se detallan los indicadores que se utilizarán para medir el cumplimiento de cada uno de los objetivos específicos identificados anteriormente.

Tabla 30

Indicadores para cada uno de los Objetivos Específicos de Norky's

\begin{tabular}{|c|c|c|}
\hline Perspectiva & Objetivos Específicos & Indicadores \\
\hline \multirow[t]{2}{*}{ Financiera } & Reducir los costos de ventas. & $\begin{array}{l}\% \text { de variación del costo de ventas } \\
\text { en relación al año anterior }\end{array}$ \\
\hline & $\begin{array}{l}\text { Reducir los gastos de } \\
\text { administración. }\end{array}$ & $\begin{array}{l}\% \text { de variación de gastos de } \\
\text { administración en relación al año } \\
\text { anterior }\end{array}$ \\
\hline \multirow[t]{3}{*}{ Clientes } & $\begin{array}{l}\text { Implementar encuestas de } \\
\text { satisfacción. }\end{array}$ & $\begin{array}{l}\text { Encuestas de satisfacción } \\
\text { implementadas }\end{array}$ \\
\hline & $\begin{array}{l}\text { Incrementar la interacción de los } \\
\text { clientes. }\end{array}$ & $\begin{array}{l}\% \text { de respuesta a los clientes a } \\
\text { través de las redes sociales }\end{array}$ \\
\hline & $\begin{array}{l}\text { Mejorar el índice de evaluación del } \\
\text { servicio. }\end{array}$ & $\begin{array}{l}\% \text { de variación del índice de } \\
\text { evaluación del servicio en relación } \\
\text { al año anterior }\end{array}$ \\
\hline \multirow[t]{4}{*}{ Procesos internos } & $\begin{array}{l}\text { Automatizar los procesos manuales } \\
\text { requeridos. }\end{array}$ & $\begin{array}{l}\text { N. de procesos manuales } \\
\text { automatizados / N. de procesos } \\
\text { manuales requeridos }\end{array}$ \\
\hline & $\begin{array}{l}\text { Estandarizar los procesos operativos } \\
\text { de las tiendas. }\end{array}$ & $\begin{array}{l}\text { N. de procesos operativos } \\
\text { estandarizados / N. de procesos } \\
\text { operativos requeridos }\end{array}$ \\
\hline & $\begin{array}{l}\text { Homologar los datos de los sistemas } \\
\text { que utilizan las áreas. }\end{array}$ & $\begin{array}{l}\text { N. de sistemas homologados / N. } \\
\text { de sistemas requeridos }\end{array}$ \\
\hline & Implementar MOF. & MOF implementado \\
\hline \multirow[t]{2}{*}{ Aprendizaje y desarrollo } & Mejorar el clima laboral. & $\begin{array}{l}\% \text { de variación del clima laboral en } \\
\text { relación al año anterior }\end{array}$ \\
\hline & $\begin{array}{l}\text { Añadir una escuela de habilidades } \\
\text { blandas. }\end{array}$ & $\begin{array}{l}\text { N. de escuelas implementadas / N. } \\
\text { de escuelas requeridas }\end{array}$ \\
\hline
\end{tabular}

\subsection{Metas para cada uno de los Objetivos Específicos}

En la Tabla 31, se muestran las metas que se deberán lograr cada año, con el fin de cumplir con los objetivos específicos identificados anteriormente. Asimismo, se indica la línea base que tiene cada objetivo específico, en base a la información entregada por los 
gerentes funcionales de Norky's durante las entrevistas (ver Anexo 7), los indicadores de los costos de ventas y gastos de administración, y el check list de estandarización de los procesos operativos (ver Anexo 10).

Tabla 31

Metas para cada uno de los Objetivos Específicos de Norky's

\begin{tabular}{|c|c|c|c|c|c|}
\hline \multirow[t]{2}{*}{ Perspectiva } & \multirow[t]{2}{*}{ Objetivos Específicos } & \multirow{2}{*}{$\begin{array}{l}\text { Línea } \\
\text { Base }\end{array}$} & \multicolumn{3}{|c|}{ Meta } \\
\hline & & & 2018 & 2019 & 2020 \\
\hline \multirow[t]{2}{*}{ Financiera } & Reducir los costos de ventas. & $45 \%$ & $44 \%$ & $43 \%$ & $42 \%$ \\
\hline & $\begin{array}{l}\text { Reducir los gastos de } \\
\text { administración. }\end{array}$ & $20 \%$ & $19 \%$ & $18 \%$ & $17 \%$ \\
\hline \multirow[t]{3}{*}{ Clientes } & $\begin{array}{l}\text { Implementar encuestas de } \\
\text { satisfacción. }\end{array}$ & - & 1 & 1 & 1 \\
\hline & $\begin{array}{l}\text { Incrementar la interacción de los } \\
\text { clientes. }\end{array}$ & $40 \%$ & $50 \%$ & $60 \%$ & $70 \%$ \\
\hline & $\begin{array}{l}\text { Mejorar el índice de evaluación } \\
\text { del servicio. }\end{array}$ & $76 \%$ & $79 \%$ & $82 \%$ & $85 \%$ \\
\hline \multirow[t]{4}{*}{ Procesos internos } & $\begin{array}{l}\text { Automatizar los procesos } \\
\text { manuales requeridos. }\end{array}$ & $60 \%$ & $70 \%$ & $80 \%$ & $90 \%$ \\
\hline & $\begin{array}{l}\text { Estandarizar los procesos } \\
\text { operativos de las tiendas. }\end{array}$ & $85 \%$ & $88 \%$ & $91 \%$ & $94 \%$ \\
\hline & $\begin{array}{l}\text { Homologar los datos de los } \\
\text { sistemas que utilizan las áreas. }\end{array}$ & $90 \%$ & $100 \%$ & $100 \%$ & $100 \%$ \\
\hline & Implementar MOF. & - & - & 1 & 1 \\
\hline \multirow{2}{*}{ Aprendizaje y } & Mejorar el clima laboral. & $70 \%$ & $75 \%$ & $80 \%$ & $95 \%$ \\
\hline & $\begin{array}{l}\text { Anadır una escuela de } \\
\text { habilidades blandas. }\end{array}$ & - & - & 1 & 1 \\
\hline
\end{tabular}

\subsection{Iniciativas para cada uno de los Objetivos Específicos}

En la Tabla 32, se detallan las iniciativas que se llevarán a cabo para cumplir con los objetivos específicos identificados anteriormente. 
Tabla 32

Iniciativas para cada uno de los Objetivos Especificos de Norky's

\begin{tabular}{|c|c|c|}
\hline Perspectiva & Objetivos Específicos & Iniciativas \\
\hline \multirow[t]{2}{*}{ Financiera } & Reducir los costos de ventas. & $\begin{array}{l}\text { Ajustar el costo de ventas real al } \\
\text { ideal. }\end{array}$ \\
\hline & $\begin{array}{l}\text { Reducir los gastos de } \\
\text { administración. }\end{array}$ & $\begin{array}{l}\text { Ajustar el gasto de la planilla real al } \\
\text { ideal. }\end{array}$ \\
\hline \multirow[t]{3}{*}{ Clientes } & $\begin{array}{l}\text { Implementar encuestas de } \\
\text { satisfacción. }\end{array}$ & Realizar encuestas de satisfacción. \\
\hline & $\begin{array}{l}\text { Incrementar la interacción de los } \\
\text { clientes. }\end{array}$ & $\begin{array}{l}\text { Incrementar la interacción con los } \\
\text { clientes por medio de las } \\
\text { publicaciones en Facebook. }\end{array}$ \\
\hline & $\begin{array}{l}\text { Mejorar el índice de evaluación del } \\
\text { servicio. }\end{array}$ & $\begin{array}{l}\text { Ajustar el índice de evaluación del } \\
\text { servicio real al ideal. }\end{array}$ \\
\hline \multirow[t]{4}{*}{ Procesos internos } & $\begin{array}{l}\text { Automatizar los procesos } \\
\text { manuales requeridos. }\end{array}$ & $\begin{array}{l}\text { Determinar los procesos manuales } \\
\text { requeridos de automatización. }\end{array}$ \\
\hline & $\begin{array}{l}\text { Estandarizar los procesos } \\
\text { operativos de las tiendas. }\end{array}$ & $\begin{array}{l}\text { Ajustar el check list operativo real al } \\
\text { ideal. }\end{array}$ \\
\hline & $\begin{array}{l}\text { Homologar los datos de los } \\
\text { sistemas que utilizan las áreas. }\end{array}$ & $\begin{array}{l}\text { Completar la homologación de los } \\
\text { datos de los sistemas. }\end{array}$ \\
\hline & Implementar MOF. & Desarrollar MOF. \\
\hline \multirow[t]{4}{*}{ Aprendizaje y desarrollo } & Mejorar el clima laboral. & $\begin{array}{l}\text { Formalizar reuniones semanales } \\
\text { entre los administradores y su } \\
\text { equipo de trabajo. }\end{array}$ \\
\hline & & Desarrollar eventos deportivos. \\
\hline & & $\begin{array}{l}\text { Desarrollar políticas de bonificación } \\
\text { para los supervisores de operaciones } \\
\text { y coordinadores de servicio. }\end{array}$ \\
\hline & $\begin{array}{l}\text { Añadir una escuela de habilidades } \\
\text { blandas. }\end{array}$ & $\begin{array}{l}\text { Identificar las escuelas requeridas y } \\
\text { desarrollarlas. }\end{array}$ \\
\hline
\end{tabular}




\subsection{Responsable de cada una de las Iniciativas}

En la Tabla 33, se muestra el responsable de cada una de las iniciativas que se llevarán a cabo para cumplir con los objetivos específicos identificados anteriormente.

Tabla 33

Responsable de cada una de las Iniciativas de Norky's

\begin{tabular}{|c|c|c|}
\hline Perspectiva & Iniciativas & Responsable \\
\hline \multirow[t]{2}{*}{ Financiera } & Ajustar el costo de ventas real al ideal. & Gerente de Auditoría y Control \\
\hline & $\begin{array}{l}\text { Ajustar el gasto de la planilla real al } \\
\text { ideal. }\end{array}$ & Gerente de Recursos Humanos \\
\hline \multirow[t]{3}{*}{ Clientes } & Realizar encuestas de satisfacción. & Gerente de Marketing \\
\hline & $\begin{array}{l}\text { Incrementar la interacción con los } \\
\text { clientes por medio de las publicaciones } \\
\text { en Facebook. }\end{array}$ & Gerente de Marketing \\
\hline & $\begin{array}{l}\text { Ajustar el índice de evaluación del } \\
\text { servicio real al ideal. }\end{array}$ & Gerente de Marketing \\
\hline \multirow[t]{4}{*}{ Procesos internos } & $\begin{array}{l}\text { Determinar los procesos manuales } \\
\text { requeridos de automatización. }\end{array}$ & Jefe de Sistemas \\
\hline & $\begin{array}{l}\text { Ajustar el check list operativo real al } \\
\text { ideal. }\end{array}$ & Gerente de Operaciones \\
\hline & $\begin{array}{l}\text { Completar la homologación de los } \\
\text { datos de los sistemas. }\end{array}$ & Jefe de Sistemas \\
\hline & Desarrollar MOF. & Gerente de Recursos Humanos \\
\hline \multirow[t]{4}{*}{ Aprendizaje y desarrollo } & $\begin{array}{l}\text { Formalizar reuniones semanales entre } \\
\text { los administradores y su equipo de } \\
\text { trabajo. }\end{array}$ & Gerente de Recursos Humanos \\
\hline & Desarrollar eventos deportivos. & Gerente de Recursos Humanos \\
\hline & $\begin{array}{l}\text { Desarrollar políticas de bonificación } \\
\text { para los supervisores de operaciones y } \\
\text { coordinadores de servicio. }\end{array}$ & Gerente de Recursos Humanos \\
\hline & $\begin{array}{l}\text { Identificar las escuelas requeridas y } \\
\text { desarrollarlas. }\end{array}$ & Gerente de Recursos Humanos \\
\hline
\end{tabular}




\subsection{Presupuesto de cada una de las Iniciativas}

A continuación, se muestra el presupuesto detallado, compuesto por gastos de administración y gastos de ventas. Los gastos de administración son gastos directos que asumen las tiendas para desarrollar las iniciativas y los gastos de ventas son gastos indirectos, para el soporte administrativo que brinda MACROSCEM S.A.C. Los gastos de ventas están sustentados en el pago de planilla, con un recargo adicional del 15\% como concepto de ganancias de MACROSCEM S.A.C y un incremento del 5\% anual como concepto de aumento de sueldos (ver Anexo 11). Finalmente, los gastos presupuestados están sujetos a las necesidades del plan estratégico, los cuales cuentan con la aprobación de la gerencia (ver Anexo 12).

- Según la Tabla 34, se realizarán encuestas de satisfacción para lo cual se contratará un encuestador en el primer año y dos en los siguientes años.

Tabla 34

Presupuesto para la realización de encuestas de satisfacción

\begin{tabular}{lccc}
\hline Concepto & 2018 & 2019 & 2020 \\
\hline Encuestador & 41,400 & 86,940 & 91,287 \\
\hline Total & 41,400 & 86,940 & 91,287 \\
\hline
\end{tabular}

- Según la Tabla 35, para incrementar la interacción con los clientes por medio de las publicaciones en Facebook se contratará un Community Manager por tres años. 
Tabla 35

Presupuesto para el incremento de interacción con los clientes por medio de las publicaciones en Facebook

\begin{tabular}{lccc}
\hline Concepto & 2018 & 2019 & 2020 \\
\hline Community Manager & 82,800 & 86,940 & 91,287 \\
\hline Total & 82,800 & 86,940 & 91,287 \\
\hline
\end{tabular}

- Según la Tabla 36, para determinar los procesos manuales requeridos de automatización se contratará personal especializado durante cuatro meses cada año.

Tabla 36

Presupuesto para la determinación de los procesos manuales requeridos para la automatización

\begin{tabular}{lccc}
\hline Concepto & 2018 & 2019 & 2020 \\
\hline Gerente de Administración & 82,800 & 86,940 & 91,287 \\
Analista de Procesos & 20,700 & 21,735 & 22,822 \\
Gerente de RRHH & 69,000 & 72,450 & 76,073 \\
Generalista de RRHH & 27,600 & 28,980 & 30,429 \\
Gerente de Operaciones & 103,500 & 108,675 & 114,109 \\
Jefe de Operaciones & 34,500 & 36,225 & 38,036 \\
Gerente de Auditoria y Control & 82,800 & 86,940 & 91,287 \\
Coordinador de Auditoria & 20,700 & 21,735 & 22,822 \\
Gerente de Logística & 55,200 & 57,960 & 60,858 \\
Gerente de Marketing & 55,200 & 57,960 & 60,858 \\
Coordinador de Marketing & 20,700 & 21,735 & 22,822 \\
Jefe de Sistemas & 82,800 & 86,940 & 91,287 \\
Analista Programador (5) & 207,000 & 217,350 & 228,218 \\
\hline Total & 862,500 & 905,625 & 950,906 \\
\hline
\end{tabular}

- Según la Tabla 37, para ajustar el check list operativo real al ideal se contratarán doce supervisores de operaciones y dos supervisores de servicio, un día al mes por cada año. 
Tabla 37

Presupuesto para el ajuste de check list operativo real al ideal

\begin{tabular}{lccc}
\hline Concepto & 2018 & 2019 & 2020 \\
\hline Supervisor de Operaciones (12) & 20,700 & 21,735 & 22,822 \\
Supervisor de Servicio (2) & 3,450 & 3,623 & 3,804 \\
\hline Total & 24,150 & 25,358 & 26,625 \\
\hline
\end{tabular}

- Según la Tabla 38, para completar la homologación de los datos de los sistemas se contratará un jefe de sistemas por dos meses, tres analistas programadores por seis meses y el resto de personal por un mes, en el primer año.

Tabla 38

Presupuesto para la homologación de los datos de sistema

\begin{tabular}{lccc}
\hline Concepto & 2018 & 2019 & 2020 \\
\hline Jefe de Sistemas & 41,400 & & \\
Analista Programador (3) & 93,150 & & \\
Gerente de Logística & 13,800 & \\
Gerente de Operaciones & 25,875 & \\
Gerente de Auditoria y Control & 20,700 & \\
Gerente de RRHH & 17,250 & \\
\hline Total & 212,175 & \\
\hline
\end{tabular}

- Según la Tabla 39, para desarrollar el MOF se contratará un gerente de recursos humanos, un generalista de recursos humanos y un gerente de operaciones por dos meses, y un jefe de reclutamiento y selección por ocho meses. 
Tabla 39

Presupuesto para el desarrollo del MOF

\begin{tabular}{lccc}
\hline Concepto & 2018 & 2019 & 2020 \\
\hline Gerente de RRHH & 34,500 & & \\
Generalista de RRHH & 13,800 & & \\
Gerente de Operaciones & 51,750 & \\
Jefe de Reclutamiento y & 69,000 & \\
Selección & 169,050 & \\
Total & & \\
\hline
\end{tabular}

- Según la Tabla 40, para formalizar reuniones semanales entre los administradores y sus equipos de trabajo se contratará un gerente de recursos humanos, un generalista de recursos humanos y un gerente de operaciones por un mes en el primer año.

Tabla 40

Presupuesto para la formalización de las reuniones semanales entre los administradores y sus equipos de trabajo

\begin{tabular}{lccc}
\hline Concepto & 2018 & 2019 & 2020 \\
\hline Gerente de RRHH & 17,250 & & \\
Generalista de RRHH & 6,900 & & \\
Gerente de Operaciones & 25,875 & & \\
\hline Total & 50,025 & \\
\hline
\end{tabular}

- En la Tabla 41, se muestra el presupuesto para desarrollar dos eventos deportivos al año para los empleados de las tiendas. 
Tabla 41

Presupuesto para el desarrollo de eventos deportivos

\begin{tabular}{lccc}
\hline Concepto & 2018 & 2019 & 2020 \\
\hline Evento deportivo & 147,200 & 147,200 & 147,200 \\
\hline Total & 147,200 & 147,200 & 147,200 \\
\hline
\end{tabular}

- Según la Tabla 42, para desarrollar políticas de bonificación para los supervisores de operaciones y coordinadores de servicio, se contratará un gerente de recursos humanos, un generalista de recursos humanos y un gerente de operaciones por cuatro meses en el primer año. Adicionalmente, se considera el bono a otorgar a los doce supervisores de operaciones y doce coordinadores de servicio durante los tres años.

Tabla 42

Presupuesto para el desarrollo de políticas de bonificación para los supervisores de operaciones y coordinadores de servicio

\begin{tabular}{lccc}
\hline Concepto & 2018 & 2019 & 2020 \\
\hline Gerente de RRHH & 69,000 & & \\
Generalista de RRHH & 27,600 & & \\
Gerente de Operaciones & 103,500 & & \\
Bono (Supervisor de Operaciones) & 19,200 & 28,800 & 28,800 \\
Bono (Coordinador de Servicio) & 14,400 & 21,600 & 21,600 \\
\hline Total & 233,700 & 50,400 & 50,400 \\
\hline
\end{tabular}

- Según la Tabla 43, para identificar las escuelas requeridas y desarrollarlas se contratará un gerente de recursos humanos, un generalista de recursos humanos, un gerente de operaciones y un jefe de capacitación por cuatro meses en el primer año. Adicionalmente, se considera un capacitador para cada tienda e insumos necesarios para llevar a cabo la capacitación un día al mes durante el primer año. 
Tabla 43

Presupuesto para la identificación de las escuelas requeridas y su desarrollo

\begin{tabular}{lccc}
\hline Concepto & 2018 & 2019 & 2020 \\
\hline Gerente de RRHH & 69,000 & & \\
Generalista de RRHH & 27,600 & & \\
Gerente de Operaciones & 103,500 & & \\
Jefe de Capacitación & 34,500 & & \\
Capacitador & 76,176 & 119,977 & 125,976 \\
Insumos & 73,600 & 110,400 & 110,400 \\
\hline Total & 384,376 & 230,377 & 236,376 \\
\hline
\end{tabular}

En la Tabla 44, se muestra un resumen del presupuesto necesario para llevar a cabo cada una de las iniciativas, con el fin de cumplir con los objetivos específicos identificados anteriormente.

Tabla 44

Presupuesto de cada una de las Iniciativas de Norky's (Expresado en soles)

\begin{tabular}{|c|c|c|c|c|c|c|c|}
\hline \multirow[b]{2}{*}{ Perspectiva } & \multirow[b]{2}{*}{ Iniciativas } & \multicolumn{6}{|c|}{ Presupuesto } \\
\hline & & \multicolumn{2}{|c|}{2018} & \multicolumn{2}{|c|}{2019} & \multicolumn{2}{|c|}{2020} \\
\hline Financiera & Ajustar el costo de ventas real al ideal. & - & - & - & - & - & - \\
\hline \multirow[b]{2}{*}{ Clientes } & Realizar encuestas de satisfacción. & - & 41,400 & - & 86,940 & - & 91,287 \\
\hline & $\begin{array}{l}\text { Incrementar la interacción con los clientes por medio } \\
\text { de las publicaciones en Facebook. }\end{array}$ & - & 82,800 & - & 86,940 & - & 91,287 \\
\hline \multirow{3}{*}{ Procesos internos } & $\begin{array}{l}\text { Determinar los procesos manuales requeridos de } \\
\text { automatización. }\end{array}$ & - & 862,500 & - & 905,625 & - & 950,906 \\
\hline & Ajustar el check list operativo real al ideal. & - & 24,150 & $=$ & 25,358 & - & 26,625 \\
\hline & $\begin{array}{l}\text { Completar la homologación de los datos de los } \\
\text { sistemas. }\end{array}$ & - & 212,175 & - & - & - & - \\
\hline $\begin{array}{l}\text { Aprendizaje y } \\
\text { desarrollo }\end{array}$ & Identificar las escuelas requeridas y desarrollarlas. & 149,776 & 234,600 & 230,377 & - & 236,376 & - \\
\hline \multirow{2}{*}{\multicolumn{2}{|c|}{ Total }} & 302,496 & $1,921,397$ & 377,577 & $1,155,263$ & 383,576 & $1,210,506$ \\
\hline & & \multicolumn{2}{|c|}{$2,223,893$} & \multicolumn{2}{|c|}{$1,532,840$} & \multicolumn{2}{|c|}{$1,594,082$} \\
\hline
\end{tabular}




\subsection{Cronograma de cada una de las Iniciativas}

En la Tabla 45, se muestra el cronograma para llevar a cabo cada una de las iniciativas, con el fin de cumplir con los objetivos específicos identificados anteriormente. 
Tabla 45

Cronograma de cada una de las Iniciativas de Norky's

\begin{tabular}{|c|c|c|c|c|c|c|c|c|c|c|c|c|c|c|c|c|c|c|c|c|c|c|c|c|c|c|c|c|c|c|c|}
\hline \multirow{2}{*}{ Perspectiva } & \multirow{2}{*}{ Objetivos Estratégicos } & \multirow{2}{*}{ Iniciativas } & \multicolumn{10}{|c|}{2018} & \multicolumn{9}{|c|}{2019} & \multicolumn{10}{|c|}{2020} \\
\hline & & & 1 & 2 & 4 & 5 & \begin{tabular}{l|l}
6 & 7 \\
\end{tabular} & 8 & $9 \begin{array}{lll}9 & 1 \\
1\end{array}$ & 10 - 1 & 11 1 1 & 12 & 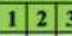 & 3. & 45 & 6 & \begin{tabular}{l|l}
7 & 8 \\
\end{tabular} & 9 & 10 & 11 & 12 & 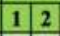 & 3 & 4 & 5 (5 & 67 & 8 & 9 . & 10 田 & 11 & 12 \\
\hline \multirow{2}{*}{ Financiera } & \multirow{2}{*}{ Maximizar la rentabilidad. } & Ajustar el costo de ventas real al ideal. & & & & & & & & & & & & & & & & & & & & & & & & & & & & & \\
\hline & & Ajustar el gasto de la planilla real al ideal. & & & & & & & & & & & & & & & & & & & & & & & & & & & & & \\
\hline \multirow{3}{*}{ Clientes } & \multirow{3}{*}{$\begin{array}{l}\text { Incrementar el nivel de } \\
\text { satisfacción de los clientes. }\end{array}$} & Realizar encuestas de satisfacción. & & & & & & & & & & & & & & & & & & & & & & & & & & & & & \\
\hline & & $\begin{array}{l}\text { Incrementar la interacción con los clientes por medio de } \\
\text { las publicaciones en Facebook. }\end{array}$ & & & & & & & & & & & & & & & & & & & & & & & & & & & & & \\
\hline & & A justar el indice de evaluación del servicio real al ideal. & & & & & & & & & & & & & & & & & & & & & & & & & & & & & \\
\hline \multirow{4}{*}{ Procesos Internos } & \multirow{4}{*}{ Mejorar los procesos. } & $\begin{array}{l}\text { Determinar los procesos manuales requeridos de } \\
\text { automatización. }\end{array}$ & & & & & & & & & & & & & & & & & & & & & & & & & & & & & \\
\hline & & \begin{tabular}{|l|} 
jjustar el check list operativo real al ideal. \\
\end{tabular} & & & & & & & & & & & & & & & & & & & & & & & & & & & & & \\
\hline & & Completar la homologación de los datos de los sistemas. & & & & & & & & & & & & & & & & & & & & & & & & & & & & & \\
\hline & & Desarrollar MOF. & & & & & & & & & & & & & & & & & & & & & & & & & & & & & \\
\hline \multirow{4}{*}{$\begin{array}{c}\text { Aprendizaje y } \\
\text { Desarrollo }\end{array}$} & \multirow{4}{*}{$\begin{array}{l}\text { Incrementar el nivel de } \\
\text { satisfacción de los } \\
\text { colaboradores. }\end{array}$} & $\begin{array}{l}\text { Formalizar reuniones entre los administradores y su } \\
\text { equipo de trabajo. }\end{array}$ & & & & & & & & & & & & & & & & & & & & & & & & & & & & & \\
\hline & & Desarrollar eventos deportivos. & & & & & & & & & & & & & & & & & & & & & & & & & & & & & \\
\hline & & $\begin{array}{l}\text { Desarrollar politicas de bonificación para los supervisores } \\
\text { de operaciones y coordinadores de servicio. }\end{array}$ & & & & & & & & & & & & & & & & & & & & & & & & & & & & & \\
\hline & & Identificar las escuelas requeridas y desarrollarlas. & & & & & & & & & & & & & & & & & & & & & & & & & & & & & \\
\hline
\end{tabular}




\section{Capítulo X. Evaluación}

\subsection{Evaluación Financiera de la Estrategia}

Los estados financieros de Norky's tienen como base el año 2017 y la proyección está basada en tres años: 2018, 2019 y 2020, periodo de análisis del planeamiento estratégico presente.

\subsubsection{Estado de resultados (situación actual y con la nueva estrategia).}

Los estados de resultados de la situación actual y con la nueva estrategia se han proyectado con un incremento de $2.50 \%$ en las ventas para los años 2018,2019 y 2020 , teniendo como referencia el promedio de la variación anual de crecimiento de la actividad de restaurantes (2013 - 2016) (ver Figura 7).

En la Tabla 46, se muestra el estado de resultados de la situación actual de Norky’s, donde la proyección es constante en todos sus conceptos.

Tabla 46

Estado de Resultados de la Situación Actual de Norky's (Expresado en soles)

\begin{tabular}{|l|c|c|c|c|c|c|}
\hline & $\mathbf{2 0 1 5}$ & $\mathbf{2 0 1 6}$ & $\mathbf{2 0 1 7}$ & $\mathbf{2 0 1 8}$ & $\mathbf{2 0 1 9}$ & $\mathbf{2 0 2 0}$ \\
\hline Ventas Netas & $258,658,552$ & $266,935,626$ & $274,142,888$ & $280,996,460$ & $288,021,372$ & $295,221,906$ \\
\hline Costo de Ventas & $-116,396,349$ & $-120,121,032$ & $-123,364,300$ & $-126,448,407$ & $-129,609,617$ & $-132,849,858$ \\
\hline Utilidad Bruta & $\mathbf{1 4 2 , 2 6 2 , 2 0 4}$ & $\mathbf{1 4 6 , 8 1 4 , 5 9 4}$ & $\mathbf{1 5 0 , 7 7 8 , 5 8 8}$ & $\mathbf{1 5 4 , 5 4 8 , 0 5 3}$ & $\mathbf{1 5 8 , 4 1 1 , 7 5 4}$ & $\mathbf{1 6 2 , 3 7 2 , 0 4 8}$ \\
\hline Gastos de Administración & $-51,938,300$ & $-53,600,326$ & $-55,047,534$ & $-56,423,723$ & $-57,834,316$ & $-59,280,174$ \\
\hline Gastos de Venta & $-62,676,966$ & $-64,682,629$ & $-66,429,060$ & $-68,089,787$ & $-69,792,031$ & $-71,536,832$ \\
\hline Utilidad Operativa & $\mathbf{2 7 , 6 4 6 , 9 3 8}$ & $\mathbf{2 8 , 5 3 1 , 6 4 0}$ & $\mathbf{2 9 , 3 0 1 , 9 9 4}$ & $\mathbf{3 0 , 0 3 4 , 5 4 4}$ & $\mathbf{3 0 , 7 8 5 , 4 0 7}$ & $\mathbf{3 1 , 5 5 5 , 0 4 3}$ \\
\hline Gastos Financieros & $-1,309,779$ & $-1,351,692$ & $-1,388,188$ & $-1,422,893$ & $-1,458,465$ & $-1,494,927$ \\
\hline Gastos Diversos & $-90,276$ & $-93,165$ & $-95,680$ & $-98,072$ & $-100,524$ & $-103,037$ \\
\hline Utilidad antes de Impuestos & $\mathbf{2 6 , 2 4 6 , 8 8 3}$ & $\mathbf{2 7 , 0 8 6 , 7 8 3}$ & $\mathbf{2 7 , 8 1 8 , 1 2 6}$ & $\mathbf{2 8 , 5 1 3 , 5 7 9}$ & $\mathbf{2 9 , 2 2 6 , 4 1 9}$ & $\mathbf{2 9 , 9 5 7 , 0 7 9}$ \\
\hline Impuesto a la Renta & $\mathbf{- 7 , 8 7 4 , 0 6 5}$ & $-8,126,035$ & $-8,345,438$ & $-8,554, \mathbf{6 7 4}$ & $-\mathbf{- 8 , 7 6 7 , 9 2 6}$ & $-8,987,124$ \\
\hline Utilidad Neta & $\mathbf{1 8 , 3 7 2 , 8 1 8}$ & $\mathbf{1 8 , 9 6 0 , 7 4 8}$ & $\mathbf{1 9 , 4 7 2 , 6 8 8}$ & $\mathbf{1 9 , 9 5 9 , 5 0 5}$ & $\mathbf{2 0 , 4 5 8 , 4 9 3}$ & $\mathbf{2 0 , 9 6 9 , 9 5 5}$ \\
\hline
\end{tabular}

En la Tabla 47, se muestra el estado de resultados con la nueva estrategia de Norky's, donde el costo de ventas disminuye en $1 \%$ y los gastos de administración disminuyen en 
$0.62 \%$ en promedio en los años proyectados. Asimismo, se incluyó el presupuesto de las

iniciativas en los gastos de administración y ventas.

Tabla 47

Estado de Resultados con la Nueva Estrategia de Norky's (Expresado en soles)

\begin{tabular}{|l|c|c|c|c|c|c|}
\hline & $\mathbf{2 0 1 5}$ & $\mathbf{2 0 1 6}$ & $\mathbf{2 0 1 7}$ & $\mathbf{2 0 1 8}$ & $\mathbf{2 0 1 9}$ & $\mathbf{2 0 2 0}$ \\
\hline Ventas Netas & $258,658,552$ & $266,935,626$ & $274,142,888$ & $280,996,460$ & $288,021,372$ & $295,221,906$ \\
\hline Costo de Ventas & $-116,396,349$ & $-120,121,032$ & $-123,364,300$ & $-123,638,442$ & $-123,849,190$ & $-123,993,201$ \\
\hline Utilidad Bruta & $\mathbf{1 4 2 , 2 6 2 , 2 0 4}$ & $\mathbf{1 4 6 , 8 1 4 , 5 9 4}$ & $\mathbf{1 5 0 , 7 7 8 , 5 8 8}$ & $\mathbf{1 5 7 , 3 5 8 , 0 1 8}$ & $\mathbf{1 6 4 , 1 7 2 , 1 8 2}$ & $\mathbf{1 7 1 , 2 2 8 , 7 0 5}$ \\
\hline Gastos de Administración & $-51,938,300$ & $-53,600,326$ & $-55,047,534$ & $-54,607,154$ & $-54,188,793$ & $-53,791,812$ \\
\hline Gastos de Venta & $-62,676,966$ & $-64,682,629$ & $-66,429,060$ & $-69,494,769$ & $-72,672,245$ & $-75,965,161$ \\
\hline Utilidad Operativa & $\mathbf{2 7 , 6 4 6 , 9 3 8}$ & $\mathbf{2 8 , 5 3 1 , 6 4 0}$ & $\mathbf{2 9 , 3 0 1 , 9 9 4}$ & $\mathbf{3 3 , 2 5 6 , 0 9 5}$ & $\mathbf{3 7 , 3 1 1 , 1 4 4}$ & $\mathbf{4 1 , 4 7 1 , 7 3 3}$ \\
\hline Gastos Financieros & $-1,309,779$ & $-1,351,692$ & $-1,388,188$ & $-1,422,893$ & $-1,458,465$ & $-1,494,927$ \\
\hline Gastos Diversos & $-90,276$ & $-93,165$ & $-95,680$ & $-98,072$ & $-100,524$ & $-103,037$ \\
\hline Utilidad antes de Impuestos & $\mathbf{2 6 , 2 4 6 , 8 8 3}$ & $\mathbf{2 7 , 0 8 6 , 7 8 3}$ & $\mathbf{2 7 , 8 1 8 , 1 2 6}$ & $\mathbf{3 1 , 7 3 5 , 1 3 0}$ & $\mathbf{3 5 , 7 5 2 , 1 5 5}$ & $\mathbf{3 9 , 8 7 3 , 7 6 9}$ \\
\hline Impuesto a la Renta & $-\mathbf{7 , 8 7 4 , 0 6 5}$ & $-8,126,035$ & $-8,345,438$ & $-9,520,539$ & $-10,725,647$ & $-11,962,131$ \\
\hline Utilidad Neta & $\mathbf{1 8 , 3 7 2 , 8 1 8}$ & $\mathbf{1 8 , 9 6 0 , 7 4 8}$ & $\mathbf{1 9 , 4 7 2 , 6 8 8}$ & $\mathbf{2 2 , 2 1 4 , 5 9 1}$ & $\mathbf{2 5 , 0 2 6 , 5 0 9}$ & $\mathbf{2 7 , 9 1 1 , 6 3 8}$ \\
\hline
\end{tabular}

En ese sentido, en la Tabla 48 se puede apreciar una diferencia positiva de la utilidad neta proyectada con la nueva estrategia en relación con la situación actual, validando la importancia de ejecutar la estrategia.

Tabla 48

Diferencia entre la Situación Actual y con la Nueva Estrategia de Norky's (Expresado en soles)

\begin{tabular}{|l|c|c|c|}
\hline & $\mathbf{2 0 1 8}$ & $\mathbf{2 0 1 9}$ & $\mathbf{2 0 2 0}$ \\
\hline Utilidad Neta (Con la nueva estrategia) & $22,214,591$ & $25,026,509$ & $27,911,638$ \\
\hline Utilidad Neta (Situación actual) & $19,959,505$ & $20,458,493$ & $20,969,955$ \\
\hline DIFERENCIA & $\mathbf{2 , 2 5 5 , 0 8 6}$ & $\mathbf{4 , 5 6 8 , 0 1 6}$ & $\mathbf{6 , 9 4 1 , 6 8 3}$ \\
\hline
\end{tabular}

\subsubsection{Balance general (situación actual y con la nueva estrategia).}

Como se puede visualizar en la Tabla 49 y 50, en el balance general de la situación actual y con la nueva estrategia de Norky's tiene mayor representatividad el activo corriente que representa el $85.28 \%$ en el 2017 , siendo esto propio del negocio, ya que los pagos de los clientes se realizan básicamente en efectivo. En el caso del total pasivo y patrimonio, el 
capital social es el que tiene mayor predominancia con un $27.55 \%$. La relevancia de las partidas mencionadas en los balances se mantiene a lo largo de los años proyectados.

Tabla 49

Balance General de la Situación Actual de Norky’s (Expresado en soles)

\begin{tabular}{|l|c|c|c|}
\hline Activo Corriente & $\mathbf{2 0 1 8}$ & $\mathbf{2 0 1 9}$ & $\mathbf{2 0 2 0}$ \\
\hline Efectivo & $94,843,997$ & $115,852,682$ & $137,432,541$ \\
\hline Cuentas por Cobrar Diversas & $3,297,452$ & $3,330,427$ & $3,363,731$ \\
\hline Inventario & $2,157,875$ & $2,222,611$ & $2,289,289$ \\
\hline Total Activo Corriente & $\mathbf{1 0 0 , 2 9 9 , 3 2 3}$ & $\mathbf{1 2 1 , 4 0 5 , 7 1 9}$ & $\mathbf{1 4 3 , 0 8 5 , 5 6 1}$ \\
\hline & & & \\
\hline Activo No Corriente & & & \\
\hline Inmueble, Maquinaria y Equipo & $17,847,617$ & $18,204,570$ & $18,568,661$ \\
\hline Depreciación & $-5,842,984$ & $-6,427,283$ & $-7,070,011$ \\
\hline Activo Diferido & $1,595,800$ & $1,611,758$ & $1,627,876$ \\
\hline Total Activo No Corriente & $\mathbf{1 3 , 6 0 0 , 4 3 3}$ & $\mathbf{1 3 , 3 8 9 , 0 4 5}$ & $\mathbf{1 3 , 1 2 6 , 5 2 5}$ \\
\hline \multicolumn{2}{|l|}{} & & \\
\hline TOTAL ACTIVO & $\mathbf{1 1 3 , 8 9 9 , 7 5 6}$ & $\mathbf{1 3 4 , 7 9 4 , 7 6 4}$ & $\mathbf{1 5 6 , 2 1 2 , 0 8 6}$ \\
\hline
\end{tabular}

\begin{tabular}{|l|c|c|c|}
\hline Pasivo Corriente & $\mathbf{2 0 1 8}$ & $\mathbf{2 0 1 9}$ & $\mathbf{2 0 2 0}$ \\
\hline Tributos y Obligaciones por Pagar & $3,665,322$ & $3,701,976$ & $3,738,995$ \\
\hline Remuneraciones por Pagar & $4,226,106$ & $4,352,890$ & $4,483,476$ \\
\hline Cuentas por Pagar Comerciales & $10,537,367$ & $10,800,801$ & $11,070,821$ \\
\hline Total Pasivo Corriente & $\mathbf{1 8 , 4 2 8 , 7 9 6}$ & $\mathbf{1 8 , 8 5 5 , 6 6 7}$ & $\mathbf{1 9 , 2 9 3 , 2 9 3}$ \\
\hline & & & \\
\hline Pasivo No Corriente & & & \\
\hline Cuentas por Pagar Diversas & 964,417 & 974,061 & 983,801 \\
\hline Total Pasivo No Corriente & $\mathbf{9 6 4 , 4 1 7}$ & $\mathbf{9 7 4 , 0 6 1}$ & $\mathbf{9 8 3 , 8 0 1}$ \\
\hline & & & \\
\hline Total Pasivo & $\mathbf{1 9 , 3 9 3 , 2 1 3}$ & $\mathbf{1 9 , 8 2 9 , 7 2 8}$ & $\mathbf{2 0 , 2 7 7 , 0 9 5}$ \\
\hline & & & \\
\hline Patrimonio & & & \\
\hline Capital Social & $25,760,000$ & $25,760,000$ & $25,760,000$ \\
\hline Reserva Legal & $6,440,022$ & $6,440,022$ & $6,440,022$ \\
\hline Resultados Acumulados & $42,347,016$ & $62,306,522$ & $82,765,014$ \\
\hline Utilidad del Ejercicio & $19,959,505$ & $20,458,493$ & $20,969,955$ \\
\hline Total Patrimonio & $\mathbf{9 4 , 5 0 6 , 5 4 4}$ & $\mathbf{1 1 4 , 9 6 5 , 0 3 6}$ & $\mathbf{1 3 5 , 9 3 4 , 9 9 2}$ \\
\hline & & & \\
\hline TOTAL PASIVO Y PATRIMONIO & $\mathbf{1 1 3 , 8 9 9 , 7 5 6}$ & $\mathbf{1 3 4 , 7 9 4 , 7 6 4}$ & $\mathbf{1 5 6 , 2 1 2 , 0 8 6}$ \\
\hline
\end{tabular}


Tabla 50

Balance General con la Nueva Estrategia de Norky's (Expresado en soles)

\begin{tabular}{|c|c|c|c|}
\hline Activo Corriente & 2018 & 2019 & 2020 \\
\hline Efectivo & $96,864,919$ & $122,195,747$ & $150,459,271$ \\
\hline Cuentas por Cobrar Diversas & $3,297,452$ & $3,330,427$ & $3,363,731$ \\
\hline Inventario & $2,157,875$ & $2,222,611$ & $2,289,289$ \\
\hline Total Activo Corriente & $102,320,245$ & $127,748,785$ & $156,112,291$ \\
\hline \multicolumn{4}{|l|}{ Activo No Corriente } \\
\hline Inmueble, Maquinaria y Equipo & $17,847,617$ & $18,204,570$ & $18,568,661$ \\
\hline Depreciación & $-5,842,984$ & $-6,427,283$ & $-7,070,011$ \\
\hline Activo Diferido & $1,595,800$ & $1,611,758$ & $1,627,876$ \\
\hline Total Activo No Corriente & $13,600,433$ & $13,389,045$ & $13,126,525$ \\
\hline TOTAL ACTIVO & $115,920,678$ & $141,137,830$ & $169,238,816$ \\
\hline
\end{tabular}

\begin{tabular}{|l|c|c|c|}
\hline Pasivo Corriente & $\mathbf{2 0 1 8}$ & $\mathbf{2 0 1 9}$ & $\mathbf{2 0 2 0}$ \\
\hline Tributos y Obligaciones por Pagar & $3,665,322$ & $3,701,976$ & $3,738,995$ \\
\hline Remuneraciones por Pagar & $4,226,106$ & $4,352,890$ & $4,483,476$ \\
\hline Cuentas por Pagar Comerciales & $10,303,204$ & $10,320,766$ & $10,332,767$ \\
\hline Total Pasivo Corriente & $\mathbf{1 8 , 1 9 4 , 6 3 2}$ & $\mathbf{1 8 , 3 7 5 , 6 3 1}$ & $\mathbf{1 8 , 5 5 5 , 2 3 8}$ \\
\hline & & & \\
\hline Pasivo No Corriente & & & \\
\hline Cuentas por Pagar Diversas & 964,417 & 974,061 & 983,801 \\
\hline Total Pasivo No Corriente & $\mathbf{9 6 4 , 4 1 7}$ & $\mathbf{9 7 4 , 0 6 1}$ & $\mathbf{9 8 3 , 8 0 1}$ \\
\hline & & & \\
\hline Total Pasivo & $\mathbf{1 9 , 1 5 9 , 0 4 9}$ & $\mathbf{1 9 , 3 4 9 , 6 9 2}$ & $\mathbf{1 9 , 5 3 9 , 0 4 0}$ \\
\hline & & & \\
\hline Patrimonio & & & \\
\hline Capital Social & $25,760,000$ & $25,760,000$ & $25,760,000$ \\
\hline Reserva Legal & $6,440,022$ & $6,440,022$ & $6,440,022$ \\
\hline Resultados Acumulados & $42,347,016$ & $64,561,607$ & $89,588,116$ \\
\hline Utilidad del Ejercicio & $22,214,591$ & $25,026,509$ & $27,911,638$ \\
\hline Total Patrimonio & $\mathbf{9 6 , 7 6 1 , 6 2 9}$ & $\mathbf{1 2 1 , 7 8 8 , 1 3 8}$ & $\mathbf{1 4 9 , 6 9 9 , 7 7 6}$ \\
\hline & & & \\
\hline TOTAL PASIVO Y PATRIMONIO & $\mathbf{1 1 5 , 9 2 0 , 6 7 8}$ & $\mathbf{1 4 1 , 1 3 7 , 8 3 0}$ & $\mathbf{1 6 9 , 2 3 8 , 8 1 6}$ \\
\hline
\end{tabular}

\subsubsection{Proyección de flujos (situación actual y con la nueva estrategia).}

En la Tabla 51 y 52, se observa el flujo de efectivo de la situación actual y con la nueva estrategia. 
Tabla 51

Flujo de Efectivo de la Situación Actual de Norky's (Expresado en soles)

\begin{tabular}{|l|c|c|c|c|}
\hline & $\mathbf{2 0 1 7}$ & $\mathbf{2 0 1 8}$ & $\mathbf{2 0 1 9}$ & $\mathbf{2 0 2 0}$ \\
\hline$(+)$ Ingreso por Ventas & $274,142,888$ & $280,996,460$ & $288,021,372$ & $295,221,906$ \\
\hline Total Ingresos & $\mathbf{2 7 4 , 1 4 2 , 8 8 8}$ & $\mathbf{2 8 0 , 9 9 6 , 4 6 0}$ & $\mathbf{2 8 8 , 0 2 1 , 3 7 2}$ & $\mathbf{2 9 5 , 2 2 1 , 9 0 6}$ \\
\hline & & & & \\
\hline$(-)$ Mercadería & $123,364,300$ & $126,448,407$ & $129,609,617$ & $132,849,858$ \\
\hline$(-)$ Planillas & $38,533,274$ & $39,496,606$ & $40,484,021$ & $41,496,122$ \\
\hline$(-)$ Alquiler & $11,009,507$ & $11,284,745$ & $11,566,863$ & $11,856,035$ \\
\hline$(-)$ Otros Gastos & $5,504,753$ & $5,642,372$ & $5,783,432$ & $5,928,017$ \\
\hline$(-)$ Gastos de Ventas & $66,429,060$ & $68,089,787$ & $69,792,031$ & $71,536,832$ \\
\hline$(-)$ Gastos Financieros & $1,388,188$ & $1,422,893$ & $1,458,465$ & $1,494,927$ \\
\hline$(-)$ Gastos Diversos & 95,680 & 98,072 & 100,524 & 103,037 \\
\hline$(-)$ Impuesto a la Renta & $8,345,438$ & $8,554,074$ & $8,767,926$ & $8,987,124$ \\
\hline Total Egresos & $\mathbf{2 5 4 , 6 7 0 , 2 0 0}$ & $\mathbf{2 6 1 , 0 3 6 , 9 5 5}$ & $\mathbf{2 6 7 , 5 6 2 , 8 7 9}$ & $\mathbf{2 7 4 , 2 5 1 , 9 5 1}$ \\
\hline & & & & \\
\hline FLUJO DE EFECTIVO & $\mathbf{1 9 , 4 7 2 , 6 8 8}$ & $\mathbf{1 9 , 9 5 9 , 5 0 5}$ & $\mathbf{2 0 , 4 5 8 , 4 9 3}$ & $\mathbf{2 0 , 9 6 9 , 9 5 5}$ \\
\hline
\end{tabular}

Tabla 52

Flujo de Efectivo con la Nueva Estrategia de Norky's (Expresado en soles)

\begin{tabular}{|l|c|c|c|c|}
\hline & $\mathbf{2 0 1 7}$ & $\mathbf{2 0 1 8}$ & $\mathbf{2 0 1 9}$ & $\mathbf{2 0 2 0}$ \\
\hline$(+)$ Ingreso por Ventas & $274,142,888$ & $280,996,460$ & $288,021,372$ & $295,221,906$ \\
\hline Total Ingresos & $\mathbf{2 7 4 , 1 4 2 , 8 8 8}$ & $\mathbf{2 8 0 , 9 9 6 , 4 6 0}$ & $\mathbf{2 8 8 , 0 2 1 , 3 7 2}$ & $\mathbf{2 9 5 , 2 2 1 , 9 0 6}$ \\
\hline & & & & \\
\hline$(-)$ Mercadería & $123,364,300$ & $123,638,442$ & $123,849,190$ & $123,993,201$ \\
\hline$(-)$ Planillas & $38,533,274$ & $38,147,941$ & $37,766,462$ & $37,388,797$ \\
\hline$(-)$ Alquiler & $11,009,507$ & $11,229,697$ & $11,454,291$ & $11,683,377$ \\
\hline$(-)$ Otros Gastos & $5,504,753$ & $5,229,516$ & $4,968,040$ & $4,719,638$ \\
\hline$(-)$ Gastos de Ventas & $66,429,060$ & $69,494,769$ & $72,672,245$ & $75,965,161$ \\
\hline$(-)$ Gastos Financieros & $1,388,188$ & $1,422,893$ & $1,458,465$ & $1,494,927$ \\
\hline$(-)$ Gastos Diversos & 95,680 & 98,072 & 100,524 & 103,037 \\
\hline$(-)$ Impuesto a la Renta & $8,345,438$ & $9,520,539$ & $10,725,647$ & $11,962,131$ \\
\hline Total Egresos & $\mathbf{2 5 4 , 6 7 0 , 2 0 0}$ & $\mathbf{2 5 8 , 7 8 1 , 8 6 9}$ & $\mathbf{2 6 2 , 9 9 4 , 8 6 3}$ & $\mathbf{2 6 7 , 3 1 0 , 2 6 8}$ \\
\hline & & & & \\
\hline FLUJO DE EFECTIVO & $\mathbf{1 9 , 4 7 2 , 6 8 8}$ & $\mathbf{2 2 , 2 1 4 , 5 9 1}$ & $\mathbf{2 5 , 0 2 6 , 5 0 9}$ & $\mathbf{2 7 , 9 1 1 , 6 3 8}$ \\
\hline
\end{tabular}

En la Tabla 53, se observa el diferencial del flujo de efectivo de la situación actual y con la nueva estrategia, el cual permitirá hallar el TIR y VAN del mismo. 
Tabla 53

Diferencial del Flujo de Efectivo de Norky's (Expresado en soles)

\begin{tabular}{|l|c|c|c|c|}
\hline & $\mathbf{2 0 1 7}$ & $\mathbf{2 0 1 8}$ & $\mathbf{2 0 1 9}$ & $\mathbf{2 0 2 0}$ \\
\hline Flujo de Efectivo Actual & & $19,959,505$ & $20,458,493$ & $20,969,955$ \\
\hline Flujo de Efectivo Esperado & $-5,350,814$ & $22,214,591$ & $25,026,509$ & $27,911,638$ \\
\hline & & & & \\
\hline DIFERENCIAL & $\mathbf{- 5 , 3 5 0 , 8 1 4}$ & $\mathbf{2 , 2 5 5 , 0 8 6}$ & $\mathbf{4 , 5 6 8 , 0 1 6}$ & $\mathbf{6 , 9 4 1 , 6 8 3}$ \\
\hline
\end{tabular}

10.1.4. Evaluación financiera (VAN, TIR y ratios financieros).

En la Tabla 54, se observan las variables utilizadas para el cálculo del Ke, así como el COK, TIR y VAN obtenidos. Para la elaboración del COK, se ha utilizado el modelo CAPM el cual vincula la rentabilidad de cualquier activo financiero con el riesgo de mercado del mismo.

Tabla 54

Variables para la Evaluación Financiera

\begin{tabular}{|l|c|}
\hline BETA DESAPALANCADA & $\mathbf{1 . 2 7}$ \\
\hline DEUDA & $\mathbf{0 . 2 0 2 8 2 7 5 0 1}$ \\
\hline PATRIMONIO & $\mathbf{0 . 7 9 7 1 7 2 4 9 9}$ \\
\hline IR & $\mathbf{2 9 . 5 0 \%}$ \\
\hline BETA APALANCADA & $\mathbf{1 . 5 0}$ \\
\hline RENDIMIENTO ACTIVO LIBRE DE RIESGO & $5.03 \%$ \\
\hline RENDIMIENTO DE MERCADO & $8.64 \%$ \\
\hline KE & $\mathbf{1 0 . 4 4 \%}$ \\
\hline RIESGO PAÍS & $1.13 \%$ \\
\hline COK MODIFICADO & $\mathbf{1 1 . 5 7 \%}$ \\
\hline TIR & $\mathbf{5 3 . 1 7 \%}$ \\
\hline VAN & $\mathbf{1 0 , 6 8 9 , 8 8 6}$ \\
\hline
\end{tabular}

Nota. Tomado de Variables para la Evaluación Financiera. Recuperado de http://pages.stern.nyu.edu/ adamodar/New_Home_Page/datafile/Betas.html, http://orientacion.sunat.gob.pe/index.php/empresas-menu/impuesto-a-la-renta- 
empresas/regimen-general-del-impuesto-a-la-renta-empresas/calculo-anual-del-impuesto-a- larenta-empresas/2900-03-tasas-para-la-determinacion-del-impuesto-a-la-renta-anual, http://pages.stern.nyu.edu/ adamodar/New_Home_Page/datafile/histret.html\#_msoanchor_2, https://www.google.com.pe/url?sa=t\&rct=j\&q=\&esrc=s\&source=web\&cd=2\&ved=0ahUKE wjs_tfGj8vXAhUHPCYKHXHDB08QFgguMAE\&url=http\%3A\%2F\%2Fwww.stern.nyu.ed u\%2F adamodar\%2Fpc\%2Fdatasets\%2FhistretSP.xls\&usg=AOvVaw3SFVdihD3qmgCw_R 1EDvCf, http://www.ambito.com/economia/mercados/riesgo-pais/info/?id=13

En la Tabla 55, se observa la liquidez para la situación actual y con la nueva estrategia, donde este último va aumentando en mayor proporción que la situación actual, lo cual muestra la gran capacidad de pago de Norky’s para los años evaluados.

Tabla 55

Ratios de Liquidez de Norky's (Expresado en soles)

\begin{tabular}{|l|c|c|c|}
\hline & $\mathbf{2 0 1 8}$ & $\mathbf{2 0 1 9}$ & $\mathbf{2 0 2 0}$ \\
\hline Liquidez (Situación actual) & 5.44 & 6.44 & 7.42 \\
\hline Liquidez (Con la nueva estrategia) & 5.62 & 6.95 & 8.41 \\
\hline
\end{tabular}

En la Tabla 56, se observa el periodo promedio de pagos para la situación actual y con la nueva estrategia, donde ambos permanecen iguales. 
Tabla 56

Ratios de Gestión de Norky's (Expresado en dias)

\begin{tabular}{|l|c|c|c|}
\hline & $\mathbf{2 0 1 8}$ & $\mathbf{2 0 1 9}$ & $\mathbf{2 0 2 0}$ \\
\hline Periodo Promedio de Pagos (Situación actual) & 30.42 & 30.42 & 30.42 \\
\hline Periodo Promedio de Pagos (Con la nueva estrategia) & 30.42 & 30.42 & 30.42 \\
\hline
\end{tabular}

En la Tabla 57, se observan los ratios de endeudamiento para la situación actual y con la nueva estrategia, donde este último muestra una disminución mayor que en la situación actual, debido a que el total de activo y patrimonio han ido aumentando en los años de evaluación, siendo conveniente la implementación de la nueva estrategia para Norky’s.

Tabla 57

Ratios de Endeudamiento de Norky's

\begin{tabular}{|l|c|c|c|}
\hline & $\mathbf{2 0 1 8}$ & $\mathbf{2 0 1 9}$ & $\mathbf{2 0 2 0}$ \\
\hline Grado de endeudamiento (Situación actual) & $17 \%$ & $15 \%$ & $13 \%$ \\
\hline Razón Deuda Patrimonio (Situación actual) & $21 \%$ & $17 \%$ & $15 \%$ \\
\hline Grado de endeudamiento (Con la nueva estrategia) & $17 \%$ & $14 \%$ & $12 \%$ \\
\hline Razón Deuda Patrimonio (Con la nueva estrategia) & $20 \%$ & $16 \%$ & $13 \%$ \\
\hline
\end{tabular}

En la Tabla 58, se observan los ratios de rentabilidad para la situación actual y con la nueva estrategia, donde los márgenes de este último van aumentando en comparación con la situación actual. 
Tabla 58

Ratios de Rentabilidad de Norky's

\begin{tabular}{|l|c|c|c|}
\hline & $\mathbf{2 0 1 8}$ & $\mathbf{2 0 1 9}$ & $\mathbf{2 0 2 0}$ \\
\hline Retorno sobre Activo - ROA (Situación actual) & $18 \%$ & $15 \%$ & $13 \%$ \\
\hline Retorno sobre Patrimonio - ROE (Situación actual) & $21 \%$ & $18 \%$ & $15 \%$ \\
\hline Margen Neto (Situación actual) & $7 \%$ & $7 \%$ & $7 \%$ \\
\hline Margen Operativo (Situación actual) & $11 \%$ & $11 \%$ & $11 \%$ \\
\hline Margen Bruto (Situación actual) & $55 \%$ & $55 \%$ & $55 \%$ \\
\hline Retorno sobre Activo - ROA (Con la nueva estrategia) & $19 \%$ & $18 \%$ & $16 \%$ \\
\hline Retorno sobre Patrimonio - ROE (Con la nueva estrategia) & $23 \%$ & $21 \%$ & $19 \%$ \\
\hline Margen Neto (Con la nueva estrategia) & $8 \%$ & $9 \%$ & $9 \%$ \\
\hline Margen Operativo (Con la nueva estrategia) & $12 \%$ & $13 \%$ & $14 \%$ \\
\hline Margen Bruto (Con la nueva estrategia) & $56 \%$ & $57 \%$ & $58 \%$ \\
\hline
\end{tabular}




\section{Conclusiones y Recomendaciones}

\section{Conclusiones}

- Respecto al objetivo estratégico “Maximizar la rentabilidad”, se realizarán actividades que permitan reducir los costos de ventas y los gastos de administración.

- Respecto al objetivo estratégico "Incrementar el nivel de satisfacción de los clientes", se implementarán encuestas relacionadas y se incrementará la interacción con los mismos, a través de las redes sociales. Además, se realizarán acciones para mejorar el índice de evaluación del servicio.

- Respecto al objetivo estratégico "Mejorar los procesos”, se llevará a cabo la institucionalización de los mismos, a través de la automatización de los procesos manuales, estandarización de los procesos operativos, homologación de los datos de los sistemas e implementación de MOF.

- Respecto al objetivo estratégico “Incrementar el nivel de satisfacción de los colaboradores", se realizarán actividades para mejorar el clima laboral y se añadirá una escuela de habilidades blandas.

- La contribución del plan estratégico es generar una base sólida normativa que sirva como punto de partida para generar nuevas estrategias enfocadas en los intereses de la organización. 


\section{Recomendaciones}

- Respecto al objetivo estratégico "Maximizar la rentabilidad", se recomienda controlar mensualmente los costos de ventas y gastos de administración, contrastando el check list real versus el ideal para cada situación.

- Respecto al objetivo estratégico "Incrementar el nivel de satisfacción de los clientes", se recomienda realizar una investigación de mercado que permita conocer mejor a los clientes y sus necesidades, con el fin de crear estrategias de venta y fidelización en base a los resultados obtenidos. Adicionalmente, se recomienda incluir la medición del indicador Net Promoter Score (NPS) como parte de las encuestas de satisfacción a los clientes. Finalmente, se recomienda implementar la estrategia contingente, ya que en el análisis realizado se determinó que el desarrollo de productos tiene un alto puntaje en la matriz PEC, después de la estrategia seleccionada.

- Respecto al objetivo estratégico "Mejorar los procesos", se recomienda tercerizar el proceso de reclutamiento y selección del personal que está por debajo del administrador de tienda, con el fin de garantizar la continuidad de la operación y trasladar el riesgo de la ausencia de personal. Además, se debe considerar profesionalizar los cargos gerenciales con personal que se ajuste al perfil requerido para el puesto. Finalmente, se recomienda obtener la certificación ISO 9001 y 14001, con el fin de mejorar la imagen de la empresa frente a los stakeholders e implementar acciones de responsabilidad social empresarial.

- Respecto al objetivo estratégico "Incrementar el nivel de satisfacción de los colaboradores", se recomienda incrementar los eventos de integración del personal e implementar nuevas políticas de bonificación para los colaborares. 


\section{Anexos}

Anexo 1. Lista de Tiendas según Tipo y Distrito en Lima Metropolitana

\begin{tabular}{|c|c|c|c|}
\hline $\mathrm{N}^{\circ}$ & Tienda & Tipo & Distrito \\
\hline 1 & Huaycán & Restaurante & Ate \\
\hline 2 & Vitarte 1 & Restaurante & Ate \\
\hline 3 & Vitarte 2 & Restaurante & Ate \\
\hline 4 & Salamanca & Restaurante & Ate \\
\hline 5 & Javier Prado & Restaurante & Ate \\
\hline 6 & Santa Clara - C.C. Real Plaza & Patio & Ate \\
\hline 7 & Santa Clara 2 & Restaurante & Ate \\
\hline 8 & C.C. La Rambla & Restaurante & Breña \\
\hline 9 & Venezuela & Restaurante & Breña \\
\hline 10 & Alfonso Ugarte & Restaurante & Cercado De Lima \\
\hline 11 & Colmena & Restaurante & Cercado De Lima \\
\hline 12 & Maruy 1 & Restaurante & Cercado De Lima \\
\hline 13 & Principal & Restaurante & Cercado De Lima \\
\hline 14 & Unión 1 & Restaurante & Cercado De Lima \\
\hline 15 & Abancay 2 & Restaurante & Cercado De Lima \\
\hline 16 & Centro Cívico - C.C. Real Plaza & Restaurante & Cercado De Lima \\
\hline 17 & Plaza Castilla - Metro & Restaurante & Cercado De Lima \\
\hline 18 & Puno & Restaurante & Cercado De Lima \\
\hline 19 & Chorrillos & Restaurante & Chorrillos \\
\hline 20 & Comas - Retablo & Restaurante & Comas \\
\hline 21 & Comas - Sta. Luzmila & Restaurante & Comas \\
\hline 22 & Comas 2 & Restaurante & Comas \\
\hline 23 & Comas 5 - San Felipe & Restaurante & Comas \\
\hline 24 & Pólvora 1 -Tottus & Restaurante & El Agustino \\
\hline 25 & Bravo Chico & Restaurante & El Agustino \\
\hline 26 & Pólvora 2 - Tottus & Restaurante & El Agustino \\
\hline 27 & Agustino - C.C. Agustino Plaza - Rest./Patio & Restaurante & El Agustino \\
\hline 28 & Megaplaza 2 & Restaurante & Independencia \\
\hline 29 & C.C. Plaza Lima Norte & Patio & Independencia \\
\hline 30 & Independencia & Patio & Independencia \\
\hline 31 & Salaverry & Restaurante & Jesús María \\
\hline 32 & Jesús María & Restaurante & Jesús María \\
\hline 33 & Garzón & Restaurante & Jesús María \\
\hline 34 & Molina & Restaurante & La Molina \\
\hline 35 & Cánepa 3 & Restaurante & La Victoria \\
\hline 36 & Parinacochas & Restaurante & La Victoria \\
\hline 37 & México 1 & Restaurante & La Victoria \\
\hline 38 & México 2 & Restaurante & La Victoria \\
\hline 39 & Cánepa 1 - C.C. Parque. Cánepa & Patio & La Victoria \\
\hline 40 & Cánepa 2 - C.C. Parque. Cánepa & Patio & La Victoria \\
\hline 41 & Lince 1 & Restaurante & Lince \\
\hline 42 & Lince 2 & Restaurante & Lince \\
\hline 43 & Olivos 2 & Restaurante & Los Olivos \\
\hline 44 & Pro & Restaurante & Los Olivos \\
\hline 45 & Chosica & Restaurante & Lurigancho \\
\hline 46 & Lurín & Restaurante & Lurín \\
\hline 47 & Playa & Restaurante & Lurín \\
\hline 48 & Lurín 02 & Restaurante & Lurín \\
\hline
\end{tabular}




\begin{tabular}{|c|c|c|c|}
\hline $\mathrm{N}^{\circ}$ & Tienda & Tipo & Distrito \\
\hline 49 & Magdalena & Restaurante & Magdalena \\
\hline 50 & Panamá & Restaurante & Miraflores \\
\hline 51 & Pardo & Restaurante & Miraflores \\
\hline 52 & Sucre & Restaurante & Pueblo Libre \\
\hline 53 & Puente Piedra 1 & Restaurante & Puente Piedra \\
\hline 54 & Puente Piedra - Tottus & Restaurante & Puente Piedra \\
\hline 55 & Rímac & Restaurante & Rímac \\
\hline 56 & Aviación 24 & Restaurante & San Borja \\
\hline 57 & Aviación 29 & Restaurante & San Borja \\
\hline 58 & Avi 1 & Restaurante & San Juan De Lurigancho \\
\hline 59 & Canto Grande 1 & Restaurante & San Juan De Lurigancho \\
\hline 60 & Canto Grande 2 & Restaurante & San Juan De Lurigancho \\
\hline 61 & Próceres 1 & Restaurante & San Juan De Lurigancho \\
\hline 62 & Zarate 1 & Restaurante & San Juan De Lurigancho \\
\hline 63 & Zarate 2 & Restaurante & San Juan De Lurigancho \\
\hline 64 & Avi 2 & Restaurante & San Juan De Lurigancho \\
\hline 65 & Canto Grande - Metro & Restaurante & San Juan De Lurigancho \\
\hline 66 & Próceres 2 & Restaurante & San Juan De Lurigancho \\
\hline 67 & Campoy -Tottus & Restaurante & San Juan De Lurigancho \\
\hline 68 & Las Flores & Restaurante & San Juan De Lurigancho \\
\hline 69 & Bolichera & Restaurante & San Juan De Miraflores \\
\hline 70 & San Juan 1 & Restaurante & San Juan De Miraflores \\
\hline 71 & San Juan 2 & Restaurante & San Juan De Miraflores \\
\hline 72 & Atocongo - C.C. Open Plaza & Patio & San Juan De Miraflores \\
\hline 73 & C.C. Mall Del Sur & Patio & San Juan De Miraflores \\
\hline 74 & Canadá & Restaurante & San Luis \\
\hline 75 & Habich & Restaurante & San Martín De Porres \\
\hline 76 & Huandoy & Restaurante & San Martín De Porres \\
\hline 77 & Perú 1 & Restaurante & San Martín De Porres \\
\hline 78 & Perú 2 & Restaurante & San Martín De Porres \\
\hline 79 & Marina 17 & Restaurante & San Miguel \\
\hline 80 & Marina 32 & Restaurante & San Miguel \\
\hline 81 & Marina 26 & Restaurante & San Miguel \\
\hline 82 & Santa Anita 2 & Restaurante & Santa Anita \\
\hline 83 & Santa Anita - Ficus & Restaurante & Santa Anita \\
\hline 84 & Santa Anita - C.C. Aventura Plaza & Restaurante & Santa Anita \\
\hline 85 & Santa Anita - Productores & Restaurante & Santa Anita \\
\hline 86 & Chacarilla & Restaurante & Surco \\
\hline 87 & Viñedos -Tottus & Restaurante & Surco \\
\hline 88 & Villa El Salvador 1 & Restaurante & Villa El Salvador \\
\hline 89 & Villa El Salvador 2 & Restaurante & Villa El Salvador \\
\hline 90 & Villa El Salvador - C.C. Megaplaza & Patio & Villa El Salvador \\
\hline 91 & Villa María Del Triunfo & Restaurante & Villa María Del Triunfo \\
\hline 92 & Villa María Del Triunfo 2 & Restaurante & Villa María Del Triunfo \\
\hline
\end{tabular}

Nota. Tomado de Página Web de Norky's. Recuperado de http://norkys.pe/restaurantes 
Anexo 2. Formato de Evaluación del Servicio de Norky’s

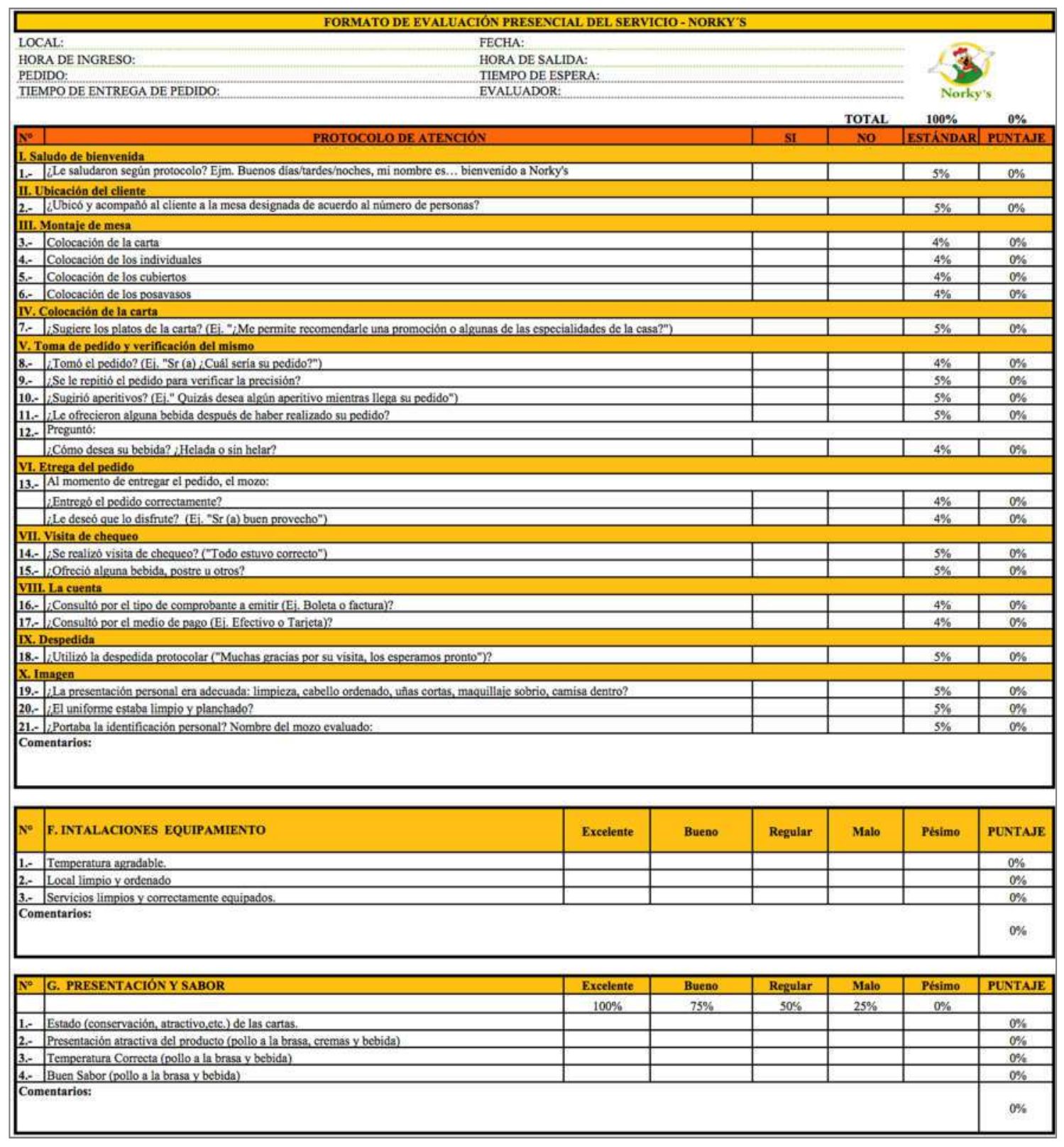


Anexo 3. Índice de Evaluación del Servicio de Norky's

\begin{tabular}{|c|c|c|c|c|c|}
\hline \multirow[b]{2}{*}{$\mathbf{N}^{\circ}$} & \multirow[b]{2}{*}{ Tienda } & \multicolumn{4}{|c|}{ Nivel de satisfacción de los clientes } \\
\hline & & Instalación & Presentación & $\begin{array}{c}\text { Atención al } \\
\text { cliente }\end{array}$ & $\begin{array}{c}\text { Cliente incógnito } \\
\text { real }\end{array}$ \\
\hline 1 & Huaycán & $73.94 \%$ & $78.52 \%$ & $76.87 \%$ & $76.44 \%$ \\
\hline 2 & Vitarte 1 & $44.95 \%$ & $47.73 \%$ & $46.73 \%$ & $46.47 \%$ \\
\hline 3 & Vitarte 2 & $44.62 \%$ & $47.39 \%$ & $46.39 \%$ & $46.13 \%$ \\
\hline 4 & Salamanca & $80.33 \%$ & $85.31 \%$ & $83.51 \%$ & $83.05 \%$ \\
\hline 5 & Javier Prado & $85.77 \%$ & $91.08 \%$ & $89.16 \%$ & $88.67 \%$ \\
\hline 6 & Santa Clara - C.C. Real Plaza & $79.22 \%$ & $84.12 \%$ & $82.35 \%$ & $81.90 \%$ \\
\hline 7 & Santa Clara 2 & $75.35 \%$ & $80.02 \%$ & $78.33 \%$ & $77.90 \%$ \\
\hline 8 & C.C. La Rambla & $67.77 \%$ & $71.97 \%$ & $70.46 \%$ & $70.07 \%$ \\
\hline 9 & Venezuela & $74.33 \%$ & $78.94 \%$ & $77.28 \%$ & $76.85 \%$ \\
\hline 10 & Alfonso Ugarte & $70.73 \%$ & $75.11 \%$ & $73.53 \%$ & $73.12 \%$ \\
\hline 11 & Colmena & $91.27 \%$ & $96.92 \%$ & $94.89 \%$ & $94.36 \%$ \\
\hline 12 & Maruy 1 & $59.19 \%$ & $62.86 \%$ & $61.54 \%$ & $61.20 \%$ \\
\hline 13 & Principal & $83.13 \%$ & $88.28 \%$ & $86.43 \%$ & $85.95 \%$ \\
\hline 14 & Union 1 & $69.04 \%$ & $73.32 \%$ & $71.78 \%$ & $71.38 \%$ \\
\hline 15 & Abancay 2 & $88.70 \%$ & $94.20 \%$ & $92.21 \%$ & $91.70 \%$ \\
\hline 16 & Centro Civico - C.C. Real Plaza & $58.03 \%$ & $61.63 \%$ & $60.33 \%$ & $60.00 \%$ \\
\hline 17 & Plaza Castilla-Metro & $71.22 \%$ & $75.63 \%$ & $74.04 \%$ & $73.63 \%$ \\
\hline 18 & Puno & $77.57 \%$ & $82.38 \%$ & $80.64 \%$ & $80.20 \%$ \\
\hline 19 & Chorrillos & $93.60 \%$ & $99.39 \%$ & $97.30 \%$ & $96.76 \%$ \\
\hline 20 & Comas - Retablo & $87.93 \%$ & $93.37 \%$ & $91.41 \%$ & $90.90 \%$ \\
\hline 21 & Comas - Sta Luzmila & $89.18 \%$ & $94.70 \%$ & $92.71 \%$ & $92.20 \%$ \\
\hline 22 & Comas 2 & $68.68 \%$ & $72.93 \%$ & $71.40 \%$ & $71.00 \%$ \\
\hline 23 & Comas 5 - San Felipe & $62.84 \%$ & $66.74 \%$ & $65.33 \%$ & $64.97 \%$ \\
\hline 24 & Polvora 1-Tottus & $79.27 \%$ & $84.18 \%$ & $82.41 \%$ & $81.95 \%$ \\
\hline 25 & Bravo Chico & $82.42 \%$ & $87.53 \%$ & $85.69 \%$ & $85.21 \%$ \\
\hline 26 & Polvora 2 - Tottus & $79.78 \%$ & $84.72 \%$ & $82.94 \%$ & $82.48 \%$ \\
\hline 27 & Agustino - C.C. Agustino Plaza - Rest./Patio & $88.07 \%$ & $93.52 \%$ & $91.55 \%$ & $91.05 \%$ \\
\hline 28 & Megaplaza 2 & $84.70 \%$ & $89.94 \%$ & $88.05 \%$ & $87.56 \%$ \\
\hline 29 & C.C. Plaza Lima Norte & $76.22 \%$ & $80.95 \%$ & $79.24 \%$ & $78.80 \%$ \\
\hline 30 & Independencia & $72.67 \%$ & $77.17 \%$ & $75.55 \%$ & $75.13 \%$ \\
\hline 31 & Salaverry & $72.67 \%$ & $77.17 \%$ & $75.55 \%$ & $75.13 \%$ \\
\hline
\end{tabular}




\begin{tabular}{|c|c|c|c|c|c|}
\hline \multirow[b]{2}{*}{$\mathbf{N}^{\circ}$} & \multirow[b]{2}{*}{ Tienda } & \multicolumn{4}{|c|}{ Nivel de satisfacción de los colaboradores } \\
\hline & & Instalación & Presentación & $\begin{array}{l}\text { Atención al } \\
\text { cliente }\end{array}$ & $\begin{array}{c}\text { Cliente incógnito } \\
\text { real }\end{array}$ \\
\hline 32 & Jesus Maria & $50.40 \%$ & $53.52 \%$ & $52.39 \%$ & $\mathbf{5 2 . 1 0} \%$ \\
\hline 33 & Garzon & $79.77 \%$ & $84.71 \%$ & $82.93 \%$ & $82.47 \%$ \\
\hline 34 & Molina & $76.79 \%$ & $81.55 \%$ & $79.83 \%$ & $79.39 \%$ \\
\hline 35 & Canepa 3 & $76.54 \%$ & $81.29 \%$ & $79.58 \%$ & $79.14 \%$ \\
\hline 36 & Parinacochas & $86.65 \%$ & $92.02 \%$ & $90.08 \%$ & $89.58 \%$ \\
\hline 37 & México 1 & $44.78 \%$ & $47.56 \%$ & $46.56 \%$ & $46.30 \%$ \\
\hline 38 & México 2 & $81.70 \%$ & $86.76 \%$ & $84.93 \%$ & $84.46 \%$ \\
\hline 39 & Canepa 1 - C.C. Parque. Canepa & $81.63 \%$ & $86.68 \%$ & $84.86 \%$ & $84.39 \%$ \\
\hline 40 & Canepa 2 - C.C. Parque. Canepa & $91.27 \%$ & $96.92 \%$ & $94.89 \%$ & $94.36 \%$ \\
\hline 41 & Lince 1 & $78.19 \%$ & $83.03 \%$ & $81.29 \%$ & $80.84 \%$ \\
\hline 42 & Lince 2 & $81.64 \%$ & $86.70 \%$ & $84.88 \%$ & $84.41 \%$ \\
\hline 43 & Olivos 2 & $81.69 \%$ & $86.75 \%$ & $84.92 \%$ & $84.45 \%$ \\
\hline 44 & Pro & $82.87 \%$ & $88.00 \%$ & $86.15 \%$ & $85.67 \%$ \\
\hline 45 & Chosica & $63.87 \%$ & $67.83 \%$ & $66.40 \%$ & $66.03 \%$ \\
\hline 46 & Lurín & $70.56 \%$ & $74.93 \%$ & $73.35 \%$ & $72.94 \%$ \\
\hline 47 & Playa & $57.23 \%$ & $60.77 \%$ & $59.49 \%$ & $59.16 \%$ \\
\hline 48 & Lurín 02 & $80.21 \%$ & $85.18 \%$ & $83.39 \%$ & $82.93 \%$ \\
\hline 49 & Magdalena & $81.04 \%$ & $86.06 \%$ & $84.25 \%$ & $83.78 \%$ \\
\hline 50 & Panamá & $82.71 \%$ & $87.84 \%$ & $85.99 \%$ & $85.51 \%$ \\
\hline 51 & Pardo & $91.10 \%$ & $96.75 \%$ & $94.71 \%$ & $94.19 \%$ \\
\hline 52 & Sucre & $71.99 \%$ & $76.45 \%$ & $74.84 \%$ & $74.43 \%$ \\
\hline 53 & Puente Piedra 1 & $75.42 \%$ & $80.09 \%$ & $78.41 \%$ & $77.97 \%$ \\
\hline 54 & Puente Piedra - Tottus & $66.93 \%$ & $71.07 \%$ & $69.58 \%$ & $69.19 \%$ \\
\hline 55 & Rímac & $83.42 \%$ & $88.59 \%$ & $86.73 \%$ & $86.25 \%$ \\
\hline 56 & Aviación 24 & $68.78 \%$ & $73.05 \%$ & $71.51 \%$ & $71.11 \%$ \\
\hline 57 & Aviación 29 & $75.96 \%$ & $80.66 \%$ & $78.97 \%$ & $78.53 \%$ \\
\hline 58 & Avi 1 & $69.59 \%$ & $73.90 \%$ & $72.34 \%$ & $71.94 \%$ \\
\hline 59 & Canto Grande 1 & $70.37 \%$ & $74.73 \%$ & $73.16 \%$ & $72.75 \%$ \\
\hline 60 & Canto Grande 2 & $52.08 \%$ & $55.30 \%$ & $54.14 \%$ & $53.84 \%$ \\
\hline 61 & Próceres 1 & $76.17 \%$ & $80.89 \%$ & $79.19 \%$ & $78.75 \%$ \\
\hline 62 & Zarate 1 & $72.40 \%$ & $76.89 \%$ & $75.27 \%$ & $74.85 \%$ \\
\hline
\end{tabular}




\begin{tabular}{|c|c|c|c|c|c|}
\hline \multirow[b]{2}{*}{$\mathbf{N}^{\circ}$} & \multirow[b]{2}{*}{ Tienda } & \multicolumn{4}{|c|}{ Nivel de satisfacción de los colaboradores } \\
\hline & & Instalación & Presentación & $\begin{array}{c}\text { Atención al } \\
\text { cliente }\end{array}$ & $\begin{array}{c}\text { Cliente incógnito } \\
\text { real }\end{array}$ \\
\hline 63 & Zarate 2 & $89.95 \%$ & $95.52 \%$ & $93.51 \%$ & $92.99 \%$ \\
\hline 64 & Avi 2 & $57.39 \%$ & $60.94 \%$ & $59.66 \%$ & $59.33 \%$ \\
\hline 65 & Canto Grande - Metro & $77.40 \%$ & $82.19 \%$ & $80.46 \%$ & $80.02 \%$ \\
\hline 66 & Proceres 2 & $68.16 \%$ & $72.38 \%$ & $70.86 \%$ & $70.46 \%$ \\
\hline 67 & Campoy-Tottus & $62.14 \%$ & $63.33\} \%$ & $64.60 \%$ & $63.37 \%$ \\
\hline 68 & Las Flores & $43.66 \%$ & $42.45 \%$ & $45.39 \%$ & $43.83 \%$ \\
\hline 69 & Bolichera & $72.40 \%$ & $76.89 \%$ & $75.27 \%$ & $74.85 \%$ \\
\hline 70 & San Juan 1 & $74.62 \%$ & $72.57 \%$ & $77.58 \%$ & $74.92 \%$ \\
\hline 71 & San Juan 2 & $73.23 \%$ & $77.76 \%$ & $76.13 \%$ & $\mathbf{7 5 . 7 0} \%$ \\
\hline 72 & Atocongo - C.C. Open Plaza & $47.69 \%$ & $55.68 \%$ & $49.57 \%$ & $50.98 \%$ \\
\hline 73 & C.C. Mall Del Sur & $64.64 \%$ & $68.64 \%$ & $67.20 \%$ & $66.83 \%$ \\
\hline 74 & Canadá & $76.67 \%$ & $79.12 \%$ & $79.71 \%$ & $78.50 \%$ \\
\hline 75 & Habich & $74.66 \%$ & $78.33 \%$ & $77.61 \%$ & $76.87 \%$ \\
\hline 76 & Huandoy & $73.70 \%$ & $78.26 \%$ & $76.62 \%$ & $76.19 \%$ \\
\hline 77 & Perú 1 & $70.68 \%$ & $75.06 \%$ & $73.48 \%$ & $73.07 \%$ \\
\hline 78 & Perú 2 & $80.49 \%$ & $85.48 \%$ & $83.68 \%$ & $83.21 \%$ \\
\hline 79 & Marina 17 & $65.03 \%$ & $69.06 \%$ & $67.60 \%$ & $67.23 \%$ \\
\hline 80 & Marina 32 & $74.32 \%$ & $78.92 \%$ & $77.26 \%$ & $76.83 \%$ \\
\hline 81 & Marina 26 & $57.39 \%$ & $57.33 \%$ & $59.66 \%$ & $58.13 \%$ \\
\hline 82 & Santa Anita 2 & $70.62 \%$ & $82.27 \%$ & $77.58 \%$ & $76.82 \%$ \\
\hline 83 & Santa Anita - Ficus & $76.67 \%$ & $81.42 \%$ & $79.71 \%$ & $79.27 \%$ \\
\hline 84 & Santa Anita - C.C. Aventura Plaza & $76.71 \%$ & $81.46 \%$ & $79.74 \%$ & $79.30 \%$ \\
\hline 85 & Santa Anita - Productores & $69.43 \%$ & $73.73 \%$ & $72.18 \%$ & $71.78 \%$ \\
\hline 86 & Chacarilla & $67.38 \%$ & $71.55 \%$ & $70.05 \%$ & $69.66 \%$ \\
\hline 87 & Viñedos -Tottus & $78.22 \%$ & $83.07 \%$ & $81.32 \%$ & $80.87 \%$ \\
\hline 88 & Villa El Salvador 1 & $75.92 \%$ & $80.62 \%$ & $78.92 \%$ & $78.49 \%$ \\
\hline 89 & Villa El Salvador 2 & $74.48 \%$ & $78.12 \%$ & $77.43 \%$ & $76.68 \%$ \\
\hline 90 & Villa El Salvador - C.C. Megaplaza & $83.04 \%$ & $88.18 \%$ & $86.33 \%$ & $85.85 \%$ \\
\hline 91 & Villa María Del Triunfo & $78.42 \%$ & $83.28 \%$ & $81.53 \%$ & $81.08 \%$ \\
\hline 92 & Villa Maria Del Triunfo 2 & $83.07 \%$ & $88.22 \%$ & $86.36 \%$ & $85.89 \%$ \\
\hline & Promedio & $73.64 \%$ & $78.27 \%$ & $76.60 \%$ & $76.12 \%$ \\
\hline
\end{tabular}


Anexo 4. Porcentaje de Ingreso de las Utilidades por Producto

Tabla 59

Porcentaje de ingreso de las utilidades por producto

\begin{tabular}{lc}
\hline Tipos Platos Norky's & $\begin{array}{c}\text { \% de Ingreso de las } \\
\text { Utilidades }\end{array}$ \\
\cline { 2 - 2 } Pollos a la Brasa & $66 \%$ \\
Pechugas a la Parrilla & $3 \%$ \\
Carnes a la Parrilla & $12 \%$ \\
Parrillas & $14 \%$ \\
Salteados & $4 \%$ \\
Ensaladas & $1 \%$ \\
\hline Total & $100 \%$ \\
\hline Nota. Tomado de Memorias financieras de Norky's.
\end{tabular}


Anexo 5. Cuestionario del Clima Laboral de Norky's

\begin{tabular}{|c|c|c|c|c|c|c|}
\hline \multirow{2}{*}{ FACTOR } & \multicolumn{5}{|c|}{ FRECUENCIA } & \multirow{2}{*}{ TOTAL } \\
\hline & NUNCA & ALGUNAS VECES & NORMALMENTE & MUCHAS VECES & SIEMPRE & \\
\hline \multicolumn{7}{|c|}{ COMUNICACIÓN } \\
\hline \multicolumn{7}{|l|}{$\begin{array}{l}\text { ¿La comunicación con tu jefe inmediato es } \\
\text { constante? }\end{array}$} \\
\hline \multicolumn{7}{|l|}{$\begin{array}{l}\text { ¿La comunicación de tu jefe inmediato es } \\
\text { correcta? }\end{array}$} \\
\hline \multicolumn{7}{|l|}{$\begin{array}{l}\text { ¿La comunicación con tus compañeros es } \\
\text { correcta? }\end{array}$} \\
\hline \multirow{2}{*}{\multicolumn{7}{|c|}{$\begin{array}{l}\text { ¿Recibe la información de la empresa a } \\
\text { través de sus canales: escrito, verbal y/o } \\
\text { virtual? }\end{array}$}} \\
\hline & & & & \multicolumn{3}{|c|}{ TRABAJO EN EQUIPO } \\
\hline \multicolumn{7}{|l|}{$\begin{array}{l}\text { ¿Existe trabajo en equipo con tus } \\
\text { compañeros? }\end{array}$} \\
\hline \multicolumn{7}{|l|}{$\begin{array}{l}\text { ¿Confias en los resultados del trabajo en } \\
\text { equipo? }\end{array}$} \\
\hline \multicolumn{7}{|l|}{$\begin{array}{l}\text { ¿Hay un seguimiento constante por parte de } \\
\text { tu jefe inmediato al encargar una tarea? }\end{array}$} \\
\hline \multirow{2}{*}{\multicolumn{7}{|c|}{$\begin{array}{l}\text { ¿La empresa promueve el trabajo en } \\
\text { equipo? }\end{array}$}} \\
\hline & & & & & & \\
\hline \multicolumn{7}{|l|}{$\begin{array}{l}\text { ¿Consideras que tu jefe inmediato es un } \\
\text { ejemplo a seguir? }\end{array}$} \\
\hline \multicolumn{7}{|l|}{$\begin{array}{l}\text { ¿Consideras que tu jefe inmediato propicia } \\
\text { un buen ambiente de trabajo? }\end{array}$} \\
\hline \multicolumn{7}{|l|}{$\begin{array}{l}\text { ¿Consideras que tu jefe inmediato se } \\
\text { preocupa por enseñarte a realizar } \\
\text { correctamente las tareas asignadas? }\end{array}$} \\
\hline \multicolumn{7}{|l|}{$\begin{array}{l}\text { ¿Tu jefe inmediato influye en realización } \\
\text { tareas cotidianas? }\end{array}$} \\
\hline \multirow{2}{*}{\multicolumn{7}{|c|}{ Te motiva trabajar con tus compañeros? }} \\
\hline \multirow{2}{*}{\multicolumn{7}{|c|}{$\begin{array}{l}\text { ¿Te motiva trabajar con tus compañeros? } \\
\text { La empresa reconoce tus logros? }\end{array}$}} \\
\hline & & & & & & \\
\hline \multicolumn{7}{|l|}{ Tu jefe inmediato reconoce tus logros? } \\
\hline \multicolumn{7}{|l|}{$\begin{array}{l}\text { ¿Te sientes motivado por hacer más de lo } \\
\text { que tu puesto te exige? }\end{array}$} \\
\hline \multicolumn{7}{|c|}{ IDENTIDAD } \\
\hline \multicolumn{7}{|l|}{ ¿Te sientes comprometido con la empresa? } \\
\hline \multicolumn{7}{|l|}{$\begin{array}{l}\text { ¿Te sientes comprometido con tus tareas } \\
\text { cotidianas? }\end{array}$} \\
\hline \multicolumn{7}{|l|}{$\begin{array}{l}\text { ¿Existe compromiso de tu jefe inmediato } \\
\text { con sus tareas? }\end{array}$} \\
\hline $\begin{array}{l}\text { ¿Existe un alto nivel de compromiso de tus } \\
\text { compañeros? }\end{array}$ & & & & & & \\
\hline
\end{tabular}


Anexo 6. Índice de Evaluación del Clima Laboral de Norky’s

\begin{tabular}{|c|c|c|c|c|c|c|c|}
\hline \multirow[b]{2}{*}{$\mathbf{N}^{\circ}$} & \multirow[b]{2}{*}{ Tienda } & \multicolumn{6}{|c|}{ Nivel de satisfacción de los colaboradores } \\
\hline & & Comunicación & $\begin{array}{c}\text { Trabajo en } \\
\text { Equipo }\end{array}$ & Liderazgo & Motivación & Identidad & $\begin{array}{c}\text { Clima labora } \\
\text { real }\end{array}$ \\
\hline 1 & Huaycán & $60.97 \%$ & $76.97 \%$ & $68.59 \%$ & $72.40 \%$ & $70.11 \%$ & $69.81 \%$ \\
\hline 2 & Vitarte 1 & $37.06 \%$ & $46.79 \%$ & $41.70 \%$ & $44.01 \%$ & $42.62 \%$ & $42.44 \%$ \\
\hline 3 & Vitarte 2 & $36.79 \%$ & $46.45 \%$ & $41.39 \%$ & $43.69 \%$ & $42.31 \%$ & $42.13 \%$ \\
\hline 4 & Salamanca & $66.24 \%$ & $83.63 \%$ & $74.52 \%$ & $78.66 \%$ & $76.18 \%$ & $75.84 \%$ \\
\hline 5 & Javier Prado & $70.72 \%$ & $89.29 \%$ & $79.56 \%$ & $83.98 \%$ & $81.33 \%$ & $80.98 \%$ \\
\hline 6 & Santa Clara - C.C. Real Plaza & $65.32 \%$ & $82.47 \%$ & $73.49 \%$ & $77.57 \%$ & $75.12 \%$ & $74.79 \%$ \\
\hline 7 & Santa Clara 2 & $62.13 \%$ & $78.44 \%$ & $69.90 \%$ & $73.78 \%$ & $71.45 \%$ & $71.14 \%$ \\
\hline 8 & C.C. La Rambla & $55.89 \%$ & $70.56 \%$ & $62.87 \%$ & $66.36 \%$ & $64.27 \%$ & $63.99 \%$ \\
\hline 9 & Venezuela & $61.29 \%$ & $77.38 \%$ & $68.95 \%$ & $72.78 \%$ & $70.49 \%$ & $70.18 \%$ \\
\hline 10 & Alfonso Ugarte & $58.32 \%$ & $73.63 \%$ & $65.61 \%$ & $69.26 \%$ & $67.07 \%$ & $66.78 \%$ \\
\hline 11 & Colmena & $75.26 \%$ & $95.01 \%$ & $84.67 \%$ & $89.37 \%$ & $86.55 \%$ & $86.17 \%$ \\
\hline 12 & Maruy 1 & $48.81 \%$ & $61.62 \%$ & $54.91 \%$ & $57.96 \%$ & $56.13 \%$ & $55.89 \%$ \\
\hline 13 & Principal & $68.55 \%$ & $86.54 \%$ & $77.12 \%$ & $81.40 \%$ & $78.83 \%$ & $78.49 \%$ \\
\hline 14 & Union 1 & $56.93 \%$ & $71.88 \%$ & $64.05 \%$ & $67.61 \%$ & $65.47 \%$ & $65.19 \%$ \\
\hline 15 & Abancay 2 & $73.14 \%$ & $92.34 \%$ & $82.28 \%$ & $86.85 \%$ & $84.11 \%$ & $83.75 \%$ \\
\hline 16 & Centro Civico - C.C. Real Plaza & $47.85 \%$ & $60.41 \%$ & $53.83 \%$ & $56.82 \%$ & $55.03 \%$ & $54.79 \%$ \\
\hline 17 & Plaza Castilla - Metro & $58.72 \%$ & $74.14 \%$ & $66.06 \%$ & $69.73 \%$ & $67.53 \%$ & $67.24 \%$ \\
\hline 18 & Puno & $63.96 \%$ & $80.75 \%$ & $71.96 \%$ & $75.96 \%$ & $73.56 \%$ & $73.24 \%$ \\
\hline 19 & Chorrillos & $77.18 \%$ & $97.44 \%$ & $86.82 \%$ & $91.65 \%$ & $88.75 \%$ & $88.37 \%$ \\
\hline 20 & Comas - Retablo & $72.50 \%$ & $91.53 \%$ & $81.56 \%$ & $86.09 \%$ & $83.38 \%$ & $83.01 \%$ \\
\hline 21 & Comas - Sta Luzmila & $73.54 \%$ & $92.84 \%$ & $82.73 \%$ & $87.32 \%$ & $84.57 \%$ & $84.20 \%$ \\
\hline 22 & Comas 2 & $56.63 \%$ & $71.49 \%$ & $63.71 \%$ & $67.25 \%$ & $65.12 \%$ & $64.84 \%$ \\
\hline 23 & Comas 5 - San Felipe & $51.82 \%$ & $65.42 \%$ & $58.30 \%$ & $61.53 \%$ & $59.59 \%$ & $59.33 \%$ \\
\hline 24 & Polvora 1 -Tottus & $65.37 \%$ & $82.52 \%$ & $73.54 \%$ & $77.62 \%$ & $75.17 \%$ & $74.84 \%$ \\
\hline 25 & Bravo Chico & $67.96 \%$ & $85.80 \%$ & $76.46 \%$ & $80.71 \%$ & $78.16 \%$ & $77.82 \%$ \\
\hline 26 & Polvora 2 - Tottus & $65.78 \%$ & $83.05 \%$ & $74.01 \%$ & $78.12 \%$ & $75.65 \%$ & $75.32 \%$ \\
\hline 27 & Agustino - C.C. Agustino Plaza - Rest./Patio & $72.62 \%$ & $91.68 \%$ & $81.69 \%$ & $86.23 \%$ & $83.51 \%$ & $83.15 \%$ \\
\hline 28 & Megaplaza 2 & $69.84 \%$ & $88.17 \%$ & $78.57 \%$ & $82.93 \%$ & $80.31 \%$ & $79.96 \%$ \\
\hline 29 & C.C. Plaza Lima Norte & $62.85 \%$ & $79.35 \%$ & $70.71 \%$ & $74.64 \%$ & $72.28 \%$ & $71.97 \%$ \\
\hline 30 & Independencia & $59.92 \%$ & $75.65 \%$ & $67.41 \%$ & $71.15 \%$ & $68.91 \%$ & $68.61 \%$ \\
\hline 31 & Salaverry & $59.92 \%$ & $75.65 \%$ & $67.41 \%$ & $71.15 \%$ & $68.91 \%$ & $68.61 \%$ \\
\hline
\end{tabular}




\begin{tabular}{|c|c|c|c|c|c|c|c|}
\hline \multirow[b]{2}{*}{$\mathrm{N}^{\circ}$} & \multirow[b]{2}{*}{ Tienda } & \multicolumn{6}{|c|}{ Nivel de satisfacción de los colaboradores } \\
\hline & & Comunicación & $\begin{array}{c}\text { Trabajo en } \\
\text { Equipo }\end{array}$ & Liderazgo & Motivación & Identidad & \begin{tabular}{|c|c|}
$\begin{array}{c}\text { Clima laboral } \\
\text { real }\end{array}$ \\
\end{tabular} \\
\hline 32 & Jesus Maria & $41.56 \%$ & $52.46 \%$ & $46.75 \%$ & $49.35 \%$ & $47.79 \%$ & $47.58 \%$ \\
\hline 33 & Garzon & $65.78 \%$ & $83.04 \%$ & $74.00 \%$ & $78.11 \%$ & $75.64 \%$ & $75.32 \%$ \\
\hline 34 & Molina & $63.32 \%$ & $79.94 \%$ & $71.24 \%$ & $75.19 \%$ & $72.82 \%$ & $\mathbf{7 2 . 5 0} \%$ \\
\hline 35 & Canepa 3 & $63.12 \%$ & $79.68 \%$ & $71.01 \%$ & $74.95 \%$ & $72.58 \%$ & $72.27 \%$ \\
\hline 36 & Parinacochas & $71.45 \%$ & $90.21 \%$ & $80.38 \%$ & $84.85 \%$ & $82.17 \%$ & $81.81 \%$ \\
\hline 37 & México 1 & $36.93 \%$ & $46.62 \%$ & $41.54 \%$ & $43.85 \%$ & $42.46 \%$ & $42.28 \%$ \\
\hline 38 & México 2 & $67.37 \%$ & $85.05 \%$ & $75.79 \%$ & $80.00 \%$ & $77.47 \%$ & $77.13 \%$ \\
\hline 39 & Canepa 1 - C.C. Parque. Canepa & $67.31 \%$ & $84.98 \%$ & $75.72 \%$ & $79.93 \%$ & $77.40 \%$ & $77.07 \%$ \\
\hline 40 & Canepa 2 - C.C. Parque. Canepa & $75.26 \%$ & $95.01 \%$ & $84.67 \%$ & $89.37 \%$ & $86.55 \%$ & $86.17 \%$ \\
\hline 41 & Lince 1 & $64.47 \%$ & $81.40 \%$ & $72.53 \%$ & $76.56 \%$ & $74.14 \%$ & $73.82 \%$ \\
\hline 42 & Lince 2 & $67.32 \%$ & $84.99 \%$ & $75.74 \%$ & $79.94 \%$ & $77.42 \%$ & $77.08 \%$ \\
\hline 43 & Olivos 2 & $67.36 \%$ & $85.04 \%$ & $75.78 \%$ & $79.99 \%$ & $77.46 \%$ & $77.12 \%$ \\
\hline 44 & Pro & $68.33 \%$ & $86.27 \%$ & $76.87 \%$ & $81.14 \%$ & $78.58 \%$ & $78.24 \%$ \\
\hline 45 & Chosica & $52.67 \%$ & $66.49 \%$ & $59.25 \%$ & $62.54 \%$ & $60.57 \%$ & $60.30 \%$ \\
\hline 46 & Lurin & $58.18 \%$ & $73.45 \%$ & $65.45 \%$ & $69.09 \%$ & $66.90 \%$ & $66.61 \%$ \\
\hline 47 & Playa & $47.19 \%$ & $59.58 \%$ & $53.09 \%$ & $56.04 \%$ & $54.27 \%$ & $54.03 \%$ \\
\hline 48 & Lurin 02 & $66.14 \%$ & $83.50 \%$ & $74.41 \%$ & $78.54 \%$ & $76.06 \%$ & $75.73 \%$ \\
\hline 49 & Magdalena & $66.82 \%$ & $84.36 \%$ & $75.17 \%$ & $79.35 \%$ & $76.84 \%$ & $76.51 \%$ \\
\hline 50 & Panamá & $68.20 \%$ & $86.10 \%$ & $76.73 \%$ & $80.99 \%$ & $78.43 \%$ & $78.09 \%$ \\
\hline 51 & Pardo & $75.12 \%$ & $94.84 \%$ & $84.51 \%$ & $89.21 \%$ & $86.39 \%$ & $86.01 \%$ \\
\hline 52 & Sucre & $59.36 \%$ & $74.94 \%$ & $66.78 \%$ & $70.49 \%$ & $68,27 \%$ & $67.97 \%$ \\
\hline 53 & Puente Piedra 1 & $62.19 \%$ & $78.52 \%$ & $69.96 \%$ & $73.85 \%$ & $71.52 \%$ & $71.21 \%$ \\
\hline 54 & Puente Piedra - Tottus & $55.19 \%$ & $69.67 \%$ & $62.09 \%$ & $65.53 \%$ & $67.47 \%$ & $63.99 \%$ \\
\hline 55 & Rímac & $68.79 \%$ & $86.85 \%$ & $77.39 \%$ & $81.69 \%$ & $79.11 \%$ & $78.76 \%$ \\
\hline 56 & Aviación 24 & $56.72 \%$ & $71.61 \%$ & $63.81 \%$ & $67.35 \%$ & $65.23 \%$ & $64.94 \%$ \\
\hline 57 & Aviación 29 & $62.63 \%$ & $79.08 \%$ & $70.46 \%$ & $74.38 \%$ & $74.03 \%$ & $72.12 \%$ \\
\hline 58 & Avi 1 & $57.38 \%$ & $72.44 \%$ & $64.55 \%$ & $68.14 \%$ & $65.99 \%$ & $65.70 \%$ \\
\hline 59 & Canto Grande 1 & $58.02 \%$ & $73.26 \%$ & $65.28 \%$ & $68.90 \%$ & $66.73 \%$ & $66.44 \%$ \\
\hline 60 & Canto Grande 2 & $42.94 \%$ & $54.21 \%$ & $48.31 \%$ & $50.99 \%$ & $53.38 \%$ & $49.97 \%$ \\
\hline 61 & Próceres 1 & $62.81 \%$ & $79.30 \%$ & $70.66 \%$ & $74.59 \%$ & $72.23 \%$ & $71.92 \%$ \\
\hline \multirow[t]{2}{*}{62} & Zarate 1 & $59.70 \%$ & $75.37 \%$ & $67.16 \%$ & $70.89 \%$ & $70.66 \%$ & $68.76 \%$ \\
\hline & & \multicolumn{6}{|c|}{ Nivel de satisfacción de los colaboradores } \\
\hline $\mathbf{N}^{0}$ & Tienda & Comunicación & $\begin{array}{c}\text { Trabajo en } \\
\text { Equipo }\end{array}$ & Liderazgo & Motivación & Identidad & \begin{tabular}{|c|c|}
$\begin{array}{c}\text { Clima laboral } \\
\text { real }\end{array}$ \\
\end{tabular} \\
\hline 63 & Zarate 2 & $74.17 \%$ & $93.64 \%$ & $83.44 \%$ & $88.08 \%$ & $85.30 \%$ & $84.92 \%$ \\
\hline 64 & Avi 2 & $47.32 \%$ & $59.74 \%$ & $53.24 \%$ & $56.19 \%$ & $54.42 \%$ & $54.18 \%$ \\
\hline 65 & Canto Grande-Metro & $63.82 \%$ & $80.57 \%$ & $71.80 \%$ & $75.79 \%$ & $73.39 \%$ & $73.07 \%$ \\
\hline 66 & Proceres 2 & $56.20 \%$ & $70.95 \%$ & $63.23 \%$ & $66.74 \%$ & $64.63 \%$ & $64.35 \%$ \\
\hline 67 & Campoy-Tottus & $51.24 \%$ & $64.69 \%$ & $57.65 \%$ & $60.85 \%$ & $58.93 \%$ & $\mathbf{5 8 . 6 7 \%}$ \\
\hline 68 & Las Flores & $36.00 \%$ & $45.45 \%$ & $40.50 \%$ & $42.75 \%$ & $41.40 \%$ & $41.22 \%$ \\
\hline 69 & Bolichera & $59.70 \%$ & $75.37 \%$ & $67.16 \%$ & $70.89 \%$ & $68.66 \%$ & $68.36 \%$ \\
\hline 70 & San Juan 1 & $61.53 \%$ & $77.68 \%$ & $69.22 \%$ & $73.07 \%$ & $70.76 \%$ & $70.45 \%$ \\
\hline 71 & San Juan 2 & $60.38 \%$ & $76.23 \%$ & $67.93 \%$ & $71.70 \%$ & $69.44 \%$ & $69.14 \%$ \\
\hline 72 & Atocongo - C.C. Open Plaza & $39.32 \%$ & $49.64 \%$ & $44.24 \%$ & $46.69 \%$ & $45.22 \%$ & $45.02 \%$ \\
\hline 73 & C.C. Mall Del Sur & $53.30 \%$ & $67.29 \%$ & $59.96 \%$ & $63.29 \%$ & $61.30 \%$ & $61.03 \%$ \\
\hline 74 & Canadá & $63.22 \%$ & $79.82 \%$ & $71.12 \%$ & $75.07 \%$ & $72.70 \%$ & $72.39 \%$ \\
\hline 75 & Habich & $61.56 \%$ & $77.72 \%$ & $69.26 \%$ & $73.10 \%$ & $72.70 \%$ & $70.87 \%$ \\
\hline 76 & Huandoy & $60.77 \%$ & $76.72 \%$ & $68.37 \%$ & $72.16 \%$ & $72.70 \%$ & $70.15 \%$ \\
\hline 77 & Perú 1 & $58.28 \%$ & $73.58 \%$ & $65.57 \%$ & $69.21 \%$ & $71.50 \%$ & $67.63 \%$ \\
\hline 78 & Perú 2 & $66.37 \%$ & $83.79 \%$ & $74.67 \%$ & $78.81 \%$ & $72.70 \%$ & $75.27 \%$ \\
\hline 79 & Marina 17 & $53.62 \%$ & $67.70 \%$ & $60.32 \%$ & $63.67 \%$ & $61.66 \%$ & $61.39 \%$ \\
\hline 80 & Marina 32 & $61.28 \%$ & $77.37 \%$ & $68.94 \%$ & $72.77 \%$ & $70.47 \%$ & $70.17 \%$ \\
\hline 81 & Marina 26 & $47.32 \%$ & $59.74 \%$ & $53.24 \%$ & $56.19 \%$ & $57.23 \%$ & $54.74 \%$ \\
\hline 82 & Santa Anita 2 & $61.53 \%$ & $77.68 \%$ & $69.22 \%$ & $73.07 \%$ & $70.76 \%$ & $70.45 \%$ \\
\hline 83 & Santa Anita-Ficus & $63.22 \%$ & $79.82 \%$ & $71.12 \%$ & $75.07 \%$ & $72.70 \%$ & $72.39 \%$ \\
\hline 84 & Santa Anita - C.C. Aventura Plaza & $63.25 \%$ & $79.85 \%$ & $71.16 \%$ & $75.11 \%$ & $71.65 \%$ & $72.20 \%$ \\
\hline 85 & Santa Anita - Productores & $57.25 \%$ & $72.28 \%$ & $64.41 \%$ & $67.98 \%$ & $65.84 \%$ & $65.55 \%$ \\
\hline 86 & Chacarilla & $55.56 \%$ & $70.14 \%$ & $62.51 \%$ & $65.98 \%$ & $68.65 \%$ & $64.57 \%$ \\
\hline 87 & Viñedos-Tottus & $64.50 \%$ & $81.43 \%$ & $72.56 \%$ & $76.59 \%$ & $74.18 \%$ & $73.85 \%$ \\
\hline 88 & Villa El Salvador 1 & $62.60 \%$ & $79.03 \%$ & $70.43 \%$ & $74.34 \%$ & $71.99 \%$ & $71.68 \%$ \\
\hline 89 & Villa El Salvador 2 & $61.42 \%$ & $77.54 \%$ & $69.09 \%$ & $72.93 \%$ & $70.63 \%$ & $70.32 \%$ \\
\hline 90 & Villa El Salvador - C.C. Megaplaza & $68.47 \%$ & $86.44 \%$ & $77.03 \%$ & $81.31 \%$ & $78.74 \%$ & $\mathbf{7 8 . 4 0 \%}$ \\
\hline 91 & Villa Maria Del Triunfo & $64.67 \%$ & $81.64 \%$ & $72.75 \%$ & $76.79 \%$ & $74.37 \%$ & $74.04 \%$ \\
\hline 92 & Villa María Del Triunfo 2 & $68.50 \%$ & $86.48 \%$ & $77.06 \%$ & $81.34 \%$ & $78.78 \%$ & $78.43 \%$ \\
\hline & Promedio & $60.76 \%$ & $76.71 \%$ & $68.35 \%$ & $72.15 \%$ & $70.13 \%$ & $69.62 \%$ \\
\hline
\end{tabular}


Anexo 7. Entrevistas en Profundidad a los Gerentes de Norky's

\begin{tabular}{|l|l|}
\hline Puesto & Nombre \\
\hline Gerente General de 29 tiendas de Norky's & Carlos Tamashiro \\
\hline Gerente de Operaciones de MACROSCEM S.A.C & Jorge Kina \\
\hline Gerente de Marketing de MACROSCEM S.A.C & Victoria Zea \\
\hline Jefe de Sistemas de MACROSCEM S.A.C & José Ramos \\
\hline Gerente de Auditoría y Control de MACROSCEM S.A.C & Samuel Casana \\
\hline
\end{tabular}

Fecha: $14 / 10 / 2017$

Hora: 11:00

Lugar: Lima, Perú

Entrevistadores: Carmen Zambrano, Elizabeth Ganoza, José Olivera y Nestor Chirinos

\section{Entrevistado:}

- Nombre: Carlos Tamashiro

- Edad: 41 años

- Género: Masculino

- Puesto: Gerente General de 29 tiendas de Norky's

\section{Objetivo:}

El propósito de esta entrevista es validar y conocer más detalles del panorama de la empresa y la gestión de recursos humanos para la elaboración del plan estratégico.

\section{Consentimiento informado:}

El señor Carlos Tamashiro ha autorizado que la información proporcionada en la entrevista sea utilizada para fines de investigación del plan estratégico.

\section{Características de la entrevista:}

La entrevista tuvo una duración de una hora. 


\section{Preguntas:}

- ¿La empresa cuenta con un plan estratégico?

Actualmente no, ya que estamos en proceso de estructuración y formalización.

Llevamos 41 años en el mercado y nunca hemos tenido un plan estratégico. En el año 2012 recién se tomó la decisión de cambiar las cosas, se pensó en profesionalizar el staff y las jefaturas, cambiar las políticas, tener un horizonte de objetivos en la empresa, si bien no lo hemos logrado en los últimos cinco años, estamos en camino a ello.

- ¿Cómo se visualiza la empresa en un futuro?

Como una empresa institucionalizada en sus procedimientos y con una estructuración y formalización acorde a su nivel de desarrollo en elmercado.

- ¿En qué consiste la institucionalización?

La institucionalización consiste en automatizar los procesos manuales que se llevan a cabo en las áreas, estandarizar los procesos operativos que se ejecutan en las tiendas, homologar los datos de los sistemas que utilizan las áreas y, finalmente, implementar un plan estratégico y los manuales de funciones del personal. Desde hace algunos años, venimos trabajando en ello, aún no hemos logrado terminar, pero creo que estamos al 70\% aproximadamente.

- ¿Cómo piensa alcanzar esa visión?

Mediante un proceso de cambio de una empresa familiar a una empresa organizacional. Actualmente, el gerente general sigue siendo parte de la familia, sin embargo, poco a poco la empresa se ha ido profesionalizando, ya que diferentes gerencias como Operaciones, Auditoría y Control, Logística y Marketing han sido asumidas por personal externo. 
- ¿Cuáles son los principales valores de la empresa?

Servicio, honestidad, responsabilidad, respeto y trabajo en equipo.

- ¿Cuáles son las oportunidades y amenazas que usted ha podido visualizar para la empresa?

El posible ingreso de nuevos competidos, no necesariamente una nueva marca, sino la inversión de grandes compañías, las cuales como estrategia de diversificación están comprando cadenas del sector de restaurantes, por ejemplo, Intercorp deseaba comprar Pardos, Roky's y Norky's, pero debido a la negativa de venta, crearon su propia cadena de pollerías Don Belisario. El crecimiento de estas compañías inversoras ha sido exponencial, pero podemos ver reflejada su inexperiencia en el mercado en el cierre de sus locales ubicados en diferentes distritos de Lima. En el mercado peruano siempre existirán empresas que deseen invertir en la compra de una cadena de restaurantes, ya que han comprado franquicias y les ha funcionado. Por ejemplo, Intercorp compró Papa John, China Wok, Dunkin Donuts, Inkafarma, Promart, Popeyes y Bembos, es decir que tienen poder de inversión.

- ¿Cuáles son las fortalezas y debilidades de laempresa?

Nuestras principales fortalezas son la alta cobertura de tiendas que poseemos en Lima, la recordación de nuestra marca, el poder de negociación con los proveedores, la diversidad de productos que ofrecemos en la carta, junto a insumos de calidad y la buena atención que ofrecemos. Las debilidades que tenemos son la falta de automatización de los procesos y la alta rotación del personal joven.

- ¿Cuál es el orden de importancia de las variables descritas?

Estoy de acuerdo con la importancia de las oportunidades y amenazas descritas. 
- ¿Cuáles son los competidores actuales de la empresa?

El principal competidor con el mismo enfoque de público objetivo es Roky’s.

- ¿A qué tipo de clientes se enfoca la empresa?

A familias que buscan consumir un producto a un precio asequible y de calidad.

- ¿Cuáles son los sustitutos del producto principal?

En la actualidad no hay productos sustitutos al pollo a la brasa como tal, sin embargo, lo que hemos podido observar en los patios de comidas es que KFC es una de las cadenas de comida rápida que ofrece un producto sustituto, ya que su insumo principal es el pollo.

- ¿Quiénes son los principales proveedores?

Nuestros principales proveedores de insumos son San Fernando, Avinca y Redondos.

- ¿Cuáles son las principales barreras de entrada y salida al negocio?

Una de las principales barreras de entrada es la dificultad para adquirir terrenos o locales en alquiler para la implementación de restaurantes. Actualmente contamos con una persona encargada de investigar la oferta de locales estratégicos para nuestra ubicación, a su vez, tenemos la inversión inicial a realizar para la implementación de una tienda (activos tangibles e intangibles). Por otro lado, tenemos el conocimiento del sector, Norky's cuenta con una trayectoria en experiencia, lo que nos permite hacer frente a los competidores.

- ¿Cuáles son las actividades de soporte de la empresa (infraestructura, recursos humanos, tecnología y abastecimiento)?

En cuanto a la infraestructura, el área de apoyo principal es Servicios Generales quien coordina con un ingeniero para la implementación de tiendas. Además, una vez que está construido el local, Servicios Generales se encarga de gestionar las licencias y permisos, 
Recursos Humanos ve el tema de personal y seguridad, y Sistemas ve el cableado y equipos. El Gerente de Operaciones se encarga de hacer seguimiento a la implementación de las tiendas.

Respecto a los recursos humanos, los canales para la selección de personal son avisos en el periódico, radio, avisos en tienda, bolsas de trabajo, página web y referidos. Una vez que el personal ingresa pasa por una inducción en tienda, donde se le muestra las instalaciones, se le da la bienvenida y se le hace un resumen de sus funciones. Luego, pasa por una escuela, dependiendo del puesto. Existen incentivos que reciben los empleados por productividad, tales como bonificaciones por llegar a metas establecidas. Por ley, todos los colaboradores pasan por un periodo de prueba.

En cuanto a la tecnología, recién está empezando a implementarse en el área de Recursos Humanos y en las tiendas hay una mejora de procesos en cuanto a revisión, pero es a nivel de área, no está engranado para que todo tenga un fin u objetivo. Por otro lado, los equipos que se utilizan en MACROSCEM S.A.C. son manejados a través de leasing, pero los equipos de las tiendas son propios.

Respecto al abastecimiento, el área de Operaciones es quien se encarga de ello, ya existe un cronograma de abastecimiento, todos los proveedores envían los productos directamente a las tiendas.

- ¿Cuáles son las actividades primarias de la empresa (logística interna, operaciones, logística externa, marketing y ventas, y servicios)?

Respecto a la logística interna, hay un espacio físico en cada una de las tiendas para almacenar los insumos, también hay cámaras de frío para la materia prima que necesita estar bajo refrigeración. El administrador es quien recibe la materia prima y verifica si cumple o no con lo requerido. El control del almacén también es llevado a cabo por el administrador al 
finalizar el día. El servicio de inventario lo brinda MACROSCEM S.A.C. una o dos veces al mes a las tiendas de Norky's.

Para la operación, hay un proceso de inducción donde se da a conocer el procedimiento para la preparación de los pollos a la brasa. El administrador hace seguimiento para que se cumpla con la limpieza y el mantenimiento de los equipos.

En cuanto a la logística externa, dentro del protocolo de pedidos para los comensales existe una segunda visita luego de la entrega del plato, esta se realiza con la finalidad de asegurarnos de que el cliente se encuentre satisfecho con su pedido.

La promoción y publicidad es gestionada por el área de marketing, se maneja la publicidad externa por medio de banners y vallas, también por medio de diferentes convenios con empresas como Diners, Ripley y Saga Falabella. La publicidad interna se maneja en las tiendas, a través de trípticos, individuales y afiches promocionales.

Durante el cierre de la venta tengo entendido que en algunas ocasiones se les solicita la información a los comensales, como su correo electrónico, entre otros. Se utilizan también los correos masivos, donde un tercero se encarga de enviar correos con información promocional, el tercero cobrará un fee dependiendo del segmento enfoque.

Actualmente, no existe una política que tenga como objetivo la fidelización de los clientes, solo existen las cortesías, donde se ofrece una porción de torta al comensal por su cumpleaños.

- ¿Cuáles son los objetivos estratégicos de la empresa?

Principalmente la organización y planificación de todas las actividades para obtener la profesionalización e institucionalización que fue mencionada anteriormente. El objetivo actual ya no es tener el crecimiento que tuvimos hace unos años. 
- ¿Cuáles son las ventajas competitivas de la empresa?

La principal ventaja competitiva es la razón por la que nos buscan nuestros clientes, un producto a un precio asequible, con insumos de calidad y un buen servicio al cliente.

- ¿Cómo se diferenciaría de la competencia en un futuro?

Excelencia en el servicio, como producto de nuestra mejora de procesos e institucionalización de políticas.

- ¿Qué rol tiene el área de Recursos Humanos para la empresa?

El área de Recursos Humanos es lo más importante de la empresa. Si no hay un personal capacitado no se puede vender adecuadamente. Actualmente, tenemos escuelas de formación para Administradores, Cajeros, Jefes de Mozo, Mozos y Producción, y estamos pensando en implementar una escuela para Barman.

- ¿Se dispone de políticas y procedimientos generales para la gestión del personal?

Las políticas y los procedimientos se están armando, estamos buscando tener orden y automatizar los procesos.

- ¿Se mide periódicamente el clima laboral de la empresa?

El clima laboral ha empezado hace año y medio, teniendo como punto de partida Lima. Recientemente, se ha implementado en provincia, de tal forma que podamos tener un impacto a nivel nacional.

- ¿Qué limitaciones tiene el área?

La deficiencia que estamos sufriendo es la alta rotación del personal, sobretodo personal joven que representa la gran masa de nuestros colaboradores. A nivel de procesos, la automatización es una de nuestras problemáticas. 
Fecha: 20/10/2017

Hora: 02:00 p.m.

Lugar: Lima, Perú

Entrevistadores: Carmen Zambrano, Elizabeth Ganoza, José Olivera y Nestor Chirinos

\section{Entrevistado:}

- Nombre: Jorge Kina

- Edad: 43 años

- Género: Masculino

- Puesto: Gerente de Operaciones de MACROSCEM S.A.C

\section{Objetivo:}

El propósito de esta entrevista es validar y conocer más detalles de la situación operativa de la empresa y tener alcances de su competencia.

\section{Consentimiento informado:}

El señor Jorge Kina ha autorizado que la información proporcionada en la entrevista sea utilizada para fines de investigación del plan estratégico.

\section{Características de la entrevista:}

La entrevista tuvo una duración de media hora. 


\section{Preguntas:}

- ¿Qué rol tiene el área de operaciones para la empresa?

La operación es vital para la empresa, ya que de ella dependen las ventas y la generación de ingresos. La operación es la que manda, en ese sentido, las demás áreas deben trabajar para adecuarse a la operatividad y poder seguir generando margen.

- ¿En qué consiste la operación para la empresa?

Una vez implementada una tienda, el paso a seguir es la compra de insumos, donde es importante la negociación con los proveedores; en ese sentido, poseemos gran poder de negociación, ya que manejamos grandes volúmenes de compra. Seguidamente, toda compra está basada en cronogramas con los proveedores, quienes dejan los productos en las tiendas, siendo recepcionados por los administradores, quienes son la máxima autoridad en una tienda. La mayoría de las compras son a crédito y el pago se hace entre 15 y 30 días, dependiendo del insumo.

Cuando los insumos ya están en tienda, comienza el proceso de producción, donde participa el personal de producción, bajo la supervisión de los administradores. Todo el proceso está enmarcado o regulado por los check lists, que son una serie de puntos que se deben cumplir para el adecuado cumplimiento de los procedimientos de producción, de estos se derivan nuestros indicadores de control.

Finalmente, ya listo el producto se despacha, a través del personal de salón, quienes tienen trato directo con los clientes. Su labor es importante, ya que de ellos depende una buena percepción de los clientes en cuanto a la atención. En general, es indispensable tener un buen servicio y mejorarlo día a día. 
- ¿Cuáles son las fortalezas y debilidades de la operación?

Dentro de las fortalezas te puedo mencionar la calidad de la preparación y presentación del pollo a la brasa, la atención hacia los clientes y la negociación de precios con los proveedores. Por otro lado, dentro de las debilidades tenemos la falta de estandarización de los procesos, ya que, si bien los procesos se explicaron durante la capacitación, hay tiendas que no siguen al pie de la letra lo indicado; y la alta rotación del personal que perjudica la fluida operatividad de la tienda.

- ¿Cuáles son los objetivos del área?

Nuestro objetivo siempre se basa en incrementar las ventas, por ello tratamos de ofrecer promociones atractivas para los clientes, así como nuevos productos.

- ¿Cuál es su opinión sobre la industria del pollo a la brasa?

La industria está marcada por una alta competencia, hace diez años el crecimiento se dio vertiginosamente, pero ahora es difícil, ya que el mercado, sobre todo limeño, se ha venido saturando, haciendo que el negocio crezca, pero a un ritmo lento.

- ¿Cuál es el principal competidor de Norky’s y qué opinión le merece?

El principal competidor de Norky's, desde hace varios años, es Roky's, que es una empresa muy similar a la nuestra tanto en cobertura, calidad del producto, recordación de marca, entre otros. Pero nosotros resaltamos, básicamente, por tener mayor participación en el mercado ante el alto volumen de ventas. Sin embargo, por la referencia que tengo, Roky's tiene sus procesos más automatizados, ya que existe una cultura de mayor presión laboral. 
- ¿Respecto a los procesos operativos que se llevan a cabo en las tiendas, en qué nivel cree usted que se encuentran estandarizados?

Hace tres años empezamos el trabajo de estandarización de los procesos operativos a nivel de toda la cadena, basándonos en la información que nos arrojan los check list mensualmente y hasta el momento hemos logrado un $85 \%$ de control. 
Fecha: 20/10/2017

Hora: 06:30 p.m.

Lugar: Lima, Perú

Entrevistadores: Carmen Zambrano, Elizabeth Ganoza, José Olivera y Nestor Chirinos

\section{Entrevistado:}

- Nombre: Victoria Zea

- Edad: 31 años

- Género: Femenino

- Puesto: Gerente de Marketing de MACROSCEM S.A.C

\section{Objetivo:}

El propósito de la entrevista es conocer las actividades principales del área de marketing en la empresa.

\section{Consentimiento informado:}

La señora Victoria Zea ha autorizado que la información proporcionada en la entrevista sea utilizada para fines de investigación del plan estratégico.

\section{Características de la entrevista:}

La entrevista tuvo una duración de media hora.

\section{Preguntas:}

- ¿El área de marketing cuenta con un plan de trabajo?

Si, el área cuenta con un plan de trabajo anual para realizar las campañas publicitarias, así como el presupuesto y recursos necesarios para llevarlos a cabo. 
- ¿Cuál es el segmento de mercado al que se dirige Norky’s?

Norky's tiene como segmento de mercado los niveles socioeconómicos C y D.

- ¿Cuáles son las últimas novedades que ha introducido la empresa en cuanto a marketing?

Debido a que se ha popularizado el uso del Facebook en nuestro país, hace algunos años hemos incursionado en esta red social, a través de concursos y promociones. Sin embargo, creo que podríamos explotar mucho más esta herramienta incrementando la interacción con los clientes. Por otro lado, en fechas donde las ventas bajan, hacemos convenios con farmacias y tarjetas Visa, de ese modo tratamos de estar presentes durante todo el año en cuanto a ingresos y recordación de la marca, esto nos ha traído buenos resultados.

- ¿Cuál es la necesidad más urgente del área en estos momentos?

En estos momentos se requiere un estudio de mercado personalizado para la empresa, que nos permita conocer mejor a los clientes y sus necesidades, y nos ayude a ver cómo nos encontramos frente a la competencia. En la actualidad, la única herramienta que tenemos para evaluar la satisfacción del cliente es el cliente incógnito, que consiste en que una persona ajena a la empresa evalúe e informe sobre los puntos que comprende el protocolo de atención al cliente, tales como: saludo de bienvenida, ubicación del cliente, montaje de mesa, colocación de la carta, toma de pedido y verificación del mismo, digitación de los productos o comandas, visita de chequeo, la cuenta, despedida y tiempo sugerido para la entrega del pedido. Sin embargo, esta información se basa solo en una visita a las tiendas y lo que necesitamos hacer es implementar encuestas de satisfacción a los clientes, inicialmente de manera semestral y posteriormente con una frecuencia trimestral, con el fin de tener una muestra representativa que se ajuste más a la realidad. 
Fecha: 21/10/2017

Hora: 11:00 a.m.

Lugar: Lima, Perú

Entrevistadores: Carmen Zambrano, Elizabeth Ganoza, José Olivera y Nestor Chirinos

\section{Entrevistado:}

- Nombre: José Ramos

- Edad: 47 años

- Género: Masculino

- Puesto: Jefe de Sistemas de MACROSCEM S.A.C

\section{Objetivo:}

El propósito de esta entrevista es validar y conocer más detalles del área de sistemas de la empresa.

\section{Consentimiento informado:}

El señor José Ramos ha autorizado que la información proporcionada en la entrevista sea utilizada para fines de investigación del plan estratégico.

\section{Características de la entrevista:}

La entrevista tuvo una duración de media hora. 


\section{Preguntas:}

- ¿Cuál es el objetivo principal del área de sistemas?

El objetivo principal es dar soporte tecnológico a todas las áreas de la empresa, automatizar sus procesos manuales, básicamente reducir el tiempo que utilizan para llevar a cabo sus tareas.

- ¿En qué nivel se encuentra la automatización de los procesos manuales?

En el 2015 se empezó el proceso de automatización de los procesos manuales, a través de los principales programas INFOREST, Control de Atenciones y Adryan, y actualmente se podría decir que estamos al $60 \%$.

- ¿En qué consisten estos programas?

INFOREST es un software modular de planificación, gestión, evaluación y control de ventas; Control de Atenciones es un software modular de planificación, gestión, evaluación y control de programas desarrollados para las distintas áreas de la empresa, así como la atención y solución de problemas con el software y hardware; y Adryan es un software modular de asistencia y planilla. Es importante mencionar que estos sistemas se manejan independientemente y los datos no están homologados, por ello uno de nuestros objetivos es lograr que insumos, productos, tiendas, entre otros, tengan una codificación única en todos los programas. En el 2015 empezamos con el proceso de homologación y actualmente se podría decir que estamos al $90 \%$. 
Fecha: 17/11/2017

Hora: 06:30 p.m.

Lugar: Lima, Perú

Entrevistadores: Carmen Zambrano, Elizabeth Ganoza, José Olivera y Nestor Chirinos

\section{Entrevistado:}

- Nombre: Samuel Casana

- Edad: 47 años

- Género: Masculino

- Puesto: Gerente de Auditoría y Control de MACROSCEMS.A.C

\section{Objetivo:}

El propósito de esta entrevista es validar y conocer más detalles de los estados financieros y la situación económica de la empresa.

\section{Consentimiento informado:}

El señor Samuel Casana ha autorizado que la información proporcionada en la entrevista sea utilizada para fines de investigación del plan estratégico.

\section{Características de la entrevista:}

La entrevista tuvo una duración de una hora. 


\section{Preguntas:}

- En base a los estados financieros proporcionados: ¿Cómo está compuesta la inversión y el financiamiento de la empresa?

La inversión de la empresa está compuesta en mayor proporción por los activos corrientes con los que cuenta, que se traducen en el efectivo que circula, la mercadería y los inventarios. No se tiene movimiento en las cuentas por cobrar debido a que las ventas son principalmente en efectivo. Los activos no corrientes también tienen una parte de la inversión en los inmuebles, maquinarias y equipos, y activos diferidos. Por otro lado, el financiamiento de la empresa está compuesto principalmente por el patrimonio y en menor medida por el pasivo corriente como los tributos, remuneraciones y cuentas por pagar, además, del pasivo no corriente que son cuentas por pagar diversas.

- ¿Cuál es el porcentaje de crecimiento anual de las ventas?

Las ventas de la empresa han entrado en una etapa de madurez, ya que hace unos cinco años se abrían muchas tiendas por año y las ventas anuales crecían año a año en un aproximado de $8 \%$, pero ahora solo llegan a un aproximado anual de $3 \%$ a $4 \%$ por año, y ya no se están abriendo más tiendas.

- ¿A qué se debe que la liquidez de la empresa sea tan alta al final del periodo?

Los ratios de liquidez de la empresa son altos debido a que están compuestos por los ingresos que ha tenido la empresa en el corto plazo y al vender un producto de consumo masivo, la cobranza es en efectivo o tarjetas, no hay ventas al crédito. Esto permite a la empresa solventar las obligaciones corrientes sin problemas. 
- ¿Considera que la empresa tiene capacidad para realizar nuevas inversiones si se dieran las condiciones de crecimiento del mercado?

La empresa tiene la capacidad de realizar inversiones sin depender de financiamiento externo, pero por ahora la alta dirección ha decidido esperar y no realizar la apertura de más tiendas, ya que está enfocándose en explotar la capacidad instalada al máximo.

- De la información del Estado de Ganancias y Pérdidas: ¿Qué representan los gastos de administración y ventas?

Los gastos de administración incluyen los sueldos de los administradores, gerentes y personal de servicio de las tiendas. Los gastos de ventas representan los servicios de outsourcing como marketing, contabilidad, legal, reclutamiento y demás, de esa forma la empresa solo se preocupa en realizar las operaciones netamente del negocio.

- ¿Cuál es el nivel de endeudamiento de la empresa?

En la empresa, la participación de los acreedores (total pasivo) es de un $24 \%$ aproximadamente y el patrimonio es de un $76 \%$ con relación al activo total de la empresa, lo cual indica que no es un escenario de riesgo. Respecto a la razón deuda patrimonio, esta tiene un $31 \%$ del patrimonio comprometido en los acreedores.

- ¿Cuál es la forma de pago a los proveedores?

La mayoría de las compras son a crédito y el pago se hace entre 15 y 30 días, dependiendo del insumo. 
Anexo 8. Materiales de Marketing de Norky's

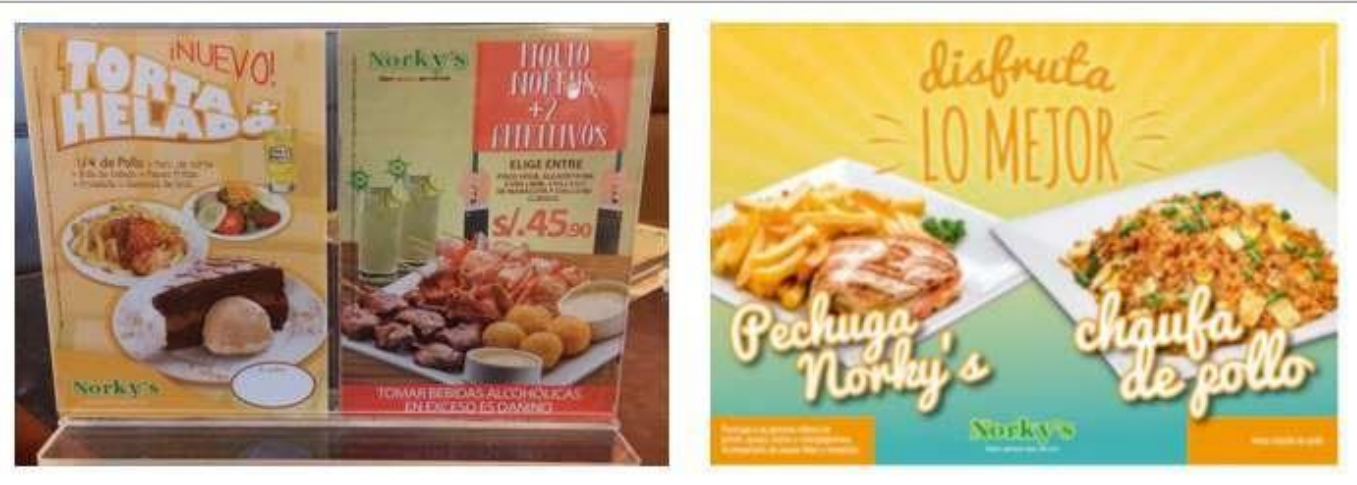

Figura 21. Acrílicos de mesa e Individuales de Norky's.

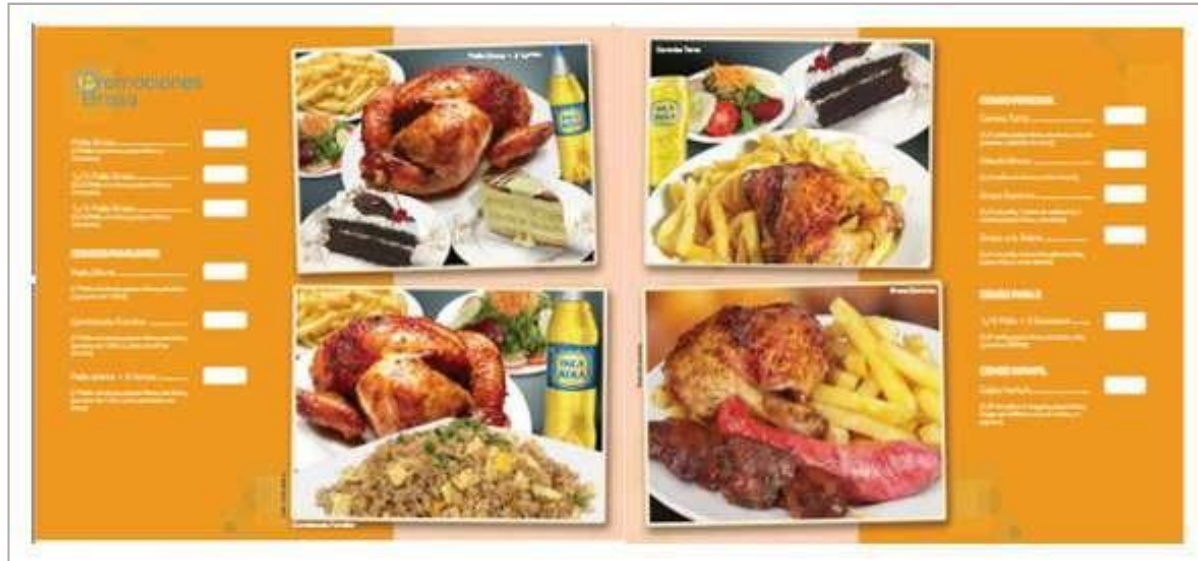

Figura 22. Carta de Menú de Norky’s.

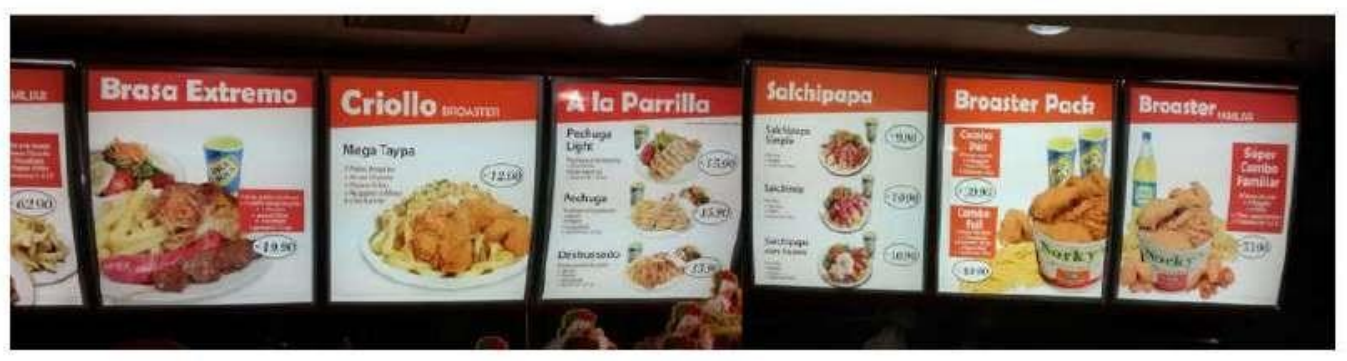

Figura 23. Backlights de Norky's en un patio de comidas. 


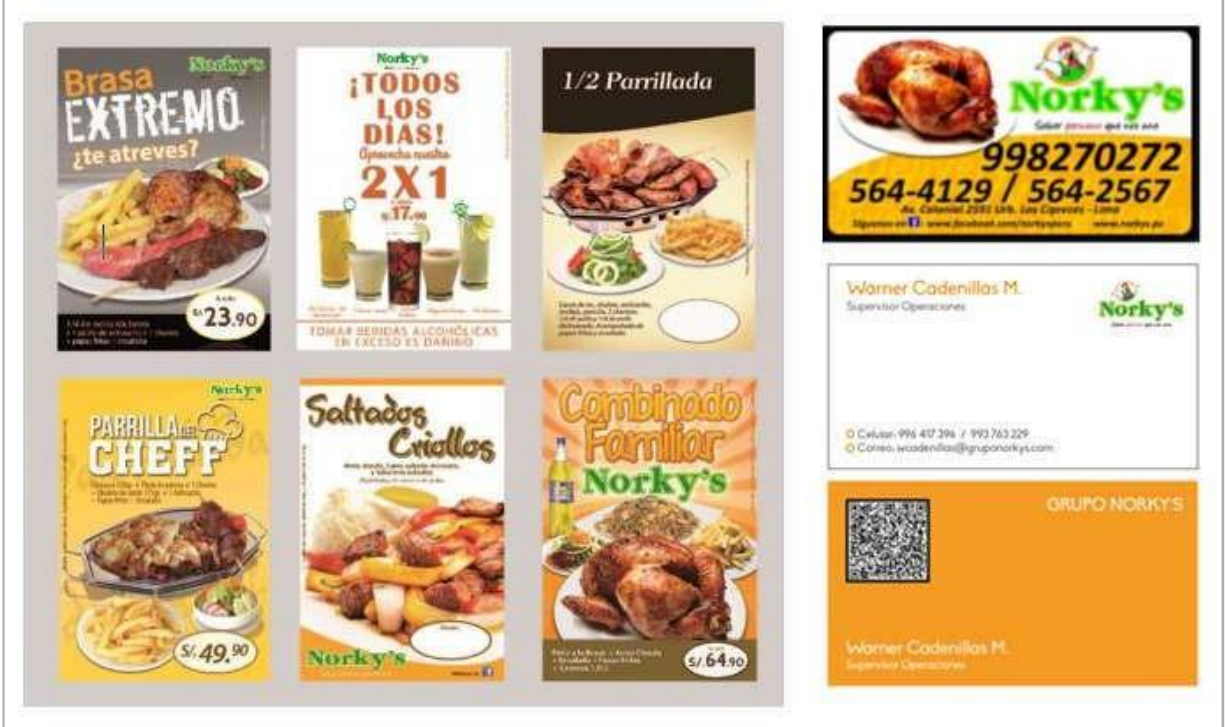

Figura 24. Afiches de pared o ventana, imantados y tarjetas de presentación de Norky's.

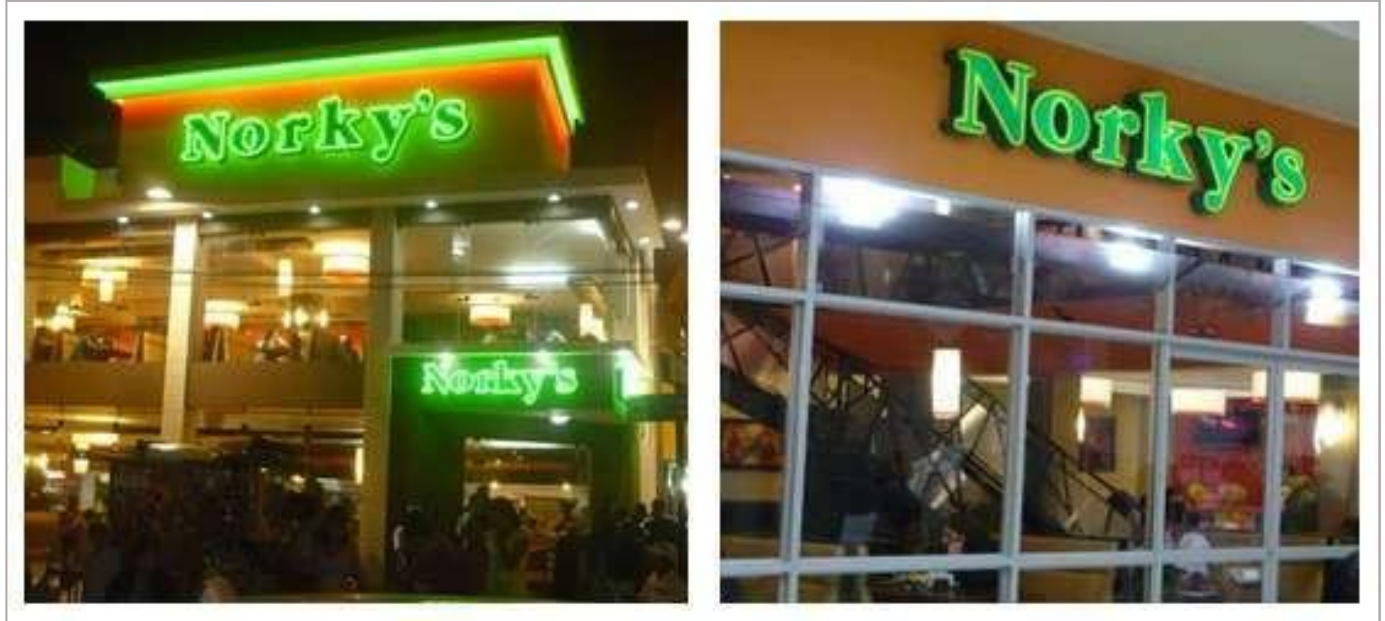

Figura 25. Letreros externos e internos de Norky's. 
Anexo 9. Línea Base de los Objetivos Estratégicos de Norky’s (Promedio de Septiembre 2016 - Octubre 2017)

\begin{tabular}{|c|c|c|c|c|c|c|c|}
\hline \multirow[b]{2}{*}{$\mathbf{N}^{\circ}$} & \multirow[b]{2}{*}{ Tienda } & \multicolumn{3}{|c|}{ Nivel de satisfacción de los colaboradores } & \multicolumn{3}{|c|}{ Nivel de satisfacción de los clientes } \\
\hline & & $\begin{array}{c}\text { Clima laboral } \\
\text { real }\end{array}$ & $\begin{array}{c}\text { Clima laboral } \\
\text { ideal }\end{array}$ & Diferencia & $\begin{array}{c}\text { Cliente } \\
\text { incógnito real }\end{array}$ & $\begin{array}{c}\text { Cliente } \\
\text { incógnito } \\
\text { ideal }\end{array}$ & Diferencia \\
\hline 1 & Huaycán & $69.81 \%$ & $85.00 \%$ & $-15.19 \%$ & $76.44 \%$ & $85.00 \%$ & $-8.56 \%$ \\
\hline 2 & Vitarte 1 & $42.44 \%$ & $85.00 \%$ & $-42.56 \%$ & $46.47 \%$ & $85.00 \%$ & $-38.53 \%$ \\
\hline 3 & Vitarte 2 & $42.13 \%$ & $85.00 \%$ & $-42.87 \%$ & $46.13 \%$ & $85.00 \%$ & $-38.87 \%$ \\
\hline 4 & Salamanca & $75.84 \%$ & $85.00 \%$ & $-9.16 \%$ & $83.05 \%$ & $85.00 \%$ & $-1.95 \%$ \\
\hline 5 & Javier Prado & $80.98 \%$ & $85.00 \%$ & $-4.02 \%$ & $88.67 \%$ & $85.00 \%$ & $3.67 \%$ \\
\hline 6 & Santa Clara - C.C. Real Plaza & $74.79 \%$ & $85.00 \%$ & $-10.21 \%$ & $81.90 \%$ & $85.00 \%$ & $-3.10 \%$ \\
\hline 7 & Santa Clara 2 & $71.14 \%$ & $85.00 \%$ & $-13.86 \%$ & $77.90 \%$ & $85.00 \%$ & $-7.10 \%$ \\
\hline 8 & C.C. La Rambla & $63.99 \%$ & $85.00 \%$ & $-21.01 \%$ & $70.07 \%$ & $85.00 \%$ & $-14.93 \%$ \\
\hline 9 & Venezuela & $70.18 \%$ & $85.00 \%$ & $-14.82 \%$ & $76.85 \%$ & $85.00 \%$ & $-8.15 \%$ \\
\hline 10 & Alfonso Ugarte & $66.78 \%$ & $85.00 \%$ & $-18.22 \%$ & $73.12 \%$ & $85.00 \%$ & $-11.88 \%$ \\
\hline 11 & Colmena & $86.17 \%$ & $85.00 \%$ & $1.17 \%$ & $94.36 \%$ & $85.00 \%$ & $9.36 \%$ \\
\hline 12 & Maruy 1 & $55.89 \%$ & $85.00 \%$ & $-29.11 \%$ & $61.20 \%$ & $85.00 \%$ & $-23.80 \%$ \\
\hline 13 & Principal & $78.49 \%$ & $85.00 \%$ & $-6.51 \%$ & $85.95 \%$ & $85.00 \%$ & $0.95 \%$ \\
\hline 14 & Union 1 & $65.19 \%$ & $85.00 \%$ & $-19.81 \%$ & $71.38 \%$ & $85.00 \%$ & $-13.62 \%$ \\
\hline 15 & Abancay 2 & $83.75 \%$ & $85.00 \%$ & $-1.25 \%$ & $91.70 \%$ & $85.00 \%$ & $6.70 \%$ \\
\hline 16 & Centro Civico - C.C. Real Plaza & $54.79 \%$ & $85.00 \%$ & $-30.21 \%$ & $60.00 \%$ & $85.00 \%$ & $-25.00 \%$ \\
\hline 17 & Plaza Castilla - Metro & $67.24 \%$ & $85.00 \%$ & $-17.76 \%$ & $73.63 \%$ & $85.00 \%$ & $-11.37 \%$ \\
\hline 18 & Puno & $73.24 \%$ & $85.00 \%$ & $-11.76 \%$ & $80.20 \%$ & $85.00 \%$ & $-4.80 \%$ \\
\hline 19 & Chorrillos & $88.37 \%$ & $85.00 \%$ & $3.37 \%$ & $96.76 \%$ & $85.00 \%$ & $11.76 \%$ \\
\hline 20 & Comas - Retablo & $83.01 \%$ & $85.00 \%$ & $-1.99 \%$ & $90.90 \%$ & $85.00 \%$ & $5.90 \%$ \\
\hline 21 & Comas - Sta Luzmila & $84.20 \%$ & $85.00 \%$ & $-0.80 \%$ & $92.20 \%$ & $85.00 \%$ & $7.20 \%$ \\
\hline 22 & Comas 2 & $64.84 \%$ & $85.00 \%$ & $-20.16 \%$ & $71.00 \%$ & $85.00 \%$ & $-14.00 \%$ \\
\hline 23 & Comas 5 - San Felipe & $59.33 \%$ & $85.00 \%$ & $-25.67 \%$ & $64.97 \%$ & $85.00 \%$ & $-20.03 \%$ \\
\hline 24 & Polvora 1 -Tottus & $74.84 \%$ & $85.00 \%$ & $-10.16 \%$ & $81.95 \%$ & $85.00 \%$ & $-3.05 \%$ \\
\hline 25 & Bravo Chico & $77.82 \%$ & $85.00 \%$ & $-7.18 \%$ & $85.21 \%$ & $85.00 \%$ & $0.21 \%$ \\
\hline 26 & Polvora 2 - Tottus & $75.32 \%$ & $85.00 \%$ & $-9.68 \%$ & $82.48 \%$ & $85.00 \%$ & $-2.52 \%$ \\
\hline 27 & Agustino - C.C. Agustino Plaza - Rest./Patio & $83.15 \%$ & $85.00 \%$ & $-1.85 \%$ & $91.05 \%$ & $85.00 \%$ & $6.05 \%$ \\
\hline 28 & Megaplaza 2 & $79.96 \%$ & $85.00 \%$ & $-5.04 \%$ & $87.56 \%$ & $85.00 \%$ & $2.56 \%$ \\
\hline 29 & C.C. Plaza Lima Norte & $71.97 \%$ & $85.00 \%$ & $-13.03 \%$ & $78.80 \%$ & $85.00 \%$ & $-6.20 \%$ \\
\hline 30 & Independencia & $68.61 \%$ & $85.00 \%$ & $-16.39 \%$ & $75.13 \%$ & $85.00 \%$ & $-9.87 \%$ \\
\hline 31 & Salaverry & $68.61 \%$ & $85.00 \%$ & $-16.39 \%$ & $75.13 \%$ & $85.00 \%$ & $-9.87 \%$ \\
\hline
\end{tabular}




\begin{tabular}{|c|c|c|c|c|c|c|c|}
\hline \multirow[b]{2}{*}{$\mathbf{N}^{\circ}$} & \multirow[b]{2}{*}{ Tienda } & \multicolumn{3}{|c|}{ Nivel de satisfacción de los colaboradores } & \multicolumn{3}{|c|}{ Nivel de satisfacción de los clientes } \\
\hline & & $\begin{array}{c}\text { Clima laboral } \\
\text { real }\end{array}$ & $\begin{array}{c}\text { Clima laboral } \\
\text { ideal }\end{array}$ & Diferencia & $\begin{array}{c}\text { Cliente } \\
\text { incógnito real }\end{array}$ & $\begin{array}{c}\text { Cliente } \\
\text { incógnito } \\
\text { ideal }\end{array}$ & Diferencia \\
\hline 32 & Jesus Maria & $47.58 \%$ & $85.00 \%$ & $-37.42 \%$ & $52.10 \%$ & $85.00 \%$ & $-32.90 \%$ \\
\hline 33 & Garzon & $75.32 \%$ & $85.00 \%$ & $-9.68 \%$ & $82.47 \%$ & $85.00 \%$ & $-2.53 \%$ \\
\hline 34 & Molina & $72.50 \%$ & $85.00 \%$ & $-12.50 \%$ & $79.39 \%$ & $85.00 \%$ & $-5.61 \%$ \\
\hline 35 & Canepa 3 & $72.27 \%$ & $85.00 \%$ & $-12.73 \%$ & $79.14 \%$ & $85.00 \%$ & $-5.86 \%$ \\
\hline 36 & Parinacochas & $81.81 \%$ & $85.00 \%$ & $-3.19 \%$ & $89.58 \%$ & $85.00 \%$ & $4.58 \%$ \\
\hline 37 & México 1 & $42.28 \%$ & $85.00 \%$ & $-42.72 \%$ & $46.30 \%$ & $85.00 \%$ & $-38.70 \%$ \\
\hline 38 & México 2 & $77.13 \%$ & $85.00 \%$ & $-7.87 \%$ & $84.46 \%$ & $85.00 \%$ & $-0.54 \%$ \\
\hline 39 & Canepa 1 - C.C. Parque. Canepa & $77.07 \%$ & $85.00 \%$ & $-7.93 \%$ & $84.39 \%$ & $85.00 \%$ & $-0.61 \%$ \\
\hline 40 & Canepa 2 - C.C. Parque. Canepa & $86.17 \%$ & $85.00 \%$ & $1.17 \%$ & $94.36 \%$ & $85.00 \%$ & $9.36 \%$ \\
\hline 41 & Lince 1 & $73.82 \%$ & $85.00 \%$ & $-11.18 \%$ & $80.84 \%$ & $85.00 \%$ & $-4.16 \%$ \\
\hline 42 & Lince 2 & $77.08 \%$ & $85.00 \%$ & $-7.92 \%$ & $84.41 \%$ & $85.00 \%$ & $-0.59 \%$ \\
\hline 43 & Olivos 2 & $77.12 \%$ & $85.00 \%$ & $-7.88 \%$ & $84.45 \%$ & $85.00 \%$ & $-0.55 \%$ \\
\hline 44 & Pro & $78.24 \%$ & $85.00 \%$ & $-6.76 \%$ & $85.67 \%$ & $85.00 \%$ & $0.67 \%$ \\
\hline 45 & Chosica & $60.30 \%$ & $85.00 \%$ & $-24.70 \%$ & $66.03 \%$ & $85.00 \%$ & $-18.97 \%$ \\
\hline 46 & Lurín & $66.61 \%$ & $85.00 \%$ & $-18.39 \%$ & $72.94 \%$ & $85.00 \%$ & $-12.06 \%$ \\
\hline 47 & Playa & $54.03 \%$ & $85.00 \%$ & $-30.97 \%$ & $59.16 \%$ & $85.00 \%$ & $-25.84 \%$ \\
\hline 48 & Lurín 02 & $75.73 \%$ & $85.00 \%$ & $-9.27 \%$ & $82.93 \%$ & $85.00 \%$ & $-2.07 \%$ \\
\hline 49 & Magdalena & $76.51 \%$ & $85.00 \%$ & $-8.49 \%$ & $83.78 \%$ & $85.00 \%$ & $-1.22 \%$ \\
\hline 50 & Panamá & $78.09 \%$ & $85.00 \%$ & $-6.91 \%$ & $85.51 \%$ & $85.00 \%$ & $0.51 \%$ \\
\hline 51 & Pardo & $86.01 \%$ & $85.00 \%$ & $1.01 \%$ & $94.19 \%$ & $85.00 \%$ & $9.19 \%$ \\
\hline 52 & Sucre & $67.97 \%$ & $85.00 \%$ & $-17.03 \%$ & $74.43 \%$ & $85.00 \%$ & $-10.57 \%$ \\
\hline 53 & Puente Piedra 1 & $71.21 \%$ & $85.00 \%$ & $-13.79 \%$ & $77.97 \%$ & $85.00 \%$ & $-7.03 \%$ \\
\hline 54 & Puente Piedra - Tottus & $63.99 \%$ & $85.00 \%$ & $-21.01 \%$ & $69.19 \%$ & $85.00 \%$ & $-15.81 \%$ \\
\hline 55 & Rímac & $78.76 \%$ & $85.00 \%$ & $-6.24 \%$ & $86.25 \%$ & $85.00 \%$ & $1.25 \%$ \\
\hline 56 & Aviación 24 & $64.94 \%$ & $85.00 \%$ & $-20.06 \%$ & $71.11 \%$ & $85.00 \%$ & $-13.89 \%$ \\
\hline 57 & Aviación 29 & $72.12 \%$ & $85.00 \%$ & $-12.88 \%$ & $78.53 \%$ & $85.00 \%$ & $-6.47 \%$ \\
\hline 58 & Avi 1 & $65.70 \%$ & $85.00 \%$ & $-19.30 \%$ & $71.94 \%$ & $85.00 \%$ & $-13.06 \%$ \\
\hline 59 & Canto Grande 1 & $66.44 \%$ & $85.00 \%$ & $-18.56 \%$ & $72.75 \%$ & $85.00 \%$ & $-12.25 \%$ \\
\hline 60 & Canto Grande 2 & $49.97 \%$ & $85.00 \%$ & $-35.03 \%$ & $53.84 \%$ & $85.00 \%$ & $-31.16 \%$ \\
\hline 61 & Próceres 1 & $71.92 \%$ & $85.00 \%$ & $-13.08 \%$ & $78.75 \%$ & $85.00 \%$ & $-6.25 \%$ \\
\hline 62 & Zarate 1 & $68.76 \%$ & $85.00 \%$ & $-16.24 \%$ & $74.85 \%$ & $85.00 \%$ & $-10.15 \%$ \\
\hline
\end{tabular}




\begin{tabular}{|c|c|c|c|c|c|c|c|}
\hline \multirow[b]{2}{*}{$\mathrm{N}^{\circ}$} & \multirow[b]{2}{*}{ Tienda } & \multicolumn{3}{|c|}{ Nivel de satisfacción de los colaboradores } & \multicolumn{3}{|c|}{ Nivel de satisfacción de los clientes } \\
\hline & & $\begin{array}{c}\text { Clima laboral } \\
\text { real }\end{array}$ & $\begin{array}{c}\text { Clima laboral } \\
\text { ideal }\end{array}$ & Diferencia & $\begin{array}{c}\text { Cliente } \\
\text { incógnito real }\end{array}$ & $\begin{array}{c}\text { Cliente } \\
\text { incógnito } \\
\text { ideal }\end{array}$ & Diferencis \\
\hline 63 & Zarate 2 & $84.92 \%$ & $85.00 \%$ & $-0.08 \%$ & $92.99 \%$ & $85.00 \%$ & $7.99 \%$ \\
\hline 64 & Avi 2 & $54.18 \%$ & $85.00 \%$ & $-30.82 \%$ & $59.33 \%$ & $85.00 \%$ & $-25.67 \%$ \\
\hline 65 & Canto Grande - Metro & $73.07 \%$ & $85.00 \%$ & $-11.93 \%$ & $80.02 \%$ & $85.00 \%$ & $-4.98 \%$ \\
\hline 66 & Proceres 2 & $64.35 \%$ & $85.00 \%$ & $-20.65 \%$ & $70.46 \%$ & $85.00 \%$ & $-14.54 \%$ \\
\hline 67 & Campoy-Tottus & $58.67 \%$ & $85.00 \%$ & $-26.33 \%$ & $63.37 \%$ & $85.00 \%$ & $-21.63 \%$ \\
\hline 68 & Las Flores & $41.22 \%$ & $85.00 \%$ & $-43.78 \%$ & $43.83 \%$ & $85.00 \%$ & $-41.17 \%$ \\
\hline 69 & Bolichera & $68.36 \%$ & $85.00 \%$ & $-16.64 \%$ & $74.85 \%$ & $85.00 \%$ & $-10.15 \%$ \\
\hline 70 & San Juan 1 & $70.45 \%$ & $85.00 \%$ & $-14.55 \%$ & $74.92 \%$ & $85.00 \%$ & $-10.08 \%$ \\
\hline 71 & San Juan 2 & $69.14 \%$ & $85.00 \%$ & $-15.86 \%$ & $75.70 \%$ & $85.00 \%$ & $-9.30 \%$ \\
\hline 72 & Atocongo - C.C. Open Plaza & $45.02 \%$ & $85.00 \%$ & $-39.98 \%$ & $50.98 \%$ & $85.00 \%$ & $-34.02 \%$ \\
\hline 73 & C.C. Mall Del Sur & $61.03 \%$ & $85.00 \%$ & $-23.97 \%$ & $66.83 \%$ & $85.00 \%$ & $-18.17 \%$ \\
\hline 74 & Canadá & $72.39 \%$ & $85.00 \%$ & $-12.61 \%$ & $78.50 \%$ & $85.00 \%$ & $-6.50 \%$ \\
\hline 75 & Habich & $70.87 \%$ & $85.00 \%$ & $-14.13 \%$ & $76.87 \%$ & $85.00 \%$ & $-8.13 \%$ \\
\hline 76 & Huandoy & $70.15 \%$ & $85.00 \%$ & $-14.85 \%$ & $76.19 \%$ & $85.00 \%$ & $-8.81 \%$ \\
\hline 77 & Perú 1 & $67.63 \%$ & $85.00 \%$ & $-17.37 \%$ & $73.07 \%$ & $85.00 \%$ & $-11.93 \%$ \\
\hline 78 & Perú 2 & $75.27 \%$ & $85.00 \%$ & $-9.73 \%$ & $83.21 \%$ & $85.00 \%$ & $-1.79 \%$ \\
\hline 79 & Marina 17 & $61.39 \%$ & $85.00 \%$ & $-23.61 \%$ & $67.23 \%$ & $85.00 \%$ & $-17.77 \%$ \\
\hline 80 & Marina 32 & $70.17 \%$ & $85.00 \%$ & $-14.83 \%$ & $76.83 \%$ & $85.00 \%$ & $-8.17 \%$ \\
\hline 81 & Marina 26 & $54.74 \%$ & $85.00 \%$ & $-30.26 \%$ & $58.13 \%$ & $85.00 \%$ & $-26.87 \%$ \\
\hline 82 & Santa Anita 2 & $70.45 \%$ & $85.00 \%$ & $-14.55 \%$ & $76.82 \%$ & $85.00 \%$ & $-8.18 \%$ \\
\hline 83 & Santa Anita - Ficus & $72.39 \%$ & $85.00 \%$ & $-12.61 \%$ & $79.27 \%$ & $85.00 \%$ & $-5.73 \%$ \\
\hline 84 & Santa Anita - C.C. Aventura Plaza & $72.20 \%$ & $85.00 \%$ & $-12.80 \%$ & $79.30 \%$ & $85.00 \%$ & $-5.70 \%$ \\
\hline 85 & Santa Anita - Productores & $65.55 \%$ & $85.00 \%$ & $-19.45 \%$ & $71.78 \%$ & $85.00 \%$ & $-13.22 \%$ \\
\hline 86 & Chacarilla & $64.57 \%$ & $85.00 \%$ & $-20.43 \%$ & $69.66 \%$ & $85.00 \%$ & $-15.34 \%$ \\
\hline 87 & Viñedos-Tottus & $73.85 \%$ & $85.00 \%$ & $-11.15 \%$ & $80.87 \%$ & $85.00 \%$ & $-4.13 \%$ \\
\hline 88 & Villa El Salvador 1 & $71.68 \%$ & $85.00 \%$ & $-13.32 \%$ & $78.49 \%$ & $85.00 \%$ & $-6.51 \%$ \\
\hline 89 & Villa E1 Salvador 2 & $70.32 \%$ & $85.00 \%$ & $-14.68 \%$ & $76.68 \%$ & $85.00 \%$ & $-8.32 \%$ \\
\hline 90 & Villa El Salvador - C.C. Megaplaza & $78.40 \%$ & $85.00 \%$ & $-6.60 \%$ & $85.85 \%$ & $85.00 \%$ & $0.85 \%$ \\
\hline 91 & Villa Maria Del Triunfo & $74.04 \%$ & $85.00 \%$ & $-10.96 \%$ & $81.08 \%$ & $85.00 \%$ & $-3.92 \%$ \\
\hline 92 & Villa María Del Triunfo 2 & $78.43 \%$ & $85.00 \%$ & $-6.57 \%$ & $85.89 \%$ & $85.00 \%$ & $0.89 \%$ \\
\hline & Promedio & $69.62 \%$ & $85.00 \%$ & $-15.38 \%$ & $76.12 \%$ & $85.00 \%$ & $-8.88 \%$ \\
\hline
\end{tabular}


Anexo 10. Línea Base de los Objetivos Específicos según el Mapa de la Estrategia de Norky’s (Promedio de Septiembre 2016 - Octubre 2017)

\begin{tabular}{|c|c|c|c|c|c|c|c|c|c|c|}
\hline \multirow[b]{2}{*}{$\mathbf{N}^{\circ}$} & \multirow[b]{2}{*}{ Tienda } & \multicolumn{3}{|c|}{ Costo de ventas } & \multicolumn{3}{|c|}{ Gastos de administración } & \multicolumn{3}{|c|}{ Estandarización de los procesos operativos } \\
\hline & & $\begin{array}{l}\text { Costo de } \\
\text { venta real }\end{array}$ & $\begin{array}{c}\text { Costo de } \\
\text { venta ideal }\end{array}$ & Diferencia & Planilla real & Planilla ideal & Diferencia & $\begin{array}{c}\text { Check list } \\
\text { real }\end{array}$ & $\begin{array}{c}\text { Check list } \\
\text { ideal }\end{array}$ & Diferencia \\
\hline 1 & Huaycán & $45.05 \%$ & $44.00 \%$ & $-1.04 \%$ & $105.55 \%$ & $100.00 \%$ & $-5.55 \%$ & $88.55 \%$ & $90.00 \%$ & $-1.45 \%$ \\
\hline 2 & Vitarte 1 & $45.05 \%$ & $44.00 \%$ & $-1.04 \%$ & $102.55 \%$ & $100.00 \%$ & $-2.55 \%$ & $85.55 \%$ & $90.00 \%$ & $-4.45 \%$ \\
\hline 3 & Vitarte 2 & $45.35 \%$ & $44.37 \%$ & $-0.99 \%$ & $106.22 \%$ & $100.00 \%$ & $-6.22 \%$ & $88.30 \%$ & $90.00 \%$ & $-1.70 \%$ \\
\hline 4 & Salamanca & $45.87 \%$ & $42.39 \%$ & $-3.48 \%$ & $107.44 \%$ & $100.00 \%$ & $-7.44 \%$ & $88.44 \%$ & $90.00 \%$ & $-1.56 \%$ \\
\hline 5 & Javier Prado & $46.82 \%$ & $44.18 \%$ & $-2.64 \%$ & $99.80 \%$ & $100.00 \%$ & $0.20 \%$ & $82.80 \%$ & $90.00 \%$ & $-7.20 \%$ \\
\hline 6 & Santa Clara - C.C. Real Plaza & $47.21 \%$ & $45.32 \%$ & $-1.89 \%$ & $108.87 \%$ & $100.00 \%$ & $-8.87 \%$ & $91.87 \%$ & $90.00 \%$ & $1.87 \%$ \\
\hline 7 & Santa Clara 2 & $47.97 \%$ & $46.07 \%$ & $-1.91 \%$ & $101.35 \%$ & $100.00 \%$ & $-1.35 \%$ & $84.35 \%$ & $90.00 \%$ & $-5.65 \%$ \\
\hline 8 & C.C. La Rambla & $48.64 \%$ & $43.18 \%$ & $-5.46 \%$ & $107.25 \%$ & $100.00 \%$ & $-7.25 \%$ & $90.25 \%$ & $90.00 \%$ & $0.25 \%$ \\
\hline 9 & Venezuela & $46.10 \%$ & $45.05 \%$ & $-1.05 \%$ & $105.52 \%$ & $100.00 \%$ & $-5.52 \%$ & $88.52 \%$ & $90.00 \%$ & $-1.48 \%$ \\
\hline 10 & Alfonso Ugarte & $47.77 \%$ & $46.95 \%$ & $-0.82 \%$ & $102.80 \%$ & $100.00 \%$ & $-2.80 \%$ & $85.80 \%$ & $90.00 \%$ & $-4.20 \%$ \\
\hline 11 & Colmena & $46.32 \%$ & $39.44 \%$ & $-6.88 \%$ & $101.83 \%$ & $100.00 \%$ & $-1.83 \%$ & $84.83 \%$ & $90.00 \%$ & $-5.17 \%$ \\
\hline 12 & Maruy 1 & $41.50 \%$ & $40.34 \%$ & $-1.17 \%$ & $102.23 \%$ & $100.00 \%$ & $-2.23 \%$ & $85.23 \%$ & $90.00 \%$ & $-4.77 \%$ \\
\hline 13 & Principal & $48.04 \%$ & $45.75 \%$ & $-2.28 \%$ & $105.89 \%$ & $100.00 \%$ & $-5.89 \%$ & $88.89 \%$ & $90.00 \%$ & $-1.11 \%$ \\
\hline 14 & Union 1 & $47.70 \%$ & $44.83 \%$ & $-2.86 \%$ & $100.20 \%$ & $100.00 \%$ & $-0.20 \%$ & $83.20 \%$ & $90.00 \%$ & $-6.80 \%$ \\
\hline 15 & Abancay 2 & $46.46 \%$ & $49.06 \%$ & $2.60 \%$ & $100.24 \%$ & $100.00 \%$ & $-0.24 \%$ & $83.24 \%$ & $90.00 \%$ & $-6.76 \%$ \\
\hline 16 & Centro Civico - C.C. Real Plaza & $46.30 \%$ & $42.40 \%$ & $-3.90 \%$ & $103.62 \%$ & $100.00 \%$ & $-3.62 \%$ & $86.62 \%$ & $90.00 \%$ & $-3.38 \%$ \\
\hline 17 & Plaza Castilla-Metro & $46.40 \%$ & $45.09 \%$ & $-1.31 \%$ & $99.45 \%$ & $100.00 \%$ & $0.55 \%$ & $82.45 \%$ & $90.00 \%$ & $-7.55 \%$ \\
\hline 18 & Puno & $46.68 \%$ & $45.32 \%$ & $-1.36 \%$ & $105.89 \%$ & $100.00 \%$ & $-5.89 \%$ & $88.89 \%$ & $90.00 \%$ & $-1.11 \%$ \\
\hline 19 & Chorrillos & $46.66 \%$ & $42.25 \%$ & $-4.42 \%$ & $104.25 \%$ & $100.00 \%$ & $-4.25 \%$ & $86.29 \%$ & $90.00 \%$ & $-3.71 \%$ \\
\hline 20 & Comas - Retablo & $45.22 \%$ & $43.66 \%$ & $-1.56 \%$ & $108.70 \%$ & $100.00 \%$ & $-8.70 \%$ & $86.63 \%$ & $90.00 \%$ & $-3.37 \%$ \\
\hline 21 & Comas - Sta Luzmila & $45.12 \%$ & $41.90 \%$ & $-3.22 \%$ & $102.96 \%$ & $100.00 \%$ & $-2.96 \%$ & $85.96 \%$ & $90.00 \%$ & $-4.04 \%$ \\
\hline 22 & Comas 2 & $45.73 \%$ & $42.18 \%$ & $-3.55 \%$ & $100.27 \%$ & $100.00 \%$ & $-0.27 \%$ & $83.27 \%$ & $90.00 \%$ & $-6.73 \%$ \\
\hline 23 & Comas 5-San Felipe & $46.11 \%$ & $44.74 \%$ & $-1.37 \%$ & $102.00 \%$ & $100.00 \%$ & $-2.00 \%$ & $85.00 \%$ & $90.00 \%$ & $-5.00 \%$ \\
\hline 24 & Polvora 1 -Tottus & $46.51 \%$ & $44.53 \%$ & $-1.97 \%$ & $104.14 \%$ & $100.00 \%$ & $-4.14 \%$ & $87.14 \%$ & $90.00 \%$ & $-2.86 \%$ \\
\hline 25 & Bravo Chico & $44.50 \%$ & $43.30 \%$ & $-1.19 \%$ & $105.89 \%$ & $100.00 \%$ & $-5.89 \%$ & $88.89 \%$ & $90.00 \%$ & $-1.11 \%$ \\
\hline 26 & Polvora 2 - Tottus & $45.43 \%$ & $43.91 \%$ & $-1.52 \%$ & $106.30 \%$ & $100.00 \%$ & $-6.30 \%$ & $89.30 \%$ & $90.00 \%$ & $-0.70 \%$ \\
\hline 27 & Agustino - C.C. Agustino Plaza - Rest./Patio & $46.18 \%$ & $32.76 \%$ & $-13.42 \%$ & $104.50 \%$ & $100.00 \%$ & $-4.50 \%$ & $87.50 \%$ & $90.00 \%$ & $-2.50 \%$ \\
\hline 28 & Megaplaza 2 & $45.32 \%$ & $44.23 \%$ & $-1.09 \%$ & $107.00 \%$ & $100.00 \%$ & $-7.00 \%$ & $90.00 \%$ & $90.00 \%$ & $0.00 \%$ \\
\hline 29 & C.C. Plaza Lima Norte & $46.72 \%$ & $44.36 \%$ & $-2.36 \%$ & $103.00 \%$ & $100.00 \%$ & $-3.00 \%$ & $86.00 \%$ & $90.00 \%$ & $-4.00 \%$ \\
\hline 30 & Independencia & $48.44 \%$ & $46.16 \%$ & $-2.28 \%$ & $102.78 \%$ & $100.00 \%$ & $-2.78 \%$ & $85.78 \%$ & $90.00 \%$ & $-4.22 \%$ \\
\hline 31 & Salaverry & $47.98 \%$ & $47.12 \%$ & $-0.86 \%$ & $102.25 \%$ & $100.00 \%$ & $-2.25 \%$ & $85.25 \%$ & $90.00 \%$ & $-4.75 \%$ \\
\hline
\end{tabular}




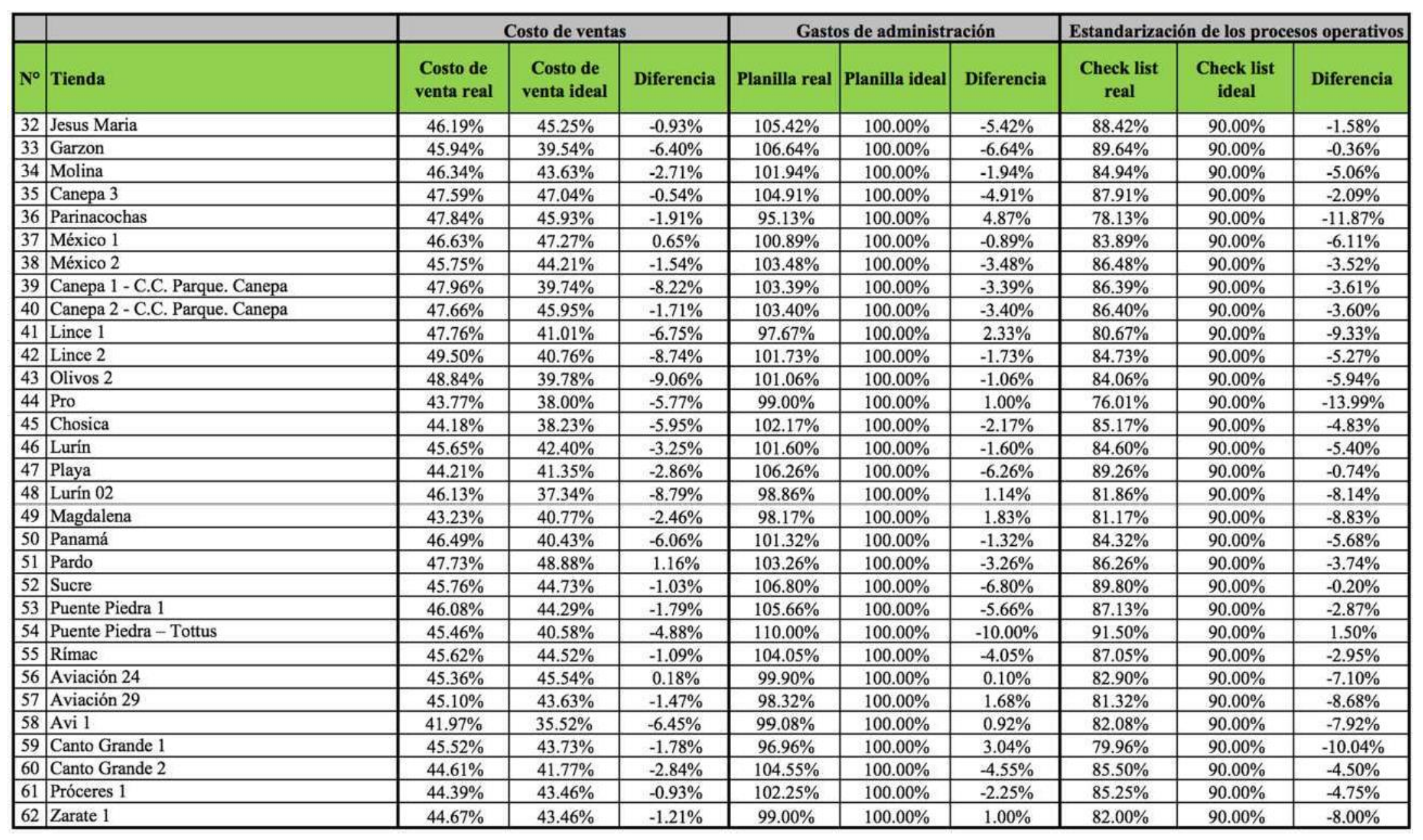




\begin{tabular}{|c|c|c|c|c|c|c|c|c|c|c|}
\hline \multirow[b]{2}{*}{$\mathbf{N}^{\circ}$} & \multirow[b]{2}{*}{ Tienda } & \multicolumn{3}{|c|}{ Costo de ventas } & \multicolumn{3}{|c|}{ Gastos de administración } & \multicolumn{3}{|c|}{ Estandarización de los procesos operativos } \\
\hline & & $\begin{array}{l}\text { Costo de } \\
\text { venta real }\end{array}$ & $\begin{array}{l}\text { Costo de } \\
\text { venta ideal }\end{array}$ & Diferencia & Planilla real & Planilla ideal & Diferencia & $\begin{array}{c}\text { Check list } \\
\text { real }\end{array}$ & $\begin{array}{c}\text { Check list } \\
\text { ideal }\end{array}$ & Diferencia \\
\hline 63 & Zarate 2 & $42.75 \%$ & $38.76 \%$ & $-3.99 \%$ & $98.14 \%$ & $100.00 \%$ & $1.86 \%$ & $81.14 \%$ & $90.00 \%$ & $-8.86 \%$ \\
\hline 64 & Avi 2 & $42.41 \%$ & $42.57 \%$ & $0.16 \%$ & $104.50 \%$ & $100.00 \%$ & $-4.50 \%$ & $86.88 \%$ & $90.00 \%$ & $-3.12 \%$ \\
\hline 65 & Canto Grande - Metro & $42.46 \%$ & $40.37 \%$ & $-2.09 \%$ & $105.08 \%$ & $100.00 \%$ & $-5.08 \%$ & $88.08 \%$ & $90.00 \%$ & $-1.92 \%$ \\
\hline 66 & Proceres 2 & $42.88 \%$ & $40.56 \%$ & $-2.33 \%$ & $105.40 \%$ & $100.00 \%$ & $-5.40 \%$ & $88.40 \%$ & $90.00 \%$ & $-1.60 \%$ \\
\hline 67 & Campoy-Tottus & $41.77 \%$ & $39.54 \%$ & $-2.24 \%$ & $106.94 \%$ & $100.00 \%$ & $-6.94 \%$ & $89.94 \%$ & $90.00 \%$ & $-0.06 \%$ \\
\hline 68 & Las Flores & $41.72 \%$ & $37.85 \%$ & $-3.87 \%$ & $106.34 \%$ & $100.00 \%$ & $-6.34 \%$ & $89.34 \%$ & $90.00 \%$ & $-0.66 \%$ \\
\hline 69 & Bolichera & $44.20 \%$ & $42.53 \%$ & $-1.67 \%$ & $103.25 \%$ & $100.00 \%$ & $-3.25 \%$ & $86.25 \%$ & $90.00 \%$ & $-3.75 \%$ \\
\hline 70 & San Juan 1 & $39.28 \%$ & $36.21 \%$ & $-3.07 \%$ & $103.25 \%$ & $100.00 \%$ & $-3.25 \%$ & $86.25 \%$ & $90.00 \%$ & $-3.75 \%$ \\
\hline 71 & San Juan 2 & $45.18 \%$ & $42.30 \%$ & $-2.88 \%$ & $101.96 \%$ & $100.00 \%$ & $-1.96 \%$ & $84.96 \%$ & $90.00 \%$ & $-5.04 \%$ \\
\hline 72 & Atocongo - C.C. Open Plaza & $43.41 \%$ & $35.34 \%$ & $-8.07 \%$ & $98.24 \%$ & $100.00 \%$ & $1.76 \%$ & $81.24 \%$ & $90.00 \%$ & $-8.76 \%$ \\
\hline 73 & C.C. Mall Del Sur & $42.82 \%$ & $38.47 \%$ & $-4.35 \%$ & $105.44 \%$ & $100.00 \%$ & $-5.44 \%$ & $86.61 \%$ & $90.00 \%$ & $-3.39 \%$ \\
\hline 74 & Canadá & $43.32 \%$ & $41.30 \%$ & $-2.02 \%$ & $102.22 \%$ & $100.00 \%$ & $-2.22 \%$ & $85.22 \%$ & $90.00 \%$ & $-4.78 \%$ \\
\hline 75 & Habich & $42.74 \%$ & $38.08 \%$ & $-4.66 \%$ & $99.24 \%$ & $100.00 \%$ & $0.76 \%$ & $81.46 \%$ & $90.00 \%$ & $-8.54 \%$ \\
\hline 76 & Huandoy & $40.48 \%$ & $37.08 \%$ & $-3.39 \%$ & $97.86 \%$ & $100.00 \%$ & $2.14 \%$ & $80.86 \%$ & $90.00 \%$ & $-9.14 \%$ \\
\hline 77 & Perú 1 & $42.72 \%$ & $34.81 \%$ & $-7.91 \%$ & $96.55 \%$ & $100.00 \%$ & $3.45 \%$ & $77.25 \%$ & $90.00 \%$ & $-12.75 \%$ \\
\hline 78 & Perú 2 & $42.92 \%$ & $38.04 \%$ & $-4.88 \%$ & $98.50 \%$ & $100.00 \%$ & $1.50 \%$ & $81.50 \%$ & $90.00 \%$ & $-8.50 \%$ \\
\hline 80 & Marina 32 & $43.06 \%$ & $38.84 \%$ & $-4.22 \%$ & $97.24 \%$ & $100.00 \%$ & $2.76 \%$ & $79.50 \%$ & $90.00 \%$ & $-10.50 \%$ \\
\hline 81 & Marina 26 & $34.43 \%$ & $32.23 \%$ & $-2.19 \%$ & $102.81 \%$ & $100.00 \%$ & $-2.81 \%$ & $85.81 \%$ & $90.00 \%$ & $-4.19 \%$ \\
\hline 82 & Santa Anita 2 & $37.15 \%$ & $41.99 \%$ & $4.84 \%$ & $109.08 \%$ & $100.00 \%$ & $-9.08 \%$ & $92.08 \%$ & $90.00 \%$ & $2.08 \%$ \\
\hline 83 & Santa Anita - Ficus & $44.55 \%$ & $39.96 \%$ & $-4.59 \%$ & $100.55 \%$ & $100.00 \%$ & $-0.55 \%$ & $82.32 \%$ & $90.00 \%$ & $-7.68 \%$ \\
\hline 84 & Santa Anita - C.C. Aventura Plaza & $45.37 \%$ & $39.07 \%$ & $-6.30 \%$ & $99.86 \%$ & $100.00 \%$ & $0.14 \%$ & $82.86 \%$ & $90.00 \%$ & $-7.14 \%$ \\
\hline 85 & Santa Anita - Productores & $46.00 \%$ & $42.95 \%$ & $-3.05 \%$ & $104.93 \%$ & $100.00 \%$ & $-4.93 \%$ & $87.93 \%$ & $90.00 \%$ & $-2.07 \%$ \\
\hline 86 & Chacarilla & $38.00 \%$ & $39.93 \%$ & $1.93 \%$ & $94.46 \%$ & $100.00 \%$ & $5.54 \%$ & $77.46 \%$ & $90.00 \%$ & $-12.54 \%$ \\
\hline 87 & Viñedos -Tottus & $45.00 \%$ & $45.48 \%$ & $0.48 \%$ & $101.97 \%$ & $100.00 \%$ & $-1.97 \%$ & $84.97 \%$ & $90.00 \%$ & $-5.03 \%$ \\
\hline 88 & Villa El Salvador 1 & $43.47 \%$ & $43.15 \%$ & $-0.32 \%$ & $96.00 \%$ & $100.00 \%$ & $4.00 \%$ & $75.12 \%$ & $90.00 \%$ & $-14.88 \%$ \\
\hline 89 & Villa El Salvador 2 & $45.23 \%$ & $42.88 \%$ & $-2.35 \%$ & $98.00 \%$ & $100.00 \%$ & $2.00 \%$ & $74.62 \%$ & $90.00 \%$ & $-15.38 \%$ \\
\hline 90 & Villa El Salvador - C.C. Megaplaza & $45.66 \%$ & $45.37 \%$ & $-0.29 \%$ & $102.59 \%$ & $100.00 \%$ & $-2.59 \%$ & $85.59 \%$ & $90.00 \%$ & $-4.41 \%$ \\
\hline 91 & Villa Maria Del Triunfo & $44.35 \%$ & $39.22 \%$ & $-5.13 \%$ & $107.52 \%$ & $100.00 \%$ & $-7.52 \%$ & $88.43 \%$ & $90.00 \%$ & $-1.57 \%$ \\
\hline \multirow{2}{*}{92} & Villa Maria Del Triunfo 2 & $45.55 \%$ & $40.99 \%$ & $-4.56 \%$ & $105.43 \%$ & $100.00 \%$ & $-5.43 \%$ & $82.22 \%$ & $90.00 \%$ & $-7.78 \%$ \\
\hline & Promedio & $45.00 \%$ & $42.06 \%$ & $-2.94 \%$ & $102.62 \%$ & $100.00 \%$ & $-2.62 \%$ & $84.98 \%$ & $90.00 \%$ & $-5.02 \%$ \\
\hline
\end{tabular}


Anexo 11. Detalle de Planilla

\begin{tabular}{|l|c|c|c|c|}
\hline \multicolumn{1}{|c|}{ Puesto } & $\begin{array}{c}\text { Sueldo } \\
\text { Mensual }\end{array}$ & $\mathbf{2 0 1 8}$ & $\mathbf{2 0 1 9}$ & $\mathbf{2 0 2 0}$ \\
\hline Gerente de RRHH & 15,000 & 17,250 & 18,113 & 19,018 \\
\hline Generalista de RRHH & 6,000 & 6,900 & 7,245 & 7,607 \\
\hline Gerente de Operaciones & 22,500 & 25,875 & 27,169 & 28,527 \\
\hline Supervisor de Operaciones & 3,750 & 4,313 & 4,528 & 4,755 \\
\hline Supervisor de Servicio & 3,750 & 4,313 & 4,528 & 4,755 \\
\hline Jefe de Capacitación & 7,500 & 8,625 & 9,056 & 9,509 \\
\hline Capacitador & 2,700 & 3,105 & 3,260 & 3,423 \\
\hline Gerente de Marketing & 12,000 & 13,800 & 14,490 & 15,215 \\
\hline Asistente de Marketing & 2,250 & 2,588 & 2,717 & 2,853 \\
\hline Jefe de Reclutamiento y Selección & 7,500 & 8,625 & 9,056 & 9,509 \\
\hline Jefe de Bienestar Social & 7,500 & 8,625 & 9,056 & 9,509 \\
\hline Jefe de Administración de Personal & 7,500 & 8,625 & 9,056 & 9,509 \\
\hline Jefe de Sistemas & 18,000 & 20,700 & 21,735 & 22,822 \\
\hline Analista Programador & 4,500 & 5,175 & 5,434 & 5,705 \\
\hline Gerente de Logística & 12,000 & 13,800 & 14,490 & 15,215 \\
\hline Gerente de Auditoria y Control & 18,000 & 20,700 & 21,735 & 22,822 \\
\hline Gerente de Administración & 18,000 & 20,700 & 21,735 & 22,822 \\
\hline Analista de Procesos & 4,500 & 5,175 & 5,434 & 5,705 \\
\hline Jefe de Operaciones & 7,500 & 8,625 & 9,056 & 9,509 \\
\hline Coordinador de Auditoria & 4,500 & 5,175 & 5,434 & 5,705 \\
\hline Coordinador de Marketing & 4,500 & 5,175 & 5,434 & 5,705 \\
\hline Community Manager & 6,000 & 6,900 & 7,245 & 7,607 \\
\hline Encuestador & 3,000 & 3,450 & 3,623 & 3,804 \\
\hline
\end{tabular}


Anexo 12. Carta de Consentimiento informado para el uso de la Información de la Empresa

\section{CONSENTIMIENTO INFORMADO PARA EL USO DE LA INFORMACIÓN DE LA EMPRESA / ORGANIZACIÓN}

Por el presente documento, aprobamos el uso de la información de la Cadena de Pollerías Norky's para que los alumnos Nestor Alejandro Chirinos Villanueva, Elizabeth Vanessa Ganoza Aguilar, José Olivera Rimachi y Carmen Rosa Zambrano Bohorquez puedan desarrollar el trabajo de grado titulado Plan Estratégico para la Cadena de Pollerías Norky's para el periodo 2018 2020 en Lima. Por tal motivo, nos comprometemos a brindar las facilidades necesarias en términos de acceso a la información relacionada para el desarrollo de su trabajo de grado, así como aceptamos su utilización con fines académicos y colocación en diversas bases de datos y/o concursos nacionales e internacionales, en formato digital y/o impreso.

Se firma el presente documento en señal de conformidad:

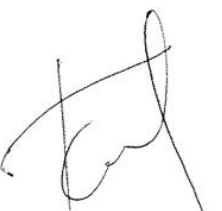

Nombres y apellidos: Carlos Javier Tamashiro Arakaki

DNI: 10222186

Correo electrónico: ctamashiro@norkys.pe

Teléfono: 996419485

Fecha: $27 / 10 / 2017$ 
Anexo 13. Entrevistas en Profundidad a Expertos Externos a la Empresa

Fecha: 05/10/2018

Hora: 07:00 p.m.

Lugar: Lima Cercado, Perú

Entrevistadores: Carmen Zambrano, Elizabeth Ganoza, José Olivera y Nestor Chirinos

\section{Entrevistado:}

- Nombre: Valencio Huamán Díaz

- Edad: 42 años

- Género: Masculino

- Puesto: Gerente General de POLLERÍAS A LA CASA S.A.C.

\section{Objetivo:}

El propósito de esta entrevista es conocer más detalles de la situación de otros negocios del mismo rubro de pollería.

\section{Consentimiento informado:}

El señor Valencio Huamán Díaz ha autorizado que la información proporcionada en la entrevista sea utilizada para fines de investigación del plan estratégico.

\section{Características de la entrevista:}

La entrevista tuvo una duración de media hora. 


\section{Preguntas:}

- ¿Cuánto tiempo lleva involucrado en esta clase de negocio?

Inicié en el negocio hace 12 años, desde junio del 2006 en un primer local ubicado en la calle Montero Rosas cuadra 12, sin embargo, por término del contrato de arrendamiento, y con cierto capital reunido hasta ese momento, tuvimos la oportunidad de realizar la compra del local en donde nos encontramos actualmente, que se encuentra en Teodoro Cárdenas cuadra 04.

- ¿Cuál es el secreto para alcanzar el éxito en un negocio de este rubro?

Hay diferentes secretos para este rubro de negocio, en primer lugar, está el conocimiento, por ejemplo: dedicación al negocio, cómo funciona, como debe de desarrollarse y crecer, qué es lo que debo de ofrecer para obtener nuevos clientes, que es lo que debo de mejorar. Por otro lado, enfocándonos en el día a día, identificar cuáles son los horarios picos de venta en donde se requiere una mayor concentración para una buena atención, identificar qué tipo de comida busca en la media tarde y en la hora de la cena, ofrecer productos de calidad, por ejemplo, desde que ofrecemos las “papas crocantes" hemos podido ofrecer a los comensales una opción más de papas, la cual difiere en S/.1 de las papas normales las cuales nosotros mismos preparamos. Podemos decir que mientras más conoces a tu cliente el éxito de tu negocio está asegurado.

- ¿Cuál es el perfil del cliente que comúnmente visita la pollería?

El perfil de clientes, en general son familias, parejas, grupos de toda edad, vienen personas de toda clase social. El perfil que puedo observar en mis clientes es que a ellos además del sabor buscan la cantidad, siempre bromean con los mozos diciendo que se les traiga bien "Taipá" los platos solicitados. 
- ¿Cuál es la clave para atraer nuevos clientes?

Principalmente hemos atraído a nuevos clientes con la recomendación boca a boca de los clientes que ya consideramos que están fidelizados, hemos oído a varios clientes que han llegado a nuestro negocio por recomendación de un amigo, vecino o un conocido. Por eso medio hasta el momento nos hemos dado a conocer

- ¿Cómo ha logrado la fidelidad de algunos clientes?

Nuestra fidelización con los clientes comenzó cuando nosotros iniciamos en nuestro primer local, en donde siempre le ofrecimos el sabor y cantidad a un precio justo. Para nosotros siempre ha sido compensar la expectativa del producto que los clientes tienen con nosotros, ofrecer el pollo a la brasa en su punto con papas recién salidas y ensalada.

Actualmente logro fidelizar a los clientes por medio de una muy buena atención además de ofrecer un producto de calidad y sabor.

- ¿Cuáles son los aspectos que el cliente toma más en cuenta para asistir a la pollería, considerando los aspectos (sabor, servicio, higiene, seguridad, etc.)?

Principalmente nuestros clientes llegan por el sabor de nuestros platos, como dicen, nuestro ají está en su punto. Por otro lado, cobramos el precio justo, comparando los precios con otras pollerías en donde dan un tamaño de pollo a la brasa pequeño, nosotros damos el tamaño promedio de pollo. Podemos decir que valoran más es el sabor y la cantidad que reciben.

- ¿Ha tenido problemas con sus clientes alguna vez? ¿Cómo lo resolvió?

Por temas de tiempo de atención, nos suele pasar pocas veces en días festivos, donde los clientes superan la capacidad de la tienda y nosotros no podemos darnos abasto. Sin 
embargo, siempre hemos buscado darle algo en compensación, como por ejemplo darles una cortesía cuando ya se encuentran en la mesa por la espera.

- ¿Cómo se da a conocer la pollería?

No contamos con una gran capacidad para invertir en marketing, por lo que la recomendación boca a boca y publicaciones de lo que ofrece nuestra pollería en el boletín semanal de la urbanización Santa Beatriz, es todo lo que hemos realizado hasta el momento para darnos a conocer, si estamos conscientes que en un futuro no muy lejano vamos a tener que hacer un esfuerzo para poder invertir en publicidad en medio sociales.

- ¿Cómo está determinada la estructura del personal del negocio?

Está compuesta por entregadores de delivery, meseros y azafatas, cocineros y de limpieza.

- ¿Cuáles son los aspectos de la situación económica del país que ha impactado más en la continuidad de su negocio?

En realidad, nos tratamos de adecuar a la canasta familiar que se publican en los medios, ello nos permite conocer de qué modo está compuesto el perfil del cliente que consume de nuestra pollería. Pese a que hay años difíciles, nos tratamos de adecuar al bolsillo de nuestro cliente y de ofrecerles casi o igual "producto" que las grandes pollerías, donde tienen en consideración factores como la atención y la marca. La continuidad del negocio creo que se ha dado por eso, a tal punto que hemos tenido que aumentar más comedores.

- ¿Considera que existe actualmente un marco regulatorio que impide o promueve el desenvolvimiento del negocio?

En la actualidad, la municipalidad es la que viene constantemente a inspeccionar nuestras instalaciones, así como el funcionamiento de nuestros equipos, cocina y la limpieza 
en general. Esto nos permitió, tener conciencia de los procesos de elaboración de pollos a la brasa y demás comidas, ya que presentábamos falencias. Hoy lo veo cómo necesario, a raíz de eso hemos mejorado y hemos puesto en práctica las buenas prácticas. En ese sentido, podemos afrontar a nuestra competencia.

- ¿Considera que la cultura y/o ideología de los clientes influyen en su momento de compra?

Hoy se habla mucho de la gastronomía peruana, para nuestros clientes eso es importante porque es parte de lo que lo identifica. Según se sabe, las comidas preferidas son las pollerías, cevicherías y chifas, lo cual permite atraer al público mediante este plato bandera. Mientras le demos lo mejor en cuanto a nuestro producto, esto nos permitirá tener vigencia y mantenernos en el negocio.

- ¿Respecto al trato al medio ambiente, en el negocio tienen algún procedimiento de gestión de residuos, reciclaje entre otros?

Como parte de la licencia de funcionamiento y demás trámites, hemos recibido capacitación del tratamiento de los residuos, es así que separamos residuos que pueden reutilizarse como alimento de animales y lo demás lo colocamos como basura a un camión recolector todos los días.

- ¿Cuáles han sido las principales oportunidades y Amenazas que ha tenido el negocio durante su crecimiento?

Definitivamente el día del pollo a la brasa nos ha dado una oportunidad de crecimiento, ya que antes el consumo durante el año era casi plano, pero al darse ese día conmemorativo, en esa semana tenemos picos de consumo y durante el año días festivos como el Día de la Madre son mayores que años pasados, ya que el pollo a la brasa es una alternativa primordial de los comensales porque se ha posicionado en el limeño. 
Es bueno que ferias como la de Mistura se den también. Ya que una vez más ayuda a que la gastronomía sea recordada durante todo un mes, y sabemos que el centro de ella es el pollo a la brasa.

- ¿Qué oportunidades y amenazas consideras en tu negocio?

Definitivamente el día del pollo a la brasa nos ha dado una oportunidad de mayor venta al igual que los años días festivos, ya que el pollo a la brasa es una alternativa primordial de los comensales porque se ha posicionado en el limeño.

Es bueno que ferias como la de Mistura se den también. Ya que una vez más ayuda a que la gastronomía sea recordada durante todo un mes, y sabemos que el centro de ella es el pollo a la brasa.

La tecnología, considero que es una buena oportunidad porque permite administrar los mejor los pedidos de nuestros clientes. He visto que de esa forma podemos trabajar más coordinadamente, desde que nos hacen pedidos, la atención y cobro. Las redes sociales también son una oportunidad, nos haría más conocidos y ello ayudaría a incrementar nuestras ventas, aunque ello implica que alguien se dedique a ello, lo tendríamos que evaluar.

El hecho que las cadenas de pollerías crezcan en la entrega del pollo a domicilio es una amenaza para nosotros, otra amenaza que ha surgido es que en los supermercados se vendan pollos con papas, lo mismo sucede con esas tiendas como Tambo, donde se vende el mismo producto. Aunque esta última no cuente con instalaciones, esto en un futuro hará pensar dos veces al comensal que lleva comida a su hogar o comprarlo en nuestro restaurante.

Una amenaza adicional es que se prohíba el uso de los envases de tecnopor en los restaurantes. Eso implicaría que tengamos que subir el precio de nuestros productos. 
- ¿Quién delega y propone las funciones en cada área, puesto y colaborador en la pollería?

El responsable de la pollería, como dueño, soy yo y tengo como apoyo a un administrador con experiencia en pollerías, es con quien revisamos el personal disponible para cada área y quien realiza el control del trabajo de cada uno de los trabajadores. Uno de los puestos claves en nuestro negocio es el cocinero y hornero, ya que son ellos los que hacen los pedidos de las cantidades de insumos necesarios para la elaboración del plato.

- ¿Cuáles son los criterios para el reclutamiento y selección del personal?

Desde la primera entrevista busco evaluar presentación y vestimenta que presenten, entran en un periodo de prueba de 03 días los cuales son pagados, en estos días tienen que demostrar que tienen la capacidad absoluta de dar un buen servicio y atención al cliente, que tenga iniciativa y puedan trabajar bajo presión durante las horas picos del negocio.

- ¿Cuáles son los aspectos financiero más importantes para un restaurante?

El control de compra de cantidades de materias primas y el control de los costos.

- ¿Cuáles han sido los problemas económicos más importantes y como se han solucionado?

El alza de los precios inesperados en el mercado mayorista, ya que al tener un menú impreso no se pueden cambiar los precios al momento, y es por eso que el control de cantidades de comida lo balanceamos semanalmente para las compras.

- ¿Cuál es la competencia más fuerte y cercana?

A una cuadra tenemos la pollería y parrilla, la cual se inauguró hace unos meses atrás ofreciendo casi en similitud la misma carta que nosotros. Sin embargo, esto no ha impactado 
en gran medida la afluencia de nuestra clientela y eso es porque no iguala el sabor de los productos que nosotros brindamos.

- ¿Realiza alguna acción para estar por encima de la competencia?

Ofrecer los tamaños, cantidades y buen sabor por un precio justo.

- ¿Qué recomienda para ser líder en el mercado?

Principalmente es la atención al cliente y a la par es ofrecer un muy buen producto, buscar en todo momento que la clientela salga satisfecha del restaurante. 


\section{Referencias}

Abell, D.F., \& Hammond, J.S. (1992). Planeación estratégica de mercado: problemas y enfoques analíticos. México, D.F., México: EditorialContinental.

Andina (2018). Perú: lineamientos de política económica tendrán tres ejes fundamentales.

Recuperado de https://andina.pe/agencia/noticia-peru-lineamientos-politicaeconomica-tendran-tres-ejes-fundamentales-713424.aspx

Arellano Marketing (27 de mayo de 2013). Un gusto por conquistar. Recuperado de http://www.arellanomarketing.com/inicio/un-gusto-por-conquistar/

Arellano R. (2010). Al medio hay sitio. El crecimiento social según los estilos de vida. Lima, Perú: Editorial Planeta Perú.

Asociación Peruana de Investigación de Mercados [APEIM] (2016). Niveles Socioeconómicos 2016. Recuperado dehttp://www.apeim.com.pe/wpcontent/themes/apeim/docs/nse/APEIM-NSE-2016.pdf

Ayestarán, R., Rangel, C., \& Sebastián, A. (2012). Planificación estratégica y gestión de la publicidad (1a ed.). Madrid, España: ESIC Editorial.

Banco Central de Reserva del Perú [BCRP] (2017). Reporte de Inflación: Junio 2017, Panorama actual y proyecciones macroeconómicas 2017-2018. Recuperado de http://www.bcrp.gob.pe/docs/Publicaciones/Reporte-Inflacion/2017/marzo/reportede-inflacion-marzo-2017.pdf

Cámara de Lima (2016). Sube el costo de la canasta básica y aún no está del todo cubierta. Recuperado de http://www.camaralima.org.pe/repositorioaps/0/0/par/r786_2/info_esp_786.pdf 
Cámara de Lima (2016). 13,6 millones de peruanos pertenecerían a la clase media al 2018.

Recuperado de http://www.camaralima.org.pe/principal/noticias/noticia/13-6-

millones-de-peruanos-pertenecerian-a-la-clase-media-al-2018/674

Correo (10 de abril de 2017). El ingreso promedio mensual por trabajo entre los peruanos asciende a S/1,366. Recuperado de http://diariocorreo.pe/economia/el-ingresopromedio-mensual-por-trabajo-entre-los-peruanos-asciende-a-s-1-366-742592/

Correo (13 de julio de 2018). Día del Pollo a la brasa: humo de los hornos son los principales contaminantes del aire. Recuperado de https://diariocorreo.pe/edicion/lima/dia-delpollo-la-brasa-humo-de-los-hornos-son-los-principales-contaminantes-del-aire$829979 /$

D’Alessio, F. (2013). El Proceso Estratégico - Un Enfoque de gerencia (2a ed.). México, D.F., México: Pearson Educación.

David, F. (2013). Conceptos de Administración Estratégica (14a ed.). México, D.F., México: Pearson Educación.

De Arte y Cultura (21 de julio de 2013). Día del Pollo a la Brasa. Recuperado de http://www.dearteycultura.com/dia-del-pollo-a-la-brasa/\#.Wu8r9E4Y9LE

El Comercio (2 de febrero de 2015). Los plásticos (incluido el tecnopor) y la salud (del ser humano y del medio ambiente). Recuperado de https://elcomercio.pe/blog/cuidatusalud/2015/02/los-plasticos-incluido-el-tecnopor-yla-salud-del-ser-humano-y-del-medio-ambiente

El Comercio (14 de julio de 2016). 130 millones de pollos a la brasa se consumen al año en el Perú. Recuperado de http://elcomercio.pe/economia/peru/130-millones-pollos-brasaconsumen-ano-peru-220734 
El Comercio (2 de enero de 2017). Inflación cerró el 2016 en 3.23\%, sobre rango meta del BCR. Recuperado de http://elcomercio.pe/economia/peru/inflacion-cerro-2016-3-23rango-meta-bcr-231455.

El Comercio (15 de julio de 2017). Pollerías moverían S/ 50 millones en el Día del Pollo a la Brasa. Recuperado de http://elcomercio.pe/economia/peru/pollerias-moverian-50millones-dia-pollo-brasa-442507

El Comercio (4 de agosto de 2017). Entérate sobre el avance de la alimentación saludable en el Perú. Recuperado de http://elcomercio.pe/suplementos/comercial/educacionnutricion/enterate-sobre-avance-alimentacion-saludable-peru-1002916

El Comercio (6 de junio de 2018). Aprueban dictamen que propone reducir uso y fabricación de plásticos. Recuperado de https://elcomercio.pe/peru/aprueban-dictamen-proponereducir-fabricacion-plasticos-noticia-525326

El Comercio (9 de septiembre de 2018). Minam: “Manejo de residuos sólidos es responsabilidad de gobiernos locales" Recuperado de https://elcomercio.pe/peru/minam-manejo-residuos-solidos-responsabilidadgobiernos-locales-noticia-nndc-555742

ESAN (7 de julio de 2016). Determinación de competencias organizacionales y capacitación en empresas del sector. Recuperado de https://www.esan.edu.pe/conexion/actualidad/2016/07/07/determinacion-decompetencias-organizacionales-y-capacitacion-en-empresas-del-sector-servicios/

Fahey, L., \& Narayanan, V.K. (1985). Análisis macro-ambiental en gestión estratégica. Minnesota, EE.UU.: United States Editores. 
Gestión (14 de julio de 2014). El pollo representa el 53\% del consumo total de carnes en el Perú. Recuperado de http://gestion.pe/economia/pollo-representa-53-consumo-totalcarnes-peru-2102934

Gestión (18 de septiembre de 2015). El 93\% de peruanos usan las redes sociales para buscar noticias o información de interés. Recuperado de https://gestion.pe/tecnologia/93peruanos-usan-redes-sociales-buscar-noticias-informacion-interes-2143129

Gestión (16 de julio de 2016). ¿Cuántos pollos a la brasa comemos los peruanos al año? Recuperado de http://gestion.pe/economia/cuantos-pollos-brasa-comemos-peruanosal-ano-2165658

Gestión (18 de enero de 2017). Entérese cómo serán las redes sociales en el 2017.

Recuperado de https://gestion.pe/tecnologia/enterese-como-seran-redes-sociales2017-2179976

Hax A. \& Majluf N. (2004). Estrategias para el liderazgo competitivo: De la visión a los resultados (1a ed.). Buenos Aires, Argentina: Ediciones Granica.

Hill, C., Jones, G., \& Schilling, M. (2015). Administración Estratégica: Un Enfoque Integral (11a ed.). México, D.F., México: Cengage Learning Editores, S.A. de C.V.

Instituto Nacional de Estadística e Informática [INEI] (7 de julio de 2016). Al año se consume en promedio 24 kilos de pollos a la brasa. Recuperado de https://www.inei.gob.pe/prensa/noticias/al-ano-se-consume-en-promedio-24-kilos-depollos-a-la-brasa-8517/

Instituto Nacional de Estadística e Informática [INEI] (2017). Encuesta Mensual del Sector Servicios. Recuperado de 
https://www.inei.gob.pe/media/MenuRecursivo/boletines/boletin-estadistico-delsector-servicios-n-07-julio-2017.pdf

Kaplan, R.S., \& Norton, D.P. (2009). El cuadro de mando integral (3a ed.). Barcelona, España: Grupo Planeta.

Kotler, P., \& Keller, K.L. (2012). Dirección de Marketing (14a ed.). México: Pearson Education.

La República (8 de marzo de 2017). Ministerio de Agricultura: Producción de pollo mantendrá niveles óptimos este 2017. Recuperado de http://larepublica.pe/economia/854638-ministerio-de-agricultura-produccion-depollo-mantendra-niveles-optimos-este-2017

Mastrantonio, P., Cáliz, R., Mármol, M., Rjadell, M., Coduras, O., Tapias, X., \& Pacreu J. (2016). Cómo hacer un plan de empresa EUNCET. Recuperado de https://books.google.com.pe/books?id=tyYHDQAAQBAJ

Martínez, W. (2014). Essay On Strategic Planning. Recuperado de https://scholar.google.com.pe/scholar?q=ESSAY+ON+STRATEGIC+PLANNING+ martinez\&btnG $=\&$ hl $=$ es\&as_sdt $=0 \% 2 \mathrm{C} 5$

Ministerio de Agricultura y Riego [MINAGRI] (2014). Proceso de Planeamiento Estratégico MINAGRI. Recuperado de http://www.minagri.gob.pe/portal/download/pdf/pnapes/actividades/comision/importa ncia.pdf

Ministerio de Agricultura y Riego [MINAGRI] (2015). Perú. Valor Bruto de la Producción Avícola. Recuperado de http://minagri.gob.pe/portal/boletin-estadistico-mensual-de- 
la-produccion-y-comercializacion-avicola/sector-avicola-2015 download=7885 :julio2015

Ministerio de Agricultura y Riego [MINAGRI] (2017). Perú. Valor Bruto de la Producción Avícola.Enero 20016-Julio2017. Recuperadodehttp://minagri.gob.pe/portal/boletinestadistico-mensual-de-la-produccion-y-comercializacion-avicola/sector-avicola2017?download=11838: sector-avicola-agosto- 2017

Ministerio de Comercio Exterior y Turismo [MINCETUR] (2018). MINCETUR instruiráa responsables de hospedajes, agencias de viaje y restaurantes en atención de calidad. Recuperado de https://www.mincetur.gob.pe/capacitaciones-gratuitas-minceturinstruira-a-responsables-de-hospedajes-agencias-de-viaje-y-restaurantes-en-atencionde-calidad

Munuera, J., \& Rodríguez, A. (2007). Estrategias del Marketing: Un enfoque basado en el proceso de dirección. Madrid, España: ESIC Editorial.

Perú 21 (9 de mayo de 2017). Conoce la evolución y proyección de la inversión privada. Recuperado de https://peru21.pe/economia/conoce-evolucion-proyeccion-inversionprivada-75633

Perú 21 (19 de septiembre de 2017). Emprendedor.21: 'Lima Delivery', a la puerta de tu casa. Recuperado de https://peru21.pe/emprendedores/emprendedor-21-lima-deliverypuerta-casa-376530

Perú Retail (30 de julio de 2014). Pardos Chicken y Norky’s lideran preferencia de pollerías en Lima. Recuperado de https://www.peru-retail.com/pardos-chicken-y-norkyslideran-preferencia-de-pollerias-en-lima/ 
Perú Retail (31 de julio de 2017). KFC, Norky’s y Rocky’s son los restaurantes con mayores ventas en su rubro en el Perú. Recuperado de https://www.peru-retail.com/kfc-norkysrockys-restaurantes-con-mayores-ventas-rubro-peru/

Perú Retail (17 de agosto de 2018). Europa: Los restaurantes hacen frente a las innovaciones tecnológicas. Recuperado de https://www.peru-retail.com/europa-restaurantesinnovaciones-tecnologicas/

Porter, M.E. (2006). Estrategia y ventaja competitiva. Bogotá, Colombia: Editorial Planeta Colombia.

Project Management Institute [PMI] (2013). Guía de los Fundamentos para la Dirección de Proyectos (5ta ed.). NewtownSquare, Pensilvania.

Porter M. (2008). Las cinco fuerzas competitivas que le dan forma a la estrategia. Recuperado de https://utecno.files.wordpress.com/2014/05/las_5_fuerzas_competitivas_michael_porter-libre.pdf

Pymex (1 de agosto de 2017). ¿Qué empresas de pollos a la brasa lideran el mercado peruano? Recuperado de https://pymex.pe/emprendedores/productos-estrella/queempresas-de-pollos-a-la-brasa-lideran-el-mercado-peruano

Sainz, J. (2015). El plan estratégico en la práctica. Recuperado de https://books.google.com.pe/books?hl=es\&lr=\&id=bIh5CgAAQBAJ\&oi=fnd\&pg=P A7\&dq=plan+estrategico+en+la+practica\&ots=bNxrCIXkbx\&sig=DQSKw9k5EX03 Ls_M8nhY2BVw9Ng\#v=onepage\&q\&f=false

Semana Económica (3 de abril de 2017). Crecimiento de sector restaurantes en enero. Recuperado de http://semanaeconomica.com/article/sectores-y- 
empresas/comercio/221896-crecimiento-de-sector-restaurantes-se-desacelero-en-

enero/

Scotiabank, (16 de octubre de 2016). Sector avícola seguiría siendo impulsado por consumo interno. Recuperado de https://scotiabankfiles.azureedge.net/scotiabankperu/PDFs/reportes/sectorial/Avicola_Oct16.pdf

Sociedad Peruana de Gastronomía [APEGA] (2010). El boom de la Cocina Peruana. Recuperado de http://www.apega.pe/noticias/prensa-y-difusion/el-boom-de-la-cocinaperuana.html

Thompson, A.A., Peteraf, M.A., Gamble, J.E., \& Strickland, A.J. (2012). Administración Estratégica: Teorías y casos (18a ed.). México D.F., México: Mc GrawHill/Interamericana Editores. 